\title{
Quality of Aquatic Habitats in Alberta: Proceedings of the Third Annual Applied Aquatic Studies Workshop, Edmonton, Alberta, February 17-18, 1987
}


$\square$ National Ubrary Bibllotheque nationale 
Quality of Aquatic Habitats in Alberta:

Proceedings of the Third Annual Applied Aquatic Studies Workshop,

Edmonton, Alberta, February 17-18, 1987

\author{
Edited by \\ James W. Moore*, Thomas A. Heming and W.C. Mackay \\ *Aquatic Ecology Branch \\ Biological Sciences Division \\ Alberta Environmental Centre \\ Postal Bag 4000 \\ Vegreville, Alberta \\ T9C 1T4
}

June 22, 1992 


\section{Disclaimer}

The information in this document has been funded in part by the Alberta Environmental Centre. Papers describing Centre-sponsored work have been subject to the Centre's peer and administrative review process, and have been approved for publication. Papers describing work that was not sponsored by the Alberta Environmental Centre have been subject to outside peer review. The contents of these latter papers do not necessarily reflect the views of the Alberta Environmental Centre and no official endorsement should be inferred.

This document may be cited as:

Moore, J.W., T.A. Heming and W.C. MacKay. 1992. Quality of Aquatic Habitats in Alberta. Proceedings of the Third Annual Applied Aquatic Studies Workshop, Edmonton, AB, February 17-18, 1987. Alberta Environmental Centre, Vegreville, AB. AECV92-P3. 240 pp.

ISBN 0-7732-1060-1 


\title{
Organizing Committee
}

Theo Beukeboom, Alberta Environment, Edmonton, Alberta

Thomas A. Heming, Alberta Environmental Centre, Vegreville, Alberta

J. Bryan Kemper, Alberta Environment, Edmonton, Alberta

William C. Mackay, University of Alberta, Edmonton, Alberta

Pat Mitchell, Alberta Environment, Edmonton, Alberta

James W. Moore, Alberta Environmental Centre, Vegreville, Alberta

Ellie Prepas, University of Alberta, Edmonton, Alberta

Dave Rimmer, Alberta Energy; Alberta Forestry, Lands and Wildlife, Edmonton, Alberta Bill Tonn, University of Alberta, Edmonton, Alberta

\section{Workshop Sponsored By:}

\author{
Alberta Energy \\ Alberta Forestry, Lands and Wildlife \\ Alberta Environment \\ Alberta Environmental Centre \\ Alberta Recreation and Parks \\ Boreal Institute for Northern Studies \\ The University of Alberta
}




\section{Table of Contents}

Edaphic and Morphometric Influences on the Trophic State of Lakes

Robert E. Stauffer . . . . . . . . . . . . . . . . . . . . . . . 1

Bridging the Lab-Field Gap in Aquatic Contamination Evaluation

Mary G. Henry . . . . . . . . . . . . . . . . . . .

Aquatic Plant Management in Irrigation Systems

Robert Burland ........................... 4

Aquatic Macrophyte Problems in Alberta

Jan Crosby . . . . . . . . . . . . . . . . . . . . . . . 11

The Potential for Lake Rehabilitation in Alberta

Patricia Mitchell ........................... 12

Environmental Fate Processes and Their Role in Aquatic Toxicology

James W. Moore . . . . . . . . . . . . . . . . . . . . . . . . 13

An Overview of the Potential Sensitivity of Alberta Lakes to Acidic Deposition

D.O. Trew . . . . . . . . . . . . . . . . . . . . . . . . . 23

The Tri-Creek Study: Impact of Logging on East Slope Streams; Program Design and Management For The Tri-Creek Experimental Watershed

D.T. Sneddon

Hydrologic Impacts of Forest Harvesting in the Tri-Creek Watershed

Gary Van Der Vinne . . . . . . . . . . . . . . . . . . . . . . . . . 34

Verification of Water Resources Evaluation for Non-Point Silvicultured Sources, A Water Yield Procedure to the Tri-Creek Experimental Watershed Allen M.K. Nip . . . . . . . . . . . . . . . . . . . . . . . .

Sediment Dynamics in a Rocky Mountain Foothills Stream Following Clear-cut Logging of Fifty Percent of the Watershed Area

Wayne J. Wasiliew . . . . . . . . . . . . . . . . . . . . . 83

Hydrochemistry of the Tri-Creek Experimental Watershed

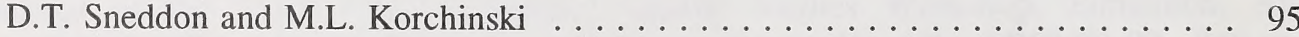

Effects of Logging on the Thermal Regime of the Streams in the Tri-Creek Basin

David Andres 
Comparison of Spawning Criteria and Fry Escapement of Rainbow Trout (Oncorhynchus mykiss) Before and After Timber Harvest in the Tri-Creek Watershed of West-Central Alberta

George Sterling

Surface Water Characteristics in Alberta Pertinent to Drinking Water

Albert van Roodselaar

An Overview of Biological Control of Aquatic Weeds

J.T. O'Donovan and A.S. McClay

Automated GC/MS Techniques for Chemical Speciation in the Aquatic Environment

G. E. Prill, L. Uchman, K. Hill, and J. V. Headley

Use of Histopathological Evaluation in Aquatic Toxicity Studies

Leonard E. Lillie and Alfonso Lopez

Aquatic Toxicology of Alum: Importance of Water $\mathrm{pH}$

Thomas A. Heming and Karen A. Blumhagen . . . . . . . . . . . . 202

Biomagnification of Chemical Residues in Alberta Aquatic Habitats

J.D. Somers, B.C. Goski and J.M. Barbeau . . . . . . . . . . . . . . 203

Winter Oxygen Depletion in Small Alberta Rivers

J. Babin and D.O. Trew

Spikerush, Eleocharis acicularis, as a Control of Aquatic Plant Growth in Irrigation Systems in Alberta

Earle G. Baddaloo and Dave Reid . . . . . . . . . . . . . . . . . . 208

Description of Two Treatment Methods for Detoxifying Oil Sands Tailings Pond Water

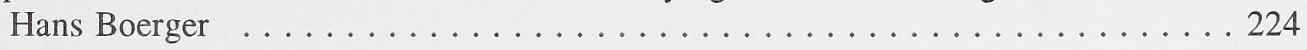

Evaluation: An Important Part of Managing the Environment

Jack Grainge

The Consequences of Muskrat Predation on the Growth of a Unionid Clam

J. Mark Hanson

Fish Tainting by Oil Sands Tailings Pond Wastewaters

C.W. Koning and S.E. Hrudey

Changes in the Abundance of Fishes in the Red Deer River Below the Dickson Dam

Wayne Roberts 
Digitized by the Internet Archive in 2015 
Edaphic and Morphometric Influences on the Trophic State of Lakes

\author{
Robert E. Stauffer \\ Merrick Place \\ Lexington, U.S.A.
}

Nutrient cycling was comparatively studied in calcareous lakes of southeast Wisconsin versus non-calcareous lakes of the northern highlands and northeast Minnesota. Because of iron-sulphur interactions, the calcareous lakes exhibit efficient internal recycling of biologically-available phosphorus on an annual basis and thus have high-spring phosphorus potential. Here, the spring diatom bloom is usually limited by silicon, and productivity during summer and early fall depends on nutrient transport through the seasonal thermocline. Because of potent iron-phosphorus interactions, the non-calcareous study lakes have relatively low phosphorus potential in spring and are inefficient at transporting phosphorus through the thermocline by vertical eddy diffusion. As a consequence, heightened productivity in mid-late summer depends on direct entrainment of sediment slurries rich in phosphorus. This dependency makes non-calcareous lake productivity hyper-sensitive to hypolimnetic depth development. These comparative studies illustrate structural flaws in widely adopted trophic-state prediction models, including the Vollenweider and Dillon-Rigler models. 


\title{
Bridging the Lab-Field Gap in Aquatic Contamination Evaluation
}

\author{
Mary G. Henry \\ U.S. Fish and Wildlife Service \\ National Fisheries Center-Great Lakes \\ Ann Arbor, Michigan 48105
}

The assessment of environmental contaminants is chiefly viewed as a biological problem since effects on biota are the foundation of the hazard evaluation process. However, despite good intentions and sound theory, the prime obstacle in this process arises from our limited ability to relate laboratory effects to definitive field impacts. The current methods available to deal with this problem do not reflect the complexity of natural systems.

Field approaches which have been adapted for use in contaminant assessments in aquatic ecosystems fall into two categories. The first approach uses standard limnological and fisheries management techniques e.g., tagging studies, mark/recapture population estimates, and sample collections. This approach attempts to evaluate changes in survival, growth and reproduction in both individual species and populations, similar to the endpoints examined in full and partial chronic-exposure laboratory tests. The second approach involves taking numerous field samples of water, sediment, plant, and animal material for residue analysis in order to evaluate the biological availability of a contaminant and determine whether trends can be detected in bioconcentration, bioaccumulation, and biomagnification.

At least three critical problems confound the interpretation of data derived from laboratory methods which have been adapted for the field: (1) the significance of the measured variable to the survival of a field population is difficult to determine; (2) the role of abiotic and biotic factors other than the contaminant are numerous and fluctuate widely but must be considered in the cause-effect analysis; and (3) relationships between observed effect and actual environmental concentrations are difficult to pinpoint. To illustrate these classical problems of interpretation and methodology, reference was made to two laboratory and field studies: (1) the effects of mining contaminants on salmonid moltification; and (2) the effects of acidification on fish populations of northern Wisconsin lakes. The rationale for methods used, determinations of environmental concentration estimates, incorporation of alternative methods, comparisons to laboratory test result and recommendations were discussed. 
The problem of approximating a more realistic assessment of biological impacts of contaminants in the field remains. Alternative field-manipulated tests (e.g. cage studies, laboratory exposed-field released-organism monitoring) using biochemical, behavioral and physiological measurements may be substituted for the more costly and time consuming traditional methods. Field findings must be qualified in view of the complex array of unmeasured variables influencing a contaminant's toxicity. In addition, interaction of these factors in the laboratory must be more thoroughly examined. 


\title{
Aquatic Plant Management in Irrigation Systems
}

\author{
Robert Burland \\ Pesticide Chemicals Branch \\ Pollution Control Division \\ Alberta Environment, Lethbridge, Alberta
}

\begin{abstract}
Excessive growth of aquatic vegetation reduces the capacity of irrigation canals to deliver water to users. Aquatic plant management is undertaken by irrigation districts to permit uninterrupted water flow to farmers.
\end{abstract}

This paper describes the problems caused by aquatic plants in canal systems, the species which are responsible and techniques that are used in canals to manage their growth.

\section{INTRODUCTION}

Agricultural irrigation in Alberta occurs mainly within the South Saskatchewan River basin. In this area, almost one million acres of land is irrigated by water which is diverted from rivers and transported through a network of more than 12000 kilometres of canals and reservoirs. These canal systems, the majority of which are earth-lined, provide conditions which are suitable for prolific growth of aquatic plants. The direct consequences of aquatic plant growth are:

1. reduction in flow velocity;

2. increase in silt deposition;

3. reduction in canal capacity; and

4. interference with irrigation equipment.

A reduction in flow velocity leads to an increase in silt deposition which ultimately leads to a reduction in channel capacity. These factors cause and contribute to secondary effects such as increased seepage and bank overflow. The latter occurs as operators try to satisfy increased water demand with less channel capacity. Three specific examples of channel reduction due to aquatic plant growth can be seen in Table 1 .

The ultimate result of overabundant aquatic plant growth in irrigation canals is, quite simply, a shortage of water available for irrigation.

Table 1. Flow reduction due to aquatic plant growth in canals of the Western Irrigation District. 


\begin{tabular}{lccccc}
\hline \hline \multicolumn{1}{c}{ Canal } & $\begin{array}{c}\text { Max. Design } \\
\text { Flow } \\
\left(\mathrm{ft}^{3} / \mathrm{sec}\right)\end{array}$ & $\begin{array}{c}\text { Max. Design } \\
\text { Flow } \\
\left.\left(\mathrm{m}^{3}\right) / \mathrm{sec}\right)\end{array}$ & $\begin{array}{c}\text { Max. Available Flow } \\
\text { Due to Weed Growth } \\
\left(\mathrm{ft}^{3} / \mathrm{sec}\right)\end{array}$ & $\begin{array}{c}\text { Max. Available Flow } \\
\text { Due to Weed Growth } \\
\left(\mathrm{m}^{3} / \mathrm{sec}\right)\end{array}$ & $\begin{array}{c}\% \\
\text { Reduction }\end{array}$ \\
\hline \hline B. Canal & 674 & 19.08 & 110 & 3.11 & 84 \\
Glenrose & 280 & 7.92 & 25 & 0.708 & 91 \\
Cluny South & 107 & 3.03 & 10 & 0.283 & 91 \\
\hline \hline
\end{tabular}

Herbicide use provides an indication of the extent of the aquatic weed problem. In 1984, about $1800 \mathrm{~km}$ of canal were chemically treated for control of submergent plants. An additional $165 \mathrm{~km}$ were treated for control of emergent aquatic plants.

\section{AQUATIC PLANT SPECIES}

Submergent, emergent, and free floating macrophytes as well as filamentous algae inhabit and cause specific problems in canals.

$\underline{\text { Submergent Plants }}$

Among the submergent macrophytes, four species predominate: sago pondweed (Potamogeton pectinatus), Richardson pondweed ( $P$. richardsonii), giant pondweed (P. vaginatus), and water plantain (Alisma gramineum). Sago pondweed is the most widespread and abundant species, probably due to its high reproductive capability.

Sago pondweed can spread by seed, tubers (subterranean and axillary), rhizomes and winter buds. An example of its productivity is provided in growth studies by Yeo (1975). In six months, a single tuber of sago pondweed produced vegetative growth filling a circular pool $5.5 \mathrm{~m}$ in diameter and $0.6 \mathrm{~m}$ deep and flowering spikes extending over a diameter of $3.3 \mathrm{~m}$. This single plant produced 36000 subterranean tubers, 800 axillary tubers and 6000 seeds. The number of propagules was correlated with the area available for growth.

In a Montana canal infested with sago pondweed, Yeo (1975) found 80 tubers per $.03 \mathrm{~m}^{3}$ of soil, most being found near the soil surface. Tubers germinating from as deep as $0.5 \mathrm{~m}$ were able to produce foliage above the soil in one season.

Richardson and giant pondweed are also fairly abundant and widespread. Both are perennials, spreading by rhizomes and seed. Giant pondweed will also produce tubers and is of particular importance in large canals where it can grow to extreme lengths, reaching the surface in flowing water $3 \mathrm{~m}$ deep. 
Narrow leaf water plantain is also very common. Although its long ribbon-like leaves do not impede water flow as do the pondweeds, the presence of water plantain may cause problems. It is a perennial which overwinters as a corm.

Other submergent plants which occur in canals and cause localized problems include water milfoil (Myriophyllum exalbescens), water buttercup (Ranunculus sp.), waterweed (Elodea longivaginia), and horned pondweed (Zannichellia palustris).

Emergent Plants

The common cattail (Typha latifolia) is a perennial which readily invades and quickly becomes established in quiescent canals. It traps considerable amounts of silt and causes water loss through evapotranspiration.

Cattail is an extremely high seed producer. Life history studies (Timmons et al., 1968) have shown than an average cattail spike (7 inches in length) can produce about 223000 seeds. A single seed planted in May gave rise, in 6 months, to a plant consisting of 63 emergent shoots (10 $\mathrm{cm}$ to $1.3 \mathrm{~m}$ in height), 35 non-emergent shoots and 104 large crown buds.

Reed canarygrass (Phalaris arundinacea) can be seen in almost any ditch or canal in southern Alberta. It is a tall, rhizomatous grass that thrives in wet or semi-wet areas. Reed canarygrass has been termed as "a sort of Dr. Jekyll and Mr. Hyde kind of grass" (Hodgson, 1968). While it is raised for hay and is a valuable crop in several areas, it causes severe problems in irrigation canals by encroaching into the water, trapping silt and creating berms along the inside banks. Eventually an entire canal can become completely choked off with silt and reed canarygrass.

Reed canarygrass is extremely widespread in some of the larger irrigation districts occupying up to $90 \%$ of canal length. It is a serious pest species that continues to spread throughout the canal system.

Other Aquatic Plants

Free-floating macrophytes and filamentous green algae plug sprinkler heads and pump screens. Lesser duckweed (Lemna minor) and star duckweed (L. trisulca) grow in reservoirs and are released with irrigation water. Algae, attached to other plants or concrete surfaces, break off to float downstream as mats or filaments. 


\section{MANAGEMENT}

Aquatic plant management in canals is done almost exclusively with herbicides. However, other techniques have been tried and some remain as options available to managers.

\section{Mechanical Control}

Aquatic weed harvesters sever plants to a certain depth and remove cuttings from the water to prevent spread of the weed growth and interference with downstream structures. Different types of harvesting equipment have been tried in canals. However, their use is limited due to expense, depth of cut, the presence of structures, speed of operation and inadvertent release of fragments which can float downstream and plug structures.

Cutting is effective on emergent plants such as cattails, if done at the correct stage and if water levels can be maintained above severed stems.

\section{$\underline{\text { Habitat Manipulation }}$}

The result of habitat manipulation is an aquatic environment unsuitable for aquatic plant growth. Habitat manipulation in canal systems consists mainly of bottom alteration. Lining irrigation canals with concrete, asphalt or gravel, however, is done primarily for bank protection and seepage control. High installation and maintenance expenses prohibit use of canal liners solely for aquatic plant control.

\section{$\underline{\text { Biological Control }}$}

Biological control of aquatic plants involves the introduction of weed-eating fish, insects or pathogenic organisms to the aquatic environment. Although some forms of this technology are in use in the U.S., none have proven adaptable to irrigation systems in Alberta as yet.

In Alberta, research is underway to characterize and determine the competitive nature of Eleocharis spp. when transplanted amongst aquatic plant infestations. This approach has been attempted in California with limited success (Yeo and Thurston, 1984).

\section{Chemical Control}

For irrigation district managers, herbicides provide the most economical and effective means available to control aquatic plant growth. Large areas can be treated within the system in a time frame compatible with the short length of the operating season.

There are considerable limiting factors associated with the use of chemical herbicides in flowing water systems. These factors include the availability of only a small number of effective products and the diverse uses to which irrigation water is subjected. 
Of more than 120 active herbicidal ingredients registered in Canada only five are approved for use on aquatic plants in irrigation canals. They are:
Acrolein
- submergent plants
Diuron
- submergent and emergent plants
Paraquat
- emergent plants
Dalapon
- emergent plants
Glyphosate
- emergent plants on ditchbanks

\section{Submergent Aquatic Plants}

Acrolein is the herbicide most often used to control submergent aquatic plants. It is a liquid which is injected underwater from a stationary point for a specified time period. Treated water moves down the canal, killing the vegetation on contact. Roots, rhizomes, tubers, etc. are not affected, nor are emergent plants.

The two main advantages of acrolein are that it can be used during the operating season without disruption of irrigation services (treated water can be used for irrigation without crop injury) and it is not persistent in water (studies by Alberta Environment [1985] have shown that acrolein persists in water for an average of about 16 hours).

The main disadvantage is that acrolein will kill fish that exist in canals during treatment. This is of particular concern in larger canals which contain transient populations of lake whitefish.

Diuron is also registered for submergent aquatic weed control in irrigation canals, although its use is limited. It is applied to the canal bottom in fall after canals are dewatered.

Diuron is not used to any great extent because application conditions must be ideal in order for it to be effective. During application, the canal bottom must be dry and free of heavy trash cover from previous weed growth, conditions which are seldom present in Alberta irrigation canals. There are also restrictions on the use of water from the initial spring flows over the treated areas.

\section{$\underline{\text { Small Aquatic Plants }}$}

For cattail control within canals, dalapon is used. Dalapon is a shortterm residual herbicide that is effective as long as it is applied during the early flowering growth stage. Later applications may also be effective; however, more regrowth will occur in the following season. 
Treatment of reed canarygrass with dalapon provides less than seasonal control.

Studies by Hardy Associates Ltd. (1985) have shown that treatment of reed canarygrass with glyphosate (Roundup ${ }^{\circledR}$ ) in late August or early September can provide up to two seasons of control. An integrated approach using early fall glyphosate treatment followed by seeding with competitive, low-growing grasses has shown promise for long-term control of reed canarygrass.

\section{CONSTRAINTS}

Aquatic plant control in irrigation canals is influenced by the multiple uses to which irrigation water is subjected. Irrigation water is used for consumption by 30 municipalities and numerous farms. Fifty-two varieties of irrigated crops are produced, many of which are sensitive to herbicides which may be effective in canals. Over 250 private trout ponds are supplied by irrigation water, as are 38 reservoirs which are popular for commercial or recreational fishing.

Use of the canal and reservoir systems for recreation is also important. Six provincial parks, as well as several campsites and picnic areas, are located adjacent to these canals or reservoirs.

Unused irrigation water is returned to rivers where it is subjected to further uses. In addition, land adjacent to irrigation canals provides habitat for several varieties of wildlife.

These multiple uses of the irrigation system place limitations on how, when and where aquatic plants can be controlled in canals. Aquatic plant management becomes a challenge as multiple use constraints must be considered in addition to the limited number of options available to system managers.

There is ample room for applied research into new and improved technology for use in solving the many serious problems caused by aquatic plants in irrigation systems.

\section{REFERENCES}

Alberta Environment. 1985. Investigation into the behaviour of acrolein in Alberta irrigation canals - 1985 Monitoring. Alberta Environment, Edmonton, Alberta.

Hardy Associates (1978) Ltd. 1985. Field evaluation of control options for reed canarygrass on irrigation ditchbanks. Alberta Environment, Edmonton, Alberta. 
Hodgson, J.M. 1968. Chemical control of reed canarygrass on irrigation canals. Weed Sci. $16: 465-468$.

Timmons, F.L., V.F. Bruns, W.O. Lee, R.R. Yeo, J.M. Hodgson, L.W. Weldon, and R.D. Comes. 1968. Studies on the control of common cattail in drainage channels and ditches. U.S. Depart. Agriculture, ARS, Techn. Bull. No. 1286.

Yeo, R.R. 1975. Life history of sago pondweed. Weeds 12:314-321.

Yeo, R.R., and J.R. Thurston. 1984. The effect of dwarf spikerush (Eleocharis coloradoensis) on several submersed aquatic weeds. J. Aquat. Plant Manage. 22:52-56. 


\title{
Aquatic Macrophyte Problems in Alberta
}

\author{
Jan Crosby \\ Alberta Environment, Planning Division \\ Edmonton, Alberta
}

\begin{abstract}
Aquatic macrophytes have always been abundant and widespread in Alberta. Increased demand for recreational waterbodies and increased development of irrigation systems have led to conflict between water users and aquatic plants.

This presentation considered primarily aquatic macrophyte conflicts with recreation and industry. Topics discussed included: an Elodea canadensis problem in Wabamun Lake and the response of TransAlta Utilities Corporation; conflicts between macrophytes, fish and recreation on the Bow and Highwood Rivers; a program to prevent Eurasian milfoil spread into Alberta; macrophyte monitoring programs in Alberta and a new weed problem in Winagami Lake.
\end{abstract}




\title{
The Potential for Lake Rehabilitation in Alberta
}

\author{
Patricia Mitchell \\ Water Quality Control Branch \\ Alberta Environment, Edmonton, Alberta
}

\begin{abstract}
Although there are a few high-quality lakes in Alberta, many suffer symptoms of eutrophication - nuisance weed growth, algal blooms and fish kills. Techniques to rehabilitate such lakes are being used all over the world with different degrees of success.

This presentation discussed the following concerns:

1. the potential for restoring or improving Alberta lakes;

2. the pros and cons of such restoration; and

3. identification of the types of lakes that yield the best results.

Techniques were outlined and examples of existing lake management projects in Alberta were included.
\end{abstract}




\title{
Environmental Fate Processes and Their Role in Aquatic Toxicology
}

\author{
James W. Moore \\ Aquatic Biology Branch \\ Alberta Environmental Centre \\ Vegreville, Alberta
}

\section{INTRODUCTION}

When a chemical agent or complex industrial effluent is discharged into surface waters, a series of complex environmental processes come into play which may significantly alter the chemical composition of the waste or agent. These processes constitute the environmental fate of the compounds in the discharge.

There are three broad fate categories: biological, chemical and physical. In many cases, chemical processes dominate the fate of a toxic agent within surface waters, whereas biological processes often have their greatest impact on fish and vegetation. Specific examples of the different types of fate processes are listed in Table 1. The potential effects of all the processes listed in Table 1 are illustrated in Figure 1.

Table 1. Examples of different environmental fate processes that may affect a chemical or wastewater discharge in surface waters.

\begin{tabular}{ccc}
\hline \hline $\begin{array}{c}\text { Chemical Fate } \\
\text { Processes }\end{array}$ & Physical Fate Processes & Biological Fate Processes \\
\hline \hline dehalogenation & sorption & uptake \& partitioning in tissues of fish, plants \& other aquatic species \\
dechlorination & desorption & enzymatic transformations by microorganisms \\
photolysis & volatilization & \\
hydrolysis & transport by water currents \\
chlorination & \\
halogenation & \\
alkylation & \\
methylation & \\
arylation & \\
redox behaviour & \\
\hline \hline
\end{tabular}




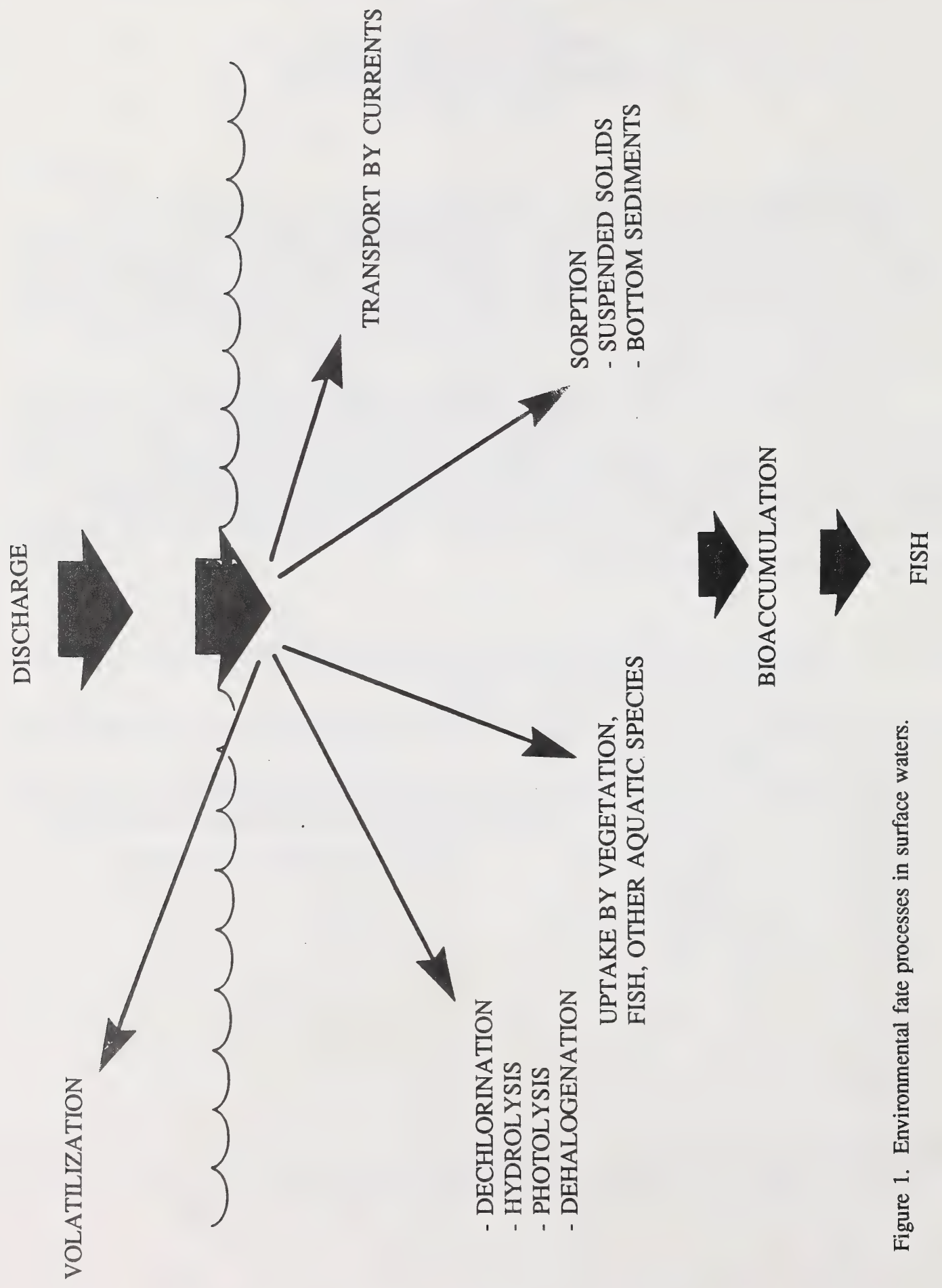


The net impact is that, for most compounds, the concentration of toxic constituents in the environment is reduced after the action of environmental fate processes. There are, of course, exceptions; for example, DDE is more likely to accumulate to higher levels in biological tissues than the parent compound, DDT. Another example is mercury, which is much more toxic after methylation, a chemical process.

This paper will discuss the fate of organic and inorganic compounds, using studies of methoxychlor, lindane and mercury as examples.

\section{ORGANIC COMPOUNDS}

Many of the organic compounds discharged to surface waters in Alberta are either moderately or highly volatile. Examples of such compounds include the pesticides methoxychlor, Magnacide-H, lindane, ammonia and chlorinated amines. Other compounds, such as polyelectrolyte flocculants, are highly water soluble. Solubility reduces loss through volatilization and may also retard sorption, particularly if the compound is non-ionic. However, those compounds carrying an appreciable charge are likely to partition favorably to sediments and/or clay particles.

\section{Methoxychlor}

This pesticide is widely used in Canada to control biting fly larvae in flowing waters. In Alberta, it has been applied to the Athabasca River for a number of years to control black flies in the vicinity of the Town of Athabasca.

Methoxychlor is structurally related to DDT. Several breakdown products have been identified, including those generated in the environment, through mammalian metabolism and through microbial metabolism (Figure 2). The most common steps of detoxification of methoxychlor are dechlorination and hydroxylation.

The effect of environmental fate processes on the concentration of methoxychlor has been investigated using laboratory microcosms. The experimental system consisted of a large experimental tank, containing land fill, sediments from the Athabasca River and Athabasca River water. Different species of fish (rainbow trout, Oncorhynchus mykiss; fathead minnow, Pimephales promelas; and spottail shiner, Notropis hudsonius) were introduced into the tanks along with snails of the genus Gyraulus. Methoxychlor was introduced at concentrations of 300 , 

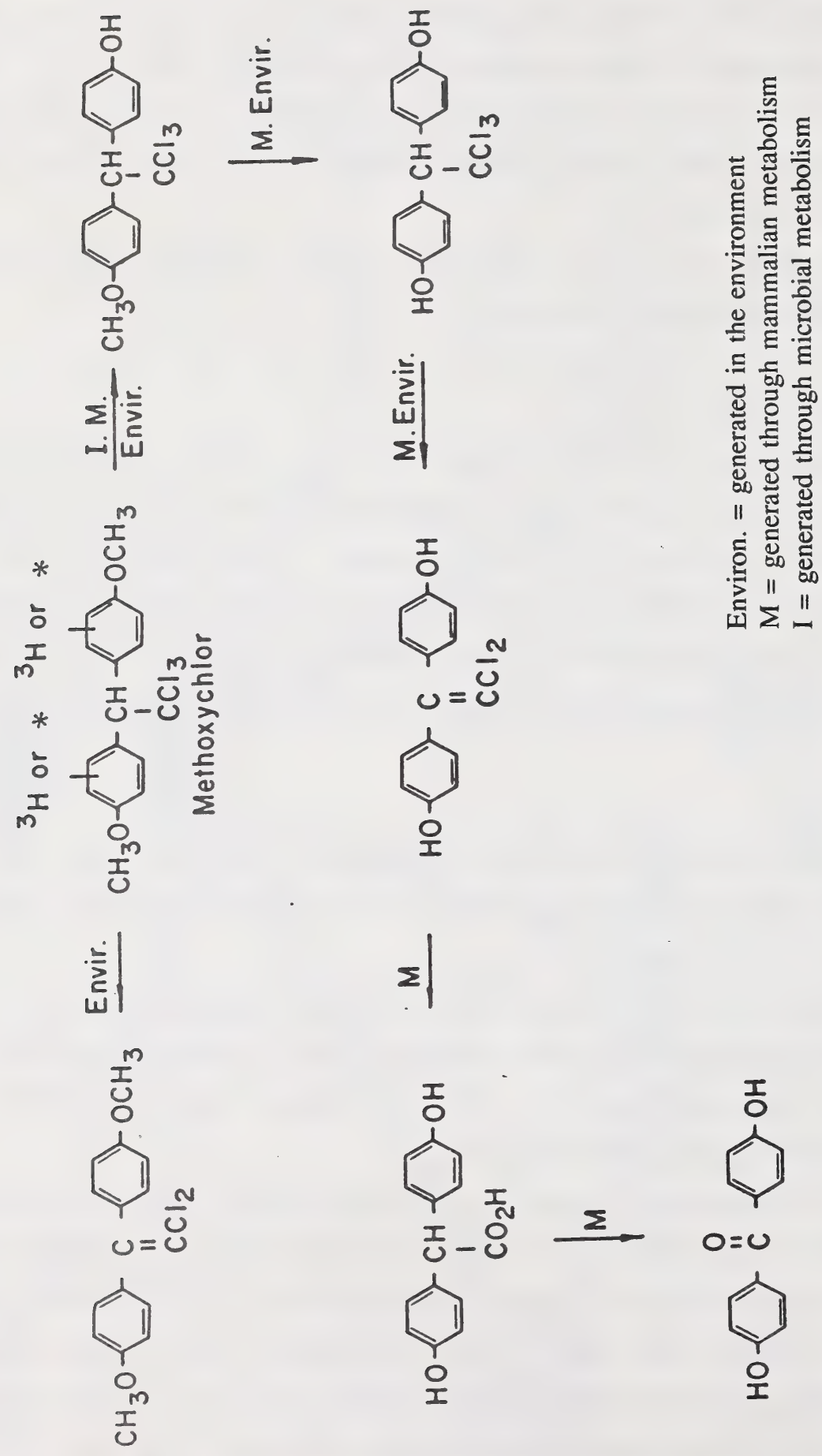

文|

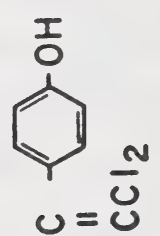<smiles>Cc1ccc(O)cc1</smiles>

$\Sigma$
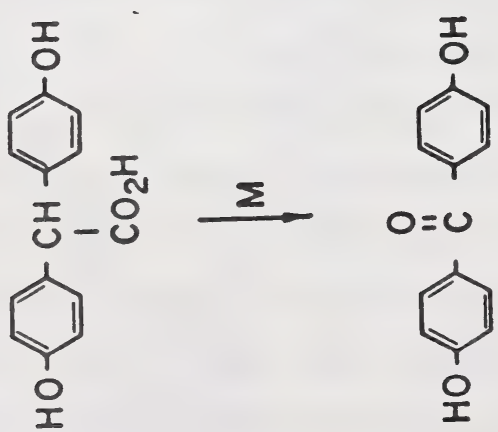
30 and $3 \mathrm{ppb}$. The entire system was aerated. A complete description of the methods and detailed analysis of the results are reported elsewhere (Alberta Environmental Centre, 1987).

After $96 \mathrm{~h}$, the partitioning of methoxychlor in the microcosm was determined. It was estimated that $42 \%$ of the added methoxychlor was lost to the atmosphere through volatilization (Figure 3). This is based on the use of Henry's Law constant (0.013), which indicates that methoxychlor is moderately volatile. The half-life of volatilization at a depth of $1 \mathrm{~cm}$ in the water column was calculated to be 1.7 days, whereas at $10 \mathrm{~cm}$ the corresponding value was 17 days.

No methoxychlor was found in the sediments of the microcosm. However, a second series of experiments, using only distilled water and Athabasca River sediments in Pyrex beakers, yielded a partition coefficient (corrected for organic carbon) of 28840 (Figure 3). This indicates that in the absence of other competing compartments, methoxychlor partitions favorably to sediments.

All three species of fish sorbed methoxychlor, with concentration factors (concentration in fish/concentration in water) ranging from 108 to 304 (Figure 3). The concentration factor for snails was slightly higher, 580 .

Only $28 \%$ of the added methoxychlor resided in the water after $96 \mathrm{~h}$. This meant that $29 \%$ of the methoxychlor sorbed to the walls of the microcosm (determined by difference).

\section{Lindane}

This chlorinated insecticide is still widely used in Alberta and many other parts of the world. It is the gamma isomer of hexachlorocyclohexane, which is less toxic to non-target organisms than most of the other isomers. Lindane is periodically recorded in surface waters of Alberta at concentrations of approximately $0.001 \mathrm{mg} / \mathrm{L}$ (Environment Canada, 1976-1981). Higher values probably occur immediately after rain storms and also during periods of heavy snow melt.

To study the partitioning of lindane in aquatic systems, small microcosms (47 L) were constructed. Surface sediments from the Vermilion River near Vegreville, Alberta were introduced into the system, followed by the addition of dechlorinated municipal water. Juvenile rainbow trout were also added to the system. Commercial grade lindane was introduced in the following concentrations: 700, 350 and $35 \mathrm{mg} / \mathrm{L}$. Chemical analysis of the different 


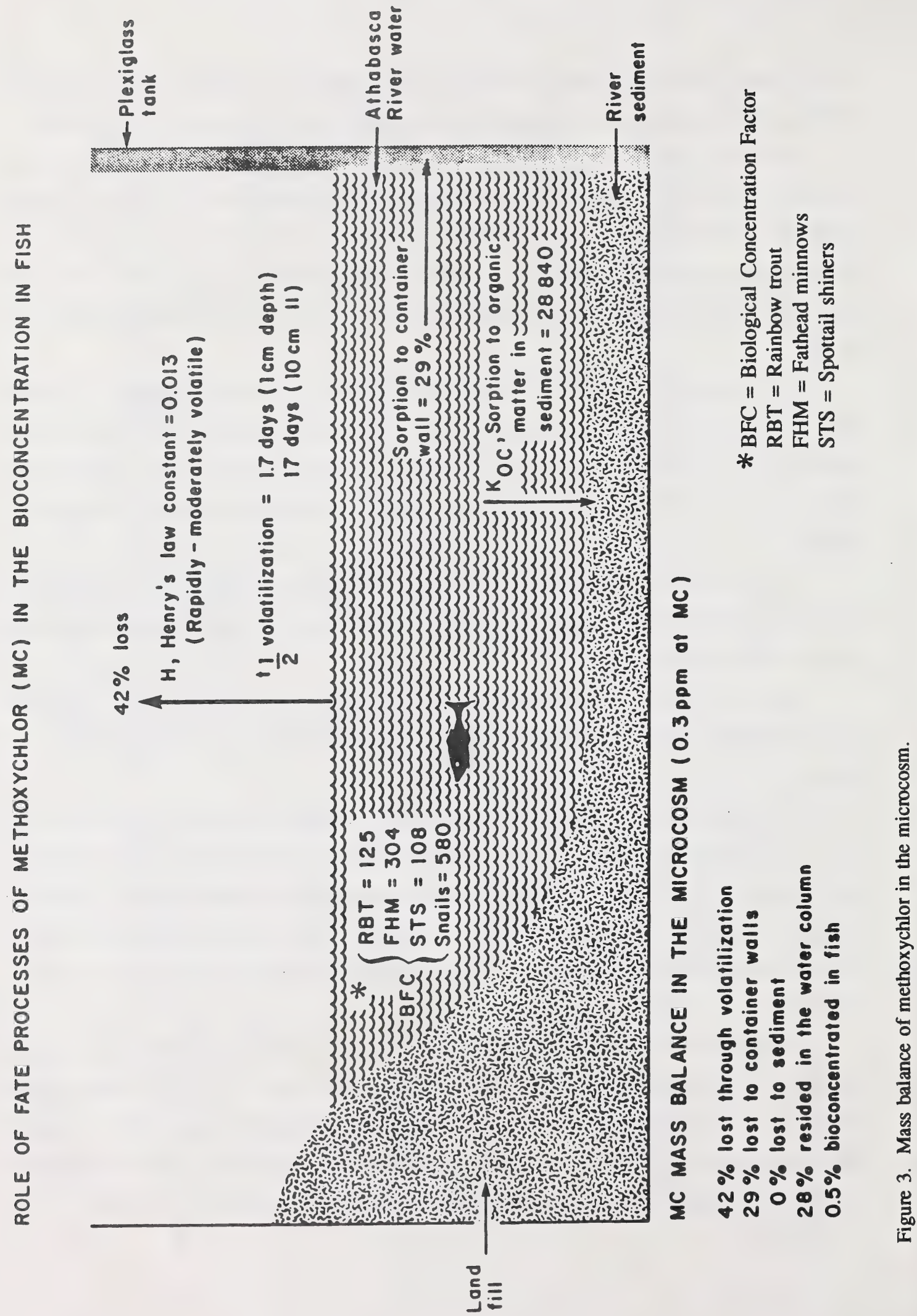


compartments was conducted at days 1, 4, 7, 15 and 33. A complete description of the methods used in these experiments and full analysis of the results is given in Ramamoorthy (1985).

Using the $350 \mu \mathrm{g} / \mathrm{L}$ exposure after $96 \mathrm{~h}$ as an example, $56.5 \%$ of the lindane was lost to the atmosphere (Table 2). This calculation is based on the use of Henry's Law constant of 0.202, which indicates that lindane partitions favorably to the atmosphere.

Table 2. Percent distribution of lindane in the experimental system after $96 \mathrm{~h}$.

\begin{tabular}{cc}
\hline \hline Compartment & Percent Distribution \\
\hline \hline Water & 0.6 \\
Sediment & 11.5 \\
Rainbow trout & 0.3 \\
Atmosphere & 56.5 \\
Walls of plexiglass & 31 \\
Loss due to isomerization & non-detectable \\
Loss due to photodegradation & non-detectable \\
\hline \hline
\end{tabular}

*exposure $350 \mathrm{mg} / \mathrm{L}$

The other major loss, $31 \%$ (calculated by difference), was to the plexiglass walls of the microcosm. The amount of lindane sorbed by the fish was only $0.3 \%$, and there was no detectable loss due to isomerization and photodegradation.

\section{INORGANIC COMPOUNDS}

The major inorganic agents of concern in Alberta waters are heavy metals. These compounds generally exhibit low volatility and sorb strongly to suspended solids and sediments. Mercury is one of the few metals that undergoes methylation in the environment. This chemical process greatly enhances its solubility and toxicity. 
$\underline{\text { Mercury }}$

Mercurials were identified as a significant contaminant of water and fish in the Minamata Bay area of Japan during the late 1940s and early 1950s. Several hundred people, exposed to high concentrations of mercury, developed central nervous system symptoms now known as Minamata disease. Other cases of Minamata disease have been reported, including an episode in northwestern Ontario during the 1970s.

The methylation process occurs primarily in the sediments of lakes and rivers. The process is mediated by methylating bacteria and may occur through two principal routes:

i. bonding to inorganic anions and organic radicals

$$
\mathrm{R}-\mathrm{Hg}^{++}-\mathrm{x}
$$

ii. bonding to two organic radicals

$$
\mathrm{R}-\mathrm{Hg}-\mathrm{R}
$$

Methylmercury generally accounts for less than $1 \%$ of all mercury in sediments and waters, and is usually not present in industrial effluents. However, methylmercury represents $60-95 \%$ of all mercury in fish.

Mercury has been identified in fish from essentially all lakes and rivers in Alberta. The highest residues have been found in fish inhabiting the lower reaches of major rivers, such as the North Saskatchewan, South Saskatchewan and Red Deer Rivers (Alberta Environmental Centre, 1983, 1984). The species of greatest concern are pike Esox lucius, walleye Stizostedion vitreum, goldeye Hiodon alosoides and sauger Stizostedion canadense.

In studies on the North Saskatchewan River between Rocky Mountain House and the Saskatchewan border, the average concentration of mercury in unfiltered water samples was $0.2 \mu \mathrm{g} / \mathrm{L}$. Periodic high values of up to $1.58 \mu \mathrm{g} / \mathrm{L}$ were detected, likely reflecting the presence of cinnabar deposits in the river basin (Ramamoorthy et al., 1985).

Analysis of sediments during the same study yielded an average residue of $53 \mu \mathrm{g} / \mathrm{kg}$ of mercury upstream of the City of Edmonton. The corresponding averages near Edmonton and immediately downstream in the Fort Saskatchewan area was $105 \mu \mathrm{g} / \mathrm{kg}$. In the rural area near the Saskatchewan border, residues averaged $92 \mu \mathrm{g} / \mathrm{kg}$.

Concentration factors of mercury were determined and are listed in Table 3 (Ramamoorthy et al., 1985). 
Table 3. Concentration factor of mercury in fish.

\begin{tabular}{cc}
\hline \hline Species & Concentration Factor \\
\hline \hline Goldeye & 2970 \\
Pike & 1560 \\
Walleye & 3225 \\
Sauger & 3715 \\
Longnose sucker & 1225 \\
White sucker & 1565 \\
Northern redhorse & 1840 \\
\hline \hline
\end{tabular}

At present, the Fish and Wildlife Division of Alberta Forestry, Lands and Wildlife has a fish consumption advisory for the North Saskatchewan River. Comparable regulations apply to the Saskatchewan part of the river. All of these regulations center on the fact that most of the mercury in fish is in the highly toxic, methylated form. Most of this mercury comes from natural sources, not industrial effluents. Man's affect on these levels occurs during disturbance of river sediments, thus releasing elemental mercury for methylation and bioconcentration.

\section{CONCLUSION}

Biological, chemical and physical processes affect different compounds in the environment at different rates and in different ways. Fish can bioaccumulate some compounds such as methoxychlor, which is similar in structure to DDT, and mercury, when it is methylated. However, the source of mercury is primarily natural, found in river sediments in the inorganic form and methylated by aquatic bacteria. Man can affect these levels through disturbance of river sediments.

\section{REFERENCES}

Alberta Environmental Centre. 1983. Chemical residues in fish tissues in Alberta. II. Mercury in the North Saskatchewan River. Alberta Environmental Centre, Vegreville, Alberta. AECV83-R2. $81 \mathrm{pp}$. 
Alberta Environmental Centre. 1984. Mercury in fish from six rivers in southern Alberta. Alberta Environmental Centre, Vegreville, Alberta. AECV84-R2. 74 pp.

Alberta Environmental Centre. 1987. Environmental chemistry and toxicity of methoxychlor to fish. Alberta Environmental Centre, Vegreville, Alberta. Research Report.

Environment Canada. 1976-1981. NAQUADAT. Inland Waters Directorate, Calgary, Alberta.

Ramamoorthy, S. 1985. Competition of fate processes in the bioconcentration of lindane. Bull. Env. Contam. Tox. 34:349-358.

Ramamoorthy, S., J.W. Moore, and L. George. 1985. Partitioning of mercury in the North Saskatchewan River. Chemosphere 14:1455-1468. 


\title{
An Overview of the Potential Sensitivity of Alberta Lakes to Acidic Deposition
}

\author{
D.O. Trew \\ Water Quality Control Branch \\ Pollution Control Division \\ Alberta Environment, Edmonton, Alberta
}

\begin{abstract}
Historical chemical data for 875 lakes throughout Alberta were assembled from provincial and federal data bases (Palmer and Trew, 1987). In addition, a preliminary water quality field program conducted in the fall of 1983 in the northern half of the province provided data on a further 107 lakes (Erickson, 1987). The chemical variables selected as criteria to identify potentially sensitive lakes were based on previous Canadian studies. These variables were $\mathrm{pH}$, calcium and alkalinity.
\end{abstract}

Values of $\mathrm{pH}$ ranged from 3.4 to 10.6; $17.0 \%$ of the total sample of Alberta lakes had $\mathrm{pH}$ values less than 7.0 and were classified as moderately to highly sensitive to acidic deposition. Calcium values ranged from 0.1 to $810.0 \mathrm{mg} / \mathrm{L} ; 18.6 \%$ of the sample had less than $8.0 \mathrm{mg} / \mathrm{L}$ calcium and were classified as moderately to highly sensitive. Alkalinity values ranged from undetectable to $7772 \mathrm{mg} / \mathrm{L} ; 9.7 \%$ of the sample had values less than $20 \mathrm{mg} / \mathrm{L}$ indicating moderate to high sensitivity.

Based upon these analyses, lakes in widely diverse areas of the province are potentially sensitive to the effects of acidic deposition. A large number of these sensitive lakes are found on the Canadian Shield, in the extreme northeastern corner of the province. Several lakes in the Rocky Mountain National Parks region, most notably Jasper National Park, are also sensitive. Most of the remaining potentially sensitive lakes are located in the northern upland regions, such as the Caribou and Birch Mountain Uplands, and the Clear Hills and Swan Hills Uplands. A number of these lakes were highly coloured, muskeg-type lakes, indicating a high natural acidity.

Alberta Environment maintains a network of 11 precipitation quality monitoring sites located throughout the province. Data from 1978 to 1984 reveal that the dominant ionic constituents in precipitation falling over most of Alberta are calcium, sulphate and ammonium, unlike the precipitation in eastern North America which is dominated by ions of hydrogen, sulphate and nitrate. The $\mathrm{pH}$ of Alberta precipitation has an approximate annual average of 5.5, 
which is considered close to the theoretical $\mathrm{pH}$ of 5.6 of uncontaminated rainwater, and is much less acidic than precipitation falling over eastern North America.

At most Alberta precipitation-monitoring stations there is a poor correlation between sulphate concentration and acidity. In other regions where acidification studies have been conducted, sulphate has been used as a surrogate for acidity in precipitation because of their close correlation. As a result, the atmospheric wet deposition rates (or target loadings) set to protect moderately sensitive lakes in eastern Canada have been expressed as sulphate and set at $20 \mathrm{~kg} / \mathrm{ha} / \mathrm{yr}$.

A target loading to protect lakes in Alberta may not be quantifiable in terms of sulphate deposition.

\section{REFERENCES}

Palmer, C.J., and D.O. Trew. 1987. The Sensitivity of Alberta Lakes and Soils to Acidic Deposition - Overview Report. Environmental Protection Services, Alberta Environment, Edmonton, Alberta. 38 pp.

Erickson, P.K. 1987. An Assessment of the Potential Sensitivity of Alberta Lakes to Acidic Deposition. Environmental Protection Services, Alberta Environment, Edmonton, Alberta. $102 \mathrm{pp}$. 


\title{
The Tri-Creek Study: Impact of Logging on East Slope Streams
}

\author{
Program Design and Management \\ For The Tri-Creek Experimental Watershed \\ D.T. Sneddon, Research Manager \\ Scientific and Engineering Services Division \\ Alberta Energy, Edmonton, Alberta
}

\begin{abstract}
A research plan was developed by the Forest Research Branch, Alberta Forest Service, in 1984 to conclude a forest harvesting impact study begun by the Alberta Fish and Wildlife Division in 1967. The purpose for the research was to establish an objective basis for watershed management guidelines and for forest harvesting ground rules. A revised set of objectives were derived from a pre-existing set and the needs of client agencies. A program design philosophy was set, based on five principles:
\end{abstract}

1. experimentation based on the scientific method;

2. the application of systems concepts to study designs;

3. the application of standard methods for data capture, analysis and reporting;

4. data quality assurance through regular application of standard statistical control techniques; and

5. data sharing in Canada among cooperating agencies to maximize information and minimize duplication of effort.

\section{INTRODUCTION}

Aquatic habitat is influenced by a complex interaction of processes and events not only in a stream channel, but also in the streamside and upland environments. A stream basin can be looked upon as a system composed of both static and dynamic elements. The dynamic elements are climate, trophic state, hydrology and hydrogeology, fluviology and hydrochemistry. The static elements are bedrock geology, surficial geology, soils and topography of the basin. The flow elements (or transport media) are air and water. Suspended and dissolved solid material, both organic and inorganic, is derived from the land surface, and the concentration of this material affects and is determined by the hydrologic cycle. 
The practice of clear-cutting followed by scarification of the land surface to promote forest renewal was thought by some members of the public to increase the rate of soil erosion and, possibly, to leach salts and nutrients from the soil. Accelerated erosion, in turn, was thought to degrade stream water quality and, thus, the habitat for desirable fish species, particularly rainbow trout. Studies conducted elsewhere in the world suggested that habitat degradation by man resulted in a drop in both the number and quality of salmonids and there was no information to suggest anything different would occur in the Alberta East Slopes region.

Synthesis of the data can be conducted through a series of before/after comparisons. The comparisons are rooted in the idea that both physical and living systems will show some kind of measurable response to increased stress. High suspended solids concentration is the most important stress, but the related stress of high dissolved solids is also of interest in relation to fish population behaviour.

\section{PROGRAM OBJECTIVES AND PLAN}

The overall objective for the research program was to determine the effects of forest harvesting operations on the physical and biotic characteristics of Deerlick and Wampus Creeks (Figure 1). Their preharvest condition and the condition of Eunice Creek, which was left unharvested, were used as controls. A complete environmental study was deemed to be too costly for this particular problem and consequently, three specific objectives were set. These objectives were intended to test the public perception that forest harvesting operations resulted in increased sedimentation and, thus degraded fish habitat.

The objectives were:

1. to determine the effects of sedimentation on bottom fauna;

2. to determine the effects of sedimentation upon the physical characteristics of channel habitat; and

3. to determine the effects of sedimentation upon fish populations. In effect, the problems consisted of two parts: 


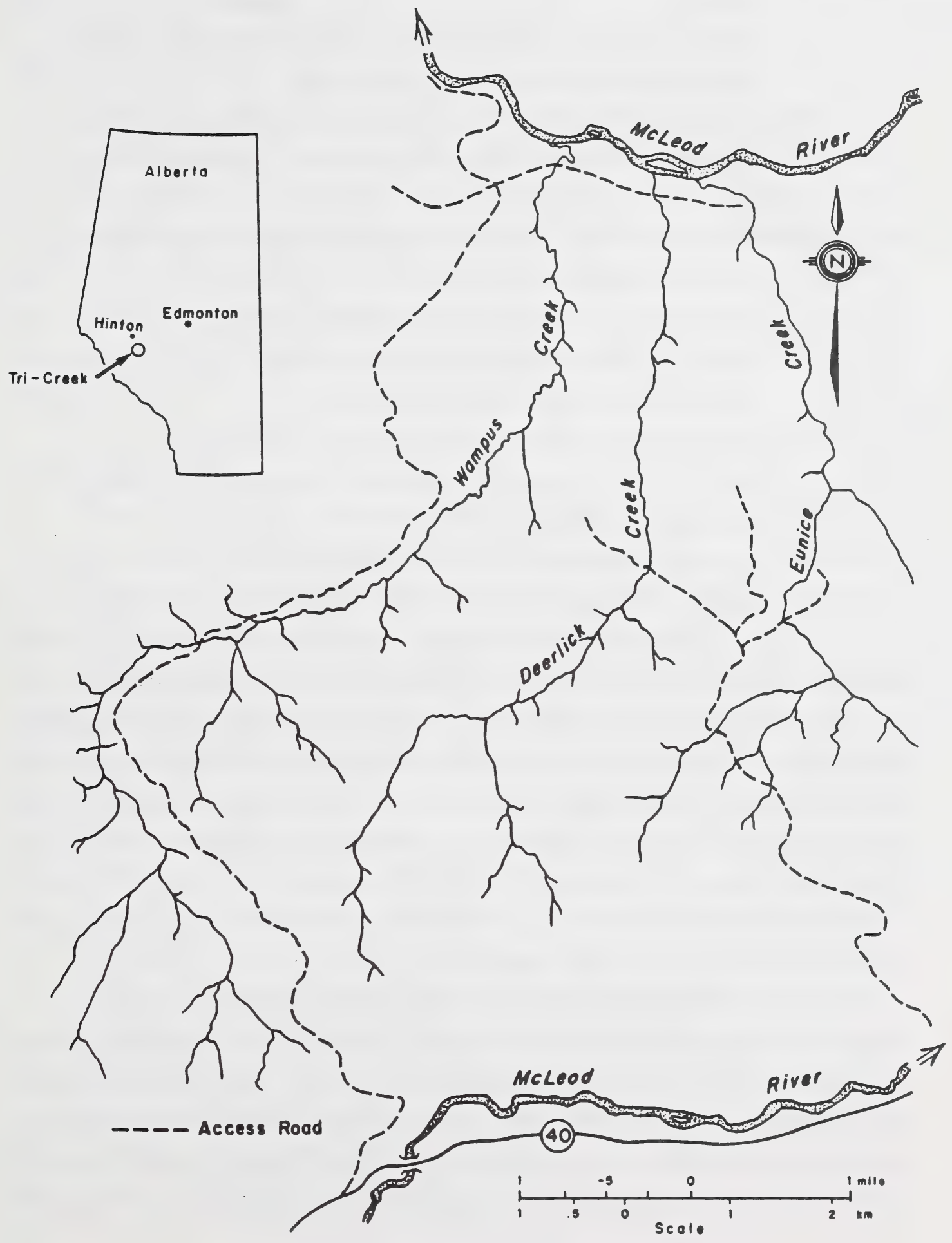

Figure 1. Location of the Tri-Creek watershed. 
1. the physical processes of erosion, transport and sedimentation and the effect of man's activities on these processes; and

2. the biological responses to a naturally harsh environment and the consequences of degrading the aquatic environment during the open water period.

Four possible cause and effect relationships for the physical processes were examined:

1. forest harvesting and soil erosion;

2. soil erosion and suspended solids loadings to the receiving streams,

3. suspended solids loadings and stream mechanics; and

4. suspended solids loadings and water chemistry.

For the biological processes, three cause and effect relationships were studied:

1. suspended solids loadings and population dynamics - in particular, spawning success and year/class/size;

2. suspended solids loadings and fish behaviour; and

3. suspended solids loadings and macroinvertebrate behaviour.

The goal of the program was to produce quantitative models for each of these cause/effect relationships which could be used for land use management in the East Slopes region of Alberta.

A secondary goal for this study was to produce information that could be incorporated into several key Alberta Forest Service land use management documents, in particular the Timber Harvest Cut Block Design Manual, the Resource Road Planning Guidelines and the Stream Crossing Guidelines. The Coal Mine Wastewater Management Guidelines issued by Alberta Environment, Standards and Approvals Division will be reviewed in the light of this program's results as well. A further use for the report will be a review of the timber harvesting ground rules for the Athabasca and McLeod areas.

Within the Alberta Fish and Wildlife Division, it is hoped that information from the program will be useful to regional fisheries managers for planning sport fishing control measures, habitat enhancement operations and regional inventory operations. The fish data may be useful as a benchmark for comparison with similar basins. The mathematical models produced by the program should be helpful to officers of the Fisheries Branch when they provide advice to the Forest Service, Alberta Transportation and municipalities on the affect of surface disturbances. 
Projects were designed to test the program null hypothesis that forest harvesting had no significant effect on natural systems. Individual projects were identified by tracing the flow of water from the atmosphere through the forest, soil, bedrock and to the surface again via the stream channel or adjacent wetlands. Each project was linked to other projects through input-output analysis and as a producer or user of data. A program team was organized from a variety of sources, including Alberta Forest Service staff; Alberta Fish and Wildlife Division staff; contractors; university staff, students and support personnel and other provincial and federal government agencies. Funding, instrumentation and logistical support were obtained in the same fashion, and a reporting schedule was imposed, based on the 31 March 1987 deadline set by the Forest Service.

\section{PROJECT DESIGN}

Research into the effects of forest harvesting on the quality of natural waters was initiated at the Tri-Creek Experimental Watershed in 1967, following about two years of planning by officers of the Alberta Fish and Wildlife Division and the Alberta Forest Service. Their research design reflects the state of knowledge and political priorities of that era.

The study proposed in 1965 was to observe the state of the habitat used by the native rainbow trout (Oncorhynchus mykiss) and the bull trout (Salvelinus confluentus) for ten years in advance of clear-cutting to establish baseline conditions. They were: harvest the forest in the shortest time possible (five years or less was hoped for); observe the same environmental and biological factors for a further five years; and then compare results statistically to quantify the changes that had occurred. Any documented habitat changes would then be correlated with any observed changes in the biology of the target species. During the study, however, the duration of the three observation periods was altered in response to several epochs of the economic cycle.

The baseline period was reduced to seven years due to a late startup (most instrumentation was not commissioned until 1969) and withdrawal of federal government funding in 1974. Harvesting operations began in 1977 and did not conclude until early 1984. Provincial government financial problems limited the post-harvest observation period to three years (1984, 1985 and 1986). Overall responsibility for the program has rested with the Alberta Forest Service continuously since 1967, first the Forest Land Use Branch and, from 1984 to the end of 
the program, with the Forest Research Branch. The Fisheries Management Branch of Alberta Fish and Wildlife Division acted in cooperation with the Forest Service from the beginning.

Given that only three years of post-harvest data collection was possible, the main emphasis for the post-harvest period was to attempt empirical explanations of observed phenomena, using published conceptual and mathematical models whenever possible. As an example, the WRENSS system for basin water yield prediction used by the U.S. Environmental Protection Agency and the U.S. Forest Service was calibrated for the basin and validated using data from the program.

Execution of the post-harvest research plan was coordinated through a study team composed of representatives from the client agencies and research staff from each of the projects that made up the plan. Meetings were chaired by the study director. The study director in turn reported to the Director of Forest Research. The program plan was approved by the Deputy Minister for Forestry, Lands and Wildlife in January 1984.

The plan was organized into five major components: climatology, forestry, water resources, geosciences and aquatic ecology (Table 1). Execution of each component was overseen by a panel of specialists in the field who reviewed project plans and proposals, received reports and advised the Study Team on matters within their expertise. Starting in 1984, 24 projects were defined and 19 initiated or continued under revised terms of reference. Six aborted before the end of 1986 for administrative reasons. The general plan for information synthesis is shown in Figure 2.

\section{Experimental Design}

An experimental approach similar to those adopted by the Hubbard Brook, New Hampshire, Nashwaak, New Brunswick and Carnation Creek, British Columbia experimental watersheds was adopted for Tri-Creek. Each component was cast as a discrete experiment, with its purpose, objectives and terms of reference written as simply and unambiguously as possible. A set of basic assumptions was also explicitly stated and a working hypothesis proposed, usually in the form of a "null" hypothesis. An experimental method was stated, with the analytical methods to be used cited as precisely as possible. If non-standard methods or a novel approach to the problem seemed justified, the details of the method or innovation were fully described in detail in the proposal. 
Table 1: Tri-Creek experimental watershed research plan.

\section{Project List}

1. Climatology Component

1.1 Climate of Tri-Creek (R. Olson, Consultant)

1.2 Hydrometeorology (AES, R. Olson, Consultant)

1.3 Snow Hydrology (FRB)

1.4 Solar Radiation (ARC)

1.5 Precipitation Chemistry (Not done)

2. Forestry Component

2.1 Harvesting (St. Regis Forest Products, Edson Forest, AFS)

2.2 Silviculture (St. Regis Forest Products, Edson Forest, AFS)

2.3 Watershed Management (FLUB)

2.4 Site Classification (REAP)

3. Water Resources Component

3.1 Hydrometeorology (WSC, FRB)

3.2 Sediment Regime (ARAC)

3.3 Hydrology (ARC)

3.4 Pool Volume Estimation (ARC)

3.5 Surface Water Thermal Regime (ARC)

3.6 Channel Regime (ARC)

3.7 Hydrochemistry Regime (AECV, FRB)

3.8 Evapotranspiration (Not done)

4. Geosciences Component

4.1 Soils Mapping (ARC)

4.2 Groundwater Regime (ARC)

4.3 Geological Mapping (ARC)

5. Aquatic Ecology

5.1 Population Dynamics for Major Salmonid Species (FWD)

5.2 Macroinvertebrates Population Dynamics (FWD)

5.3 Microbial Ecology (University of Calgary, preharvest only)

Agency Codes:

AECV - $\quad$ Alberta Environmental Centre, Vegreville

AES - $\quad$ Atmospheric Environment Service, Environment Canada

ARC - $\quad$ Alberta Research Council

ESD - $\quad$ Earth Sciences Division, Alberta Environment

FLUB - $\quad$ Forest Land Use Division, Alberta Forest Service

FWD - $\quad$ Fish and Wildlife Division, Alberta Forestry, Lands and Wildlife

St. Regis- $\quad$ Now Champion Forest Products Limited

WSC - Water Survey of Canada, Environment Canada 


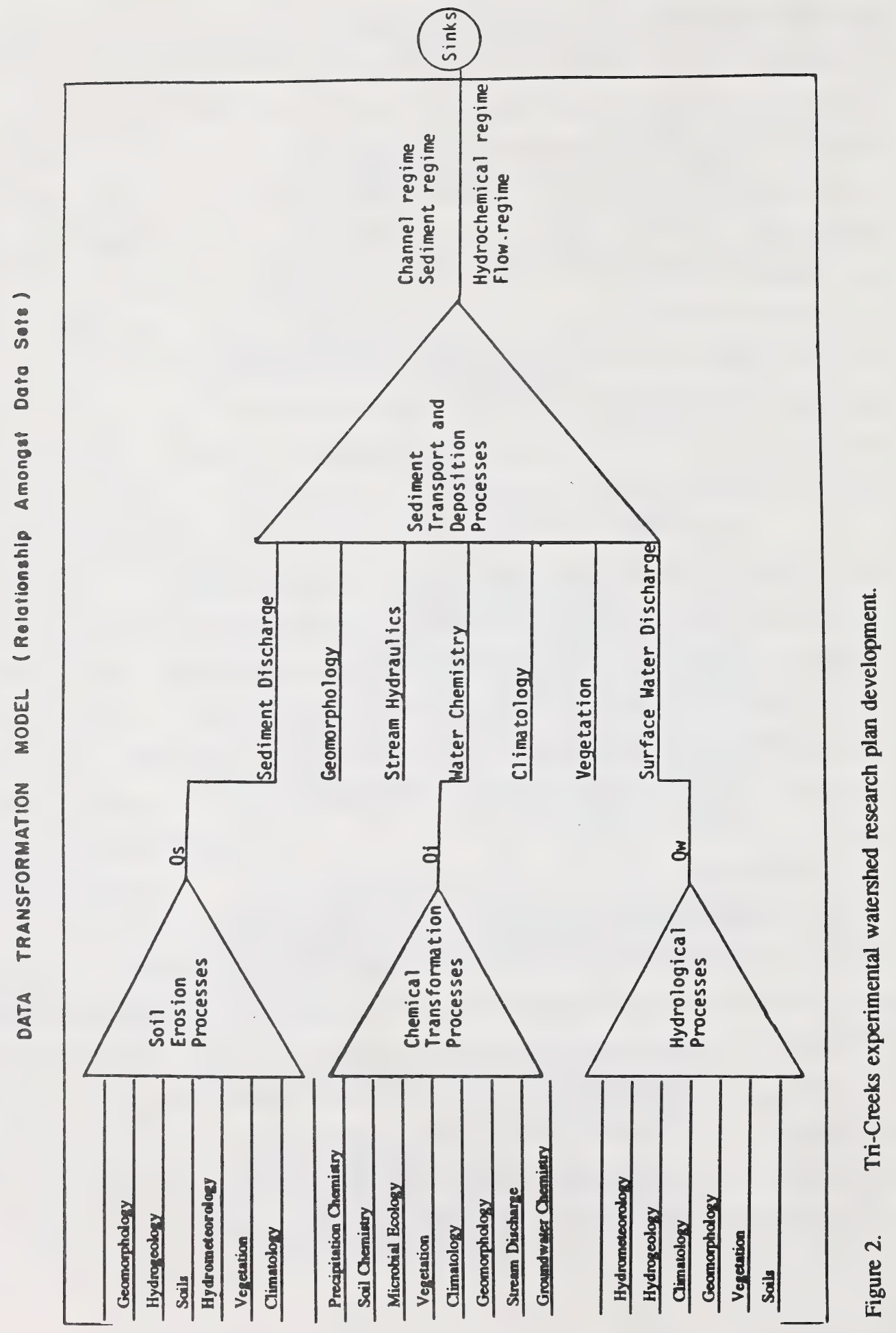




\section{$\underline{\text { Data Evaluation }}$}

Each data set was assessed for its accuracy and precision. In parallel, a data quality control process was developed to ensure the scientific integrity of the data. As data were added to each data base, they were appraised for quality, either through an explicit procedure as was the case for water quality data, or by inspection by the engineer, forester or scientist responsible for the project.

\section{Reporting}

Annual reports and data summaries were prepared throughout the life of the program, although they were not published. Summaries of the state of the system were published by the Forest Land Use Branch, Watershed Management Section, at the end of the baseline period. A final report synthesizing the results of the completed program is in preparation.

The following papers describe some of the projects in this program and their results. 


\title{
Hydrologic Impacts of Forest Harvesting in the Tri-Creek Watershed
}

\author{
Gary Van Der Vinne \\ Civil Engineering Department \\ Alberta Research Council \\ Edmonton, Alberta
}

\section{INTRODUCTION}

The Tri-Creek Experimental Watershed Study was set up in 1965 as part of the International Hydrologic Decade. The study was part of the Alberta Watershed Program initiated by the Department of Lands and Forests. The objectives of the study were to determine the effects of pulpwood harvesting on trout streams in the foothills of Alberta's Rocky Mountain eastern slopes in order to improve forest harvesting guidelines.

\section{OBJECTIVES}

This paper briefly summarizes the hydrologic impacts of forest harvesting which were examined in much greater detail by Andres et al. (1987) as part of the contribution of the Alberta Research Council to the overall Tri-Creek investigation. Two specific areas were addressed: streamflow volume and storm runoff. The annual water yields of the three sub-basins and their monthly distributions were examined and compared so that any impacts of forest harvesting on the water balance in the basin could be detected. Storm hydrographs were also examined to observe if the shape of the runoff hydrograph changes due to forest harvesting. A paired basin approach was used to elucidate differences between the logged and unlogged conditions.

\section{Basin Description}

The Tri-Creek Watershed is located about $30 \mathrm{~km}$ southeast of Hinton, Alberta at $53^{\circ} 09^{\prime}$ north latitude and $117^{\circ} 15^{\prime}$ west longitude. It consists of three sub-basins: Wampus Creek, Deerlick Creek and Eunice Creek. Wampus Creek has the largest drainage area at $28.2 \mathrm{~km}^{2}$ followed by Eunice Creek and Deerlick Creek at $16.1 \mathrm{~km}^{2}$ and $14.8 \mathrm{~km}^{2}$ respectively. Figure 1 shows the shape and relative location of these basins. All three creeks flow into the McLeod River.

The basin is underlain by bedrock consisting of folded sequences of clastic rock overlaid with glacial till (Currie, 1976). Most of the watershed is covered by a sandy loam till except for 


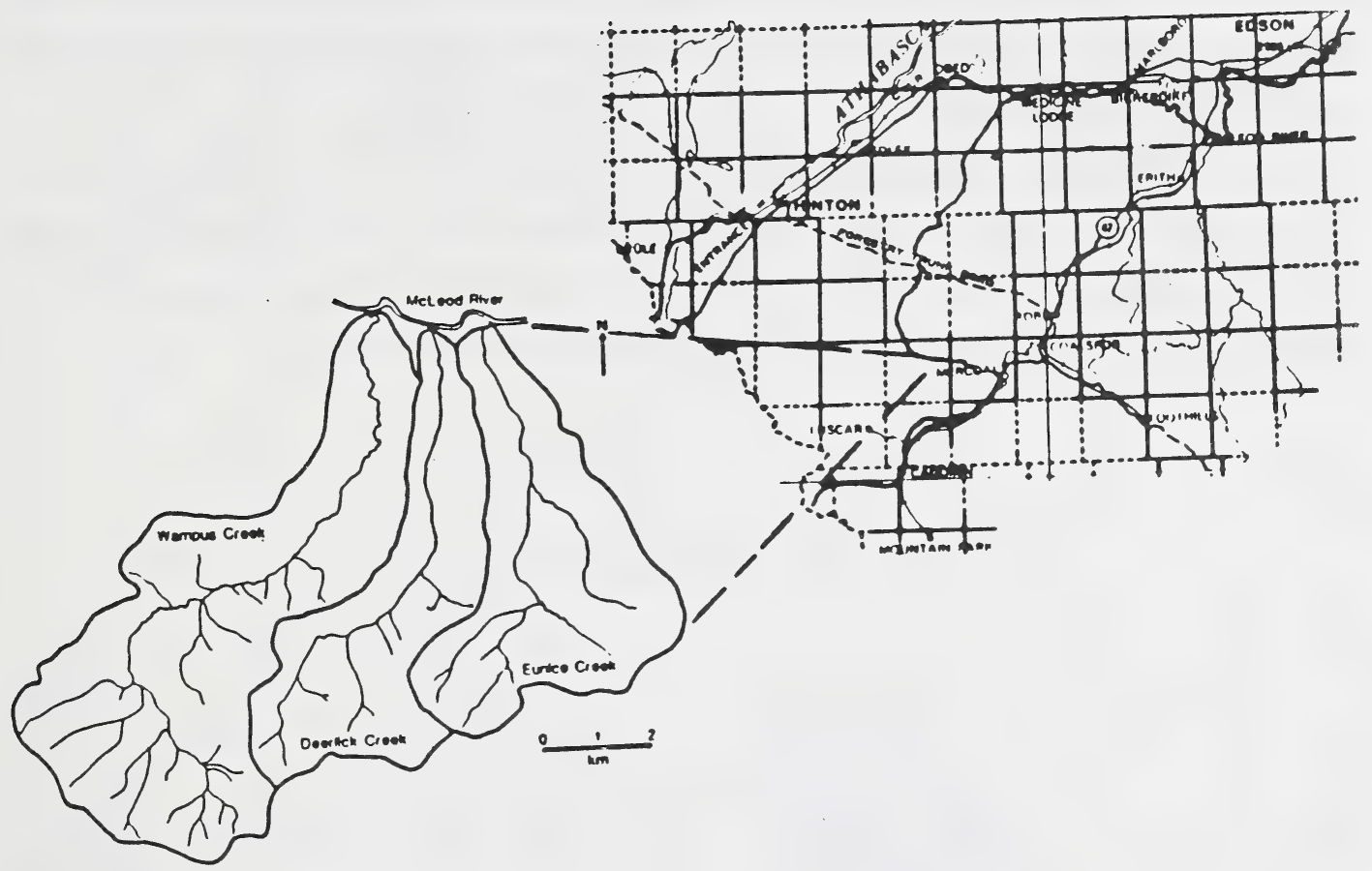

Figure 1. Location and relative position of the Tri-Creek basins.

the northern part, which is covered by a clay-loam till. These tills have weathered to produce the various soils in the basin, which range in texture from sand to clay (Hudson et al., 1985).

The climate is classified as humid, micro thermal and subarctic (Atlas of Canada, 1957). The mean precipitation is $688 \mathrm{~mm}$ with $38 \%$ falling as snow (Winkler, 1980). Winters are subject to chinook winds which can raise the temperature $20^{\circ} \mathrm{C}$ or more in a few hours. The watershed is covered with subalpine forest except for some high ridges and some parts of the valley bottoms which have meadow environments. On the high slopes which drain well, lodgepole pine is the main species of tree. In the valley bottoms where the soil is usually saturated, black spruce predominates. Other species found here include white spruce, alpine fir and balsam poplar.

After ten years of calibration in the pristine basins, logging was initiated in Wampus Creek basin in the winter of 1977-1978 and in Deerlick Creek basin in 1981-1982. When 
logging was completed in Wampus Creek basin in 1982-1983, 39\% of the basin area had been clear-cut, while by 1983-1984, $41 \%$ of Deerlick Creek basin had been clear-cut. The logging schedules are shown in Figure 2.

Precipitation and discharge records were available for 1968 to 1985. Seven Sacramento storage gauges were used to measure seasonal precipitation and three tipping bucket gauges recorded hourly precipitation. The Water Survey of Canada placed water level gauges near the mouths of each of the creeks so that discharge records could be obtained.
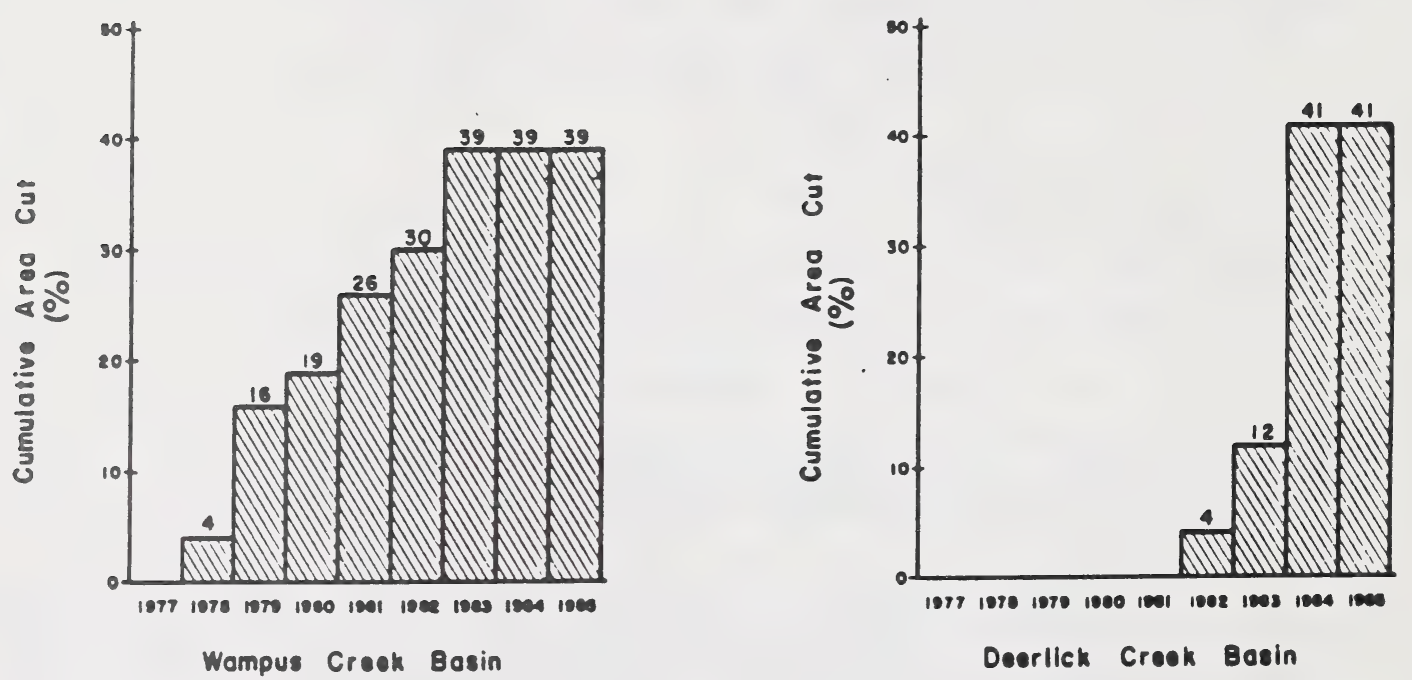

Figure 2. Logging schedules for Wampus and Deerlick Creeks.

\section{RESULTS AND DISCUSSION}

\section{Annual Water Yield}

Annual water yields from the three sub-basins vary considerably from year to year depending on the amount of precipitation, the antecedent moisture conditions and the seasonal distribution of that precipitation. Figure 3 shows that the annual yield varied linearly with precipitation for the three basins. Annual runoff tended to increase with increased precipitation, 

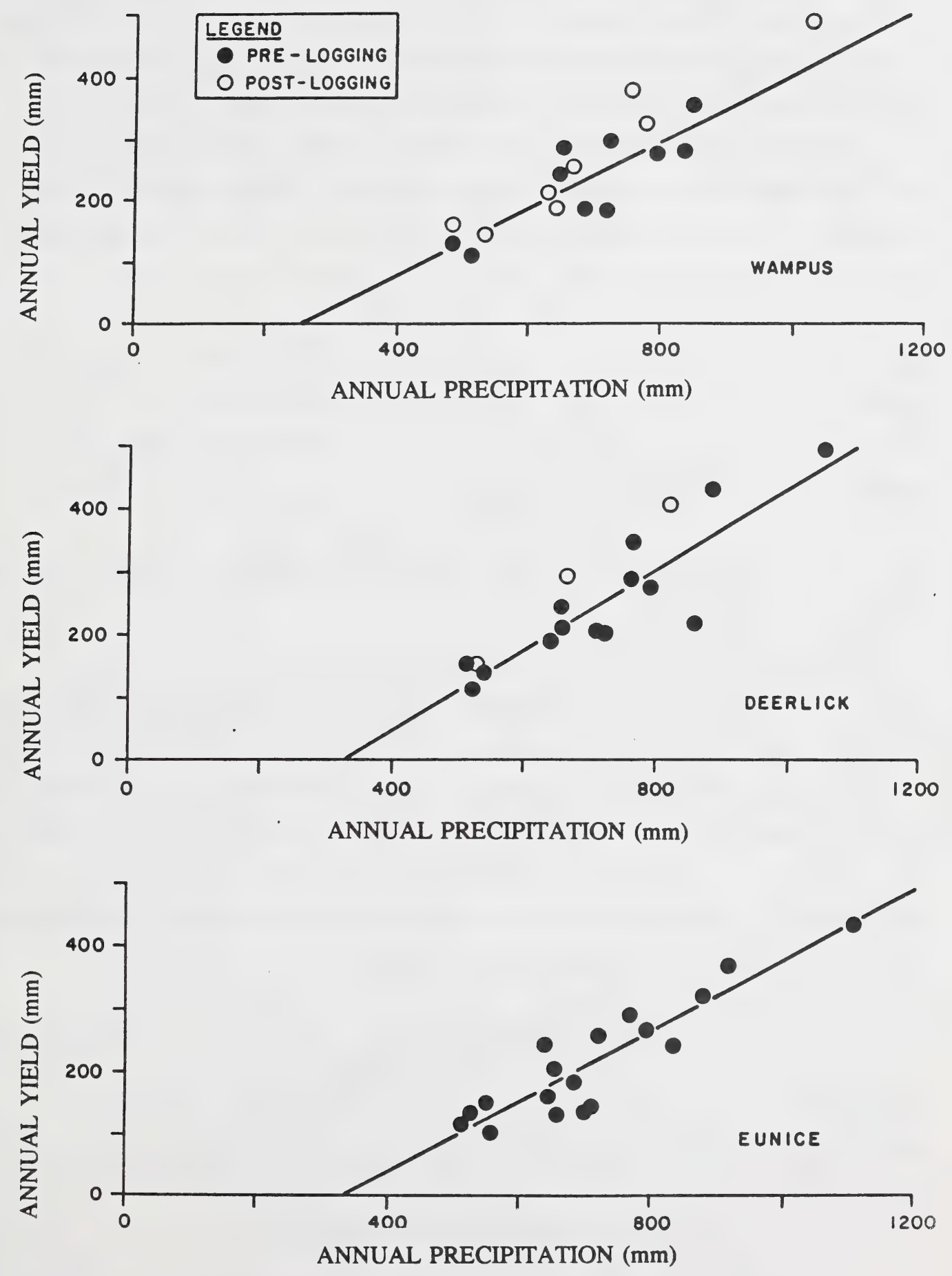

Figure 3. Annual yield vs. precipitation from 1968 to 1985 from Wampus, Deerlick and Eunice Creeks. 
but there was a considerable amount of scatter. The lack of winter flow records, the variation in soil moisture conditions and the seasonal distribution of precipitation accounts for this scatter. The negative $y$-intercepts for these lines indicate that some precipitation occurred without generating runoff. This precipitation contributed to groundwater storage and evapotranspiration losses.

Following logging, most of the annual yields were higher than the yields associated with the best-fit lines passing through the pre-logging data for both Wampus and Deerlick Creek. This indicates that there may have been an increase in annual yield caused by logging. To separate the effects of timber harvesting from variations in yield caused by natural processes, the annual yields of Wampus and Deerlick Creeks were compared with those from Eunice Creek. Antecedent moisture conditions and seasonal distribution of precipitation should have been similar for all three basins. Figure 4 shows that the relationships between basin yields is essentially linear. Regression analysis of the pre-logging data for Wampus Creek yield $\left(\mathrm{Y}_{\mathrm{W}}\right)$ and Eunice Creek yield $\left(\mathrm{Y}_{\mathrm{E}}\right)$ produces the equation:

$$
\mathrm{Y}_{\mathrm{W}}=1.76 \mathrm{Y}_{\mathrm{E}}+518
$$

which has a correlation coefficient (r) of 0.97 . The comparable equation for Deerlick Creek yield $\left(\mathrm{Y}_{\mathrm{D}}\right)$ is:

$$
\mathrm{Y}_{\mathrm{D}}=0.99 \mathrm{Y}_{\mathrm{E}}=210
$$

and this equation has a correlation coefficient of 0.97 as well. Both the above equations have small $y$-intercepts compared to the magnitude of the data. This indicates that little error would occur if the ratios of the yields were assumed to be constant for the pre-logging conditions, that is, if the regression lines were forced through the origin. For post-logging conditions these ratios were assumed to vary linearly with the fraction of basin area clear-cut (F). A linear regression of the data in this manner would quantify the increases in yield associated with timber harvesting. The equations obtained from the regression analysis are:

$$
\frac{Y_{W}}{Y_{E}}=0.824 F+1.92
$$

and:

$$
\frac{Y_{D}}{Y_{E}}=0.695 F+1.07
$$



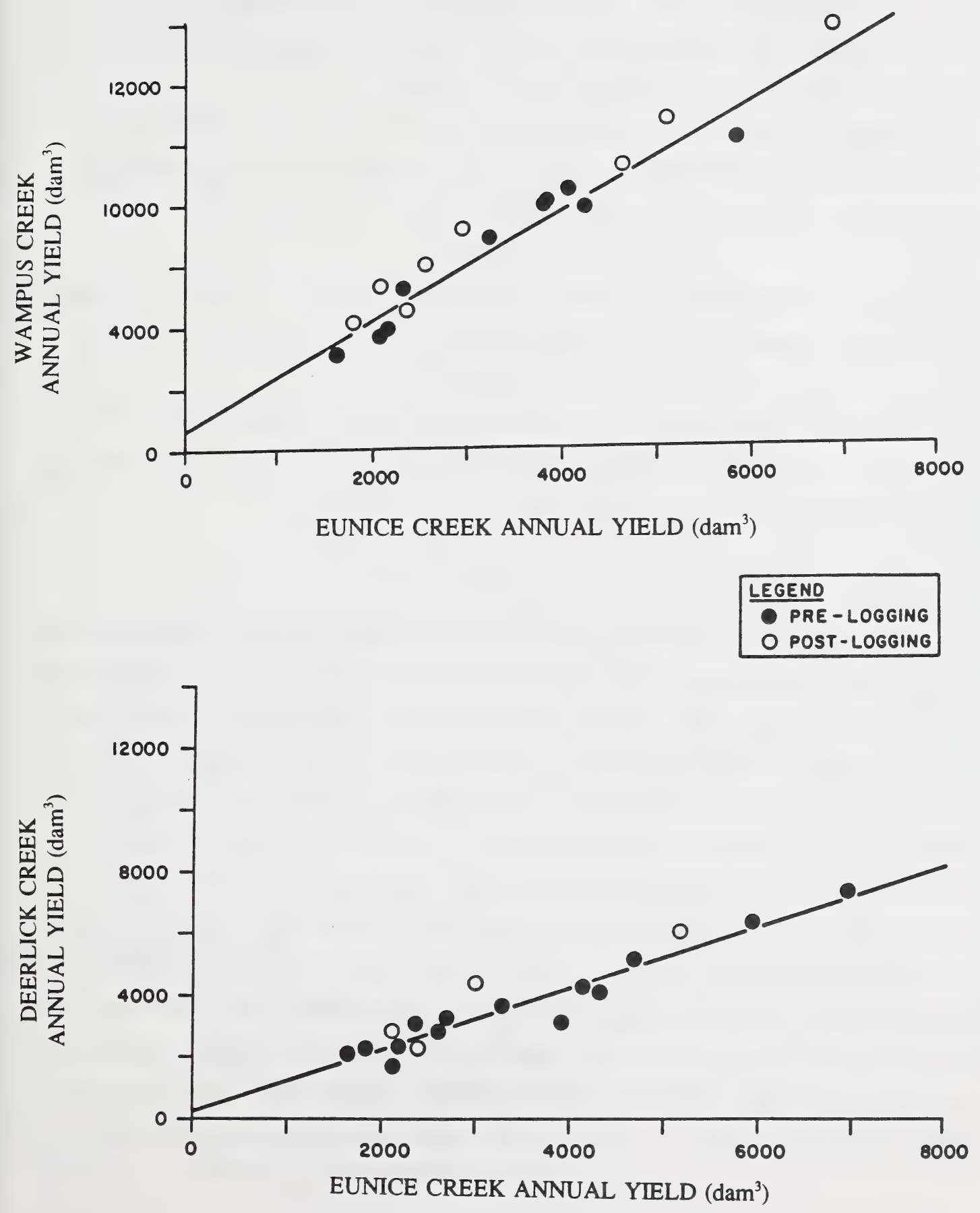

Figure 4. Comparison of annual yield between basins from 1968 to 1985 . 
The correlation coefficients for these equations are low, $r=0.60$ for equation 3 and $4=0.54$ for equation 4 , although equation 3 has a level of significance of $1 \%$ and equation 4 has a level of significance of $2 \%$. Although there is a lot of scatter, the general trend indicates an increase in annual water yield following an increase in the area logged.

Dividing equation 3 by the pre-logging yield ratio $\left(\mathrm{Y}_{\mathrm{W}} / \mathrm{Y}_{\mathrm{E}}=1.92\right)$ and subtracting one produces an equation describing the percentage increase in annual yield in Wampus Creek $\left(\Delta \mathrm{Y}_{\mathrm{w}}\right)$ as a function of the percentage of timber harvested:

$$
\Delta \mathrm{Y}_{\mathrm{w}}=0.43 \% \mathrm{~F}
$$

Performing the same operations on equation 4, using the ratio $\mathrm{Y}_{\mathrm{D}} / \mathrm{Y}_{\mathrm{E}}=1.07$, produces a similar equation for the percentage increase in Deerlick Creek yield $\left(\Delta \mathrm{Y}_{\mathrm{D}}\right)$ due to timber harvesting:

$$
\Delta \mathrm{Y}_{\mathrm{D}}=0.65 \% \mathrm{~F}
$$

Plotting these two equations with their associated data (Figure 5) shows that there is some justification for assuming a linear relationship between an increase in the basin yield and percent of area cut, especially for Wampus Creek basin.

\section{DISCUSSION}

When logging was completed, 39\% of the Wampus Creek basin area had been clear-cut, resulting in an average increase in the water yield of $17 \%$ above what would have been produced had logging not occurred. This amounts to an increase in the average yield of about $690 \mathrm{dam}^{3}$, or $25 \mathrm{~mm}$ between 1983 and 1985. In Deerlick Creek basin, 41\% clear-cutting produced a 27\% increase in annual yield. On average, this was approximately $815 \mathrm{dam}^{3}$, or $55 \mathrm{~mm}$ for the years 1984 to 1985 . The difference between increases of $17 \%$ and $27 \%$ was not large considering the pre-logging yields for Wampus and Deerlick Creeks varied by as much as $25 \%$ compared to Eunice Creek. However, the equation for Deerlick Creek basin was derived using only four years of data after logging started in the basin. If data for more years had been available, the increase in water yield for Deerlick Creek basin might have been more similar to that for Wampus Creek basin, where eight years' data were available after logging commenced. One difference between the two harvested basins was the presence of buffer strips along the banks of Wampus Creek, although this was not expected to produce the difference in increased yield that was observed. 

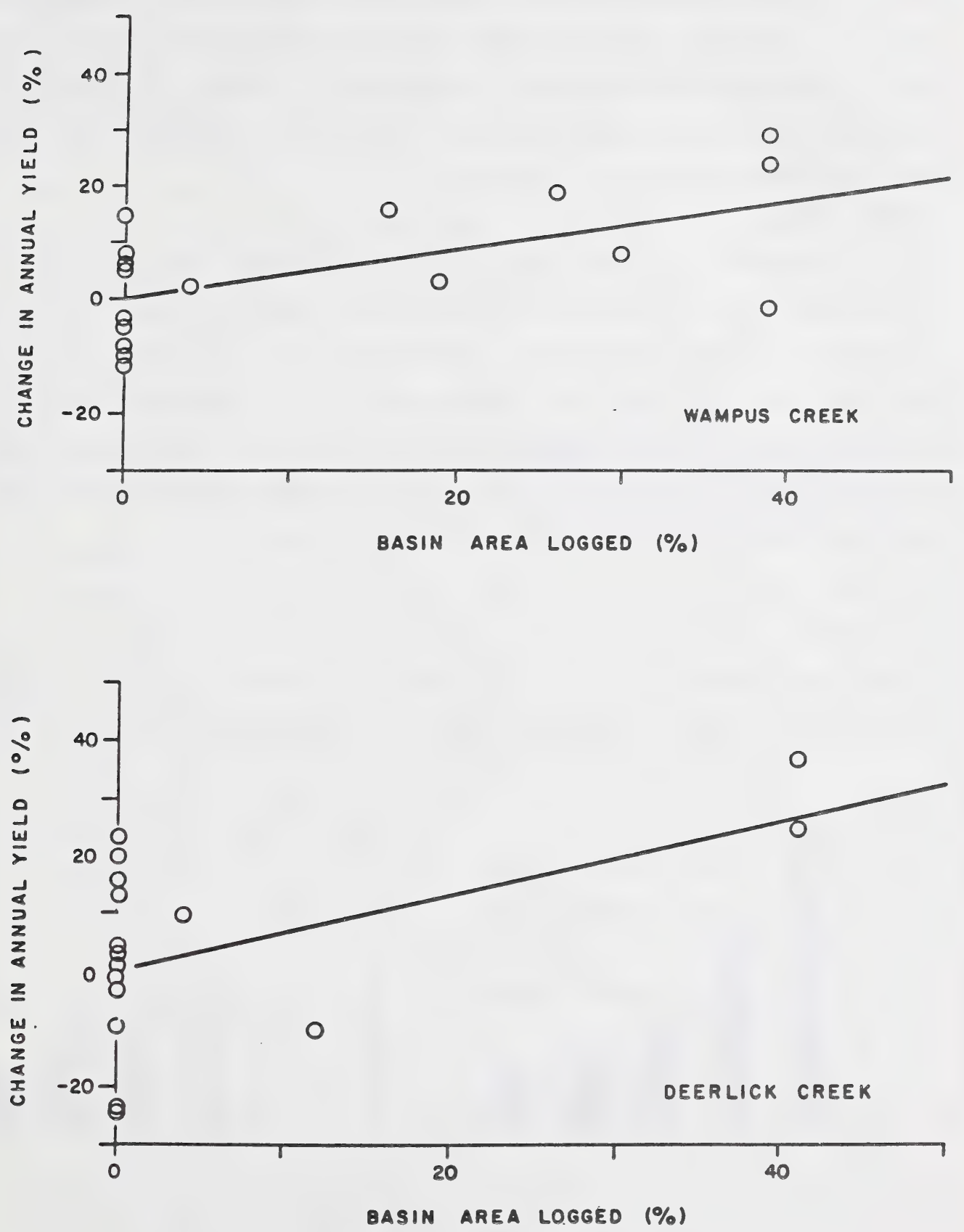

Figure 5. Increase in annual yield vs. basin area. 
The increase in annual water yield found in the Tri-Creek basins due to logging was likely caused by a reduction in evapotranspiration. When the vegetation was removed, evaporation losses from interception and transpiration no longer occurred. Although evaporation directly from the ground surface likely increased, the increase in annual yield indicated that a net reduction in evapotranspiration occurred.

\section{Monthly Yields}

Comparison of the monthly yields of Wampus and Deerlick Creeks with those of Eunice Creek shows that changes in yield occurred after logging took place (Figure 6). These changes in yield were obtained by calculating and comparing the ratios of Wampus Creek and Deerlick Creek over Eunice Creek both before logging started and after logging was completed. The post-logging monthly yields were greater than the pre-logging monthly yields, except during July in Wampus Creek when the yield was actually lower after logging occurred. This decrease was probably not significant compared to the magnitude of the runoff.

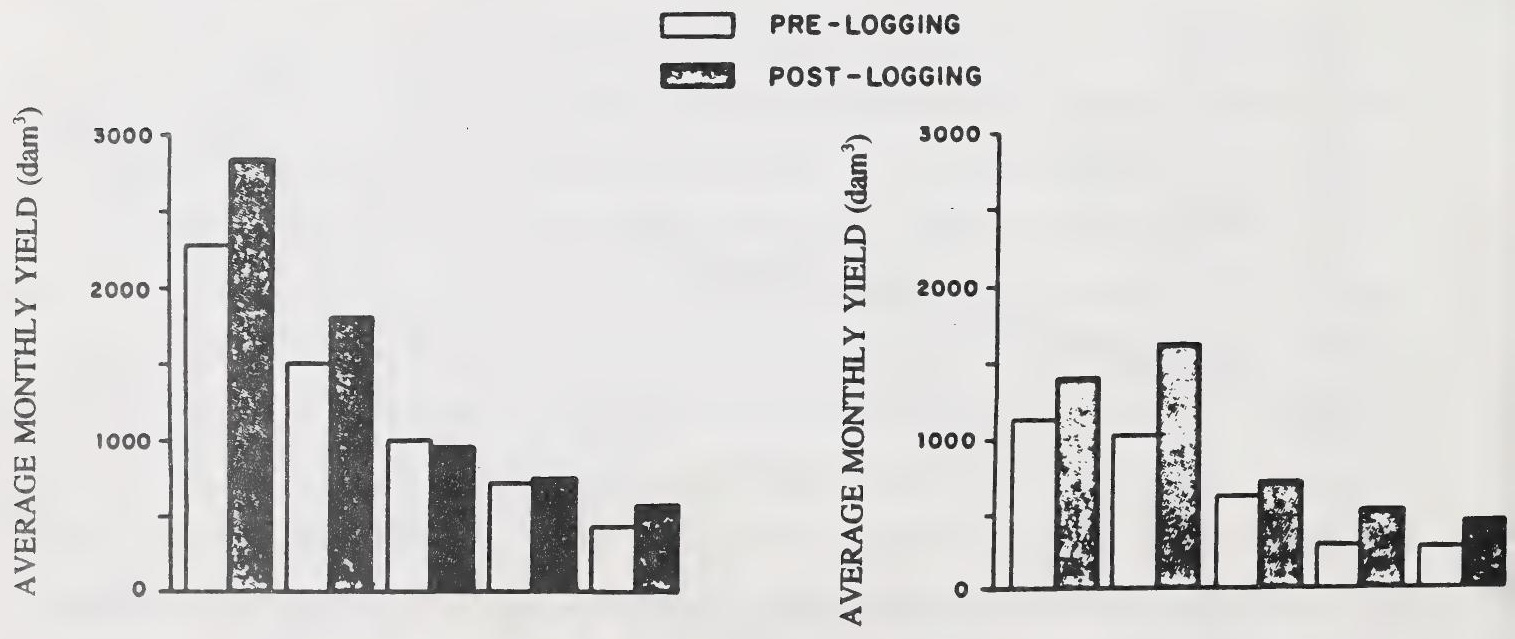

Figure 6. Average monthly yields before and after logging. 
The average monthly runoff did not follow the same trend as the average monthly precipitation (Figure 7). Monthly precipitation was greatest in July, but the peak runoff, mostly due to snowmelt, occurred in May and June. The largest increase in runoff volume also occurred in May and June, which suggests that the snowmelt processes were affected by forest harvesting. If the snow melted more quickly in the exposed cutblocks, less of the meltwater would be lost to evapotranspiration because runoff would occur more quickly.

The percentage increase in monthly yield was large in August and September, although the runoff volumes were much smaller than in May and June. Only in July (and in August in Wampus Creek) was the percentage increase in yield small or even negative. During this hot period, a soil moisture deficit may have occurred which could have limited the actual evapotranspiration losses. A reduction in the evapotranspiration potential, produced by removing vegetation, would not affect the actual rate as much as it would in September, when the potential evapotranspiration declined. This was caused by lower temperatures and fewer daylight hours.

It must be remembered that data for only two or three years were available after logging was completed, and the variation in monthly yield was large from year to year compared to the variation in annual yield because of the random nature of rainfall events. The increases in monthly yield shown in Figure 6 may not be statistically significant (Andres et al., 1987).

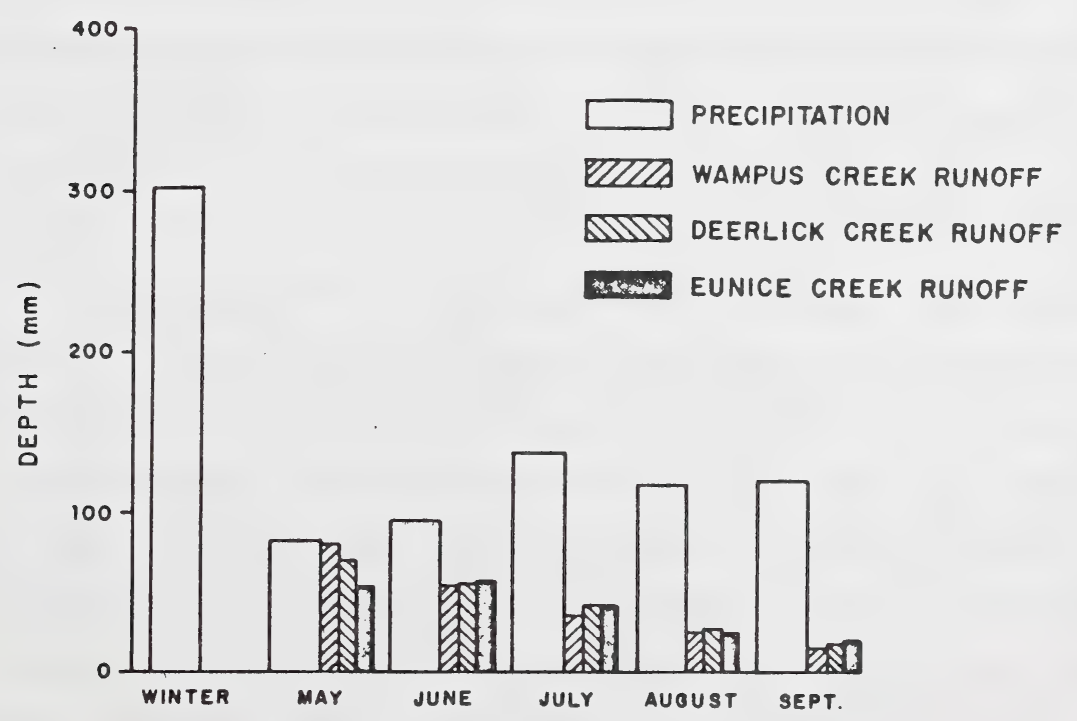

Figure 7. Average monthly precipitation and runoff depths. 


\section{$\underline{\text { Storm Hydrographs }}$}

The analysis of storm hydrographs was used in an attempt to detect changes in the runoff characteristics of a basin due to timber harvesting. Logging operations change the surface characteristics of a basin and it is these characteristics, along with the shape of the basin, which dictate the shape of the storm hydrograph. Unit hydrograph analysis was used to standardize the hydrographs of various storms so that a comparison could be made between pre-logging and post-logging conditions. The analysis accounted for variations in storm duration and intensity, as well as changes in the loss rates from evaporation and infiltration, while preserving the shape of the hydrograph.

From all the years examined, six reasonably large storms were found with both precipitation and discharge measurements available over the duration of the rainfall and runoff period, as well as a seventh storm in August 1985 that had no discharge data for Deerlick Creek. These storms were among the largest of their particular year. Small convective storms were more likely to have greater variation in time and distribution across the basins, while these larger storms were more likely to be regional weather systems which covered the whole area with a more even distribution of rain.

\section{Hydrograph Development}

A one centimeter unit hydrograph is defined as a discharge hydrograph resulting from one centimeter of direct runoff generated uniformly over the basin area at a uniform rate during a specified period of time (Gray, 1970). The time period adopted for this analysis was one hour since the basins were small and had relatively rapid responses. Also, the precipitation data for the seven storms were recorded hourly.

The first step in calculating a unit hydrograph is to determine the direct runoff volume of a storm. Since the direct runoff forms the peak of the hydrograph, as shown in Figure 8, the volume of direct runoff is equal to the area under the hydrograph less the groundwater or base flow. The base flows of each of the hydrographs were separated by drawing a straight line from the point where the hydrographs started to rise from storm runoff to a point later in the hydrographs where the flow was supplied mainly by groundwater again. This latter point was established as the time when the groundwater recession curve became a straight line, when plotted on semi-log paper. The slope of the baseflow separation line varied considerably from storm to storm but was usually in the range of 0.003 to $0.006 \mathrm{~m}^{3} / \mathrm{s} / \mathrm{h}$ (Table 1 ). 


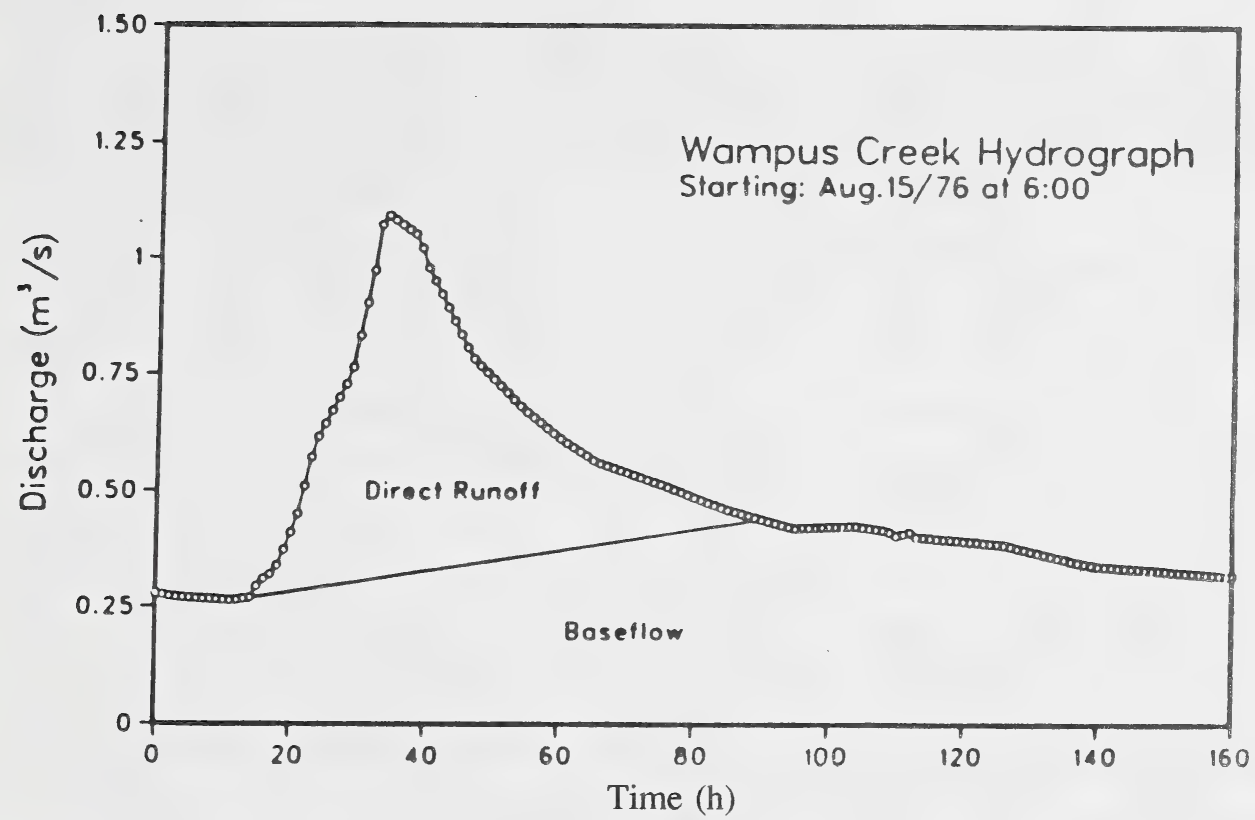

Figure 8. Hydrograph separation.

Table 1. Runoff data summary.

\begin{tabular}{|c|c|c|c|c|c|c|c|}
\hline Date & $\begin{array}{l}\text { Start } \\
\text { Time }\end{array}$ & Basin & $\begin{array}{l}\text { Runoff } \\
\text { Volume } \\
\left(\text { dam }^{3}\right)\end{array}$ & $\begin{array}{l}\text { Duration } \\
\text { (h) }\end{array}$ & $\begin{array}{c}\text { Peakflow } \\
\left(\mathrm{m}^{3} / \mathrm{s}\right)\end{array}$ & $\begin{array}{c}\text { Baseflow } \\
\left(\mathrm{m}^{3} / \mathrm{s}\right)\end{array}$ & $\begin{array}{c}\text { Baseflow } \\
\text { Separation } \\
\text { Slope } \\
\left(\mathrm{m}^{3} / \mathrm{s} / \mathrm{h}\right)\end{array}$ \\
\hline \multirow[t]{3}{*}{ July 11,1974} & \multirow[t]{3}{*}{$7: 00$} & Wampus & 105.0 & 69 & 1.750 & 0.173 & 0.0042 \\
\hline & & Deerlick & 50.0 & 59 & 0.733 & 0.086 & 0.0036 \\
\hline & & Eunice & 37.2 & 43 & 0.823 & 0.105 & 0.0038 \\
\hline \multirow[t]{3}{*}{ June 15,1975} & \multirow[t]{3}{*}{$6: 00$} & Wampus & 73.1 & 59 & 1.430 & 0.379 & 0.0061 \\
\hline & & Deerlick & 25.9 & 39 & 0.585 & 0.145 & 0.0053 \\
\hline & & Eunice & 19.2 & 33 & 0.575 & 0.163 & 0.0057 \\
\hline \multirow[t]{3}{*}{ Aug. 15, 1976} & \multirow[t]{3}{*}{$6: 00$} & Wampus & 79.5 & 76 & 1.090 & 0.269 & 0.0023 \\
\hline & & Deerlick & 61.6 & 66 & 0.807 & 0.153 & 0.0019 \\
\hline & & Eunice & 31.5 & 50 & 0.552 & 0.110 & 0.0017 \\
\hline
\end{tabular}




\begin{tabular}{|c|c|c|c|c|c|c|c|}
\hline Date & $\begin{array}{l}\text { Start } \\
\text { Time }\end{array}$ & Basin & $\begin{array}{c}\text { Runoff } \\
\text { Volume } \\
\left(\text { dam }^{3}\right)\end{array}$ & $\begin{array}{l}\text { Duration } \\
\text { (h) }\end{array}$ & $\begin{array}{c}\text { Peakflow } \\
\left(\mathrm{m}^{3} / \mathrm{s}\right)\end{array}$ & $\begin{array}{c}\text { Baseflow } \\
\left(\mathrm{m}^{3} / \mathrm{s}\right)\end{array}$ & $\begin{array}{c}\text { Baseflow } \\
\text { Separation } \\
\text { Slope } \\
\left(\mathrm{m}^{3} / \mathrm{s} / \mathrm{h}\right)\end{array}$ \\
\hline \multirow[t]{3}{*}{ June 5,1978} & \multirow[t]{3}{*}{$17: 00$} & Wampus & 109.0 & 68 & 2.020 & 0.511 & 0.0039 \\
\hline & & Deerlick & 53.4 & 51 & 1.050 & 0.291 & 0.0048 \\
\hline & & Eunice & 29.0 & 40 & 0.773 & 0.262 & 0.0032 \\
\hline \multirow[t]{3}{*}{ June 19,1979} & \multirow[t]{3}{*}{$23: 00$} & Wampus & 87.4 & 71 & 1.570 & 0.281 & 0.0049 \\
\hline & & Deerlick & 54.9 & 42 & 1.330 & 0.169 & 0.0060 \\
\hline & & Eunice & 57.7 & 38 & 1.330 & 0.105 & 0.0041 \\
\hline \multirow[t]{3}{*}{ June 23,1985} & \multirow[t]{3}{*}{$7: 00$} & Wampus & 264.0 & 104 & 2.510 & 0.218 & 0.0049 \\
\hline & & Deerlick & 156.0 & 73 & 1.910 & 0.165 & 0.0090 \\
\hline & & Eunice & 45.8 & 52 & 0.854 & 0.154 & 0.0038 \\
\hline \multirow[t]{3}{*}{ Aug. 14, 1985} & \multirow[t]{3}{*}{$15: 00$} & Wampus & 228.0 & 81 & 2.970 & 0.534 & 0.004 \\
\hline & & Deerlick & -- & -- & -- & - & -- \\
\hline & & Eunice & 81.8 & 75 & 1.090 & 0.199 & 0.0028 \\
\hline
\end{tabular}

The net precipitation is defined as that portion of rainfall that reaches the stream as direct runoff (Gray, 1970); therefore, the direct runoff volumes obtained from the baseflow separations were divided by the basin areas to obtain the net rain depths for each of the storms (Table 2). The distribution of net rain was obtained by applying a uniform loss rate to the basin rainfall so that only the rainfall intensities higher than this loss rate contributed to the runoff volume. This net rainfall distribution and the storm runoff hydrograph (hydrograph minus baseflow) were used to find a $1 \mathrm{~cm}$ unit hydrograph for a one hour rainfall. Collin's method (Gray, 1970) was used to separate the complex hydrographs into a number of identical one hour unit hydrographs. If the procedure did not converge to produce a smooth unit hydrograph (ie. if the discharge fluctuated rapidly), the loss rate was adjusted. A decreasing loss rate was used to account for a higher infiltration rate at the beginning of the storm due to lower moisture levels in the soil at that time (Figure 9). Three or four iterations, using various loss rates, were calculated for some of the storms before a suitable loss rate was found. Some storms, such as the June 23, 1985 storm, would not produce a smooth unit hydrograph, so an average curve was drawn through the scatter, taking care to conserve the unit nature of the graph. 
Table 2. Storm data summary.

\begin{tabular}{|c|c|c|c|c|c|c|c|c|}
\hline Date & $\begin{array}{l}\text { Start } \\
\text { Time }\end{array}$ & Basin & $\begin{array}{l}\text { Total } \\
\text { Rain } \\
(\mathrm{mm})\end{array}$ & $\begin{array}{l}\text { Net Rain } \\
(\mathrm{mm})\end{array}$ & $\begin{array}{l}\text { Duration } \\
\text { (h) }\end{array}$ & $\begin{array}{c}\text { Peak } \\
\text { Intensity } \\
(\mathrm{mm} / \mathrm{h})\end{array}$ & $\begin{array}{c}\text { Average } \\
\text { Loss Rate } \\
\text { (mm/h) }\end{array}$ & $\begin{array}{c}\text { Runoff } \\
\text { Coefficient }\end{array}$ \\
\hline \multirow[t]{3}{*}{ July 11, 1974} & \multirow[t]{3}{*}{$7: 00$} & Wampus & 37.1 & 3.7 & 20 & 3.2 & 2.4 & 0.10 \\
\hline & & Deerlick & 38.1 & 3.4 & 20 & 3.9 & 2.5 & 0.09 \\
\hline & & Eunice & 39.6 & 2.3 & 20 & 5.1 & 3.0 & 0.06 \\
\hline \multirow[t]{3}{*}{ June 15, 1976} & \multirow[t]{3}{*}{$6: 00$} & Wampus & 24.1 & 2.6 & 26 & 3.6 & 2.2 & 0.11 \\
\hline & & Deerlick & 22.4 & 1.8 & 26 & 3.6 & 2.3 & 0.08 \\
\hline & & Eunice & 22.4 & 1.2 & 26 & 3.5 & 2.8 & 0.05 \\
\hline \multirow[t]{3}{*}{ Aug. 15, 1976} & \multirow[t]{3}{*}{$6: 00$} & Wampus & 32.5 & 2.8 & 34 & 5.9 & 3.2 & 0.09 \\
\hline & & Deerlick & 32.0 & 4.2 & 34 & 5.2 & 2.7 & 0.13 \\
\hline & & Eunice & 33.5 & 2.0 & 34 & 6.3 & 4.3 & 0.06 \\
\hline \multirow[t]{3}{*}{ June 5, 1978} & \multirow[t]{3}{*}{$17: 00$} & Wampus & 21.3 & 3.9 & 17 & 4.2 & 2.2 & 0.18 \\
\hline & & Deerlick & 20.8 & 3.6 & 17 & 3.5 & 2.2 & 0.17 \\
\hline & & Eunice & 19.3 & 1.8 & 17 & 3.8 & 2.7 & 0.09 \\
\hline \multirow[t]{3}{*}{ June 19, 1979} & \multirow[t]{3}{*}{$23: 00$} & Wampus & 29.2 & 3.1 & 9 & 8.8 & 6.1 & 0.11 \\
\hline & & Deerlick & 30.5 & 3.7 & 9 & 9.4 & 6.0 & 0.12 \\
\hline & & Eunice & 30.2 & 3.6 & 9 & 9.9 & 6.5 & 0.12 \\
\hline \multirow[t]{3}{*}{ June 23,1985} & \multirow[t]{3}{*}{ 7:00 } & Wampus & 95.8 & 9.4 & 43 & 10.1 & 7.1 & 0.10 \\
\hline & & Deerlick & 91.7 & 10.6 & 43 & 9.7 & 5.0 & 0.11 \\
\hline & & Eunice & 85.6 & 2.8 & 43 & 9.3 & 7.5 & 0.03 \\
\hline \multirow[t]{3}{*}{ Aug. 14, 1985} & \multirow[t]{3}{*}{ 15:00 } & Wampus & 106.7 & 8.1 & 30 & 10.1 & 7.1 & 0.08 \\
\hline & & Deerlick & 108.5 & $\mathrm{n} / \mathrm{a}$ & 30 & 10.5 & $\mathrm{n} / \mathrm{a}$ & $\mathrm{n} / \mathrm{a}$ \\
\hline & & Eunice & 112.5 & 5.1 & 30 & 13.9 & 9.4 & 0.05 \\
\hline
\end{tabular}




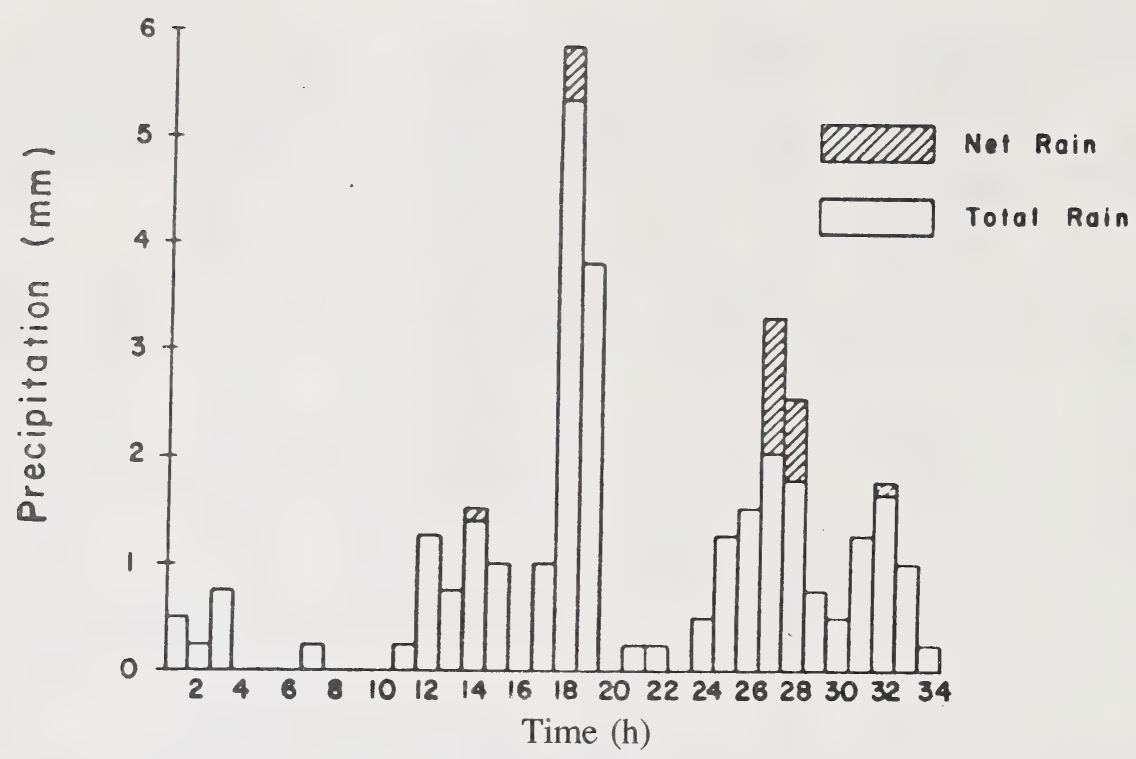

Figure 9. Net rainfall using decreasing loss rate - Wampus Creek, August 15, 1985.

\section{$\underline{\text { Hydrograph Characteristics }}$}

Runoff characteristics such as runoff volumes and durations, peak flow rates and baseflow rates are given in Table 1. Rainfall characteristics such as total and net rain depths, peak intensities and average loss rates, as well as runoff coefficients, are listed in Table 2. The basic characteristics of the unit hydrographs, such as peak flowrates, times to peak and duration, are listed in Table 3. Greater net rains and loss rates occurred when higher total rains and rainfall intensities occurred. In fact, Figure 10 shows a direct proportionality between average loss rate $(\emptyset)$ and peak rainfall intensity $\left(\mathrm{P}_{\max }\right)$. The equation for the line in the graph is:

$$
\emptyset=0.65 \mathrm{P}_{\max }
$$

Hypothetically, if one hour of uniform rainfall fell on a basin, if $100 \%$ of the rain falling on saturated soil ran off, and if $100 \%$ of the rain falling on the unsaturated soil infiltrated, the loss rate would be a constant fraction of the peak intensity. In reality, variations in the rainfall distribution and soil moisture levels cause some fluctuations from the average. From equation 7 , it cannot be said that $35 \%$ of the basin was saturated and contributed to runoff. Subsurface flow 
Table 3. Characteristics of the 1-hour unit hydrographs for Wampus, Deerlick and Eunice Creeks.

\begin{tabular}{|c|c|c|c|}
\hline \multicolumn{4}{|c|}{ Wampus Creek } \\
\hline Storm & Peak Flow $\left(\mathrm{m}^{3} / \mathrm{s}\right)$ & Time to Peak (h) & Duration (h) \\
\hline July 11, 1974 & 5.00 & 6.0 & 56 \\
\hline June 15, 1976 & 4.00 & 9.0 & 56 \\
\hline August 15, 1976 & 3.30 & 9.0 & 62 \\
\hline June 5, 1978 & 3.50 & 10.0 & 62 \\
\hline June 19,1979 & 4.25 & 4.0 & 63 \\
\hline June 23, 1985 & 2.40 & 4.5 & 62 \\
\hline August 14, 1985 & 3.70 & 4.0 & 62 \\
\hline Average & 3.70 & 7.0 & 60 \\
\hline \multicolumn{4}{|c|}{ Deerlick Creek } \\
\hline July 11, 1974 & 1.95 & 11.0 & 50 \\
\hline June 15, 1976 & 2.35 & 9.0 & 37 \\
\hline August 15, 1976 & 1.75 & 7.5 & 41 \\
\hline June 5, 1978 & 1.95 & 7.5 & 47 \\
\hline June 19, 1979 & 3.10 & 4.5 & 38 \\
\hline June 23, 1985 & 1.75 & 5.0 & 52 \\
\hline August 14, 1985 & $\mathrm{n} / \mathrm{a}$ & $\mathrm{n} / \mathrm{a}$ & $\mathrm{n} / \mathrm{a}$ \\
\hline Average & 2.10 & 7.0 & 44 \\
\hline \multicolumn{4}{|c|}{ Eunice Creek } \\
\hline July 11, 1974 & 3.35 & 11.5 & 35 \\
\hline June 15,1976 & 3.00 & 7.0 & 29 \\
\hline August 15, 1976 & 2.35 & 9.0 & 43 \\
\hline June 5,1978 & 2.85 & 9.0 & 37 \\
\hline June 19, 1979 & 3.45 & 6.5 & 36 \\
\hline June 23, 1985 & 2.35 & 9.0 & 45 \\
\hline August 14, 1985 & 1.90 & 6.0 & 60 \\
\hline Average & 2.80 & 8.0 & 39 \\
\hline
\end{tabular}




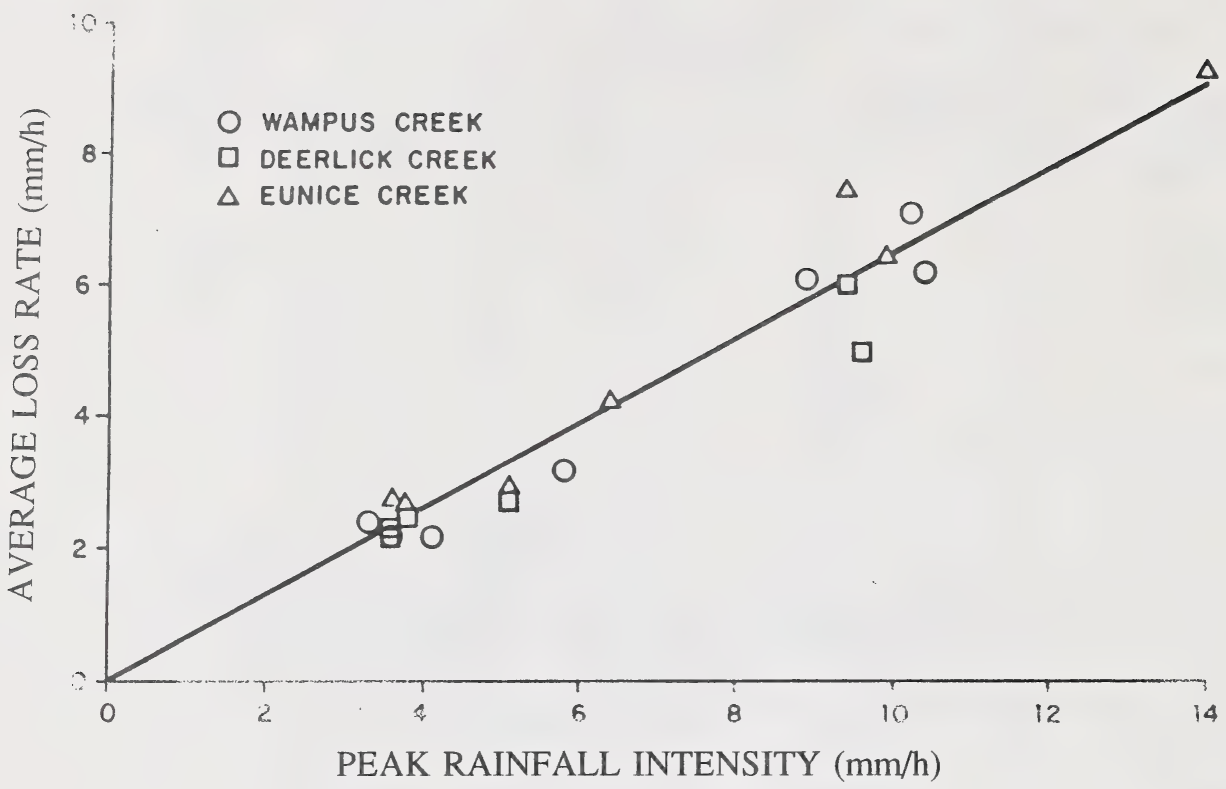

Figure 10. Average loss rates vs. peak rainfall intensities.

from unsaturated areas contributed to direct runoff as well, so the actual percentage of saturated soil may have been much lower. The ratio of the net rain depth over the total rain depth for a particular storm is called the runoff coefficient. The runoff coefficients for the Tri-Creek basins ranged from 0.03 to 0.18 (Table 2). The largest runoff coefficients occurred for the June, 1978 storm in the Wampus and Deerlick basins, before logging occurred. This storm occurred earlier in the year than any of the other storms analysed, so higher soil moisture levels due to snowmelt may have caused the large runoff coefficient. This explanation is supported by the fact that the pre-storm baseflows (Table 1) in the streams were large in comparison with those of the other storms. Excluding this storm, the average runoff coefficient for Wampus basin was 0.10 ; for Deerlick basin, 0.11; and for Eunice basin, 0.06 .

The difference between the pre-logging and post-logging averages was negligible compared to the variation between individual storms. Eunice basin had a lower average runoff coefficient than either Wampus or Deerlick basin. Larger amounts of surface storage in Eunice 
basin compared with Wampus and Deerlick basins may have caused the lower runoff coefficients in Eunice basin. The surface storage component would have been in ponds and surface depressions; therefore, the water would have more time, after the storm is over, to evaporate or infiltrate and percolate down to the groundwater table. Both these processes would have reduced the amount of direct runoff for a given storm event.

The unit hydrographs developed from the various storms differed significantly from one another. There was a large variation in the peak flow rates and periods of rise, although the durations were more consistent, at least for Wampus Creek (Table 3). The pre-logging unit hydrograph peak flow rates for Wampus and Deerlick Creeks were higher than the peak flow rates which occurred after logging commenced. The peak flow rates of the Eunice Creek unit hydrographs, however, dropped during the same period even though no logging occurred in that basin. This also occurred with the periods of rise of the unit hydrographs. The post-logging unit hydrographs from all three basins reached their peaks earlier than the unit hydrographs from storms which occurred before Wampus and Deerlick Creek basins were clear-cut. Possible effects of logging on the unit hydrographs could not be detected; only some general comments on the hydrograph characteristics can be made.

Average unit hydrographs were synthesized from all the storms. These are shown in Figure 11. The average peak flow rate of Wampus Creek was highest because it had the largest drainage area. The peak for Eunice Creek was higher than that for Deerlick Creek because its drainage area was larger and because it had two main streams in its upper basin which drained the basin more quickly. This is likely why the recession limb of the Eunice Creek hydrograph drops below that of Deerlick Creek.

The shape of the storm runoff hydrograph could change due to timber harvesting. The exposure and disturbance of the soil could alter the basin response. A decrease in infiltration may not only increase the peak flow from a storm, but also may reduce the time to peak because surface runoff flows more quickly than subsurface flow. Roads and logging trails may channel the runoff towards the streams which may also increase the peak flow rate and decrease the response time. These effects may be neutralized by the scarification procedures. Deep furrows may trap the surface runoff, delaying it, and thereby reducing the peak flow rate. It was found that precipitation patterns and basin responses were too variable for these effects to be seen. 


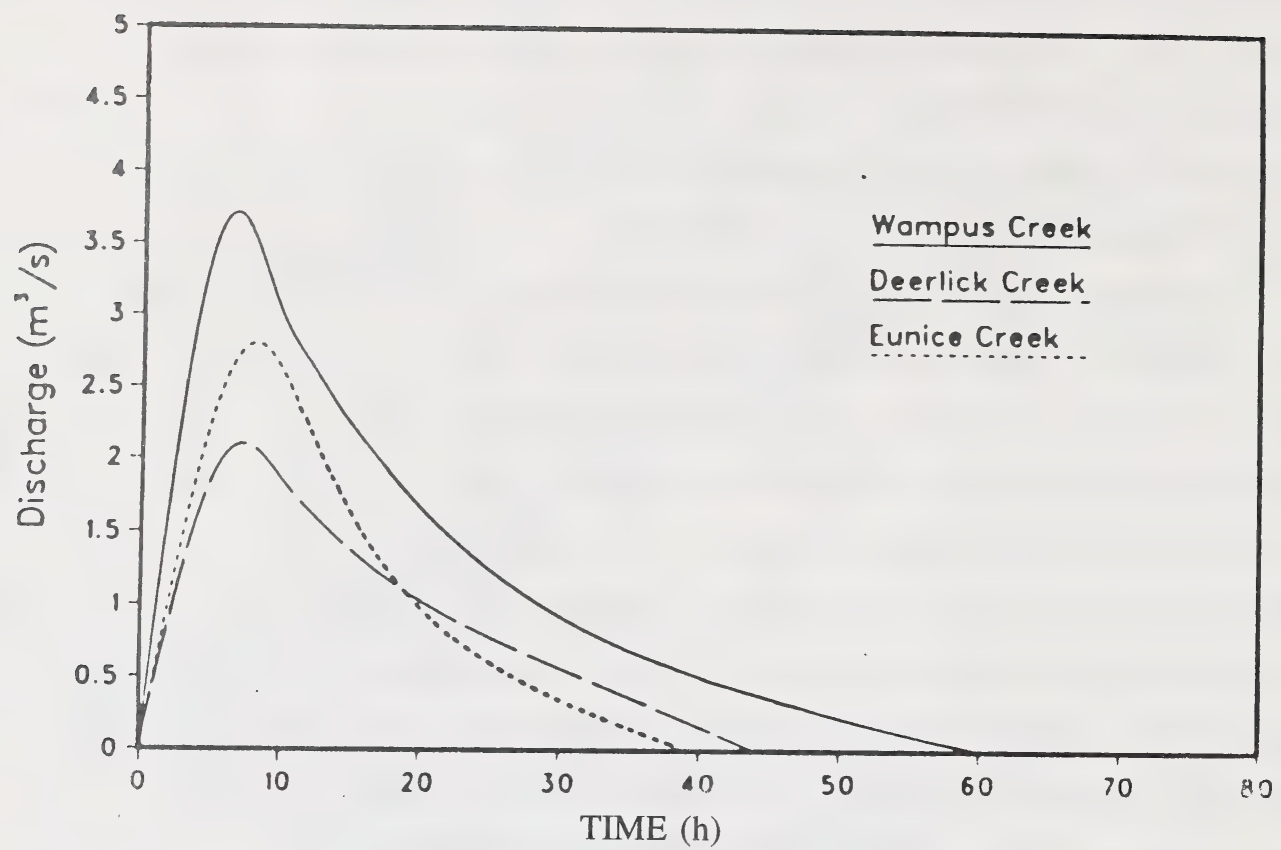

Figure 11. Average $1 \mathrm{~cm}$ unit hydrographs.

\section{CONCLUSIONS}

Parts of Wampus Creek and Deerlick Creek basins were clear-cut to determine if the water yield of the basins changed due to changes in vegetal cover. Post-logging years showed higher annual yields for a given precipitation than did pre-logging years, but variations in evapotranspiration and groundwater storage made the change in yield difficult to quantify. A trend of increased annual yield was observed when clear-cutting occurred. The increase in annual yield for Wampus Creek was 17\% after 39\% of the basin was clear-cut, while the increase in yield for Deerlick Creek was $27 \%$ after $41 \%$ of the basin was clear-cut. Buffer strips along Wampus Creek may have contributed to this difference, but the strips were not large enough to cause the total difference. The bulk of the increases occurred in May and June when the bulk of runoff occurred, although the percentage increase in September was just as large as those in May or June. 
These increases in yield may be explained by the fact that the removal of trees caused a reduction in the evapotranspiration losses. The elimination of interception and a reduction in the transpiration potential are only partially offset by an increase in the evaporation from the ground surface. Also, more rapid snowmelt in open areas may reduce the time available for evaporation, but this may be offset by the increased evaporation rate caused by greater exposure to wind and sun. No definite conclusions on the contribution of snowmelt to changes in the monthly yield can be drawn.

The analysis of individual storm hydrographs did not produce any significant results in evaluating the effects of logging on the runoff process. There was too much variation in the spacial and temporal distribution of the storms and in the basin conditions to detect any changes in basin response due solely to timber harvesting. Runoff coefficients and average loss rates were determined for seven storms spanning the logging period. The average runoff coefficient for Wampus Creek was 0.10, for Deerlick Creek, 0.11, and for Eunice Creek, 0.06. The deviation from these average runoff coefficients due to varying soil moisture conditions was greater than any effects due to timber harvesting practices. As well, the variation in average loss rates was mostly due to differences in precipitation intensity. No effects of logging were detected.

The unit hydrograph analysis was inconclusive in showing any differences in pre-logging and post-logging storm hydrographs; the only distinct change in the hydrologic regime of the Tri-Creek basins due to logging activity was the increase in annual water yield. Indications of other possible changes were seen but no definite conclusions could be drawn. A more detailed exploration of the processes in the basins is needed to compliment the lumped basin approach in order to differentiate between random variations and actual changes due to logging.

\section{REFERENCES}

Andres, D.D., P.G. Van Der Vinne, and G. Sterenberg. 1987. Hydrologic, hydrogeologic, thermal, sediment, and channel regimes of the Tri-Creek experimental basin. Resource Technologies Department, Alberta Research Council, Edmonton, Alberta.

Atlas of Canada. 1957. Department of Mines and Technical Surveys, Geographical Branch, Ottawa, Ontario.

Currie, D.V. 1976. Hydrogeology of the Tri-Creek Basin, Alberta. Alberta Research Council Bull. 33. Edmonton, Alberta. 
Gray, D.M. 1970. Handbook on the Principles of Hydrology. National Research Council of Canada, Ottawa, Ontario.

Hudson, H.R., G.M. Greenlee, and R.W. Howitt. 1985. Soils and Soil Erosion in the Tri-Creek Experiment Watershed, Alberta. Civil Engineering Dept., Alberta Research Council, Edmonton, Alberta.

Winkler, R.D. 1980. Watershed Stratification for Flow Prediction. Univ. Alberta, Edmonton, Alberta. 


\title{
Verification of Water Resources Evaluation for Non-Point Silvicultured Sources, A Water Yield Procedure to the Tri-Creek Experimental Watershed
}

\author{
Allen M.K. Nip \\ Alberta Forest Service, Research Branch \\ Spruce Grove, Alberta
}

\section{ABSTRACT}

WRENSS (Water Resources Evaluation for Non-Point Silvicultural Sources) is a procedure for predicting potential impact on the hydrologic cycle. The Tri-Creek Experimental Watershed, a lodgepole pine forest in the Edson-Hinton area of Alberta, was chosen for comparison between actual measurement of water flow in an undisturbed and a harvested forest. Total water yield was estimated by WRENSS. Results indicate that WRENSS can provide good estimates of water yield for 2 of the 3 experimental watershed sub-basins. It appears that further adjustment of some of the variables required by WRENSS is needed to provide a more accurate representation of the actual conditions of the study area.

\section{INTRODUCTION}

WRENSS (Water Resources Evaluation for Non-Point Silvicultural Sources), developed by the U.S. Forest Service (Troendle and Leaf, 1980) and the U.S. Environmental Protection Agency, is a procedure for predicting the potential impacts of silvicultural activities on the hydrologic cycle. The procedure was formulated using two hydrologic models: PROSPER, an evapotranspiration model, (Goldstein et al., 1974) and WATBAL, a snowmelt model (Leaf and Brink, 1973). The data bases used in the simulation were derived from representative experimental watersheds in the U.S.A., and their relationships were extrapolated for regional application (Troendle and Leaf, 1980).

The hydrologic cycle can be expressed by a simple water balance equation:

$$
\mathrm{P}=\mathrm{Q}+\mathrm{ET} \pm \mathrm{S}
$$

$\begin{array}{lll}\text { where } \mathrm{P} & = & \text { gross precipitation } \\ \mathrm{Q} & = & \text { streamflow or total water yield } \\ \mathrm{ET} & = & \text { evapotranspiration } \\ \mathrm{S} & = & \text { change in storage }\end{array}$

Small-scale silvicultural activities cannot increase the amount of precipitation entering the system, but it can influence the disposition of rain or snow in both time and space in a small local scale. Overall, the removal of vegetation may increase the net precipitation received by 
reducing the amount of interception storage. The reduction of transpiration associated with the elimination of vegetation is very significant in determining the amount of water available for streamflow. Higher soil moisture levels contribute to both higher base flow and wetter antecedent conditions which may result in a greater direct or faster flow during storm events (Troendle and Leaf, 1980)

Numerous studies throughout North America have been conducted to determine the effects of forest cover removal on water yield. Hibbert (1967) and Bosch and Hewlett (1982) provided a summary and review of catchment experiments throughout the world and concluded that removal of forest cover increases water yield. A number of factors affecting changes in water yield have been identified and considered by Troendle and Leaf (1980) in the WRENSS procedure:

1. Vegetative cover, expressed as cover density, is an index of the capability of the stand to utilize incoming radiant energy to transpire water. It is also significant in defining the energy transmitted to the ground. Both vary according to crown closure, vertical foliage, distribution and species.

The removal of forest cover may change the aerodynamic flow of air over the forest opening, leading to a change in pattern of snow accumulation. Golding and Swanson (1978) have shown significant increases in snow accumulation near the center of the forest opening, but these increases are largely offset by decreases in snowpack in the adjacent forest so that the total snow storage is not changed. However, when openings are greater than $14 \mathrm{H}(\mathrm{H}=$ height of surrounding trees $)$ in diameter, the total snow may decrease through sublimation losses and transport of snow out of the basin by wind scour. This represents a net loss of precipitation, thus a net decrease of water available for streamflow.

2. The significance of a snow modifier coefficient lies in the opportunity to alter the melt rates and decrease net water losses from the snowpack. Any large retention of snow as a result of forest cutting can be important in determining the amount of spring runoff (Swanson and Hillman, 1977). It is expected that the change in snow accumulation patterns produced by timber harvesting will persist until the regeneration of new trees approaches the height of the surrounding forest. 
3. Evapotranspiration, referring to the moisture loss through evaporation and transpiration, provides the greatest mechanism for potential changes in the quantity of water available for streamflow as compared to the other water-balance components. Ovington (1962) reported that evapotranspirative losses from conifers may range from 60 to $70 \%$ of the total precipitation received in a coniferous forest. Leaf and Brink (1973) showed that seasonal evapotranspiration can be expressed as a function of seasonal precipitation, solar radiation, vegetative cover density and stomata resistance. Baseline evapotranspiration, derived from normalized averages based on simulations, provides an estimate for a particular precipitation condition. An evapotranspiration modifier coefficient is required to quantify the hydrologic impact resulting from forest cover removal. For hydrologic zone no. 4 (Rocky Mountain/Inland Intermountain) and no. 6 (Continental Maritime of the Pacific Coast Region) the winter evapotranspirative losses were found to be dependent on aspect, but independent of precipitation received since losses are essentially from interception and evaporation of transported snow. Precipitation-evapotranspiration relationships for the spring season are influenced by aspect as well as the amount of precipitation received. The summer-fall season evapotranspirative losses remain constant with aspect, but vary with the amount of precipitation received.

4. The aspect is of important significance in terms of the energy available to melt snow and transpire water.

5. The condition of the analysis by WRENSS refers to the hydrologic state of the watershed. Two conditions are available: baseline and proposed. The baseline condition assumes complete hydrologic utilization is achieved. This is usually thought of as a fully forested watershed (primarily coniferous trees) capable of maximum evapotranspiration. The proposed condition is the hydrologic state following a proposed silviculture activity.

To assess the overall hydrologic effect of a silvicultural treatment with the WRENSS procedure, each method receiving a different treatment is considered individually. The watershed must be divided into subunits by aspect, homogeneous stands of timber (species and cover 
density) and proposed silvicultural prescription (size of openings). The summation of hydrologic effects in each treatment area equals the overall effect of the prescription.

\section{OBJECTIVES}

The purpose of this study is to verify the accuracy of the WRENSS procedure to the Tri-Creek region. The results of the WRENSS procedure will be compared with total discharge under actual ice-free conditions, together with the simulated winter and early spring conditions to determine the following:

1. The capability of WRENSS to estimate water yield accurately under non-harvested and harvested conditions.

2. The accuracy of WRENSS to estimate water yield under varied seasonal and annual precipitation conditions.

3. The most suitable hydrologic zone for use in the foothills of Alberta.

\section{Description of the Study Area}

The Tri-Creek Experimental Watershed study area, comprising three small tributaries of the McLeod River - Wampus, Deerlick and Eunice Creeks, is approximately $40 \mathrm{~km}$ southeast of Hinton, Alberta at 53 $09^{\prime}$ north latitude and $117^{\circ} 15^{\prime}$ west longitude. The basin covering $52 \mathrm{~km}^{2}$ includes $30.6 \mathrm{~km}$ of channel in Deerlick Creek, $49 \mathrm{~km}$ in Eunice and $74.5 \mathrm{~km}$ in Wampus Creek.

The Tri-Creek Experimental Watershed was initiated to document the effects of logging practices on the biological, physical and chemical parameters of an Alberta foothills stream. Wampus Creek was logged according to existing ground rules governing logging practices in the forest management area. A buffer strip of uncut timber was left along Wampus Creek. A similar operation was conducted in the Deerlick Creek sub-basin except the buffer strip along the creek was removed. Eunice Creek sub-basin remained undisturbed, serving as a control watershed basin.

The Tri-Creek basin is predominantly forested with conifers to the summit except for a few of the highest south-aspect ridges. Lodgepole pine (Pinus contorta var. latifolia) is the predominant species on well-drained upland sites. Other species found include white spruce (Picea glauca), black spruce (Picea mariana), alpine fir (Abies lasiocarpa) and balsam poplar (Populus balsamifera). 


\section{METHODS}

The WRENSS procedure was computerized by Pierre Bernier of the Northern Forest Research Centre in Edmonton. Simulations were done to determine the applicability of the following zones to Alberta conditions:

1. Zone no. 4 is characterized by dry snowpacks subjected to a high degree of snow redistribution and wind scour in large forest openings in the winter and summer thunderstorms;

2. Zone no. 6 is characterized by warm winters, wet snowpacks, little or no redistribution of snow due to the wetness of the snowpack and little summer precipitation. Both zones were used in this study.

Accurate precipitation data are critical to the success of the WRENSS procedure. Data were collected from 15 precipitation gauges throughout the basin. Summer precipitation was collected in standard rain gauges ( 5 per sub-basin) and winter precipitation was collected in Sacramento precipitation gauges ( 7 in total throughout the watershed). Only stations which were not affected by forest harvesting were used as part of the database. Where rain gauge data were available, they replaced the monthly Sacramento data. Monthly values were summed to obtain a seasonal value as outlined in the WRENSS procedure. The seasons were as follows: Winter (October 1 - February 28), Spring (March 1 - June 30), and Summer (July 1 - September 30).

Seasonal precipitation was measured at each station and area-weighted using the Thiessens polygon method to obtain a total seasonal precipitation.

Additional climatological data input were used. For example, wind speed data are required to compute direct snowpack evaporation. Where no data were available, as in this case, the option was not used: The procedure also asks for the presence of wind scour. If yes, as in this case where mean cutblock size exceeds $14 \mathrm{H}$ for a particular year, then the procedure computes snow redistribution due to wind scour on a snowpack in large forest openings greater than $14 \mathrm{H}$.

The second parameter was vegetation type and basal area of the species. To simplify the data input, it was assumed that the dominant vegetation type is lodgepole pine, the actual basal area is $32.1 \mathrm{~m}^{2} / \mathrm{ha}$ and the maximum basal area of $45.9 \mathrm{~m}^{2} / \mathrm{ha}$. The average height was $21 \mathrm{~m}$. The above information was derived from Forest Inventory Phase III maps of Alberta. Individual cutblocks were also labelled with individual aspects. 
In the post-treatment phase, the following parameters are required for input:

1. total area cut or in openings;

2. basal area of trees left in the openings (equal to zero);

3. average windward length of openings or average size of openings;

4. height of trees; and

5. roughness coefficient.

The prevailing winds in the winter were assumed to be north-westerly. The maximum width of the cutblock was derived from the maximum windward length in a north-westerly direction. The average windward length was calculated by obtaining a mean of windward length of the cutblocks. The height of trees remained at $21 \mathrm{~m}$ and the roughness coefficient, which is a measure of snow catch efficiency due to protrusions above the ground surface in the cutblock, was approximately $0.3 \mathrm{~m}$.

Actual measurement of streamflow extends only for the ice-free period for most years of analysis. This ice-free period commences approximately April 1 and ends October 31. Underice streamflow conditions have been recorded in the winter-spring periods of 1984, 1984-85, 1985-86 and the fall-winter of 1986. The absence of streamflow data from November to April 1 made it necessary to derive the missing discharge via other methods.

In cooperation with the Hydrology Branch, Alberta Environment, a discharge recession curve was developed for the period from November 1 to March 15. This curve assumes a decline of $67 \%$ of total winter discharge by January 7 (the period of November 1 to January 7 was equivalent to $50 \%$ of the winter period). A reversal of the recession curve was applied to the period commencing March 15 to April 1. A regression analysis was conducted to derive an estimate of discharge for March 15. This resulted in multiplying the discharge of October 31 by 0.1 to derive a value for March 15. The correlation coefficient $r^{2}$ ranged between 0.63 and 0.84 .

The output of the procedure (discharge, evapotranspirative losses and precipitation) was divided into seasons. Although the WRENSS procedure is tailored for annual results, comparisons were made between actual and predicted evapotranspirative losses and discharges on a seasonal and annual basis to determine the procedure's deficiencies. 


\section{RESULTS AND DISCUSSION}

Various assumptions must be made before analysis can begin. These include the following:

1. Aerial precipitation is representative of the basin;

2. Evapotranspirative losses predicted by WRENSS are representative of the basin;

3. Actual streamflow obtained from the Water Survey of Canada (WSC) plus predicted winter flow are accurate; and

4. Change in storage is equal to zero on an annual basis.

These assumptions allowed the complex hydrological relationships involved in estimating total annual water yield to be addressed in a simple, manageable manner.

The first assumption above must be made before proceeding with any interpretation of the results. Since precipitation is the most important data input, any incorrect data input will result in an incorrect output of water available for streamflow.

The second assumption is that the predicted evapotranspirative losses are representative of the actual conditions. A comparison between annual ET losses simulated by WRENSS and those calculated by a simple water balance equation $(\mathrm{P}-$ actual runoff \pm 0 storage $=$ actual ET) indicated that WRENSS underestimates ET by varying degrees, depending on the sub-basin basis (Figure 1). Actual annual losses in the Wampus and Deerlick sub-basins closely resembled those simulated by WRENSS during years with low ET. This, in turn, produced the closest results between actual and WRENSS-predicted water yield. The largest difference between actual and WRENSS ET occurred in the Eunice sub-basin. This, in turn, produced the largest differences between actual and WRENSS water yield.

Comparison of winter ET (Figure 2) in each sub-basin indicates that WRENSS consistently underestimates ET by a large degree. The difference between the actual precipitation and low flows in the winter resulted in high actual ET values. Although the WRENSS procedure considers part of the snowpack to be held in storage, it appears that a greater portion of the snowpack must be allocated as a storage component. This will assist in decreasing the amount of precipitation available for streamflow. Under natural conditions, it is expected that most of the snowpack is held in storage until spring snowmelt. ET losses from WRENSS hydrologic zone no. 4 , identical to those of zone no. 6 , remained relatively constant throughout the study period. Actual ET losses were variable throughout the winter period. Storage conditions also 

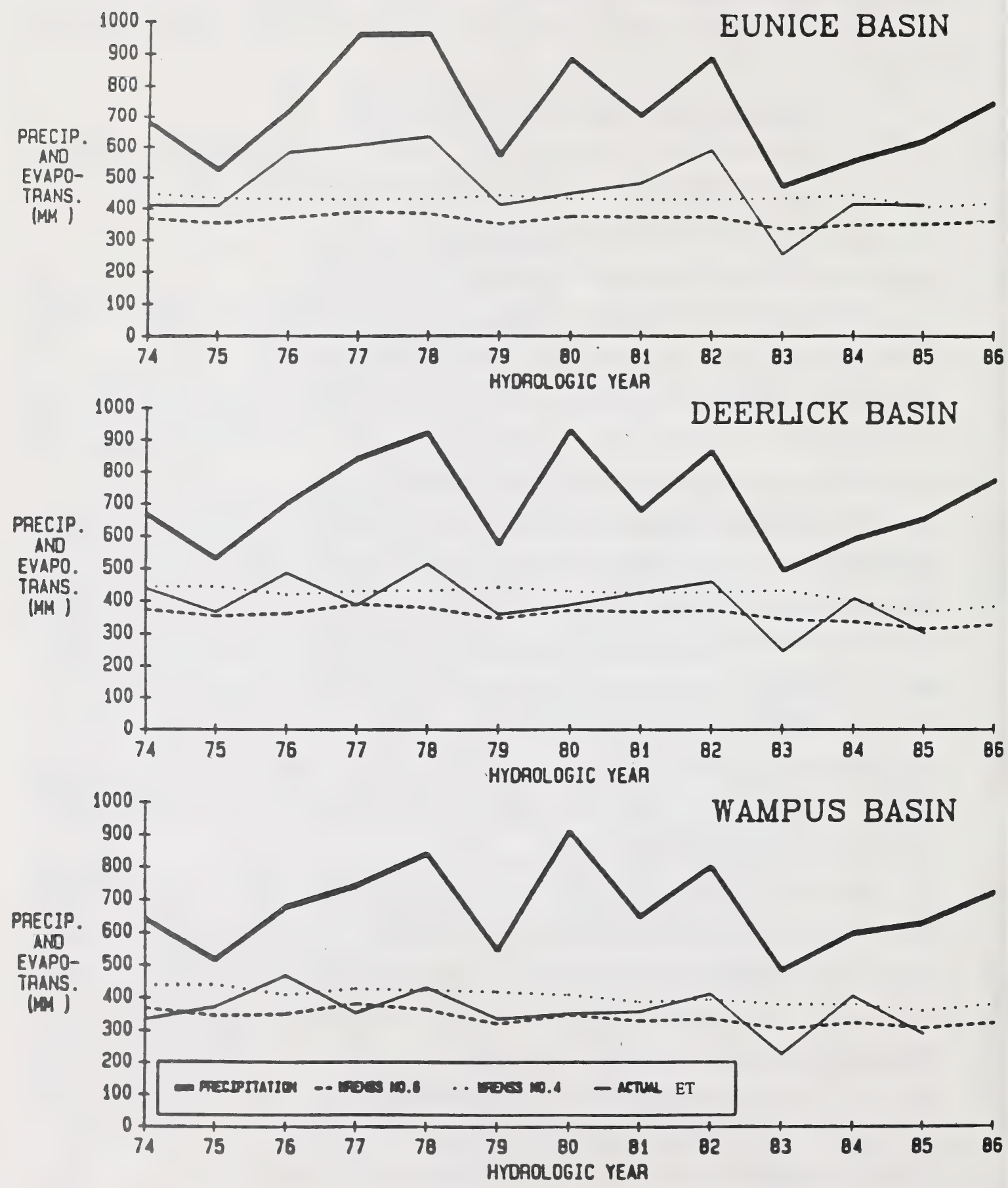

Figure 1. Annual precipitation and evapotranspirative losses. 

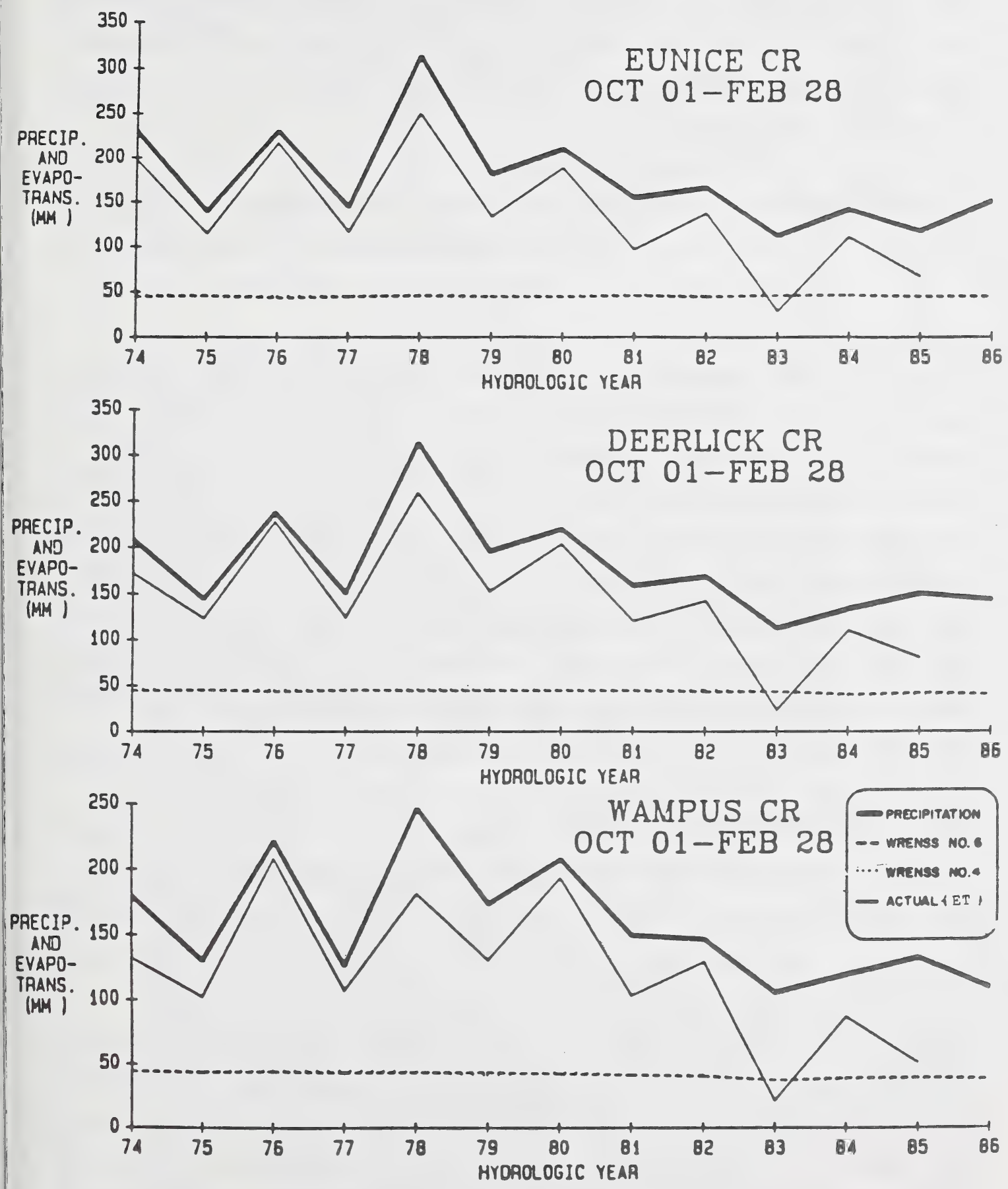

Figure 2. Winter precipitation and evapotranspirative losses. 
were variable, dependent on the amount of precipitation received on the ground surface and actual ET losses. This discrepancy between actual and WRENSS-predicted ET suggests that WRENSS may require an adjustment to predict more accurately actual ET conditions and storage. Four adjustments can be proposed:

1. ET losses from trees may be increased;

2. Sublimation losses can be increased to account for frequent chinook winds;

3. Evaporative losses resulting from the redistribution of snow and wind scour in large cutblocks may not be adequate to account for actual conditions, thus may be increased; and

4. A larger storage component is required to account for the snowpack in the winter.

The latter 3 conditions are more likely to occur than the first condition. Golding (1982) reported a loss of $40 \mathrm{~mm}$ due to sublimation in large openings in the East slopes of Alberta. High ET losses, resulting from wind scour and chinook winds, can create a net reduction of precipitation below pre-silvicultural conditions. This, in turn, represents a reduction in water available for spring runoff. A comparison of seasonal ET losses (shown in Table 1) between actual (from Water Survey of Canada data) and WRENSS-predicted losses indicate that the largest differences occur in the winter period. It also appears that no change in winter ET losses occurred as a result of forest harvesting. This indicates that adjustments 2 to 4 had not been adequately accounted for in the WRENSS procedure.

Table 1. Actual vs WRENSS predicted ET losses.

\begin{tabular}{||l|c|c|c||}
\hline \multicolumn{1}{||c|}{ Season } & Actual ET* & WRENSS ET* & Difference \\
\hline Winter & $31 \%$ & $13 \%$ & $18 \%$ \\
Spring & $27 \%$ & $34 \%$ & $7 \%$ \\
Summer & $41 \%$ & $53 \%$ & $12 \%$ \\
\hline \multicolumn{2}{|c||}{ Deerlick Creek } \\
\hline Winter & $30 \%$ & $12 \%$ & $18 \%$ \\
Spring & $22 \%$ & $34 \%$ & $12 \%$ \\
Summer & $47 \%$ & $54 \%$ & $7 \%$ \\
\hline
\end{tabular}




\begin{tabular}{||l|c|c|c||}
\hline \multicolumn{1}{||c|}{ Season } & Actual ET* & WRENSS ET* & Difference \\
\hline \multicolumn{3}{|c||}{ Eunice Creek } \\
\hline Winter & $28 \%$ & $12 \%$ & $16 \%$ \\
Spring & $32 \%$ & $34 \%$ & $2 \%$ \\
Summer & $40 \%$ & $54 \%$ & $14 \%$ \\
\hline
\end{tabular}

*Expressed as percentage of total annual ET losses

During the spring season, ET losses (Figure 3) from WRENSS remained relatively constant and independent of precipitation. ET losses from hydrologic zone no. 4, although $50 \mathrm{~mm}$ greater than those of zone no. 6, more closely approximated actual conditions when subjected to below-average precipitation conditions. It is recommended that spring ET losses from zone no. 4 be used in the procedure. It should be noted that WRENSS assumes that snow is the dominant form of precipitation in the spring, when subjected to conditions similar to those of winter. In actual conditions, the snowpack from the winter period that is held in storage is carried over to the spring period in the first half of the season and followed by snowmelt, spring freshet and summer rain showers.

In the summer season, WRENSS ET losses (Figure 4) remained fairly constant again (approximately $200 \mathrm{~mm}$ ). As expected, the general trend observed was a decrease in ET losses as the total harvested area increases. Summer ET losses from zone no. 4 were approximately $10 \mathrm{~mm}$ greater than those of no. 6 , but zone no. 6 was recommended for use since it more closely approximated actual conditions. Predicted ET losses tended to be more accurate during the post-harvest evaluation phase than the pre-harvest phase as well as in below-average precipitation conditions as compared to average or above-average conditions. .

Wampus Creek appeared to be more responsive to vegetation removal, as indicated by a larger decrease in actual annual ET losses (Figure 5), compared to Deerlick Creek. This, in turn, resulted in the largest amount of water available for streamflow in Wampus (as shown in Figure 6). In contrast, it was expected that the Deerlick Creek basin should be more responsive to ET losses. The timber along the streamside, often the largest due to unlimited water availability, allows complete hydrologic utilization to occur. The removal of these trees would result in the largest possible decrease in ET losses. Preliminary analysis of actual streamflow 

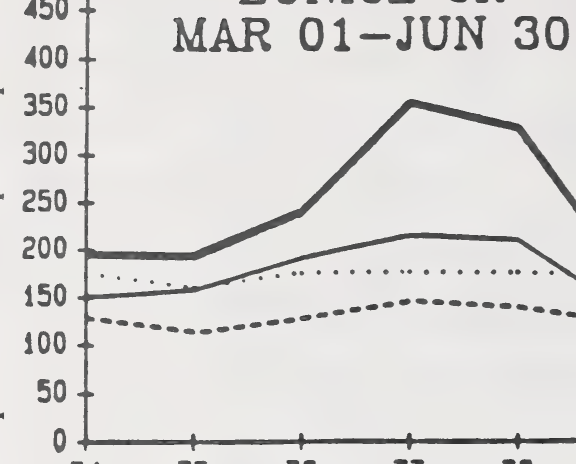

MAR 01-JUN 30

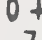

74
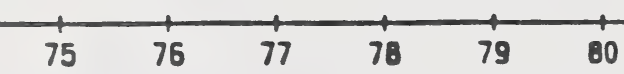

Hydrologic Year

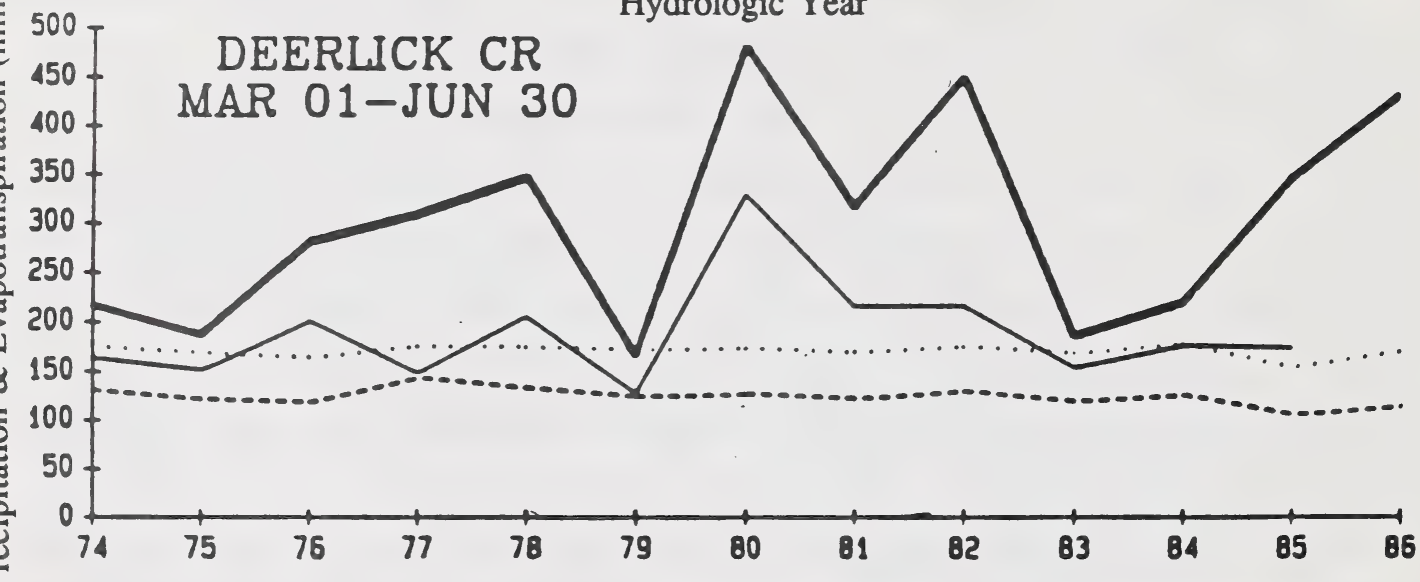

Hydrologic Year

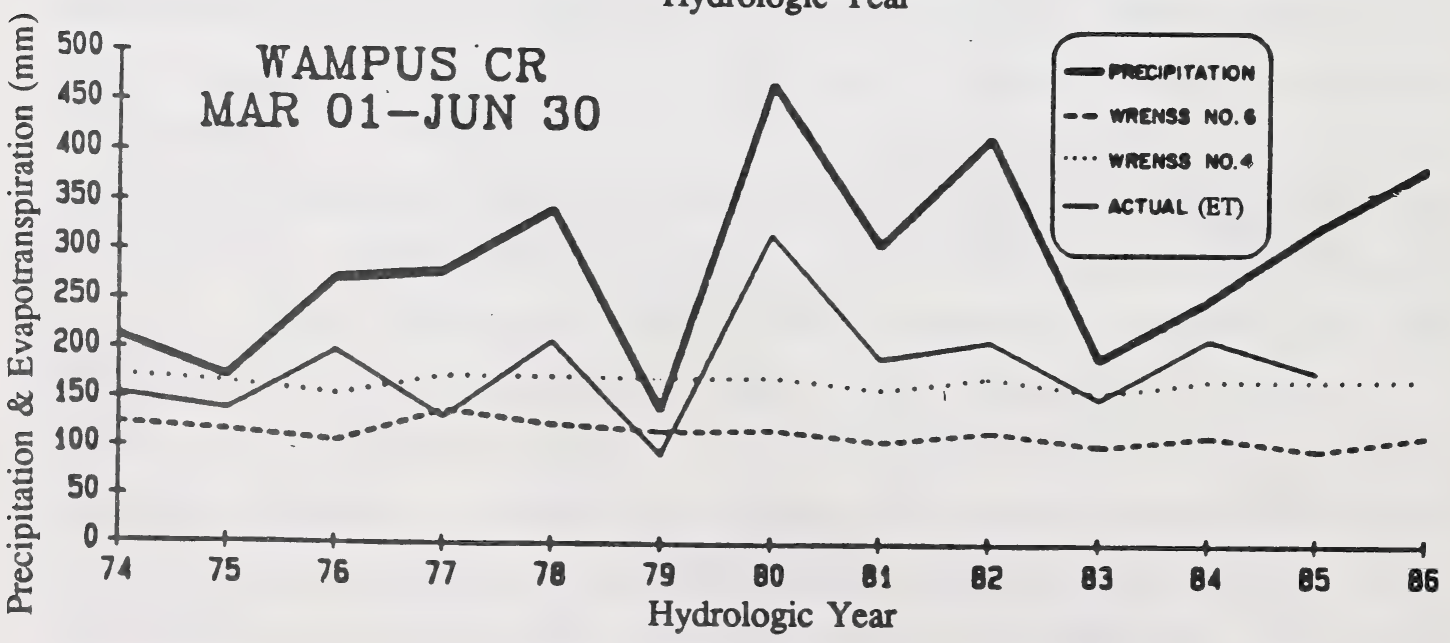

Figure 3. Spring precipitation and evapotranspirative losses. 
हิ

EUNICE CR
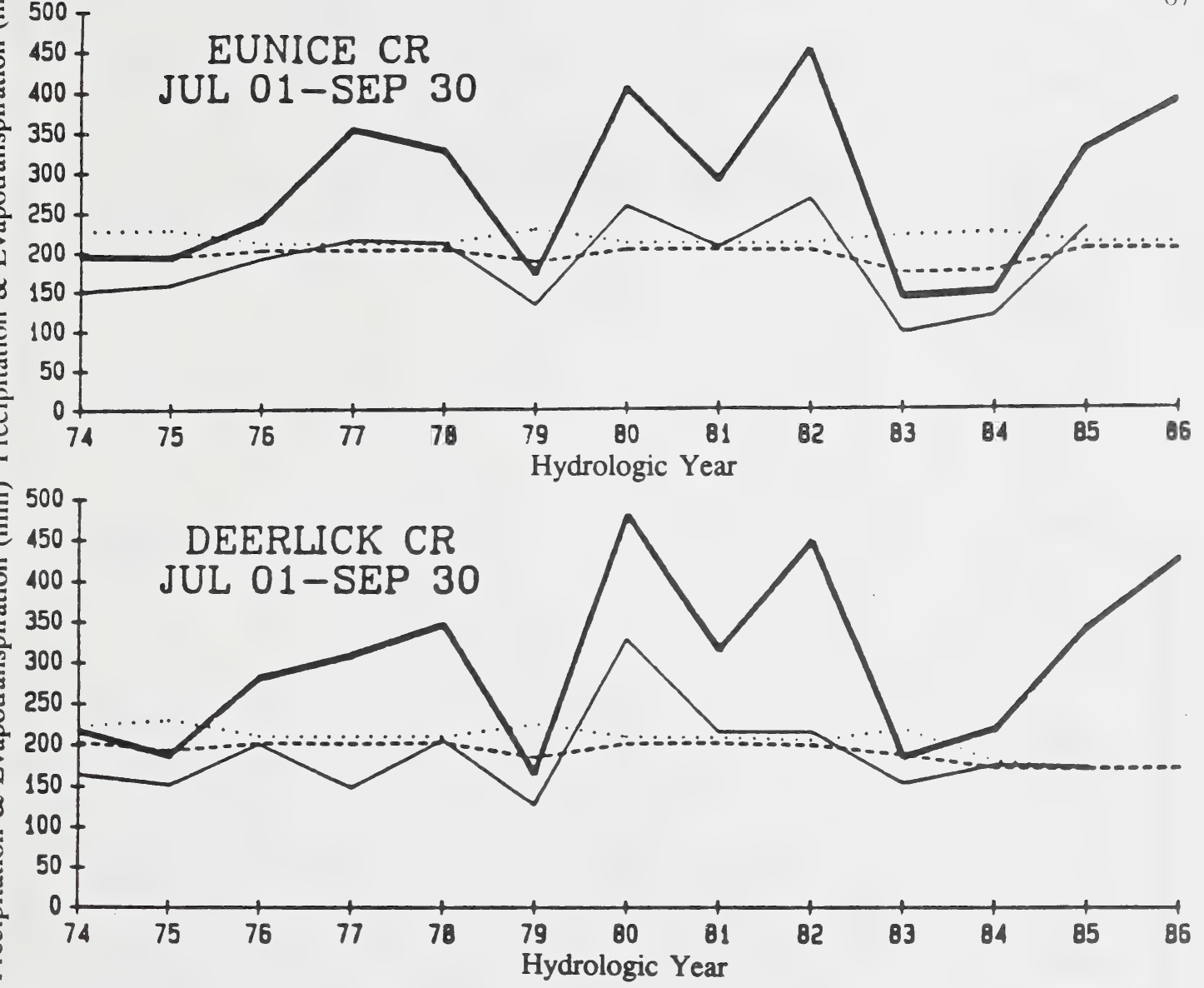

.

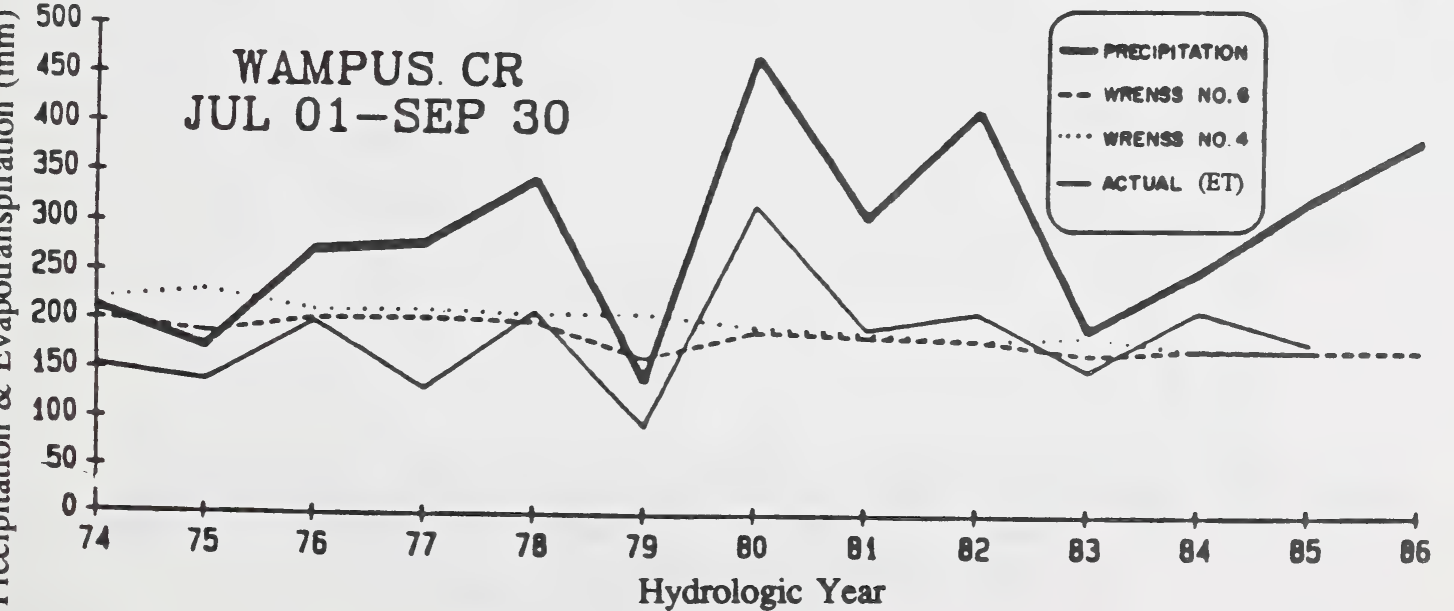

Figure 4. Summer precipitation and evapotranspirative losses. 


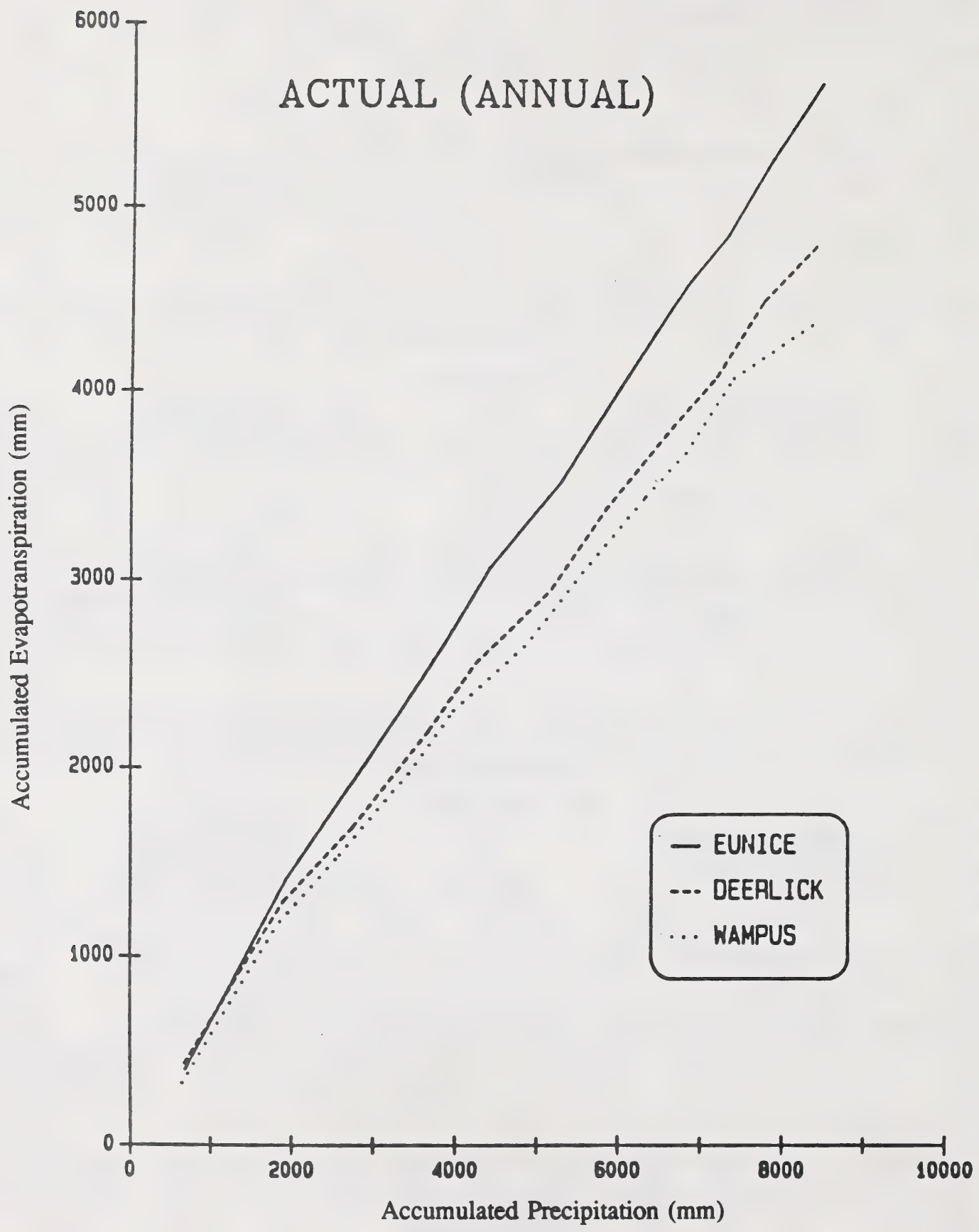

Figure 5. Cumulative precipitation vs. evapotranspirative losses. 


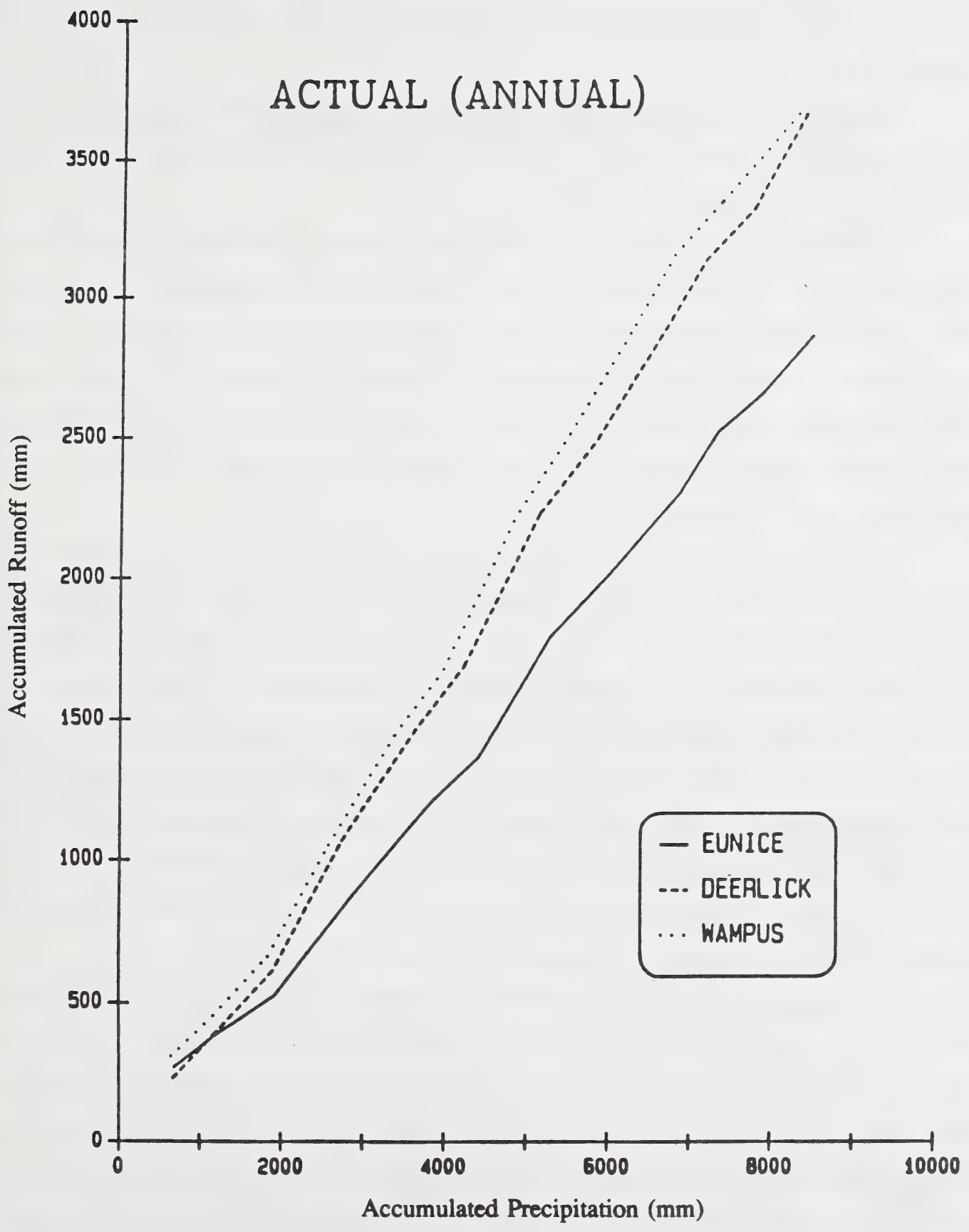

Figure 6. Cumulative precipitation vs. runoff. 
indicated that water yield increases resulting from forest harvesting were slightly higher in the Deerlick basin.

The precipitation-evapotranspiration and precipitation-runoff relationships in Eunice Creek can be expressed as a linear function. This was expected since Eunice Creek was the control basin, not subjected to forest harvesting.

Double mass curves (Figures 7-9) of ET losses generated by WRENSS in zones 4 and 6 were also examined. Results indicate ET losses in Wampus showed a logarithmic function until 1982. After 1982, the steady rate of decline in ET losses predicted by WRENSS no longer existed; instead a smaller rate of decline occurred. Prediction by WRENSS of ET losses in zone no. 6 more closely approximated the actual losses. Similar trends were observed in Deerlick and Eunice Creek except that the changes in the rate of decline occurred earlier (1978) and to a lesser degree than those of Wampus Creek.

In contrast, the prediction of ET losses in zone no. 4 more closely approximated the actual losses in Deerlick and Eunice creeks. Comparison of winter flow (Figure 10) between those predicted by WRENSS and those generated by a recession curve indicate that WRENSS overestimates winter flow by a significant amount in all three sub-basins. This is a result of the WRENSS procedure underestimating the storage component of the snowpack and possibly underestimating the ET losses, as discussed previously. It appears that actual winter flow is not highly dependent on precipitation as compared to flows estimated by WRENSS. Results from 1983 stand out in the graph because the actual flow exceeds those in WRENSS. A possible explanation is that high precipitation levels experienced in late September which generate high antecedent moisture conditions and streamflow are carried over into October.

Examination of pre- and post-treatment years indicates a significantly smaller difference between actual and WRENSS winter flow for post-harvest years as compared to pre-harvest years. A similar trend is also seen in Eunice Creek for the same time period. The reason for this is unknown. For the period of study, it is possible that the actual winter flow does not change significantly over time, thus indicating that base flow conditions derived from groundwater contribution might exist as a result of most of the snowpack being held in storage.

Accuracy of flow precipitation (correlation coefficient between actual and predicted flow) estimated by WRENSS during the spring season (Figure 11) differs by sub-basin and by hydrologic zone. The best results were obtained in Deerlick Creek basin in an unharvested 


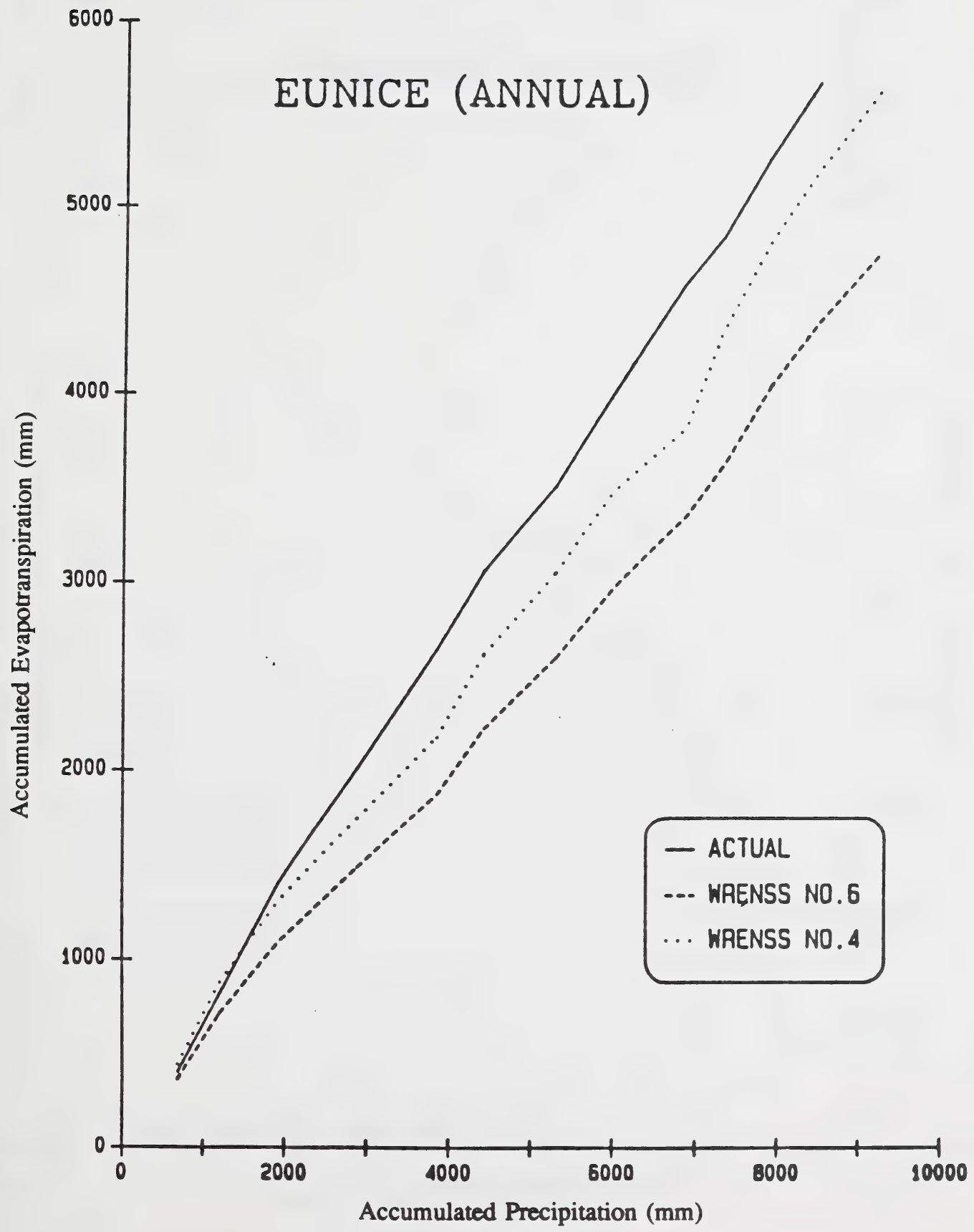

Figure 7. Eunice Creek cumulative precipitation vs. evapotranspirative losses. 


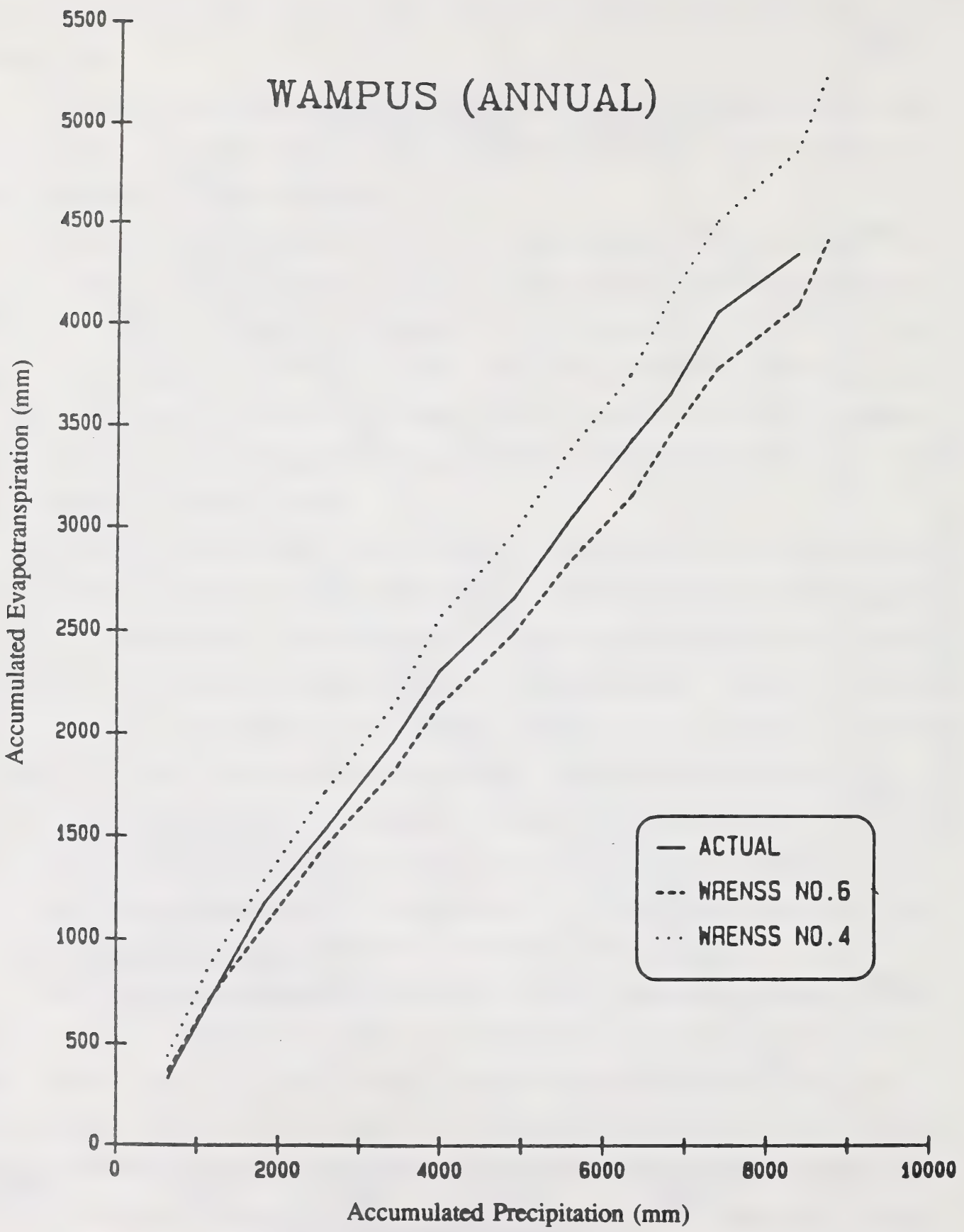

Figure 8. Wampus Creek cumulative precipitation vs. evapotranspirative losses. 


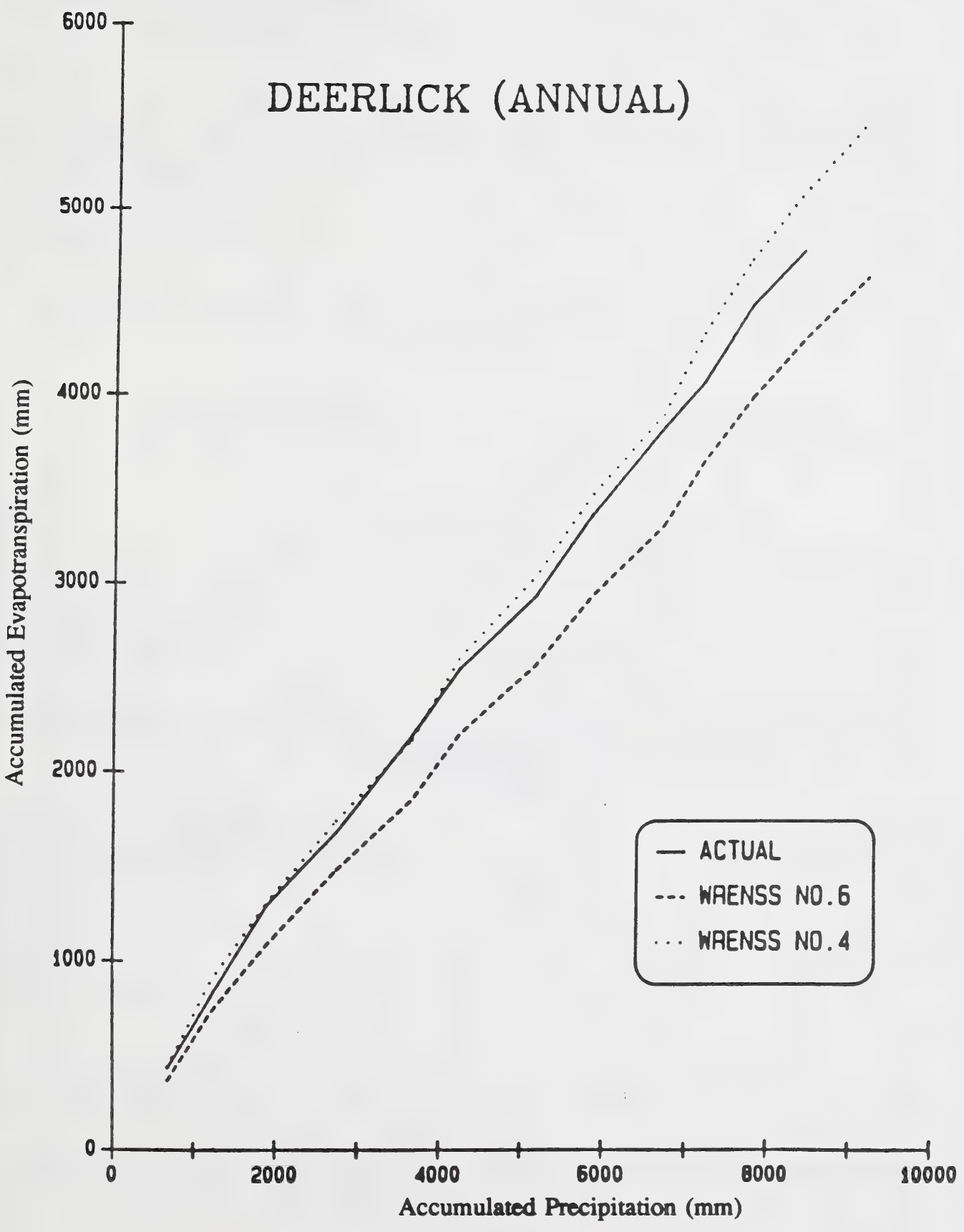

Figure 9. Deerlick Creek cumulative precipitation vs. evapotranspirative losses. 

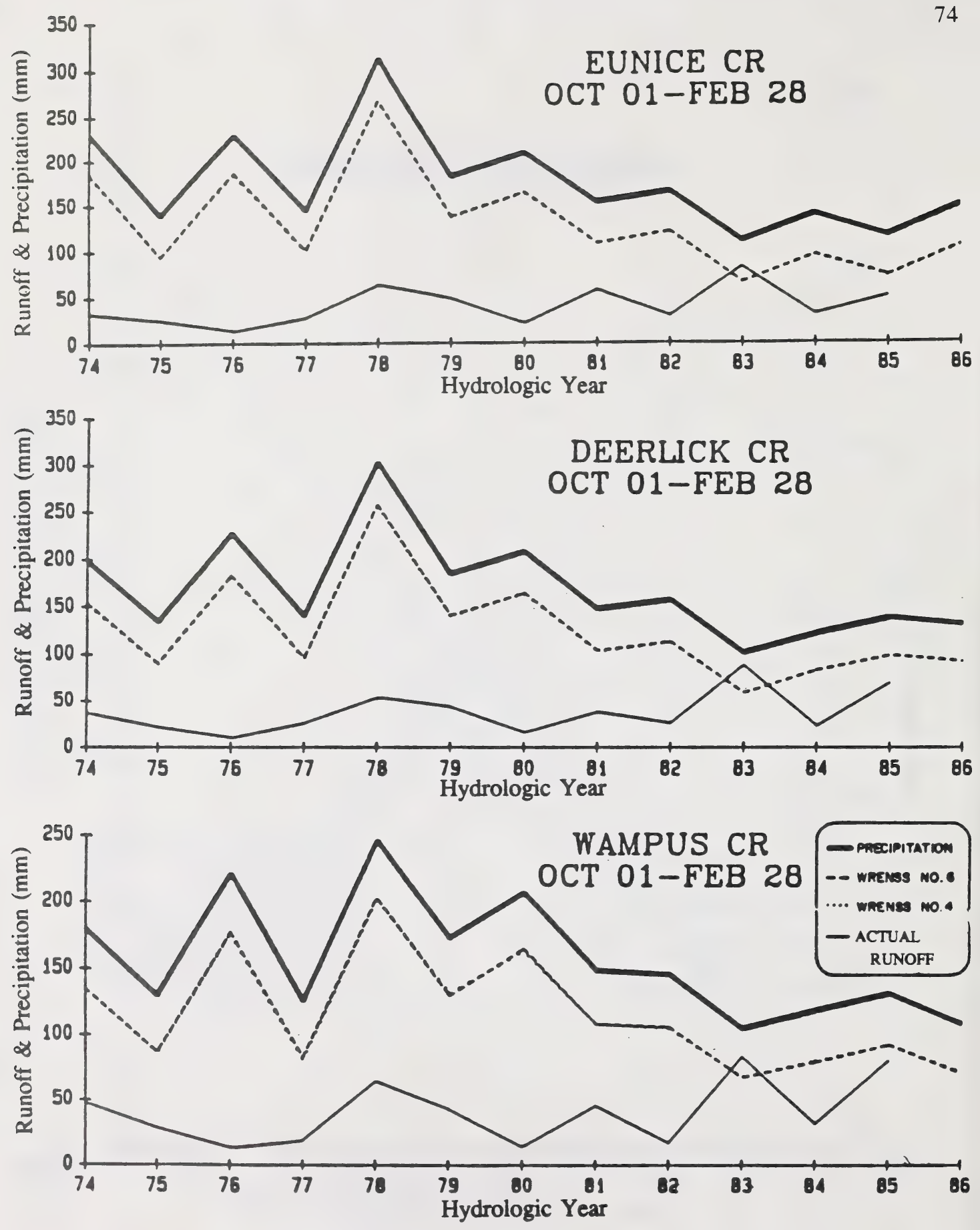

Figure 10. Comparison of winter runoff between sub-basins and hydrologic zones. 

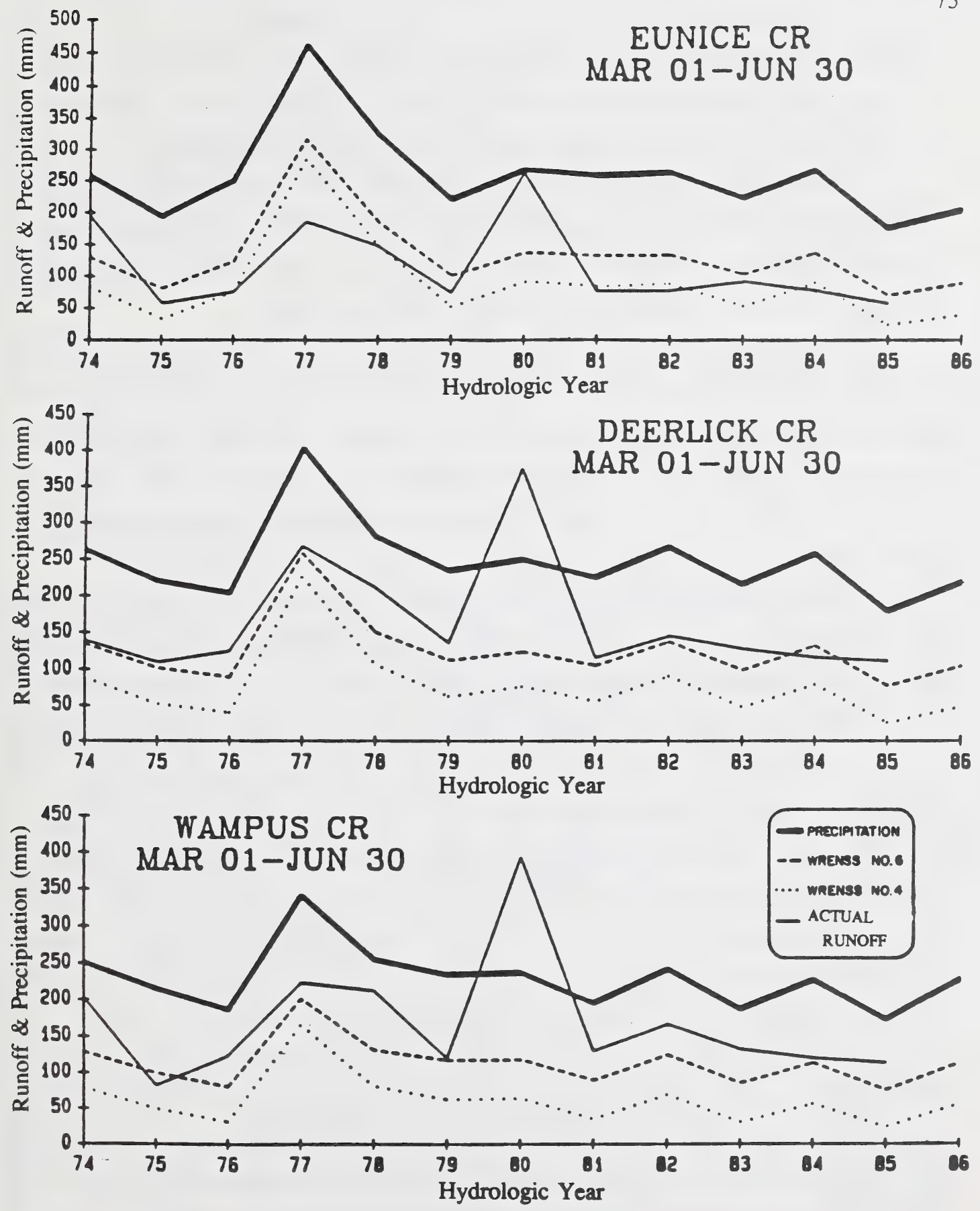

Figure 11. Comparison of spring runoff between sub-basins and hydrologic zones. 
condition $\left(\mathrm{r}^{2} 0.98\right)$ for both hydrologic zones. The second best results were obtained in Wampus Creek basin, also in an unharvested condition $\left(r^{2} 0.815\right)$. The largest difference between actual and predicted flow occurred in Deerlick Creek in a harvested condition $\left(\mathrm{r}^{2} 0.361\right)$.

The highest accuracy of flow estimated by WRENSS on a seasonal basis occurs during the summer period (Figure 12). The highest accuracy was obtained in all sub-basins in average precipitation conditions during the summer period. Excellent predictions were obtained especially during the post-harvest evaluation in the Deerlick and Wampus basins.

It appears that WRENSS is more accurate in predicting annual available streamflow conditions under below-average precipitation conditions. A possible explanation is that a higher ET/precipitation ratio exists under low precipitation conditions. This means that ET losses are proportionately higher under low precipitation conditions as compared to high precipitation conditions. As discussed before, annual ET predicted by WRENSS is low when compared with actual conditions.

Comparison between predictions using different hydrologic zones (Figures 13-15 and Table 2) indicate that there is no significant difference between the zones. The mean $r^{2}$ for both harvested basins is 0.880 . Although the mean difference between actual and predicted flow is $\pm 10 \%$ for Deerlick Creek basin, it ranges from $\pm 7 \%$ (zone no. 6) to $-17 \%$ (zone no. 4). Zone 4

Table 2. Actual vs. predicted streamflow $\left(\mathrm{r}^{2}\right)$.

\begin{tabular}{||l|c|c||}
\hline & WRENSS Zone 4 & WRENSS Zone 6 \\
\hline \hline \multicolumn{3}{||c||}{ Eunice Creek } \\
\hline Untreated & 0.793 & 0.805 \\
\hline Pre-harvest & Deerlick Creek \\
\hline Post-harvest & 0.887 & 0.891 \\
\hline & 0.879 & 0.889 \\
\hline Pre-harvest & Wampus Creek \\
\hline Post-harvest & 0.768 & 0.760 \\
\hline \hline
\end{tabular}



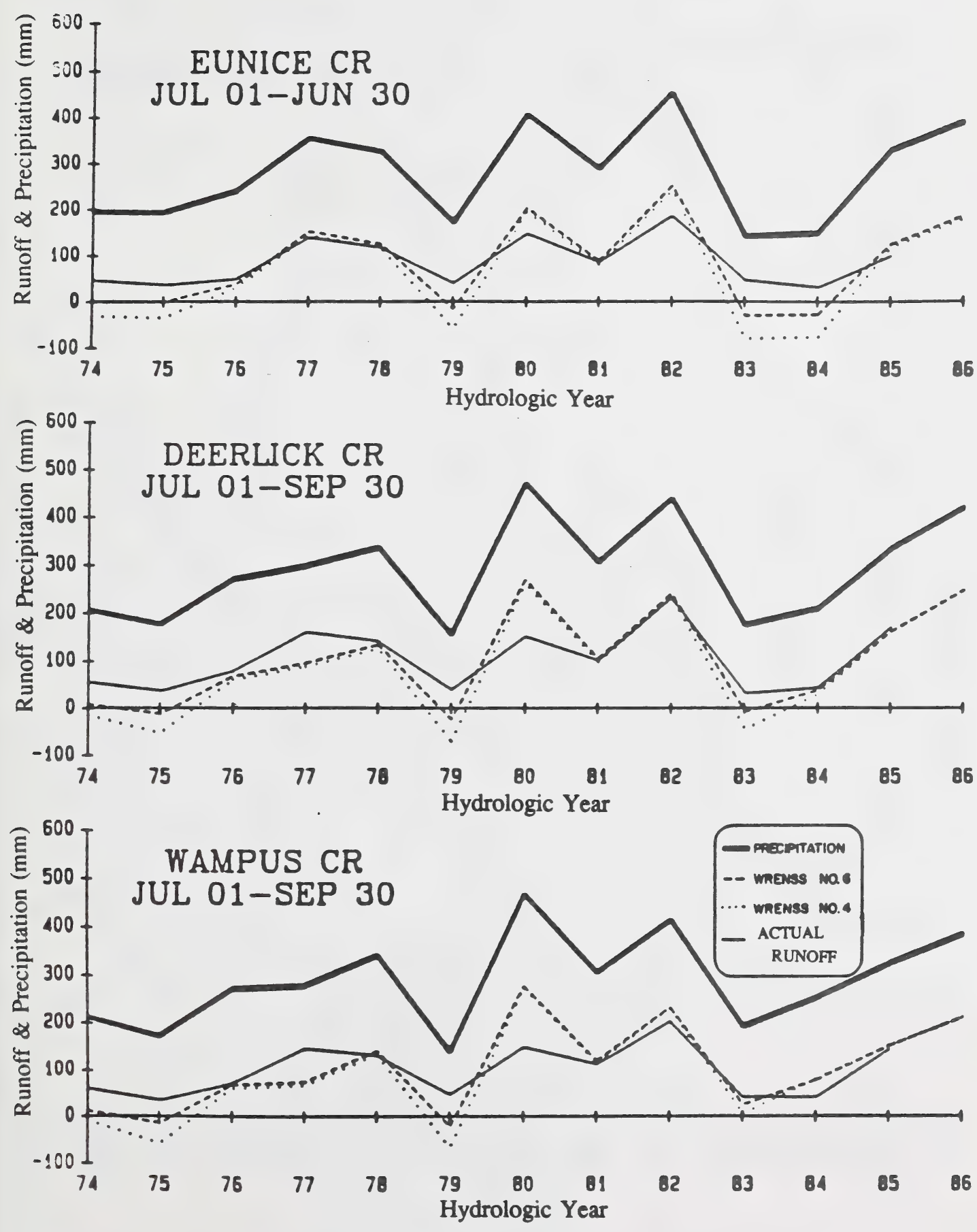

Figure 12. Comparison of summer runoff between sub-basins and hydrologic zones. 


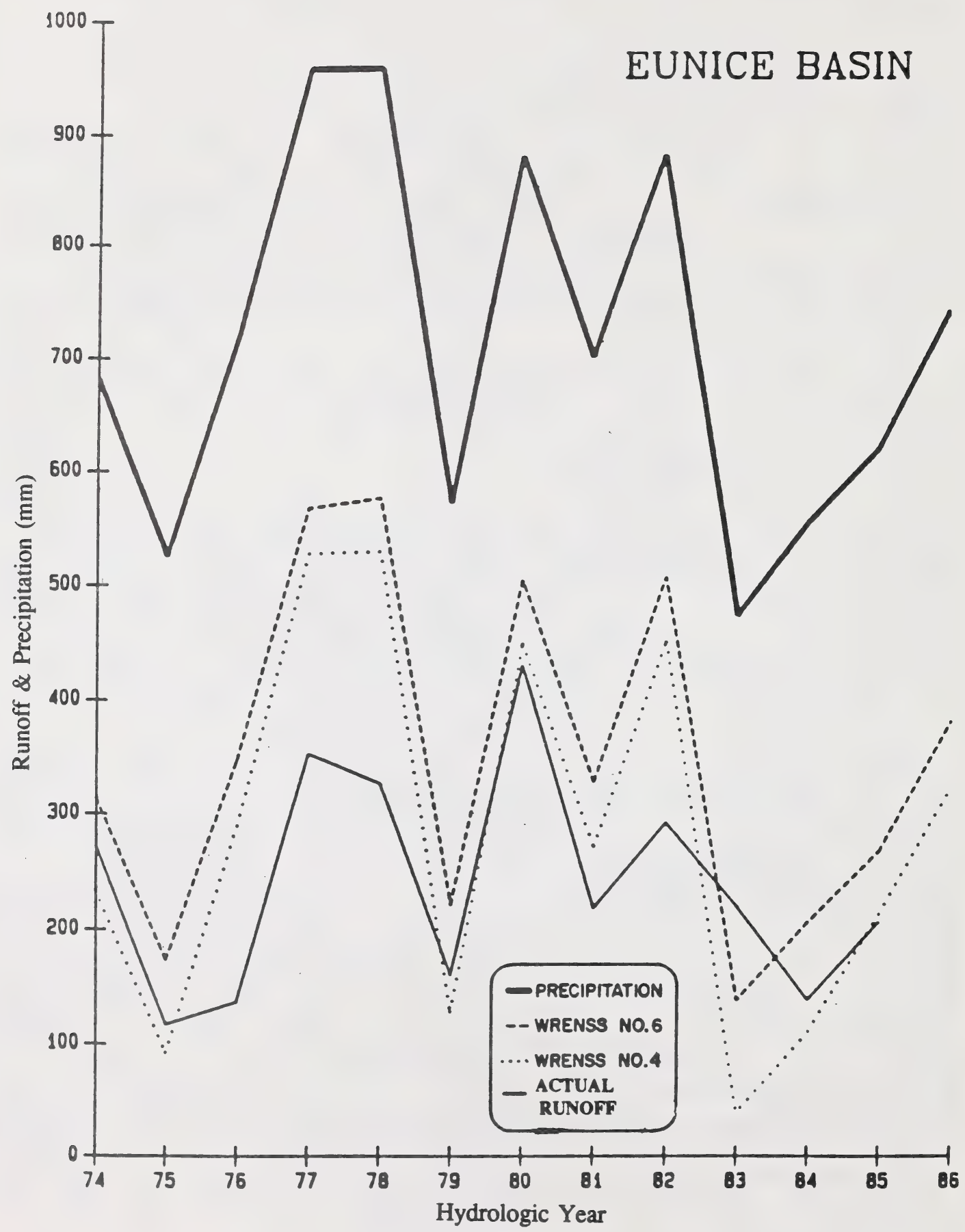

Figure 13. Annual runoff in Eunice Creek. 


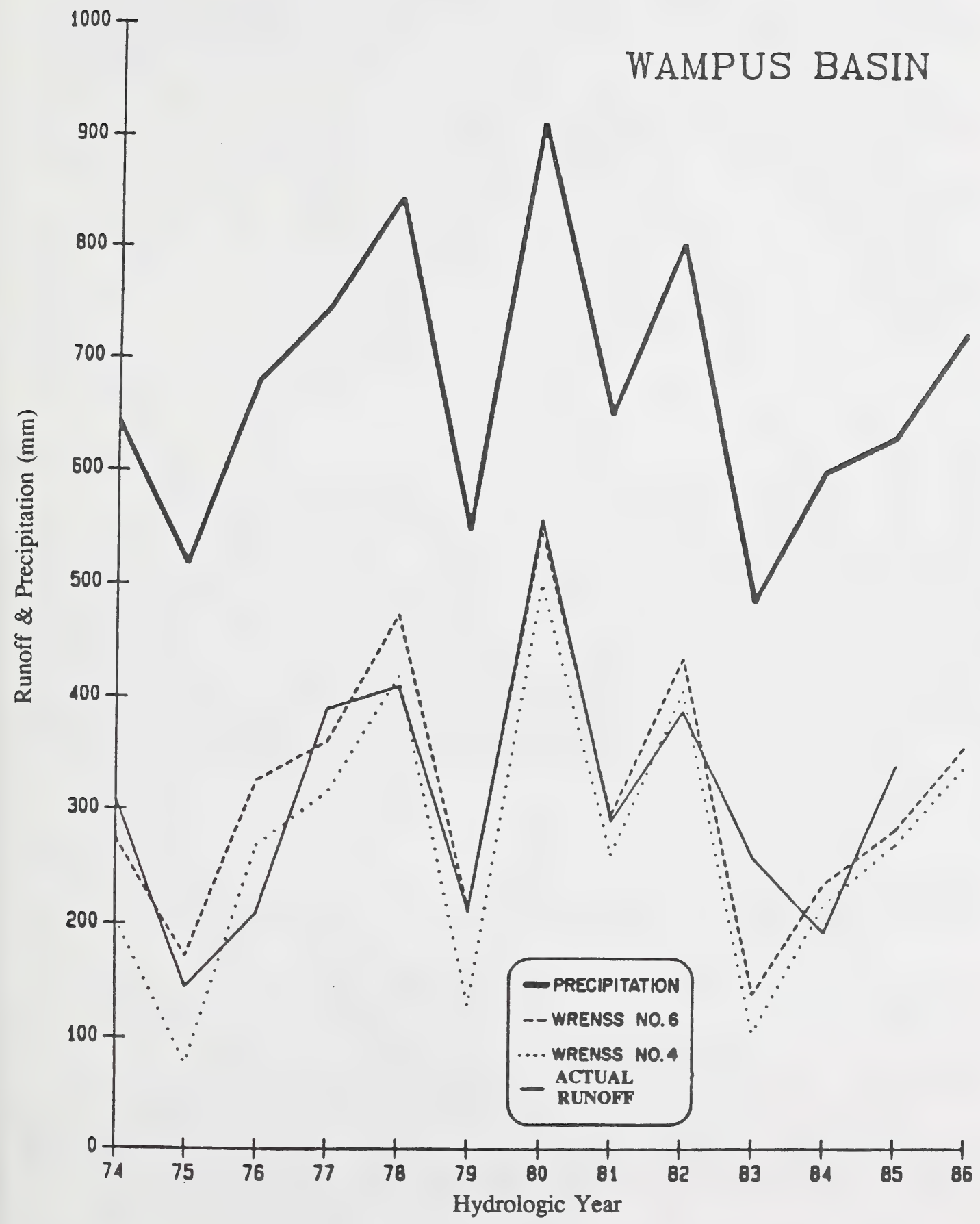

Figure 14. Annual runoff in Wampus Creek. 


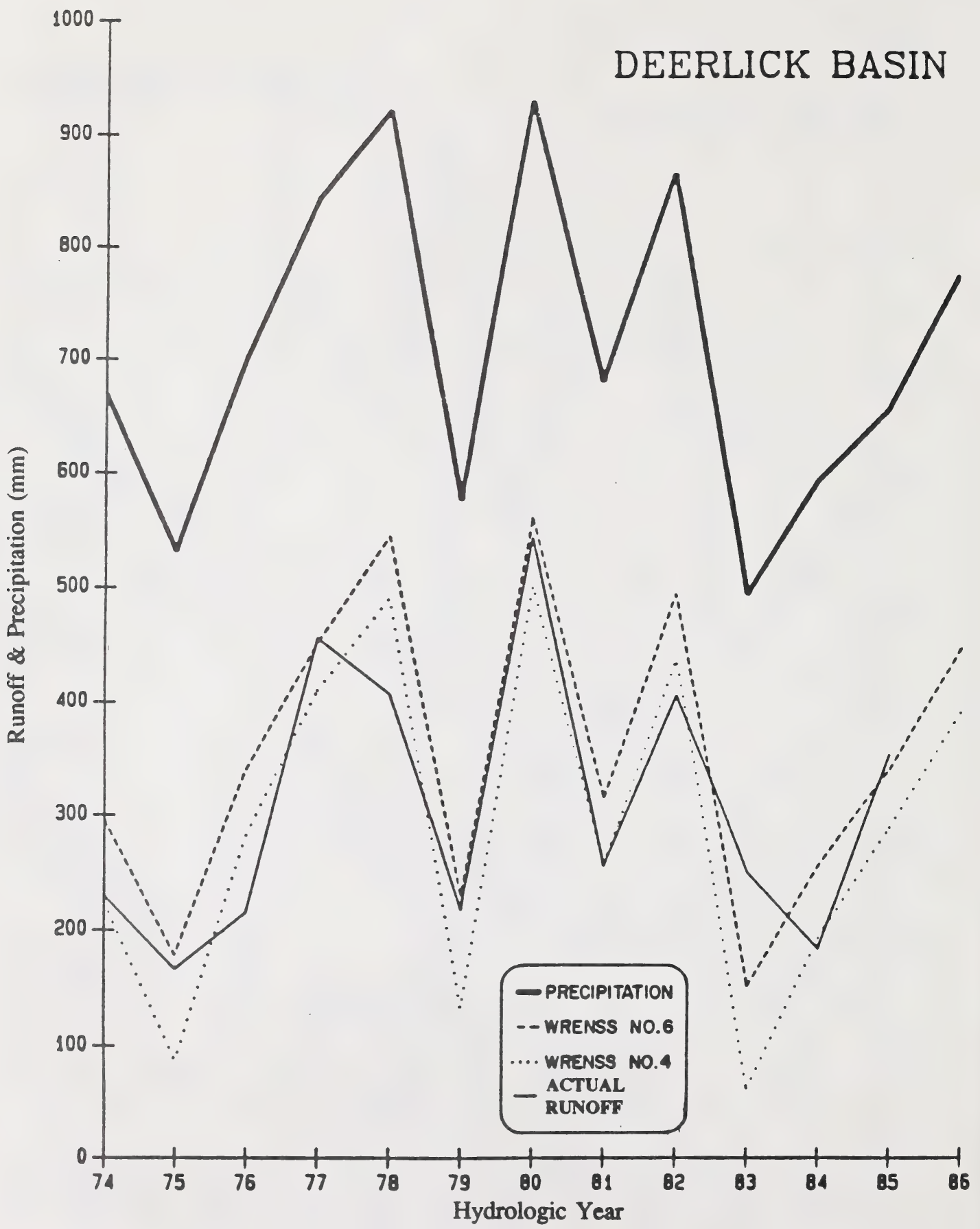

Figure 15. Annual runoff in Deerlick Creek. 
is more accurate in predicting flow in Eunice Creek (mean difference of $14 \%$ for zone 4 as compared to $31 \%$ for zone 6). Mean $r^{2}$ for Eunice Creek is 0.799 . Higher spring and summer ET losses for region 4 resulted in a lower amount of water available for streamflow, and this increased the accuracy of predicting flow in the Eunice Creek basin. Higher ET losses are also indicative of complete hydrologic utilization (closer to the baseline condition).

To improve the accuracy of the WRENSS procedure, adjustments in ET losses as well as the introduction of a storage component, especially for the winter season, are needed. It appears that actual ET losses are probably somewhere in between those predicted for hydrologic zones 4 and 6 . Overall, as indicated by the $r^{2}$ coefficients, the WRENSS procedure provides a good estimate of available water for streamflow.

\section{SUMMARY}

A comparison of actual and predicted evapotranspirative losses indicates that adjustments are required, especially during the winter season to account for storage of the snowpack, to increase the accuracy of the WRENSS procedure in predicting the amount of water available for streamflow. The WRENSS procedure has demonstrated that it is capable of providing good estimates of water available for streamflow following a silvicultural prescription, especially during below-precipitation conditions. It is recommended that the procedure be used in a sub-basin level, rather than a basin level, whenever possible.

\section{REFERENCES}

Bosch, J.M., and J.D. Hewlett. 1982. A review of catchment experiments to determine the effect of vegetation changes on water yield and evapotranspiration. J. Hydrol. 44:2-23.

Golding, D.L. 1982. Snow accumulation patterns in openings and adjacent forest. Can. Hydrol. Sympos. Proc. pp. 131-146.

Golding, D.L., and R.H. Swanson. 1978. Snow accumulation and melt in small forest openings in Alberta. Can. J. For. Res. 8:380-388.

Goldstein, R.A., J.B. Mankin, and R.J. Luxmore. 1974. Documentation of PROSPER: A model of atmospheric-soil plant water flow. Environ. Sci. Div. Public. No. 579. Oak Ridge Natl. Lab. Tenn. 75 pp.

Hibbert, A.R. 1967. Forest treatment effects on water yield. In: W.E. Supper and H.W. Lull (Editors), Int. Symp. For. Hydrol. Pergamon, Oxford. 813 pp. 
Leaf, C.F., and G.E. Brink. 1973. Hydrologic simulation model of Colorado sub-alpine forest. U.S.D.A. For. Res. Paper RM-107. 23 pp. Rocky Mt. Forest and Ranger Exp. Stn. Fort Collins, Colorado.

Ovington, J.D. 1962. Quantitative ecology and woodland ecosystem. In: Advances in Ecological Research, Vol. 1, Ed. J.B. Cragg. pp. 103-192. Academic Press, London and New York.

Swanson, R.H., and G.R. Hillman. 1977. Predicting increased water yield after clearcutting verified in west central Alberta. Inform. Rep. NOR-198. Nor. For. Res. Centre, Edmonton, Alberta. $40 \mathrm{pp}$.

Troendle, C.A., and C.F. Leaf. 1980. Hydrology. Chapter III In: An Approach to Water Resources Evaluation of Non-Point Silvicultural Sources (A Procedural Handbook). U.S. Forest Service, U.S. Dept. Agriculture. 5PA-600/88-80-012. 173 pp. 


\title{
Sediment Dynamics in a Rocky Mountain Foothills Stream Following Clear-cut Logging of Fifty Percent of the Watershed Area
}

\author{
Wayne J. Wasiliew, RPF \\ Forest Resource Department, Champion Forest Products \\ (Alberta) Ltd., 760 Switzer Drive, Hinton, Alberta
}

\section{ABSTRACT}

Fifty percent of the Wampus Creek watershed was timber harvested for pulp production by Champion Forest Products (Alberta) Ltd. from 1979-1982. In 1983, five erosion sources caused by logging were selected and characterized. The sediment dynamics within the stream channel were related to a critical power-of-discharge parameter with respect to stream bed scour and deposition. Road crossings, road ditches, banks slumping, and cutover areas were the main sources of sediment into Wampus Creek following timber harvesting. Sediment deposition and transport processes depended on physical factors such as stream discharge, stream slope profile, bed paving, beaver dam activity and pool volumes.

The rate of discharge and suspended solids concentrations were found to have a strongly non-linear relationship. Two critical stream powers of discharge were shown to affect sediment transport and deposition processes. At 4500 watts, silts that had been previously deposited were then transported within the stream channel. Sediment concentrations did not increase again until the power of discharge reached 12000 watts where stream bed scour began to occur. Sediment loads were calculated for 1,10 and 100 year return-period storms using a simple extreme-value model.

\section{INTRODUCTION}

The materials transported by streams originate from such sources as groundwater flowing through erodible soils, rainwash, landslides and wedge work by ice and roots (Twenhofel, 1961). Streams also resuspend particulate matter through bank undermining, abrasion of its bed, impact and solution. Although these erosion processes occur naturally in the environment, man's activities affect the land and can accelerate the natural erosion processes.

One forest management objective for the land base is the production of high quality water. It is the intent of this experiment to investigate the effects of pulpwood timber harvesting on point sources of sediment and the sediment dynamics within the stream channel. 
Wampus Creek is located in the Tri-Creek watershed near Hinton, Alberta. From 1979 to $1982,50 \%$ of the Wampus Creek watershed was timber harvested by Champion Forest Products. The predominant tree species harvested were lodgepole pine (Pinus contorta var. latifolia Englem), white spruce (Picea glauca [Moench Voss]) and black spruce (Picea mariana [Mill] B.S.P.). A buffer strip of timber was left alongside the creek.

The geology of the area is very complex, with evidence of intense folding, faulting and uplifting (Currie, 1969). Dumanski et al. (1972) and Hudson et al. (1985) provide a detailed discussion of the soil associations present in the Tri-Creek watershed area.

In brief, the study area is composed of three major soil associations which cover over $80 \%$ of the study area (Hudson et al., 1985). Marlboro soils, the most extensive soil association, are Brunisolic Gray Luvisols. Tri-Creek soils, which are classified as bleached Orthic Gray Luvisols, develop in heterogeneous, fine to medium textured glaciolacustrine sediment. Robb soils are classified as Eluviated Dystic Brunisols which are developed in parent materials that are a mixture of medium textured till and colluvium.

In 1983, five significant point sources of sediment were identified in Wampus Creek during storm events (Wasiliew, in prep.). The five point sources included two bridge crossings, a slump, a cutblock and a culvert crossing. Hudson et al. (1985) observed and verified that moderate to high erosion exists in the valley bottoms, primarily in the middle and upper Wampus basin. The slopes are long and steep, and the soils are highly erodible.

\section{OBJECTIVES}

The objectives of this study were:

1. to determine erosion, sediment deposition and transport processes within the stream channel during storm events; and

2. to investigate the effects of pulpwood timber harvesting on point sources of sediment and sediment dynamics within the stream channel.

\section{METHODS}

Wampus Creek was subdivided into ten different reaches depending on the type of point source. These subdivided reaches were named as follows: WA (bridge crossing), W3 (slump), WC (bridge crossing), W8 (cutblock) and W10 (culvert crossing). In order to measure stage 
levels for the storm event, crest gauges were installed at W3, below W8, above W8 and at W10. WA and WC had Steven's recorders installed for more precise hydrograph readings.

Suspended sediment samples were obtained by collecting twinned grab samples at the five point sources both above and below the disturbance. Samples were taken at the crest of the storm event following methods as described by Nip (1987).

Discharge was determined following standard procedures as described by Porterfield (1978). Occasionally, the float method using mean velocity as 0.85 of the float velocity (Linsley et al., 1958) was used for discharge determination. Each time a discharge measurement of sediment sample was taken, the stream level or stage was also taken in order to develop a stream rating curve.

An erosion survey was imposed on cutblock 8 to determine if erosion was occurring within the cutblock and if the sediment was entering the stream. The survey involved measuring the percent of mineral soil exposed, in milliacre plots, every $75 \mathrm{~m}$ over the cutblock area.

Suspended solids were determined gravimetrically following methods as described by Nip (1987). The laboratory procedures involved filtering approximately $400 \mathrm{~mL}$ of sample water through a $0.45 \mu \mathrm{m}$ filter membrane which was then dried at $105^{\circ} \mathrm{C}$ for at least four hours. Subsequently, the sediment was weighed.

An extreme value analysis was used to determine sediment production for a 1, 10 and 100 year return-period storm. The statistical methods from Benjamin and Cornell (1970) required calculating the sediment load in tonnes/day, as a first step. Actual sediment concentrations were used to calculate the load for each of the 14 storm events from May to October, 1985. The sediment load was determined by calculating the stream discharge $\left(\mathrm{m}^{3} / \mathrm{sec}\right)$, multiplying by the sediment concentration $(\mathrm{mg} / \mathrm{L})$ and then multiplying by the conversion factor of 0.864 to obtain tonnes/day. The means and variances were computed for the sediment load populations. The probability of an event occurring in ith year was then calculated by the function

$$
F y_{s}=\exp ^{[\mathrm{e}-\alpha(y s-u)]}
$$

where: $\quad y_{s}$ is the sediment load,

the population variance was used to calculate $\alpha$ where $\alpha=1.282 / 0-\mathrm{y}_{\mathrm{s}}$ and $\mathrm{u}$ was the population mean. 


\section{RESULTS}

\section{Population Distribution for Each Station}

Frequency histograms were developed by determining the sediment load for each station and then graphing the frequency of events in the particular class size. Table 1 shows sediment load for each station as well as population means and variances.

\section{$\underline{\text { Sediment Production }}$}

Figure 1 and Table 2 illustrate the sediment production by station for 1, 10 and 100 year return-period storms. For changes in sediment production that were greater than or equal to zero, net addition or erosion and sediment transport processes were occurring. When the change in sediment production was less than or equal to zero, storage or deposition processes were occurring.

Although the bridge crossing at Wampus-A did not contribute significant amounts of sediment into Wampus Creek, the channel between the slump at Wampus-3 and Wampus-A did contribute a significant amount of sediment. In the channel between Wampus- $\mathrm{C}$ and Wampus-3 sediment disposition occurred due to the activity of beaver. The channel below Wampus- 8 and above Wampus-C showed sediment erosion and transport. Also the section of stream along the Wampus-8 cutblock showed sediment transport.

Erosion and revegetation surveys were conducted on cutblock 8 in 1983 and 1985. Results indicated that cutblock 8 has revegetated. Results also showed a reduction of exposed mineral soil from $38 \%$ to $33 \%$ during the period 1983 to 1985 .

Although clear-cutting was extensive in the headwaters of the Wampus Creek watershed, results have shown very low sediment transport processes. Results have shown that the slump at Wampus- 3 contributes sediment into Wampus Creek, but the Wampus-C bridge crossing did not contribute significant amounts of sediment into Wampus Creek.

A three-dimensional graph (Figure 2) relating mass, energy and time was developed by graphing sediment load (tonnes/day) versus power of water (watts), or discharge $\left(\mathrm{m}^{3}\right)$ versus distance $(m)$ from the headwaters to the mouth of Wampus Creek.

Results from graphs (Figure 2) appear to indicate that the Wampus Creek watershed is a non-linear system. There were two different powers of discharge producing sedimentation. When the power of discharge reached $2000-5000$ watts $\left(0.50-1.00 \mathrm{~m}^{3} / \mathrm{s}\right)$ fine clays and silts appeared to be transported and deposited within the stream channel. Suspension of particles and 


\begin{tabular}{|c|c|c|c|c|c|c|c|c|c|c|c|c|}
\hline & & ${ }_{8}$ & $\begin{array}{l}\infty \\
\stackrel{\circ}{8} \\
\stackrel{0}{0}\end{array}$ & $\begin{array}{l}\overline{0} \\
8 \\
0\end{array}$ & $\begin{array}{l}\text { స్ర } \\
0\end{array}$ & 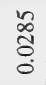 & $\stackrel{\circ}{\stackrel{0}{0}}$ & $\begin{array}{l}\stackrel{\infty}{0} \\
\stackrel{0}{0}\end{array}$ & $\begin{array}{l}\overrightarrow{\tilde{\Xi}} \\
\dot{0}\end{array}$ & $\begin{array}{l}\infty \\
n \\
\delta \\
0 \\
0\end{array}$ & $\begin{array}{l}\overline{\mathbf{D}} \\
\text { i } \\
0\end{array}$ & \\
\hline & & $\varkappa_{0}$ & $\begin{array}{l}\infty \\
\infty \\
\infty \\
\infty \\
\infty\end{array}$ & $\begin{array}{l}\vec{\infty} \\
\dot{0} \\
\dot{\mathbf{N}}\end{array}$ & $\begin{array}{l}\text { ते } \\
\text { हैं }\end{array}$ & $\begin{array}{l}\stackrel{8}{8} \\
\dot{f}\end{array}$ & $\begin{array}{l}\stackrel{\infty}{\infty} \\
\stackrel{0}{=}\end{array}$ & $\begin{array}{l}\text { 웅 } \\
\stackrel{0}{0}\end{array}$ & $\stackrel{m}{\stackrel{m}{n}}$ & $\begin{array}{l}\text { ते } \\
\text { ते }\end{array}$ & $\stackrel{\mathscr{n}}{\rightarrow}$ & $\overrightarrow{\dot{m}}$ \\
\hline & & $\tilde{\varkappa}_{x}$ & $\begin{array}{l}+ \\
\stackrel{+}{\text { S }}\end{array}$ & $\begin{array}{l}\vec{n} \\
\vdots \\
0\end{array}$ & 离 & $\begin{array}{l}\infty \\
\infty \\
\infty \\
\infty\end{array}$ & 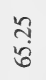 & $=$ & $\begin{array}{l}\text { ڤ̀ } \\
\text { Oे }\end{array}$ & 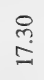 & $\underset{i}{\stackrel{t}{i}}$ & $\underset{\text { i }}{\stackrel{\Delta}{*}}$ \\
\hline \multirow{14}{*}{ 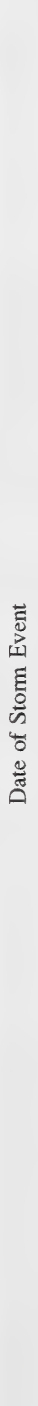 } & \multirow{2}{*}{ 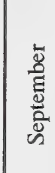 } & $m$ & $\begin{array}{l}\underset{0}{+} \\
\text { tid }\end{array}$ & तิ & $\stackrel{\widetilde{\alpha}}{\stackrel{\Xi}{ \pm}}$ & $\begin{array}{l}\stackrel{3}{3} \\
\stackrel{n}{n}\end{array}$ & 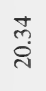 & $\stackrel{g}{\stackrel{g}{g}}$ & $\stackrel{\circ}{\stackrel{m}{m}}$ & $\stackrel{\text { os }}{i}$ & & $\stackrel{\mathbb{\delta}}{\delta}$ \\
\hline & & 은 & $\stackrel{n}{\stackrel{n}{?}}$ & $\stackrel{\sigma}{\sigma}$ & त) & $\stackrel{f}{\circ}$ & $\stackrel{n}{\varrho}$ & $\stackrel{\overrightarrow{-}}{-}$ & $\exists$ & $\stackrel{t}{0}$ & $\stackrel{n}{0}$ & $\stackrel{0}{0}$ \\
\hline & \multirow{4}{*}{$\begin{array}{l}\overrightarrow{\mathrm{g}} \\
\overrightarrow{\mathrm{m}} \\
\vec{z}\end{array}$} & $\cong$ & $\underset{\mathrm{a}}{\mathrm{i}}$ & $\begin{array}{l}\hat{n} \\
\stackrel{a}{d}\end{array}$ & 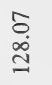 & $\stackrel{n}{\cong}$ & 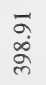 & ڤ్ & $\frac{n}{\tilde{d}}$ & $\vec{m}$ & & $\underset{\dot{m}}{\stackrel{F}{*}}$ \\
\hline & & $\simeq$ & $\begin{array}{l}\mathcal{Y} \\
\stackrel{\tilde{I}}{ \pm}\end{array}$ & $\begin{array}{l}\stackrel{\sim}{\mathcal{J}} \\
\stackrel{\Xi}{ \pm}\end{array}$ & $\begin{array}{l}\text { तి } \\
\mathscr{f}\end{array}$ & 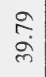 & 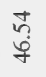 & \begin{tabular}{l}
4 \\
\multirow{2}{*}{} \\
6
\end{tabular} & $\underset{\dot{\sim}}{\stackrel{\leftrightarrow}{+}}$ & $\stackrel{8}{6}$ & $\begin{array}{l}\infty \\
\infty \\
0\end{array}$ & $\underset{\text { İ }}{ }$ \\
\hline & & $\stackrel{\infty}{\circ}$ & $\begin{array}{l}\vec{\infty} \\
\stackrel{0}{0} \\
=\end{array}$ & 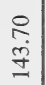 & $\begin{array}{l}\hat{\infty} \\
\stackrel{i}{\Lambda}\end{array}$ & $\begin{array}{l}\stackrel{0}{-} \\
\dot{\vec{\lambda}}\end{array}$ & స్ & $\stackrel{\infty}{=}$ & $\stackrel{\text { న్ }}{\sim}$ & ఫे & 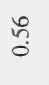 & : \\
\hline & & $\delta$ & $\stackrel{\infty}{\stackrel{\infty}{0}}$ & $\stackrel{\oplus}{\oplus}$ & $\begin{array}{l}\overrightarrow{3} \\
\text { ni }\end{array}$ & $\begin{array}{l}\stackrel{\infty}{\circ} \\
+ \\
+\end{array}$ & $\begin{array}{l}\text { nू. } \\
\text { nू. }\end{array}$ & $\begin{array}{l}\sqrt[n]{n} \\
\text { I }\end{array}$ & $\stackrel{\aleph}{\check{n}}$ & 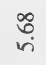 & $\stackrel{8}{8}$ & ते \\
\hline & 斑 & \pm & $\stackrel{\circ}{i}$ & 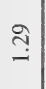 & $\stackrel{\infty}{\stackrel{\infty}{-}}$ & $\stackrel{?}{i}$ & $\stackrel{\infty}{\stackrel{\infty}{ \pm}}$ & $\stackrel{\Xi}{\Xi}$ & $\frac{ \pm}{6}$ & $\stackrel{\infty}{\infty}$ & ठ̊. & $\stackrel{ }{\circ}$ \\
\hline & \multirow{3}{*}{ 害 } & $\stackrel{+}{\sim}$ & $\begin{array}{l}\bar{n} \\
\stackrel{2}{ }\end{array}$ & 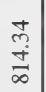 & $\begin{array}{l}\text { ¿̊ } \\
\text { 心్ర }\end{array}$ & 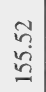 & 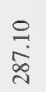 & 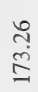 & $\begin{array}{l}\stackrel{\infty}{+} \\
\stackrel{\omega}{\omega}\end{array}$ & $\tilde{\widetilde{\sigma}}$ & $\stackrel{\beth}{\beth}$ & $\stackrel{\swarrow}{\underline{\Xi}}$ \\
\hline & & \pm & $\stackrel{\widetilde{b}}{0}$ & $\stackrel{\infty}{\rightarrow}$ & $\frac{t}{0}$ & $\stackrel{6}{-}$ & $\stackrel{+}{-}$ & $\frac{7}{8}$ & $\vec{m}$ & $\stackrel{\infty}{5}$ & $\ddot{\widetilde{o}}$ & ֻั \\
\hline & & \% & $\underset{\text { స్ }}{\text { r. }}$ & $\overrightarrow{-}$ & $\begin{array}{l}\infty \\
\infty \\
i\end{array}$ & $\stackrel{\infty}{\stackrel{\infty}{m}}$ & $\stackrel{\Xi}{\beth}$ & $\stackrel{+}{-}$ & 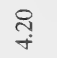 & $\stackrel{\text { ल }}{-}$ & 8 & 8 \\
\hline & \multirow{4}{*}{$\sum_{\mathrm{i}}^{\mathrm{a}}$} & নे & $\stackrel{\infty}{\stackrel{\infty}{\beth}}$ & $\stackrel{0}{\stackrel{\longrightarrow}{=}}$ & $\stackrel{\infty}{=}$ & $\stackrel{m}{q}$ & $\underset{\infty}{\stackrel{\infty}{\infty}}$ & ڤึ & $\begin{array}{l}\stackrel{a}{\otimes} \\
\stackrel{0}{\dot{\omega}}\end{array}$ & 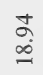 & fo & ֶิ \\
\hline & & $\stackrel{\sim}{\sim}$ & 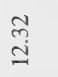 & $\begin{array}{l}\stackrel{q}{0} \\
\stackrel{0}{0}\end{array}$ & $\stackrel{\sim}{\stackrel{\Omega}{I}}$ & $\stackrel{\infty}{\stackrel{త}{త}}$ & $\underset{\sigma}{n}$ & $\begin{array}{l}\underset{\infty}{\infty} \\
\infty\end{array}$ & $\begin{array}{l}\dddot{m} \\
\stackrel{\Xi}{\simeq}\end{array}$ & $\begin{array}{l}3 \\
\dot{0} \\
\dot{I}\end{array}$ & $\stackrel{8}{8}$ & $\begin{array}{l}8 \\
0\end{array}$ \\
\hline & & $\approx$ & $\stackrel{m}{\stackrel{2}{a}}$ & $\begin{array}{l}\infty \\
\stackrel{\alpha}{0} \\
\stackrel{i}{0}\end{array}$ & 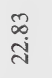 & 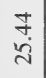 & $\begin{array}{l}\vec{\infty} \\
\text { i } \\
\end{array}$ & $\stackrel{\infty}{\stackrel{m}{m}}$ & 8 & $\stackrel{\infty}{\stackrel{\infty}{\Omega}}$ & $\stackrel{8}{8}$ & $\begin{array}{l}8 \\
0\end{array}$ \\
\hline & & $\stackrel{\infty}{\stackrel{\infty}{0}}$ & $\stackrel{\text { f }}{0}$ & $\stackrel{m}{0}$ & ஃ̊ & $\underset{0}{\mathbb{0}}$ & $\stackrel{8}{\stackrel{8}{-}}$ & $\stackrel{m}{i}$ & 8 & 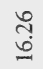 & $\stackrel{8}{8}$ & 8 \\
\hline & & 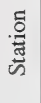 & $\begin{array}{l}5 \\
\frac{5}{3} \\
3\end{array}$ & $\begin{array}{l}\Xi \\
\vdots \\
3\end{array}$ & $\begin{array}{l}\tilde{\xi} \\
\tilde{\xi}\end{array}$ & $\begin{array}{c}3 \\
3 \\
3\end{array}$ & $\begin{array}{l}5 \\
0 \\
\vdots\end{array}$ & 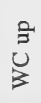 & $\begin{array}{l}5 \\
5 \\
\infty \\
3\end{array}$ & $\begin{array}{l}\stackrel{2}{3} \\
\infty \\
3\end{array}$ & $\begin{array}{l}\frac{5}{5} \\
\stackrel{0}{3}\end{array}$ & $\begin{array}{l}3 \\
\vdots \\
\vdots \\
3\end{array}$ \\
\hline
\end{tabular}




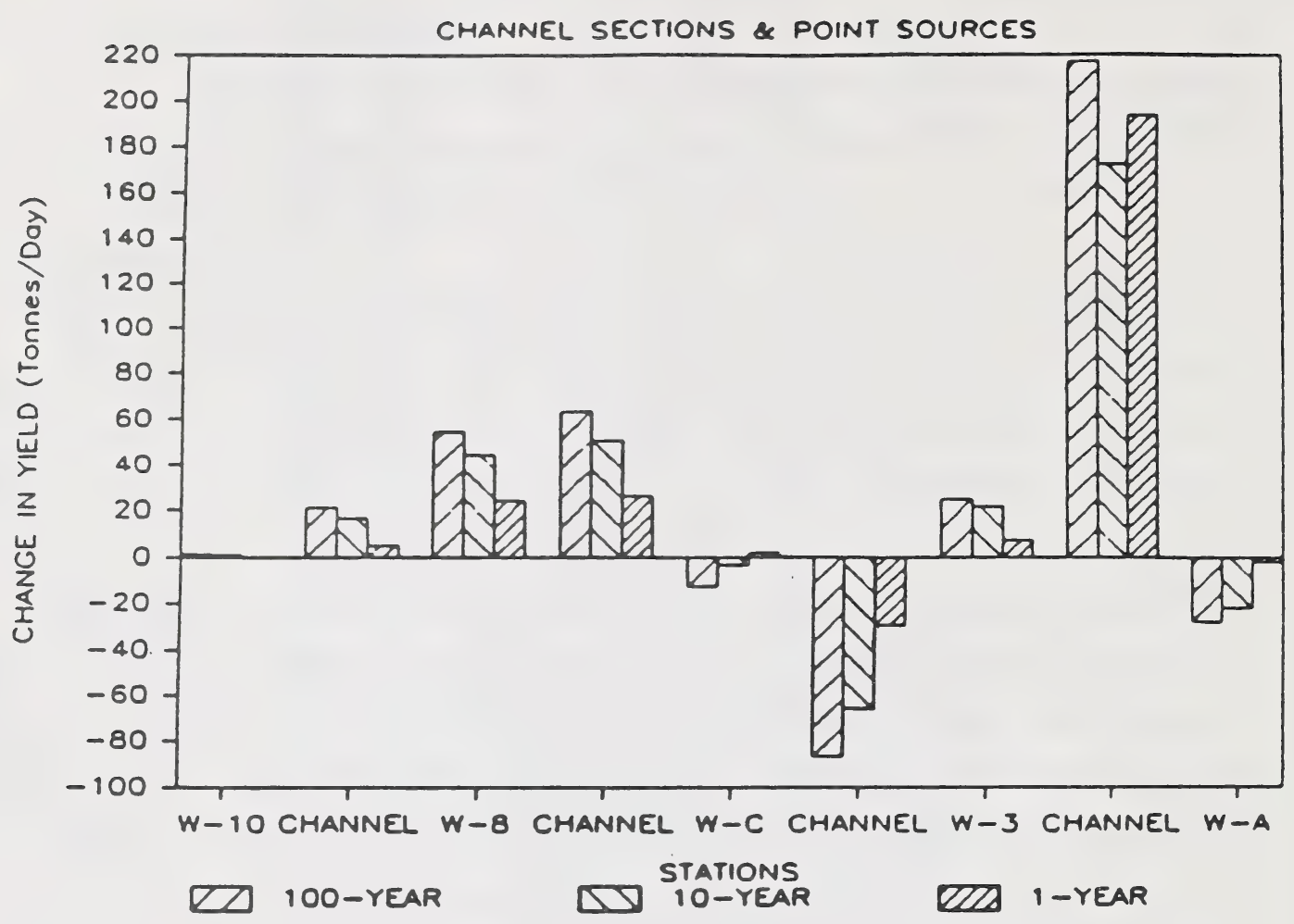

Figure 1. Sediment dynamics - predicted sediment.

Table 2. Calculations of sediment dynamics in the Wampus basin.

\begin{tabular}{||l|l|c|c|c|c|c|c|c||}
\hline \hline Return & $\mathrm{P}(\mathrm{f})$ & $\alpha$ & $\mathrm{W}$ & $\mathrm{Y}$ & $\alpha$ & $\mathrm{W}$ & $\mathrm{Y}$ & $\Delta \mathrm{Y}$ \\
\hline \hline & & & \multicolumn{2}{|c|}{ Wampus A down } & & \multicolumn{2}{|c|}{ Wampus A up } & \\
\hline 1 & 0.1 & 0.0068 & -0.80 & 118 & 0.0061 & -0.80 & 120 & -2.00 \\
10 & 0.01 & 0.0068 & -1.52 & 216 & 0.0061 & -1.52 & 238 & -22.00 \\
100 & 0.001 & 0.0068 & -1.90 & 272 & 0.0061 & -1.90 & 300 & -28.00 \\
\hline
\end{tabular}




\begin{tabular}{|c|c|c|c|c|c|c|c|c|}
\hline Return & $P(f)$ & $\alpha$ & W & $\mathrm{Y}$ & $\alpha$ & W & Y & $\Delta \mathrm{Y}$ \\
\hline & & & \multicolumn{2}{|c|}{ Wampus 3 down } & & \multicolumn{2}{|c|}{ Wampus 3 up } & \\
\hline 1 & 0.1 & 0.0227 & -0.80 & 27 & 0.0285 & -0.80 & 19.5 & 7.50 \\
\hline 10 & 0.01 & 0.0227 & -1.52 & 66 & 0.0285 & -1.52 & 44.7 & 21.30 \\
\hline \multirow[t]{2}{*}{100} & 0.001 & 0.0227 & -1.90 & 83 & 0.0285 & -1.90 & 58.1 & 24.90 \\
\hline & & & \multicolumn{2}{|c|}{ Wampus $\mathrm{C}$ down } & & \multicolumn{2}{|c|}{ Wampus C up } & \\
\hline 1 & 0.1 & 0.011 & -0.80 & 45.1 & 0.0178 & -0.80 & 57.5 & -12.40 \\
\hline 10 & 0.01 & 0.011 & -1.52 & 110.5 & 0.0128 & -1.52 & 113.70 & -3.20 \\
\hline \multirow[t]{2}{*}{100} & 0.001 & 0.011 & -1.90 & 145.1 & 0.0128 & -1.90 & 143.4 & 1.70 \\
\hline & & & \multicolumn{2}{|c|}{ Wampus 8 down } & & \multicolumn{2}{|c|}{ Wampus 8 up } & \\
\hline 1 & 0.1 & 0.0221 & -0.80 & 31.4 & 0.0558 & -0.80 & 7.37 & 24.00 \\
\hline 10 & 0.01 & 0.221 & -1.52 & 63.9 & 0.0558 & -1.52 & 20.30 & 43.60 \\
\hline \multirow[t]{2}{*}{100} & 0.001 & 0.0221 & -1.90 & 81.1 & 0.0558 & -1.90 & 27.10 & 54.00 \\
\hline & & & \multicolumn{2}{|c|}{ Wampus 10 down } & & \multicolumn{2}{|c|}{ Wampus 10 up } & \\
\hline 1 & 0.1 & 0.2811 & -0.80 & 2.2 & 0.3551 & -0.80 & 1.80 & 0.40 \\
\hline 10 & 0.01 & 0.2811 & -1.52 & 4.7 & 0.3551 & -1.52 & 3.90 & 0.80 \\
\hline 100 & 0.001 & 0.2811 & -1.90 & 6.1 & 0.3551 & -1.90 & 4.90 & 1.20 \\
\hline
\end{tabular}

scouring of the stream bed appeared to occur when the stream power reached 10000 13000 watts $\left(25-30 \mathrm{~m}^{3} / \mathrm{s}\right)$. Results show that for high powers of discharge, for example during the June 24, 1985 storm event, sediment loads were calculated to be over 800 tonnes/day. This would be equivalent to filling approximately four 170 ton coal dump trucks in a 24 hour period at the mouth of Wampus Creek.

\section{DISCUSSION}

The results of the sediment dynamics analysis indicate that natural and forest harvesting practices cause sedimentation in Wampus Creek during storm events.

In the lower Wampus basin, glaciolacustrine soils contribute to sedimentation. The channel extending above Wampus-A to the Wampus-3 slump had the highest sediment transport and erosion processes. Beaver dams in the stream channel caused sediment deposition processes 


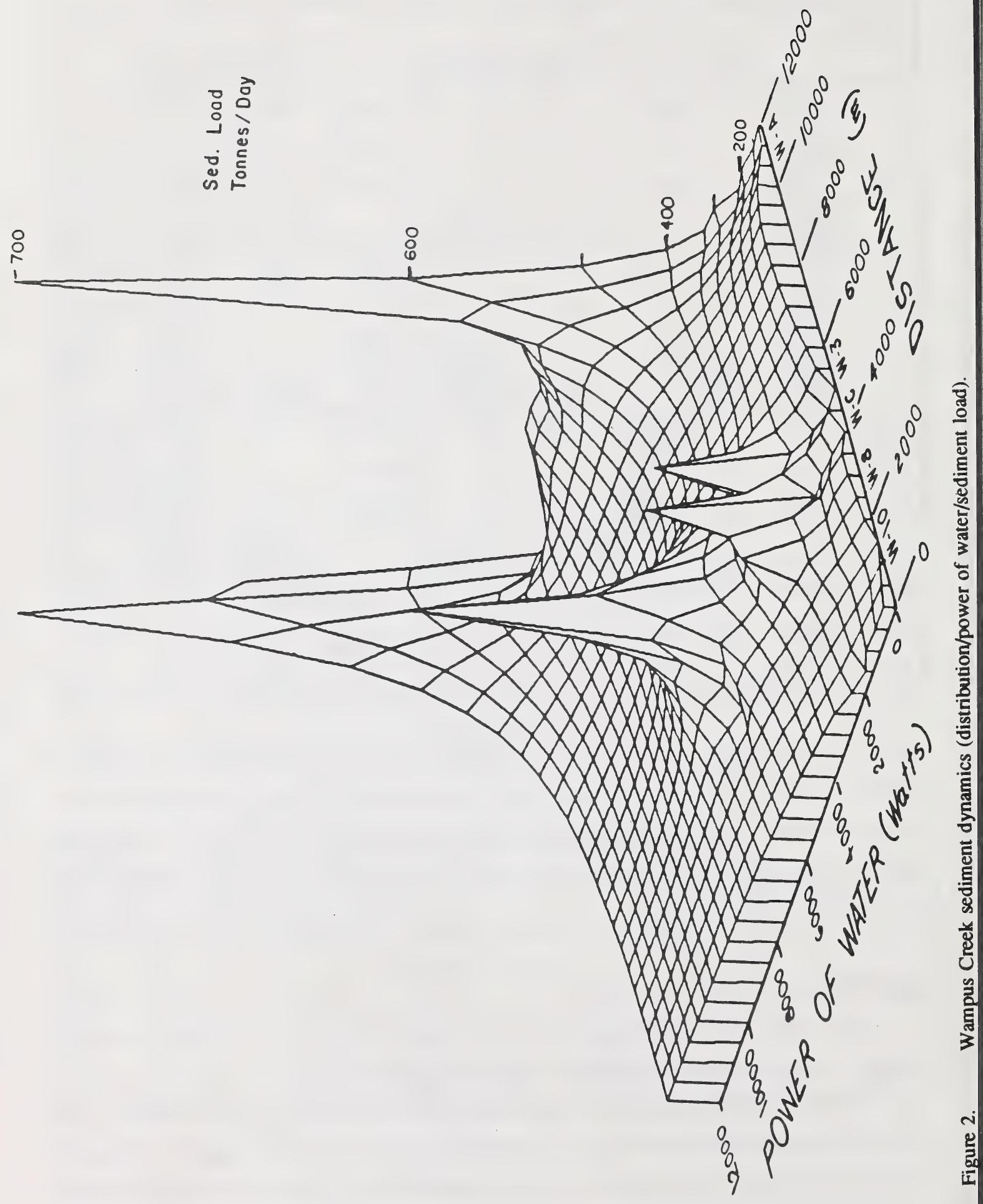


to occur during storm events. The Wampus-C bridge crossing point source produced evidence of sediment deposition. The contributing factor for the above sediment deposition may have been the level stream profile (Figure 3) at that section of the stream reach. Erosion and sediment transport processes occurred in the channel extending above Wampus- $\mathrm{C}$ to the Wampus- 8 cutblock during storm events. The stream channel extending along the Wampus- 8 cutback showed erosion and sediment transport processes during storm events.

Evapotranspiration rates are reduced as a result of forest harvesting. This allows greater amounts of rainfall to infiltrate through the soil and move towards the stream as groundwater. As the variable source area expands during a storm event the soil becomes well saturated with moisture. These saturated areas along the stream banks may become unstable, possibly leading to mass movement. Reconnaissance surveys have indicated that mass movement occurred along the length of the stream channel where cutblock 8 is located.

Erosion and revegetation surveys conducted on cutblock 8 in 1983 and 1985 indicated that cutblock 8 has revegetated. In addition, there was a reduction of exposed mineral soil from $38 \%$ to $33 \%$ during the period 1983 to 1985 . Nevertheless, areas of gully erosion still persisted in cutblock 8 after completion of timber harvesting five years ago.

The headwaters of Wampus Creek watershed show low erosion and sediment transport rates even though clear-cutting was extensive. This may be attributed to lower stream discharge at the headwaters causing lower stream power and resulting in less stream bed erosion, sediment transport and deposition.

Power of discharge, where sediment transport and stream bed scouring occurred, was determined through sediment load and power-of-water calculations. It was observed that Wampus Creek assumes non-linear characteristics (Sneddon, pers. comm.) i.e. erosion, transport and deposition processes occur at two different thresholds of stream power. When the stream power of discharge reaches $2000-5000$ watts through supply-related processes and a function of rain, fine clays and silts are transported and deposited within the stream channel. Scouring of the stream bed, a transport process related to channel hydraulics, occurs when the stream power of discharge reaches $10000-13000$ watts. 


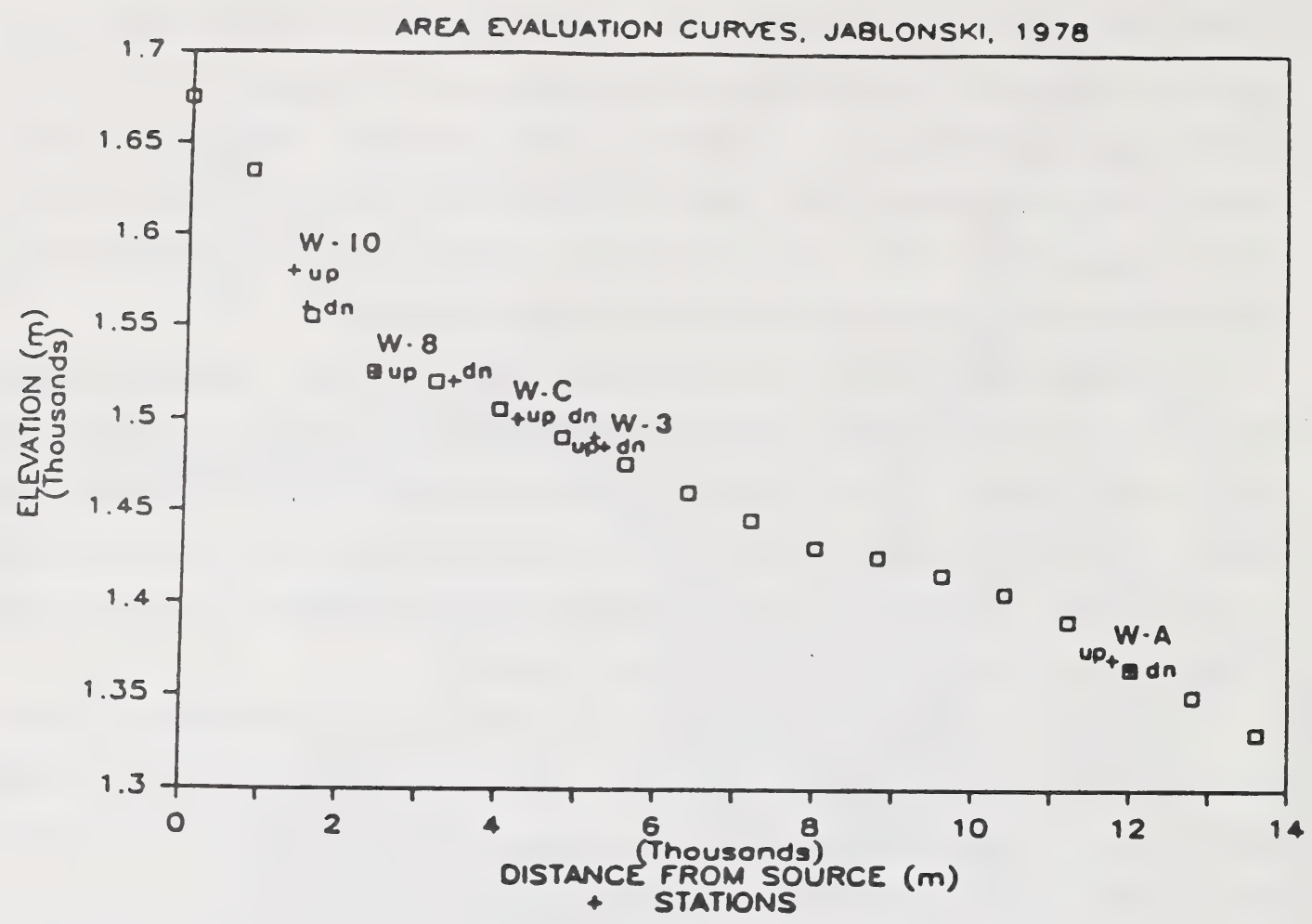

Figure 3. Wampus stream slope profile.

\section{CONCLUSIONS}

1. The channel extending above the Wampus-A to the Wampus-3 slump had the highest sediment transport and erosion processes during storm events. This conclusion appeared to be a result of the lower Wampus basin soils being primarily of glaciolacustrine origin.

2. The channel extending above Wampus-3 to the Wampus-C bridge crossing was observed to have the highest sediment deposition processes during storm events. This was a result of beaver dam activity in that section of the stream reach.

3. The Wampus-C bridge crossing, the channel extending above Wampus- $\mathrm{C}$ to the Wampus- 8 cutblock, the Wampus- 8 cutblock, the channel extending above Wampus- 8 to the Wampus- 10 culvert crossing and the Wampus-10 culvert crossing all showed sediment transport and erosion processes during storm events. 
4. It appears that during storm events the Wampus Creek watershed assumes non-linear characteristics. There are two critical power of discharge levels. When the discharge reaches 2000 - 5000 watts, silts and clays from the stream bed are transported. When the power of discharge reaches 10 000-13 000 watts, stream bed scour and sediment transport processes related to channel hydraulics occur.

5. Predicted sediment loads for 1, 10 and 100 year return-period storms were determined for each sediment point source. It was observed that, near the mouth of the watershed, high levels of sediment transport and erosion occur. In the construction of roads and creek crossings near the mouth of a watershed, forest engineering design guidelines should be upgraded to accommodate high return-period events.

\section{REFERENCES}

Benjamin, J.R., and J. Cornell. 1970. Probability Statistics and Decisions for Civil Engineers. Civil Engineering Series. McGraw Hill Book Co. Inc., New York.

Currie, D.V. 1969. Hydrogeology of the Tri-Creek Basin. M.Sc. Thesis, Univ. Alberta, Edmonton, Alberta.

Dumanski, J., M. Macyk, C. Veuvy, and J. Linsay. 1972. Soil Survey and Land Evaluation of the Hinton-Edson Area. Alberta Report No. 31. Research Council of Alberta, Edmonton, Alberta.

Hudson, H.R., G.M. Greenlee, and R.W. Howitt. 1985. Soil and Soil Erosion in the Tri-Creek Experimental Watershed, Alberta. Civil Eng. Depart., Alberta Research Council, Report No. SWE 85/08, Edmonton, Alberta.

Jablonski, P.D. 1978. Tri-Creek Watershed. A study into the Effects of Logging on the Physical, Chemical and Biotic Conditions of the Three East Slopes Streams. Alberta Energy and Natural Resources, Forest Land Use Branch, Watershed Management Section. Tri-Creek Report \#1, Edmonton, Alberta. 35 pp.

Linsley, R.K., M. A. Kohla, and J.L.H. Paulhus. 1958. Hydrology for Engineers. Civil Engineering Series. McGraw Hill Book Co. Inc., New York.

Nip, A. 1987. Watershed Management Field and Laboratory Methods. Alberta Forest Services. Forest Research Branch, Edmonton, Alberta.

Porterfield, G. 1978. National Handbook of Recommended Methods for Water-Data Acquisition. Office of Water Data Coordination Geological Survey. U.S. Depart. Interior, Reston, Virginia. 
Sneddon, D.T. (n.d.) Personal Communication. Scientific and Engineering Services and Research Division, Alberta Energy, Edmonton, Alberta.

Twenhofel, W.H. 1961. Treatise on Sedimentation 2nd Edition. Dover Publications, Inc., New York, New York.

Wasiliew, W.J. In prep. Sediment Study on Wampus Creek. Open file report, Forest Land Use Branch, Alberta Forest Service, Energy and Natural Resources, Edmonton, Alberta. 


\title{
Hydrochemistry of the Tri-Creek Experimental Watershed
}

\author{
D.T. Sneddon ${ }^{1}$ \\ Scientific and Engineering Services Division \\ Alberta Energy, Edmonton, Alberta \\ and \\ M.L. Korchinski ${ }^{2}$ \\ Energy Resources Conservation Board, Calgary, Alberta
}

\begin{abstract}
The effects of forest harvesting on chemical water quality were evaluated in a before/after comparison study spanning 19 years. Twenty-four parameters were assessed during a six-year baseline (pre-harvest) period from 1967 to 1973. The same parameters were assessed again for two years in the post-disturbance period (May 1983 to June 1986). No significant changes were observed in any of the parameters, suggesting there is insufficient information to reject the null hypothesis.
\end{abstract}

\section{INTRODUCTION}

Forest harvesting should produce some degradation of surface and groundwaters in wildland areas. Road construction, off-road vehicle operations and detritus from the harvesting operation itself would be expected to lead to land surface erosion. Leaching of nutrients and salts from forest soils and parent geological materials wherever they are exposed would also be expected.

Using this assertion as a working hypothesis, a series of experiments was designed to determine the effects of clear-cutting on the annual and storm chemical hydrographs, nutrient loadings, toxic substances and nonfilterable residues. These experiments formed part of a larger program of experimentation intended to assess the effects of forest harvesting on the aquatic environment at the Tri-Creek Experimental Watershed near Cadomin, Alberta. The larger experiment involved harvesting two of the three basins using the patch clear-cut technology and

${ }^{1}$ Formerly Research Manager, Watershed Forest Research Branch, Alberta Forest Service.

${ }^{2}$ Formerly Senior Water Analyst, Water Analysis and Research Group, Alberta Environmental Centre, Vegreville, Alberta. 
reforesting using the methods appropriate to individual cutblocks. The third basin, Eunice Creek, was left untouched to act as a control for the experiments.

The harvested basins were each treated differently, although about the same amount of forest was removed (between 40 and 50\%). Wampus Creek, the northernmost, was harvested according to the prevailing ground rules for the McLeod Working Circle, that is, a three chain buffer strip of timber was left at the streamside. Deerlick, the middle basin, was harvested using a comparable technology, but the forest was removed to the stream bank. Care was taken not to damage stream banks or allow machinery to enter the stream channel: all crossings of Deerlick Creek were bridged.

The detailed geography of the experimental watershed is described elsewhere in these proceedings.

This paper deals only with the hydrochemical regime, or average condition of the three streams at the outlet gauging stations.

Pre- and post-harvest comparisons of monthly and annual average concentrations were made for each parameter. The baseline period was from January 1968 to November 1974 and determinations were done by Environment Canada in Calgary. The post-treatment period was from May 1984 to June 1986, and analyses were done for the project by the Chemistry Wing, Alberta Environmental Centre, Vegreville.

A series of assumptions underlie the work:

1. All three streams are subject to the same hydrologic influences.

2. The hydrologic response to a given rainfall/snowmelt event is predictable, for each stream.

3. The sediment sources (i.e. erosion sites) for each stream are known.

A series of related experiments was also designed to explore the dynamics of the various parameters. These will be reported separately.

\section{OBJECTIVES}

The objectives of this study were to determine the effects of clear-cutting on the annual and storm chemical hydrographs, nutrient loading, toxic substances and nonfilterable residues. 


\section{METHOD}

Water samples for chemical analysis were taken from each stream weekly during 1968 and 1969, then more or less monthly during the open-water period of the year until 1974. During the post-treatment period, samples were taken weekly during the spring freshet; the rising limb, peak and recession limb of storm hydrographs; and monthly at other times. Weekly samples were taken during December 1985 to establish the variability of each parameter under ice-cover conditions. Sampling was done according to the method prescribed in the Environment Canada publication "Sampling for Water Quality" (Environment Canada, 1983).

Laboratory analytical methods were those described in the Alberta Environmental Centre publication "Manual for Chemical Analysis of Water and Wastes" (AEC, 1980). Korchinski conducted or supervised the analyses, both during the baseline and post-treatment periods. Considerable effort went into assuring the comparability and quality of determinations reported here. Other data were obtained, but, because of problems with reliability or comparability, were not interpreted.

Determinations can be divided into two categories: those done in the field and those done in the Calgary or Vegreville laboratories. The field determinations included $\mathrm{pH}$, specific conductance (SC), turbidity, stream water discharge (Q) and non-filterable residue (NFR). Laboratory determinations were made for:

- the major ions:

Alkalinity (both phenol [PA] and total [TA]), chloride $\left(\mathrm{Cl}^{-}\right)$, sulfate $\left(\mathrm{SO}_{4}^{--}\right)$, sodium $\left(\mathrm{Na}^{+}\right)$, calcium $\left(\mathrm{Ca}^{++}\right)$, potassium $\left(\mathrm{K}^{+}\right)$, magnesium $\left(\mathrm{Mg}^{++}\right)$, silica $\left(\mathrm{SiO}_{2}\right)$; -the nitrogen species:

nitrite plus nitrate $\left(\mathrm{NO}_{2}+\mathrm{NO}_{3}\right)$, ammonium $\left(\mathrm{NH}_{4}{ }^{+}\right)$, total Kjeldahl nitrogen (TKN), and particulate or total nitrogen (PN) [for the post-treatment period only]; -the phosphorus species:

total phosphate (TP) and orthophosphate (OP);

-and the carbon species:

dissolved organic carbon (DOC) and particulate carbon (PC).

As a quality control check, SC, $\mathrm{pH}$ and NFR were also determined in the laboratory.

Data quality control was implemented in the post-treatment period. Field determined parameters were subjected to daily control checks through the use of United States Environmental 
Protection Agency approved standard solutions. Alberta Environmental Centre (AEC) prepared secondary standards and multiple determination or sampling techniques.

Laboratory results for the major ions were subjected to an ion balance procedure. Determinations were also labelled good, questionable or bad. Unreliable determinations were deleted from the data base. All data reported here have been corrected to $25^{\circ} \mathrm{C}$.

Preharvest data were subjected to the same data quality appraisals as the post-treatment database, wherever practical. All units were transformed to the System International d'Unites, according to published standards (International Standards Organization, 1981).

\section{EXPERIMENTAL RESULTS}

\section{$\underline{\text { Specific Conductance and Major Ions }}$}

Specific conductance (SC) can be related nearly deterministically to total dissolved solids (TDS) and the concentration of major ions in a natural water (Lane, 1975). For the Tri-Creek area, the post-treatment regression is:

$$
\text { TDS }=0.634 \mathrm{~K}-2.2 \quad \mathrm{r}^{2}=0.87, \mathrm{n}=78 \text { determinations }
$$

where TDS was determined from the sum of masses from major ion determinations, K is SC field data and $r^{2}$ is the coefficient of determination. The determinations were from all three study streams. This is similar to Lane's (1975), who found the relationship to be

$$
\operatorname{TDS}=0.65 \% 0.10
$$

If it can be shown that:

1. the hypothesis is true that forest harvesting does not affect the relationship between SC and discharge $(\mathrm{Q})$, and $\mathrm{SC}$ is determined by the mass of dissolved major ions; and

2. the relative proportion of each constituent is also unaffected by forest harvesting, it follows that no change to the major ion regime has occurred. A 95\% acceptance criterion will be applied.

Table 1 and Figure 1 show the relationship between discharge and specific conductance during pre- and post-harvest conditions. Eunice and Deerlick creeks behave in a similar way, which is different from the regime that characterizes Wampus Creek.

By inspection, it is apparent that only Deerlick Creek, a treated basin, is significantly different from the baseline and post-harvest periods. There is also some justification for believing that a slight change has also occurred to Wampus Creek, which was treated in a less 
Table 1. Relationship $[\log (\mathrm{Q})=\mathrm{a} * \log (\mathrm{SC})+\mathrm{b}]$ between discharge and specific conductance during pre- and post-harvest conditions.

\begin{tabular}{||l|c|c|c|c|c||}
\hline Site & $\mathrm{a}$ & $\mathrm{b}$ & $\mathrm{r}^{2}$ & Std. Err. & D.F. \\
\hline \hline Wampus Creek, Base & -0.3780 & 2.0 & 0.878 & 0.015 & 86 \\
Wampus Creek, Post-harvest & -0.3147 & 2.0 & 0.819 & 0.074 & 58 \\
\hline Deerlick Creek, Base & -0.3213 & 1.9 & 0.710 & 0.089 & 96 \\
Deerlick Creek, Post-harvest & -0.1713 & 2.1 & 0.725 & 0.073 & 75 \\
\hline Eunice Creek, Base & -0.3603 & 2.0 & 0.717 & 0.088 & 67 \\
Eunice Creek, Post-harvest & -0.3755 & 1.9 & 0.838 & 0.068 & 77 \\
\hline
\end{tabular}

severe way than Deerlick Creek. Both streams show lowered salt concentrations in the posttreatment data sets. Upon examination of Figure 1c, however, it appears that the regressions have been biased by the presence of more high-discharge data during the post-treatment period. This is an artifact of the different sampling strategies pursued during the two periods. Inspection of Figure 1 shows the difference between the two regressions for Wampus Creek is simply the result of variability. No discernible difference in regime is evident from the scattergram.

Analysis of regressions for each constituent of the major ions group with SC showed strong linear correlations. When the concentration data were reduced to milliequivalents per litre, a linear multiple regression was attempted, to explore the variability in constituent proportions between the baseline and post-treatment periods. The results are shown in Table 2 .

While three regressions are very tight, there were not enough data to complete adequately a full set of regressions which included all the anions; consequently, the results should be used with caution. Since the shifts in proportions are similar in both the Eunice and Deerlick basins, it would appear that they are caused by something other than forest harvesting.

Metals: Iron

Because of differences in analytical techniques and concern about the accuracy of the preharvest determinations, the only metal included in the post-harvest suite was total iron. Upon review, it was found that only a few baseline determinations were for total iron, the rest being for dissolved iron. The number of baseline determinations was too small to be useful and therefore no attempt will be made to interpret the results. 


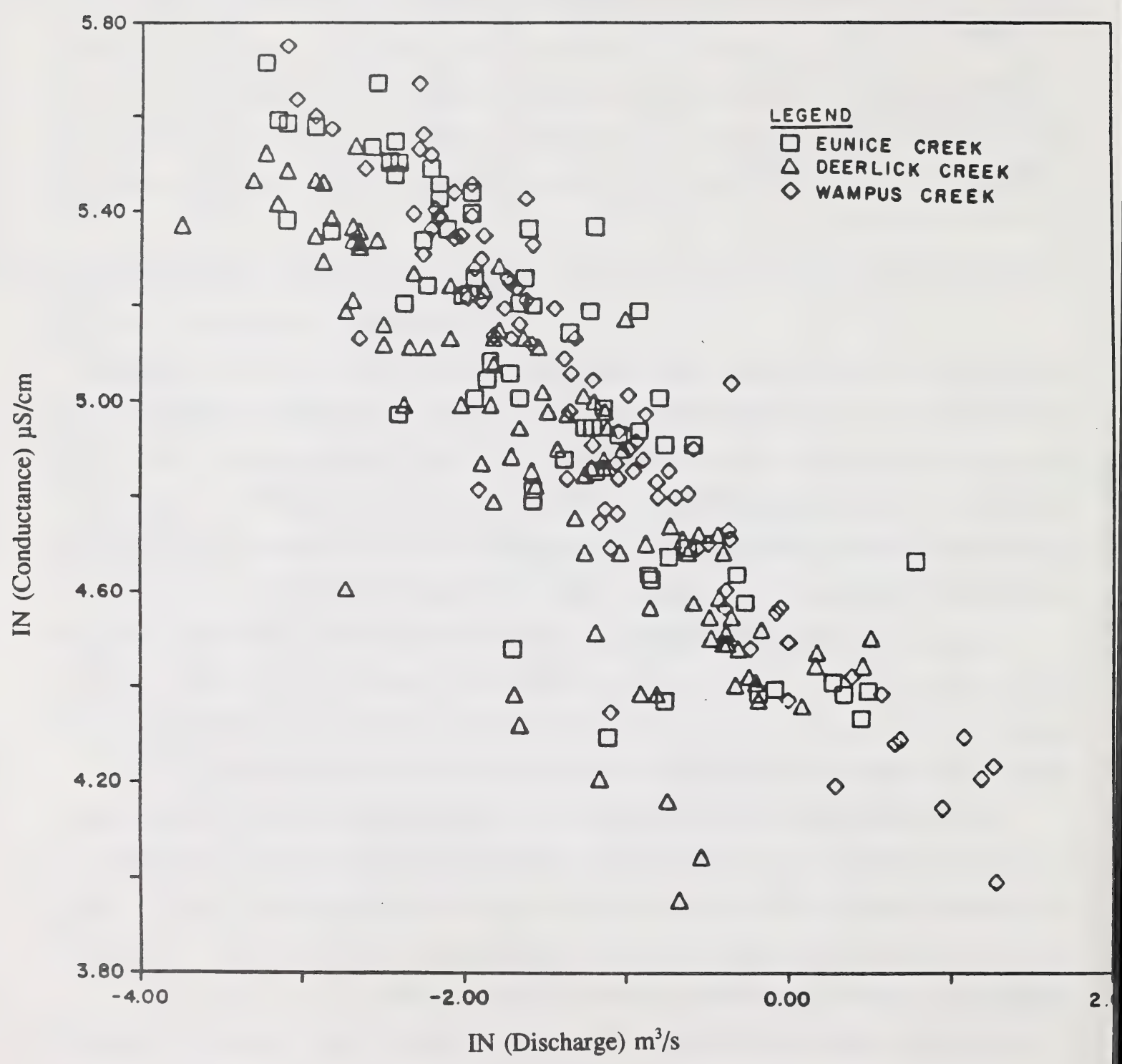

Figure 1. Relationship between discharge and specific conductance in three creeks. 
Table 2. Multiple regression of major ions versus specific conductance.

\begin{tabular}{||l|r|r|r|r|r|r|r|r|c||}
\hline \hline Site & $\mathrm{Ca}$ & $\mathrm{Mg}$ & $\mathrm{Na}$ & $\mathrm{K}$ & $\mathrm{Cl}$ & $\mathrm{T}$ & $\mathrm{g}$ & $\mathrm{r}^{2}$ & $\mathrm{DF}$ \\
\hline \hline Wampus Creek, Pre-harvest & - & - & - & - & - & - & - & - & - \\
Wampus Creek, Post-harvest & 1.76 & 0.76 & 1.93 & 0 & 0 & 1.17 & 12.89 & 0.92 & 58 \\
\hline Deerlick Creek, Pre-harvest & 1.67 & -1.7 & 7.95 & 0 & 0 & 0.49 & 45.04 & 0.97 & 56 \\
Deerlick Creek, Post-harvest & -0.10 & 0.7 & 0.35 & 0 & 0 & 1.79 & 12.04 & 0.99 & 70 \\
\hline Eunice Creek, Pre-harvest & 2.70 & 8.20 & 15.24 & 0 & 0 & 0.11 & -4.78 & 0.96 & 39 \\
Eunice Creek, Post-harvest & 1.92 & 5.84 & -1.92 & 0 & 0 & 0.97 & 31.81 & 0.62 & 39 \\
\hline
\end{tabular}

\section{Nutrients}

Nitrogen Species

As has been reported by others, (Lane, 1975; Sopper, 1975; Likens et al,. 1977; Singh and Kalra, 1977; Feller and Kimmins, 1979), no statistical relationship between discharge and TKN, $\mathrm{NO}_{2}+\mathrm{NO}_{3}$ or $\mathrm{NH}^{4+}$ concentrations was found. Figure 2 shows that concentrations are time related. This phenomenon has been reported by the same workers cited above and is commonly assigned to the annual cycle of vegetation growth. Unlike in the reports by others, no significant change in concentrations for any of the species occurred. Statistically significant changes appear in Table 3, but these are mirrored by changes of a similar magnitude in the performance of the control basin; consequently, they are unlikely to have been related to forest harvesting.

Table 3. Changes to nitrogen concentrations (parts per million).

\begin{tabular}{||l|l|l|l||}
\hline \multicolumn{1}{|c|}{ Site } & $\mathrm{NH}_{4}$ & $\mathrm{TKN}$ & $\mathrm{NO}_{2}+\mathrm{NO}_{3}$ \\
\hline \hline Wampus Creek & -0.144 & -0.039 & -0.038 \\
\hline Deerlick Creek & -0.139 & -0.059 & -0.019 \\
\hline Eunice Creek & -0.155 & -0.039 & -0.038 \\
\hline
\end{tabular}

\section{Phosphorus Species}

Like the nitrogen species, the phosphorus species also behaved contrary to expectation, and declined in abundance following forest harvesting. The differences in observed concentrations (change $=$ post-harvest - pre-harvest) are shown in Table 4 and Figure 3. This 


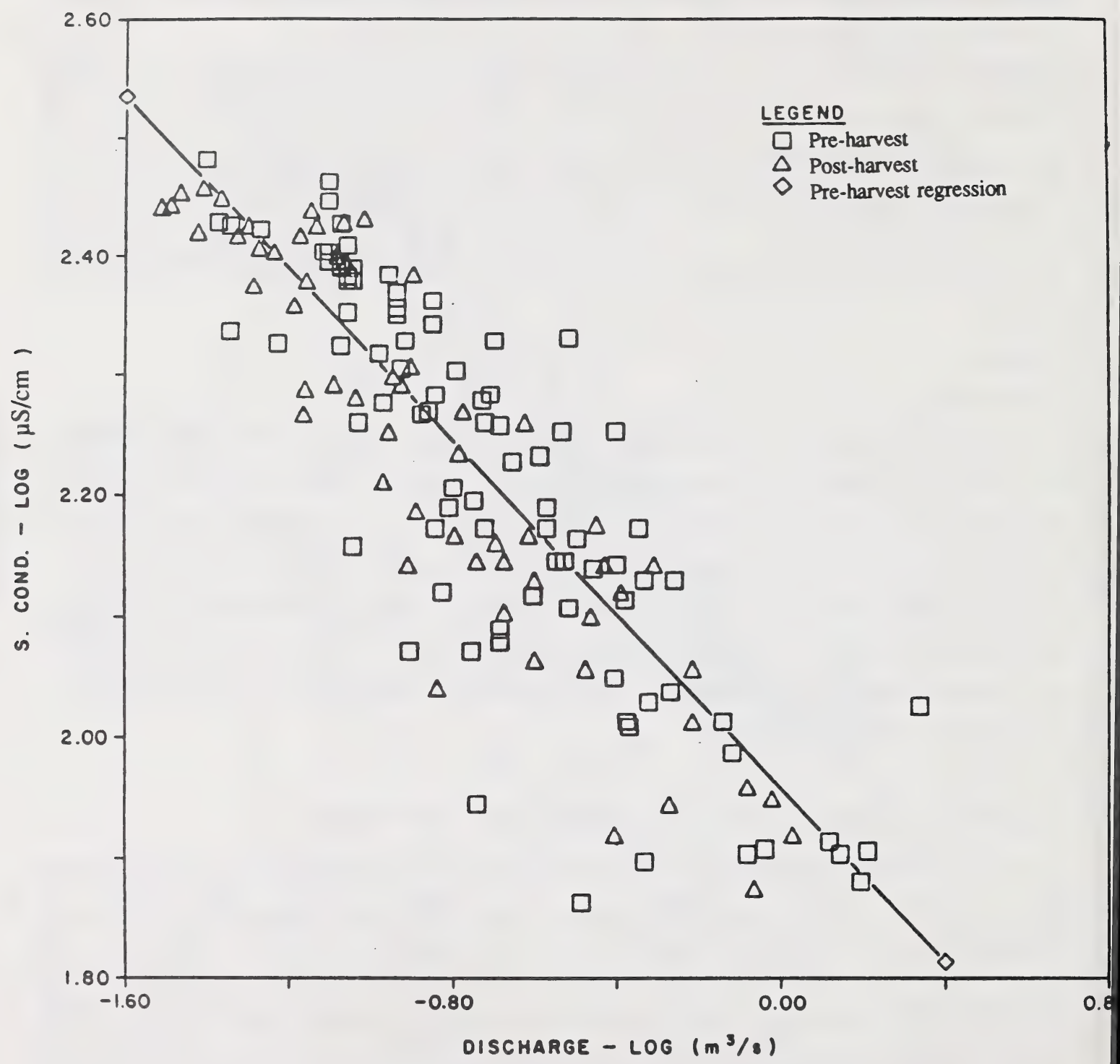

Figure 2a. Relationship between specific conductance and discharge in Eunice Creek. 


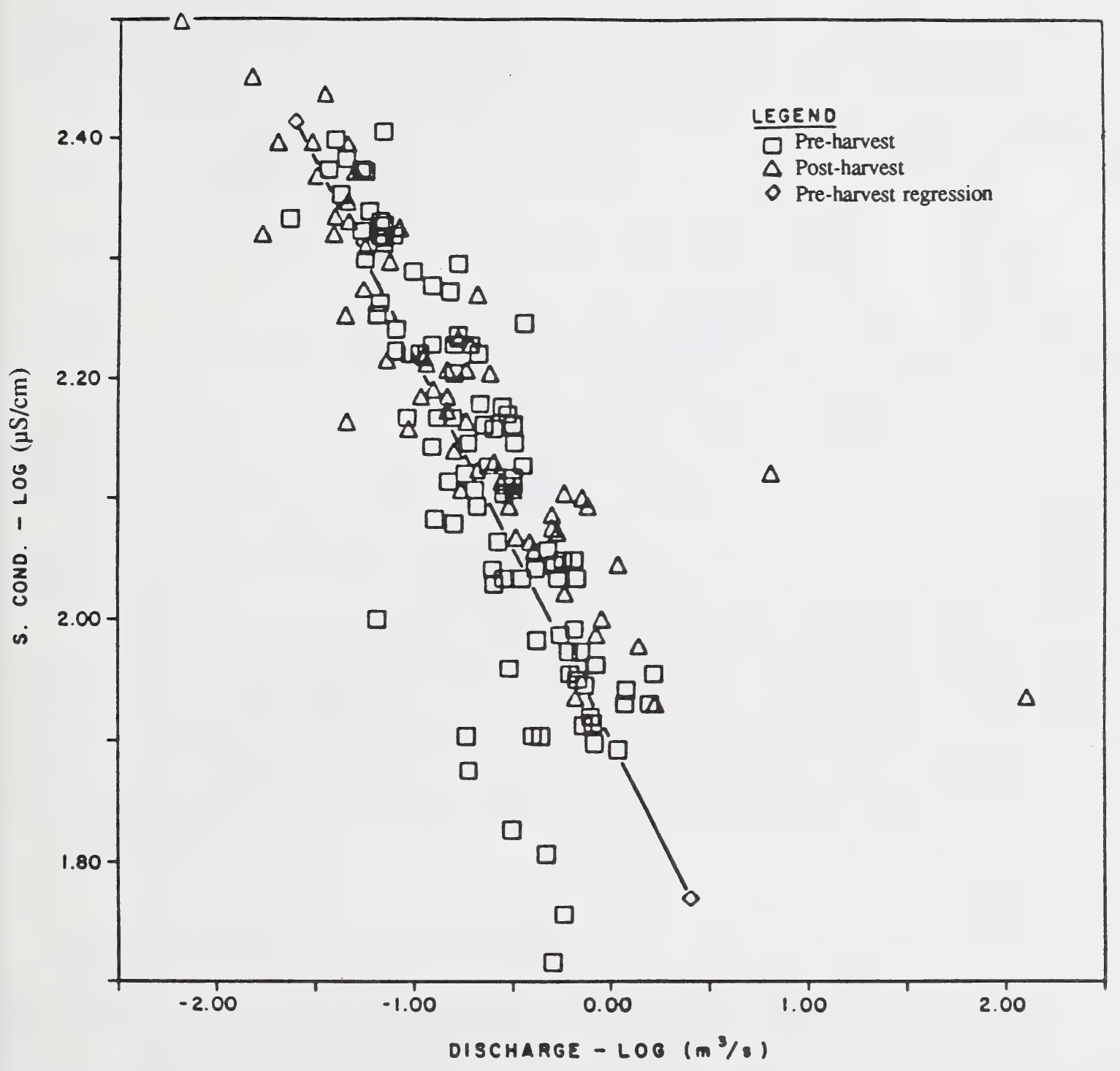

Figure 2b. Relationship between specific conductance and discharge in Deerlick Creek. 


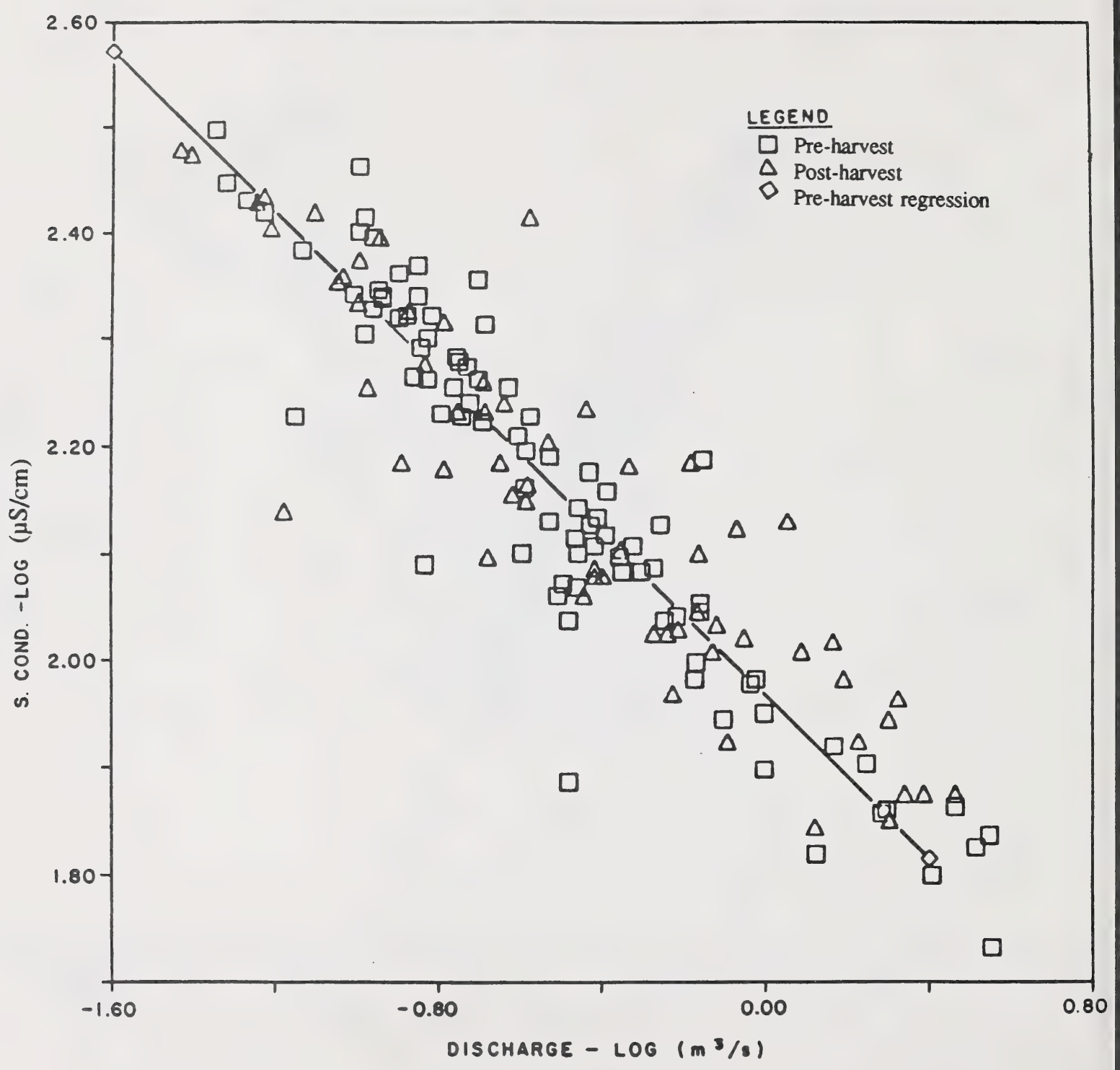

Figure 2c. Relationship between specific conductance and discharge in Wampus Creek. 
apparent reduction in abundances might be related to analytical differences to some extent since interference to phosphate analysis was a major problem until comparatively recently. We cannot satisfactorily explain these data in the light of comparable studies elsewhere in the world. Singh and Kalra (1977) observed concentrations of orthophosphate of about the same magnitude in this same region when comparing logged versus undisturbed watersheds during the summer of 1975 , but found no differences that could be related to logging activity.

Table 4. Changes in phosphorus concentrations (mg/L).

\begin{tabular}{||l|c|c|}
\hline \multicolumn{1}{|c|}{ Site } & TP & OP \\
\hline \hline Wampus Creek & -0.007 & -0.003 \\
\hline Deerlick Creek & -0.004 & -0.040 \\
\hline Eunice Creek & +0.004 & -0.002 \\
\hline
\end{tabular}

\section{Hydrogen $\mathrm{pH}$}

Hydrogen ion concentrations, as measured by $\mathrm{pH}$, have declined throughout the area by about $0.1 \mathrm{pH}$ unit since the baseline period (Table 5 and Figure 4). This is well within the precision of the method, and the significance levels computed for each site were high $(\mathrm{P}<0.001$ for " $t$ " of 3.5 or better). This trend is also independent of logging activity. Most of the studies cited above also include $\mathrm{pH}$ amongst their observed parameters, and none show a change that can be directly linked to logging.

Table 5. Changes to $\mathrm{pH}$ in the three creeks.

\begin{tabular}{||l|c|c|c||}
\hline \multicolumn{1}{|c|}{ Site } & $\begin{array}{c}\text { Average Pre-harvest } \\
\mathrm{pH}\end{array}$ & $\begin{array}{c}\text { Average Post- } \\
\text { harvest pH }\end{array}$ & Change \\
\hline \hline Wampus Creek & 8.05 & 7.89 & -0.16 \\
\hline Deerlick Creek & 7.88 & 7.83 & -0.05 \\
\hline Eunice Creek & 8.08 & 7.99 & -0.09 \\
\hline
\end{tabular}




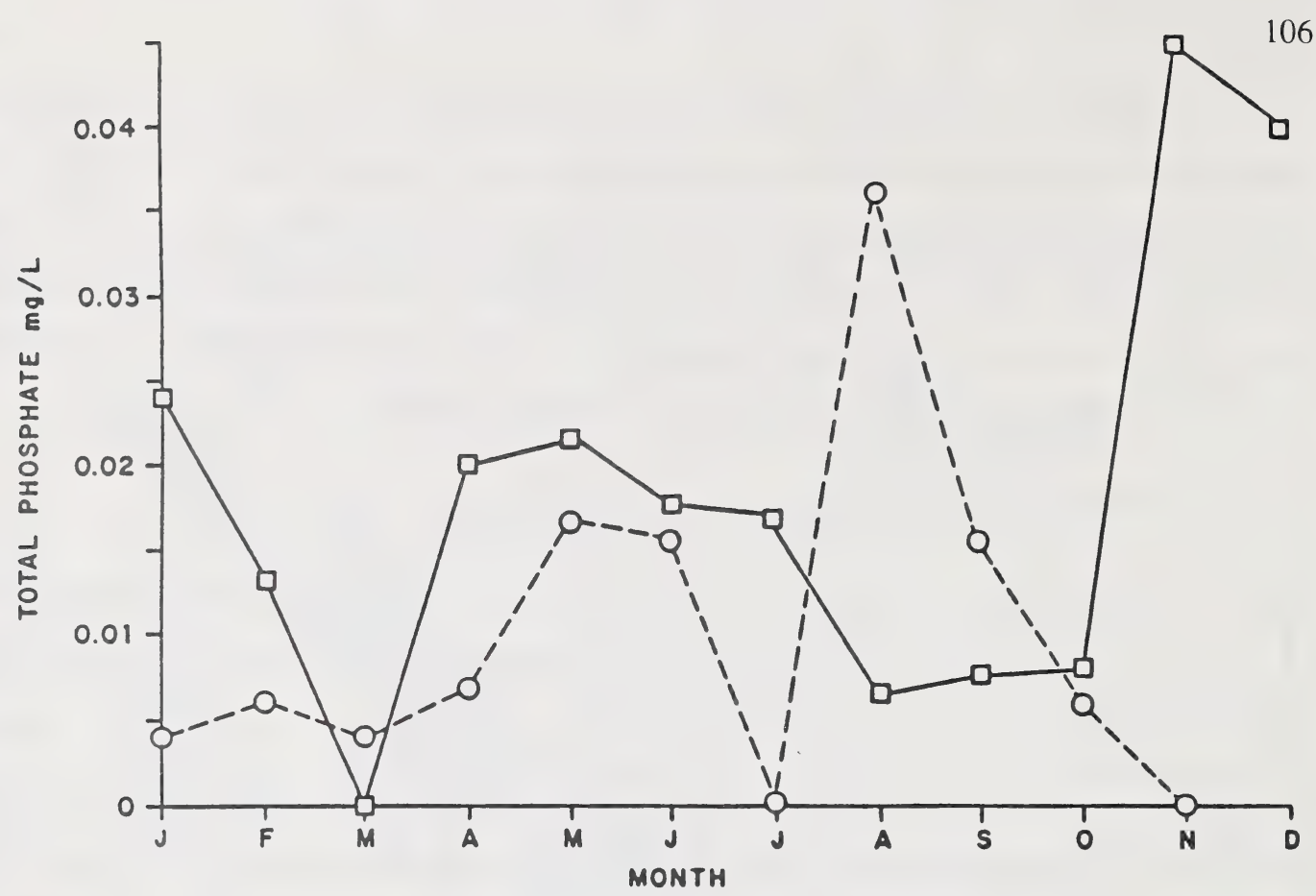

Figure 3a. Seasonal changes in the average concentration of total phosphate in Eunice Creek.

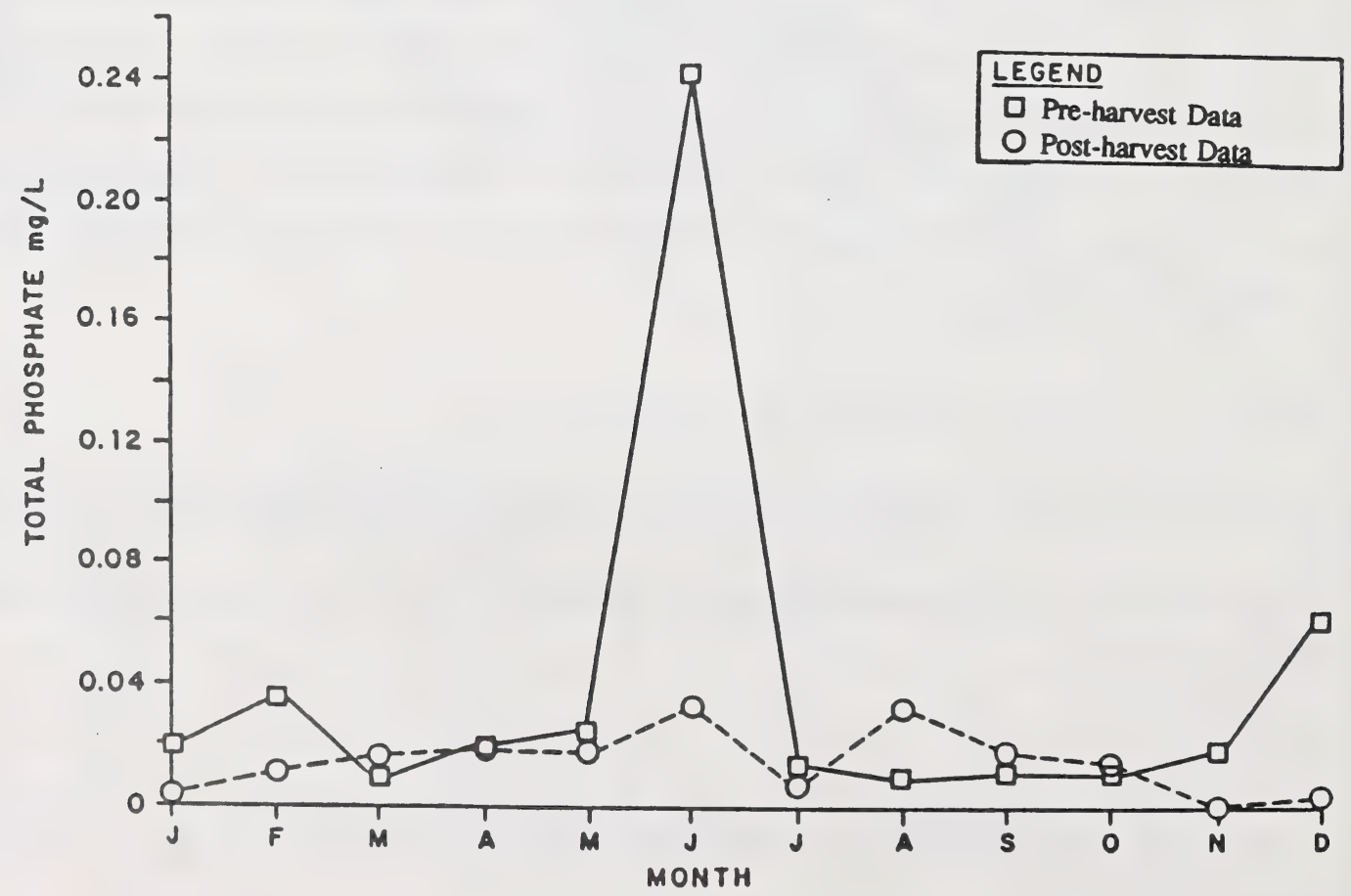

Figure 3b. Seasonal changes in the average concentration of total phosphate in Deerlick Creek. 


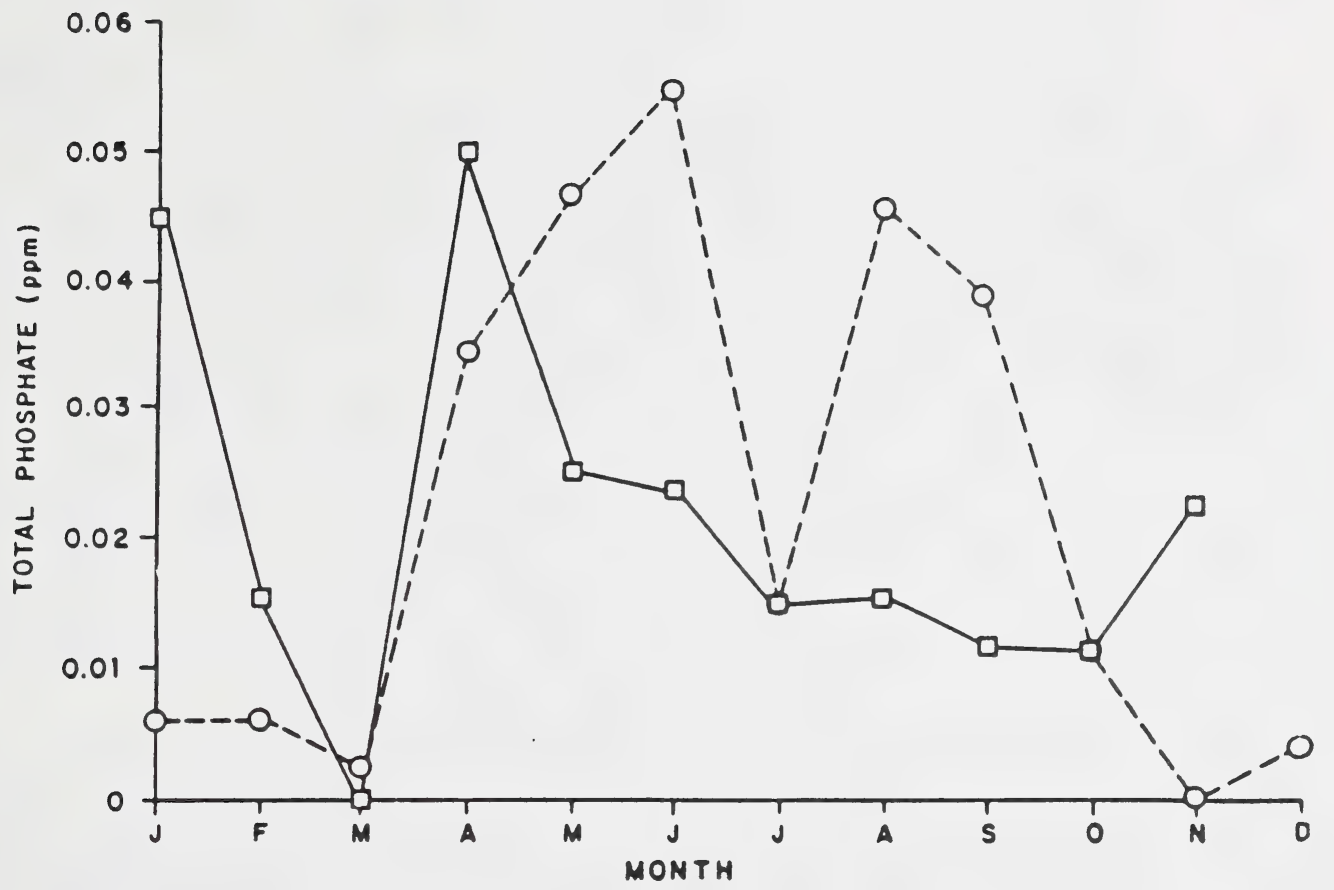

Figure 3c. Seasonal changes in the average concentration of total phosphate in Wampus Creek.

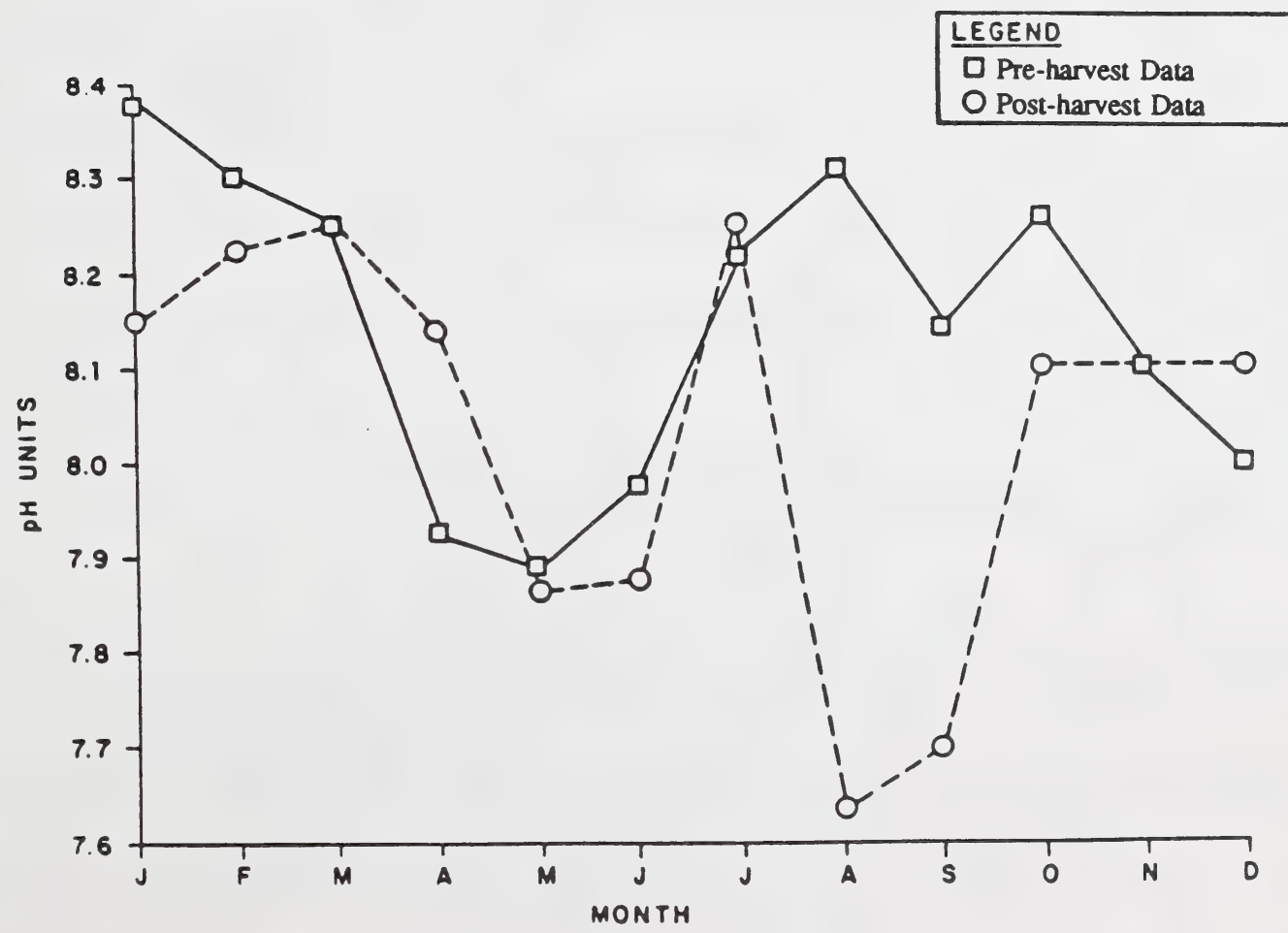

Figure 4a. Seasonal changes in the average $\mathrm{pH}$ in Eunice Creek. 


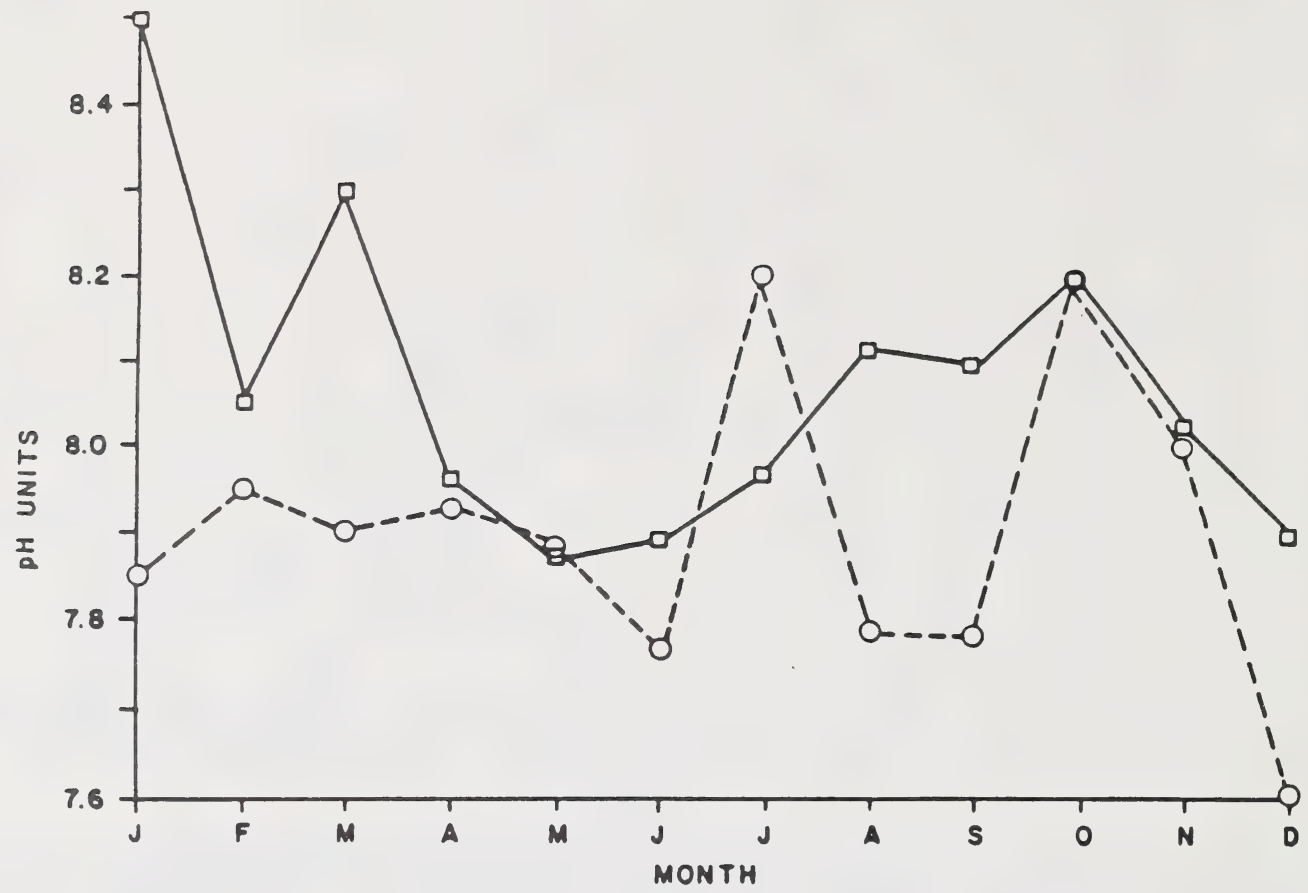

Figure 4b. Season changes in average $\mathrm{pH}$ in Deerlick Creek.

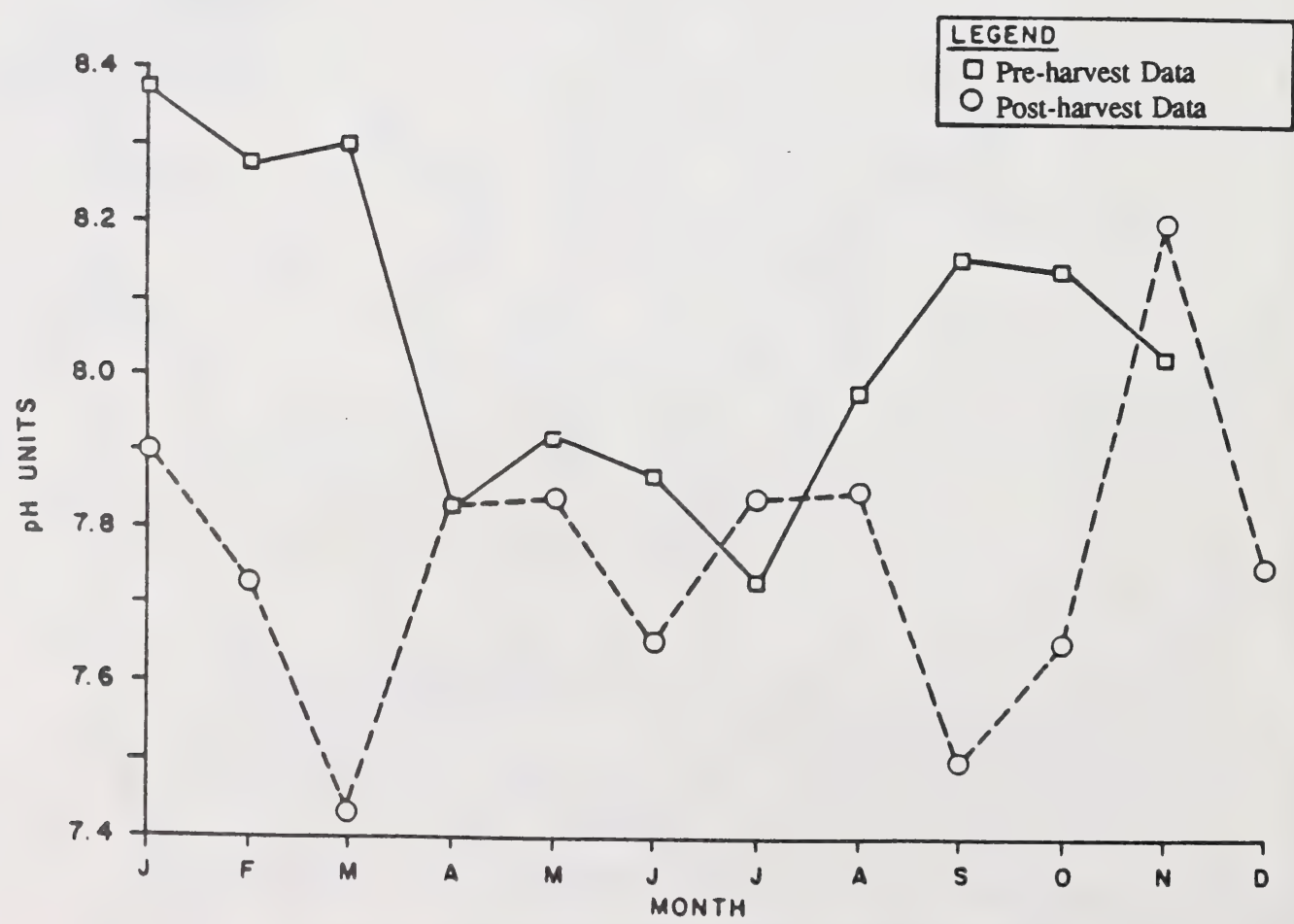

Figure $4 \mathrm{c}$. Seasonal changes in average $\mathrm{pH}$ in Wampus Creek. 


\section{$\underline{\text { Turbidity }}$}

Table 6 and Figure 5 document changes to average turbidity in the three streams. None of the t-tests are significant, indicating that the mean turbidity has not changed, but is correlated with algal blooming and diatom activity. These phenomena were noted during the post-harvest period, but were not rigorously documented. From Figure 5, the post-harvest peaks occurred during the summer low flow periods. Intuitively, turbidity should be at least weakly correlated with periods of high suspended load. This is correct, as $\mathrm{r}^{2}$ values of 0.5 to 0.6 were observed with discharge; however, the particle sizes that respond most strongly to scattering are in the range of 100 to $450 \mathrm{~nm}$. In this range, one of the authors (DTS) was able to demonstrate correlation coefficients of 0.808 for the model:

$$
[\mathrm{NFR}]=5.288 \exp (0.063 \mathrm{~T})
$$

where [NFR] is the concentration of suspended solids, and T is turbidity in Nephelometric Turbidity Units. By experiment, it was found that about $50 \%$ of the suspended solids at Tri-Creek were greater than $450 \mathrm{~nm}$ in diameter, hence the weak logarithmic correlation with flow.

From these data, forest harvesting has had no demonstrable effect on the proportion of suspended particles in the fraction smaller than $450 \mathrm{~nm}$.

Table 6. $\quad$ Changes to turbidity (nephelometric turbidity units).

\begin{tabular}{||l|c|c|c||}
\hline \multicolumn{1}{|c|}{ Site } & $\begin{array}{c}\text { Pre-harvest } \\
\text { Turbidity }\end{array}$ & $\begin{array}{c}\text { Post-harvest } \\
\text { Turbidity }\end{array}$ & Change \\
\hline \hline Wampus Creek & 4.27 & 7.29 & +3.02 \\
\hline Deerlick Creek & 6.44 & 4.28 & -2.16 \\
\hline Eunice Creek & 6.08 & 4.36 & -1.72 \\
\hline
\end{tabular}

\section{CONCLUSIONS}

1. No discernable difference in specific conductance was evident between pre- and postharvest data for all creeks.

2. There was insufficient data to determine if there was any effect from timber harvesting on total ion concentration in the water. 


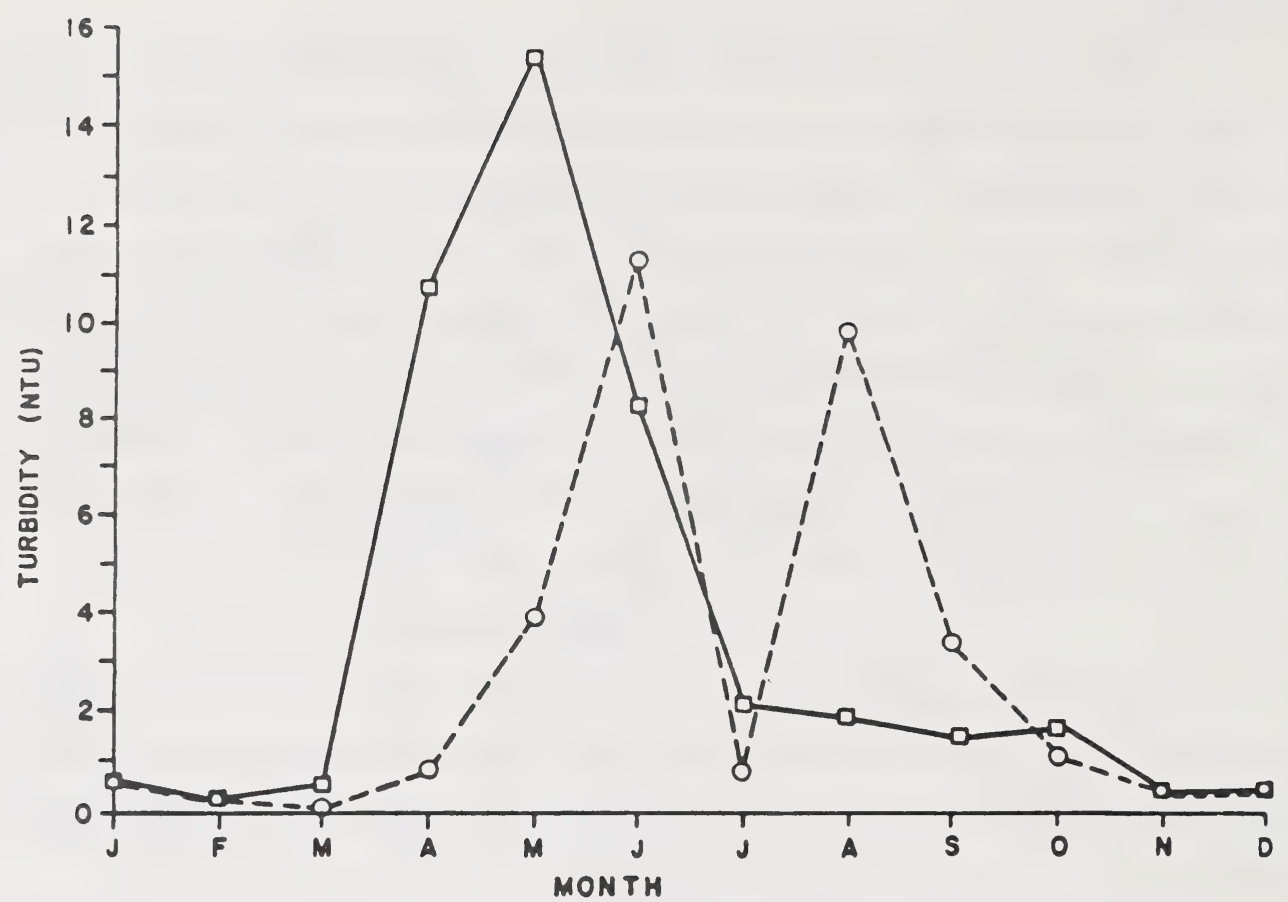

Figure 5a. Seasonal changes in average turbidity in Eunice Creek.

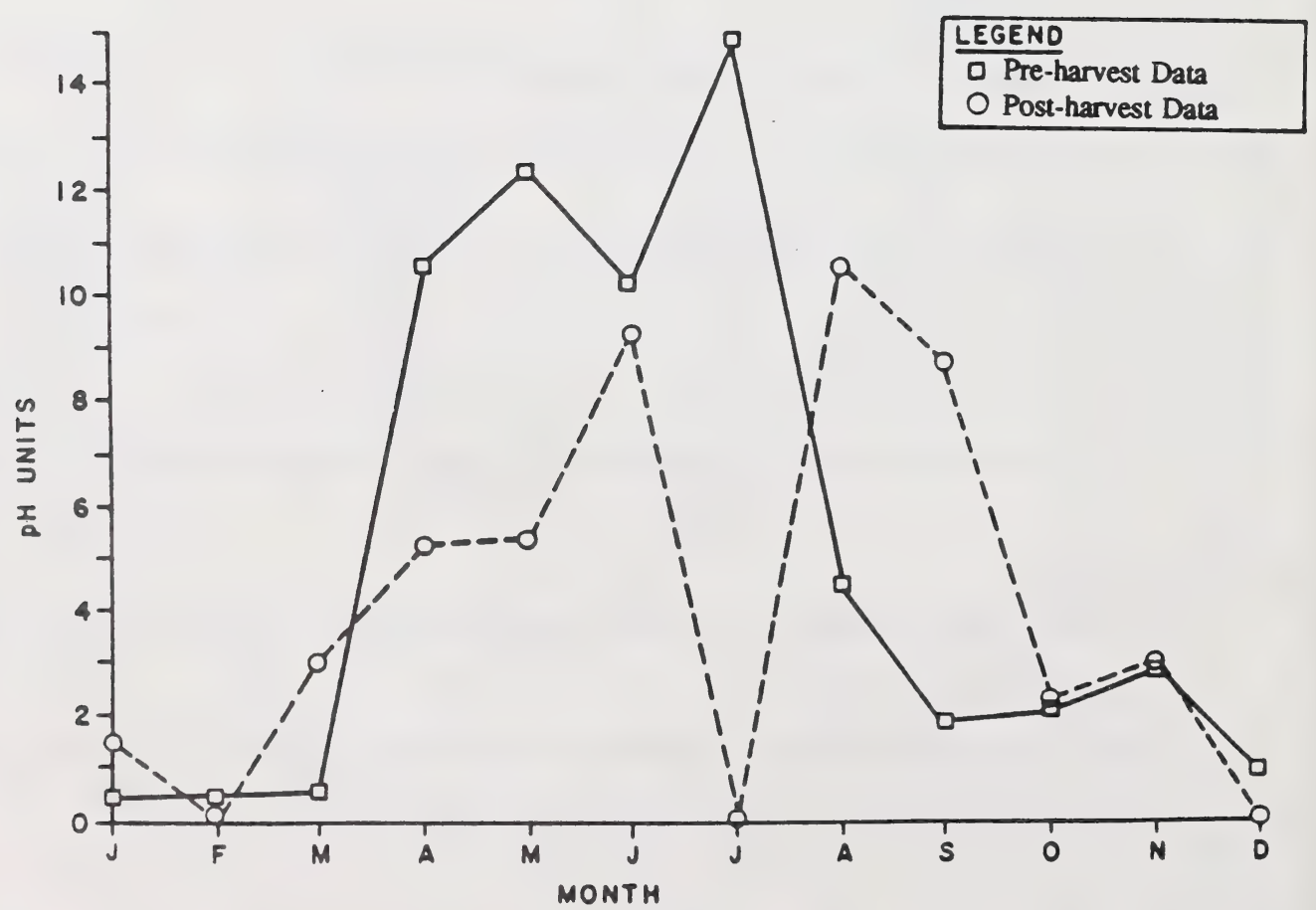

Figure 5b. Seasonal changes in average $\mathrm{pH}$ in Deerlick Creek. 


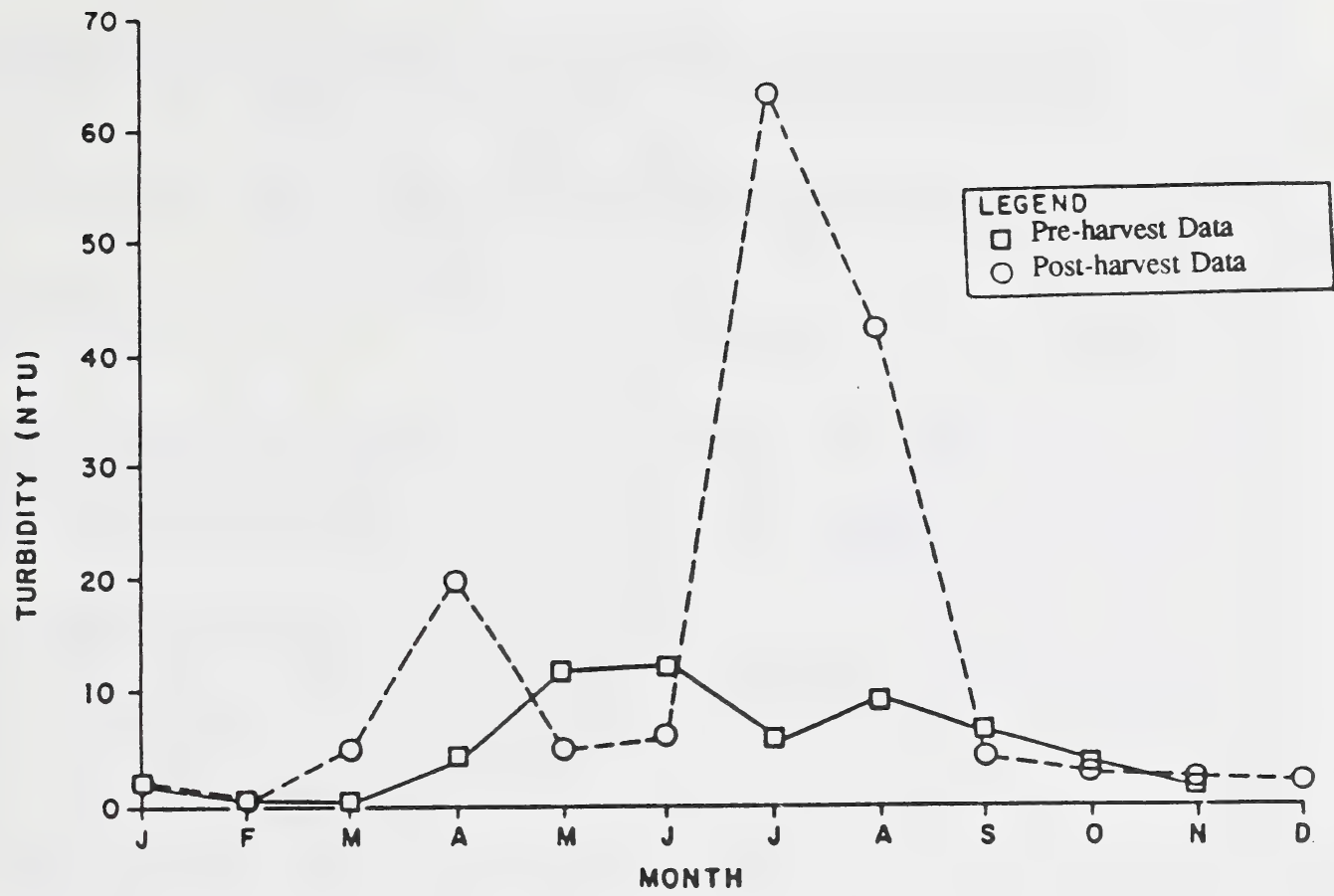

Figure 5c. Seasonal changes in average turbidity in Wampus Creek.

3. Concentrations of nitrogen species were time-, not discharge-related, as reported by other workers. However, no significant change in concentrations was noted. Significant changes which do occur are unlikely to be related to forest harvesting.

4. The concentration of phosphate species also declined following harvest, but this may be due to analytical difficulties.

5. The pH also declined slightly during the sampling period, but this was independent of logging activity.

6. Turbidity changes appeared to be correlated to algal bloom and diatom activity; however, forest harvesting appeared to have no effect on the turbidity (particles $<450 \mathrm{~mm}$ ).

\section{REFERENCES}

Alberta Environmental Centre. 1980. Manual for Chemical Analysis of Water and Wastes. Alberta Environmental Centre, Vegreville, Alberta.

Environment Canada. 1983. Sampling for Water Quality. Inland Waters Directorate. Cat. No. En37-64/1983E, Environment Canada, Ottawa, Ontario. 
Feller, M.C., and J.P. Kimmins. 1979. Chemical characteristics of small streams near Haney in southwestern British Columbia. Wat. Res. Res. 15:247-258.

Lane, W.L. 1975. Extraction of Information on Inorganic Water Quality. Hydrology Paper No. 73, Colorado State University, Fort Collins, Colorado.

Likens, G.E. et al. 1977. Biogeochemistry of a Forested Ecosystem. Springer-Verlag New York Inc., New York, New York.

Singh, T., and Y.P. Kalra. 1977. Impact of pulpwood clearcutting on stream water quality in west central Alberta. In: Proceedings of the Alberta Watershed Research Program Symposium. Compiled by R.H. Swanson and P.A. Logan. Northern Forest Research Centre. Report NOR-X-176, Edmonton, Alberta. pp. 272-284.

Sopper, W.E. 1975. Effects of timber harvesting and related management practices on water quality in forested watersheds. J. Environ. Qual. 4:24-29. 


\title{
Effects of Logging on the Thermal Regime of the Streams in the Tri-Creek Basin ${ }^{1}$
}

\author{
David Andres ${ }^{2}$ \\ Civil Engineering Department \\ Alberta Research Council, Edmonton, Alberta
}

\section{INTRODUCTION}

The temperature regime of a stream plays a major role in determining its ecological value. Water temperature regulates many of the biological activities. For example, as water temperature increases, the dissolved oxygen content decreases and the growth of aquatic bacteria, some of which may be pathogenic to fish, increases (Brown, 1983). The removal of vegetation from the basin from which a stream derives its flow may cause a significant change in its thermal regime. If most of the riparian vegetation is removed and the stream surface is exposed to direct sunlight, then some temperature increase in the stream flow will occur due to the increase in the absorbed solar radiation. The removal of the vegetation along the bank will also increase the wind and air temperature above the water surface and promote greater heat flux. The removal of significant amounts of upland vegetation may also contribute to higher stream temperature because the exposed basin surface will absorb more radiation, and the runoff entering the stream will be at a higher temperature.

This paper addresses changes in the thermal energy balance at the water surface and in the overall water temperature regime of the affected streams due to forest harvesting in the Tri-Creek basin. A comparison of monthly pre- and post-logging water temperatures is made and heat transfer processes at the surface water are discussed and quantified.

\section{OBJECTIVES}

The objectives of this study were to assess changes in the thermal energy balance at the water surface and in the overall water temperature regime of the affected streams due to forest harvesting in the Tri-Creek basin.

\footnotetext{
${ }^{1}$ Alberta Research Council Contribution Series Number 1474.

${ }^{2}$ Research Officer, Resource Technologies Department, Alberta Research Council.
} 


\section{BACKGROUND}

The Tri-Creek Watershed Study was initiated in 1965, under the auspices of the International Hydrologic Decade (IHD) by the Department of Lands and Forests, as part of the Alberta Watershed Program. The overall objectives were to determine the effects of pulpwood harvesting on the trout streams of the foothills and to change or strengthen the ground rules of the forest-cutting practices applied at that time. A study of the thermal regime is just one component of many ongoing studies.

The Tri-Creek catchment is located in the foothills region of the Rocky Mountains approximately $30 \mathrm{~km}$ southeast of Hinton (Figure 1). It consists of the drainage areas of three creeks: Wampus Creek, Deerlick Creek and Eunice Creek. All three sub-basins have a NNE aspect, and range in elevation from about $1700 \mathrm{~m}$ to $1275 \mathrm{~m}$. The drainage pattern is dendritic and the streams range from first order intermittent channels to fourth order irregularly meandering streams.

The basin is covered with subalpine forest, except for some of the high ridges and some parts of the valley bottoms which have meadow environments. On the higher slopes, which are well drained, Lodgepole pine is the main species of tree. In the valley bottoms, where the soil is usually saturated, black spruce dominates. Other tree species include white spruce, alpine fir, and balsam poplar. The undergrowth consists of Labrador Tea, willow, alder, grasses and numerous berry varieties (Nip, 1983). Muskeg exists in some wet areas (Hudson et al. 1985).

The climate in the area of the Tri-Creek basins is classified as humid, micro-thermal and subarctic (Atlas of Canada, 1957). The mean annual precipitation is $688 \mathrm{~mm}$, with $38 \%$ of this falling as snow (Winkler, 1980). The mean annual temperature is about $\mathrm{O}^{\circ} \mathrm{C}$. Summers are cool and short, and the mean daily temperature exceeds $10^{\circ} \mathrm{C}$ for 2 to 3 months. Winters are cold except for occasions when chinooks occur.

The average monthly mean water temperature at the outlets of all three basins (under natural conditions) varies between approximately $2^{\circ} \mathrm{C}$ in May and September to a high of about $10^{\circ} \mathrm{C}$ in August (Figure 2). In all months, Wampus Creek contains the warmest water, followed by Deerlick Creek and then Eunice Creek. During the cooler, low radiation months of May and September, there is no significant temperature difference between the three creeks, probably because most of the flow is derived from groundwater, and limited heat transfer occurs at the water surface. In the warm, high radiation months between June and September, Wampus Creek 


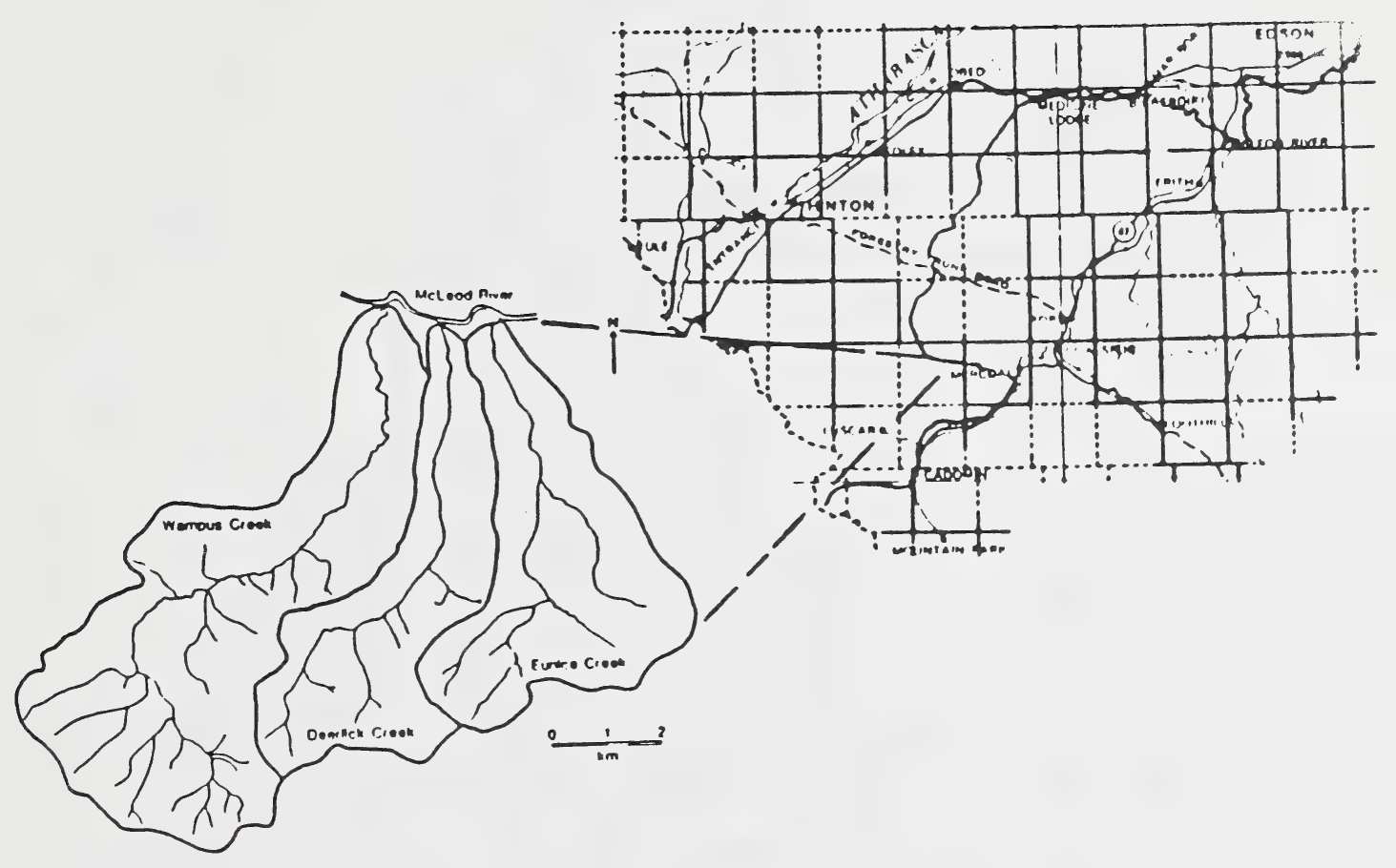

Figure 1. Location and relative position of the Tri-Creek basins.

and Deerlick Creek are significantly warmer than Eunice Creek. This is most likely due to the more extensive areas of an open meadow adjacent to the stream banks in both Wampus and Deerlick basins. Similar trends are also evident for the average monthly maximum temperatures shown in Figure 3. For the months of May and October the maximum water temperatures are about $6^{\circ} \mathrm{C}$ for all three creeks. However, during the warmer months, the average maximum water temperature approaches $17^{\circ} \mathrm{C}$ in Wampus Creek. On the average, this is about $2^{\circ} \mathrm{C}$ warmer than Deerlick Creek and about $6^{\circ} \mathrm{C}$ warmer than Eunice Creek.

Logging occurred in the Wampus Creek basin and the Deerlick Creek basin, whilst the Eunice Creek basin was maintained in a pristine condition to serve as a control (Figure 4). In the Deerlick Creek basin, the trees were removed right to the stream banks. Between 1981 and $1984,41 \%$ of the basin was cut, and the proportion of channel protected by riparian vegetation was reduced from $57 \%$, under natural conditions, to $35 \%$ in 1984. In the Wampus Creek basin, 


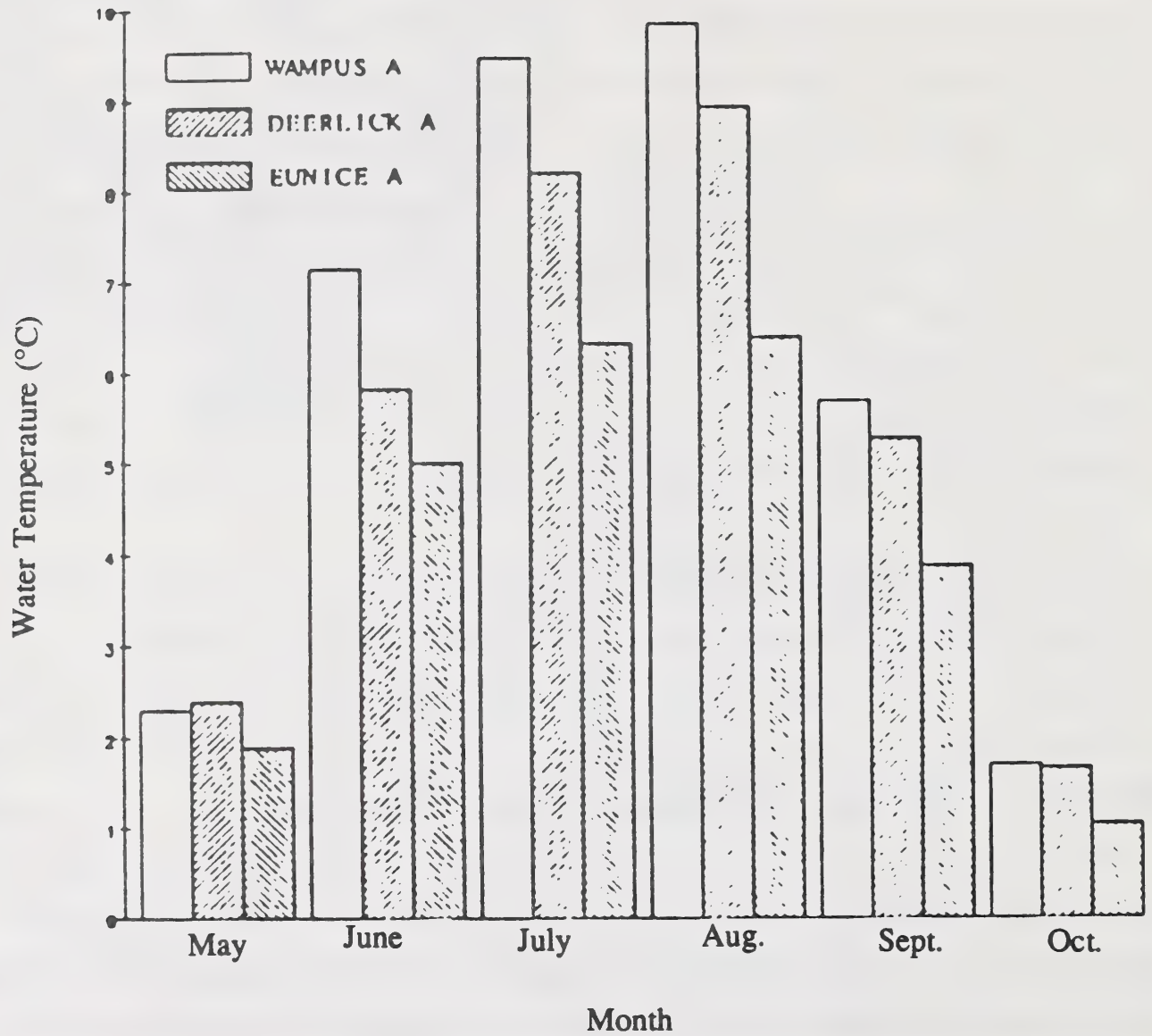

Figure 2. Average monthly mean water temperature at the outlets of all three basins under natural conditions.

logging took place between 1977 and 1984, and 39\% of the basin was harvested. The trees adjacent to the streams were not removed and, therefore, the naturally vegetated channel (48\% of the total stream length) was maintained throughout this period. It is interesting to note, that in the Eunice Creek basin, $71 \%$ of the channel is naturally vegetated. 


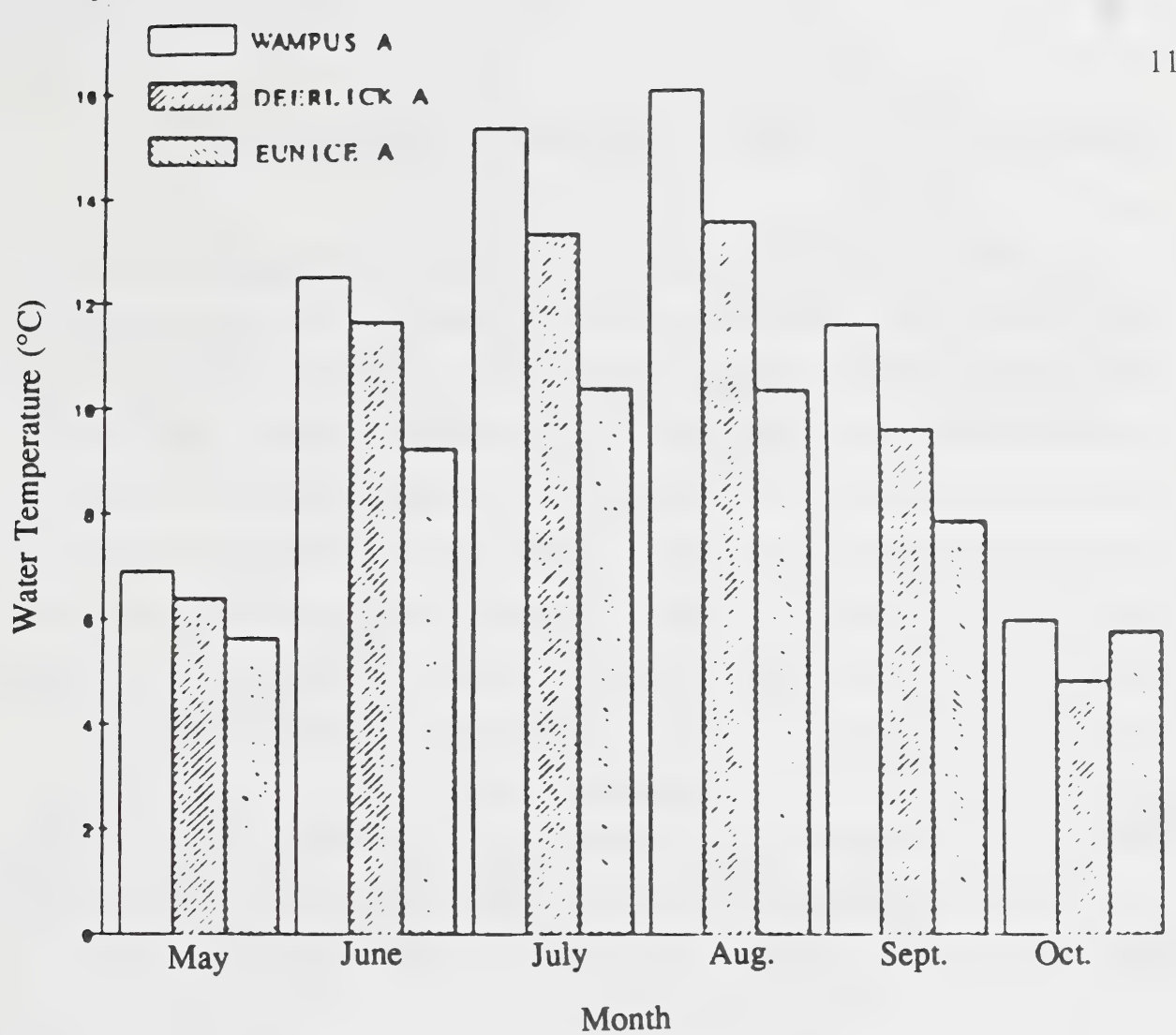

Figure 3. Average monthly maximum water temperature at the outlets of all three basins under natural conditions.

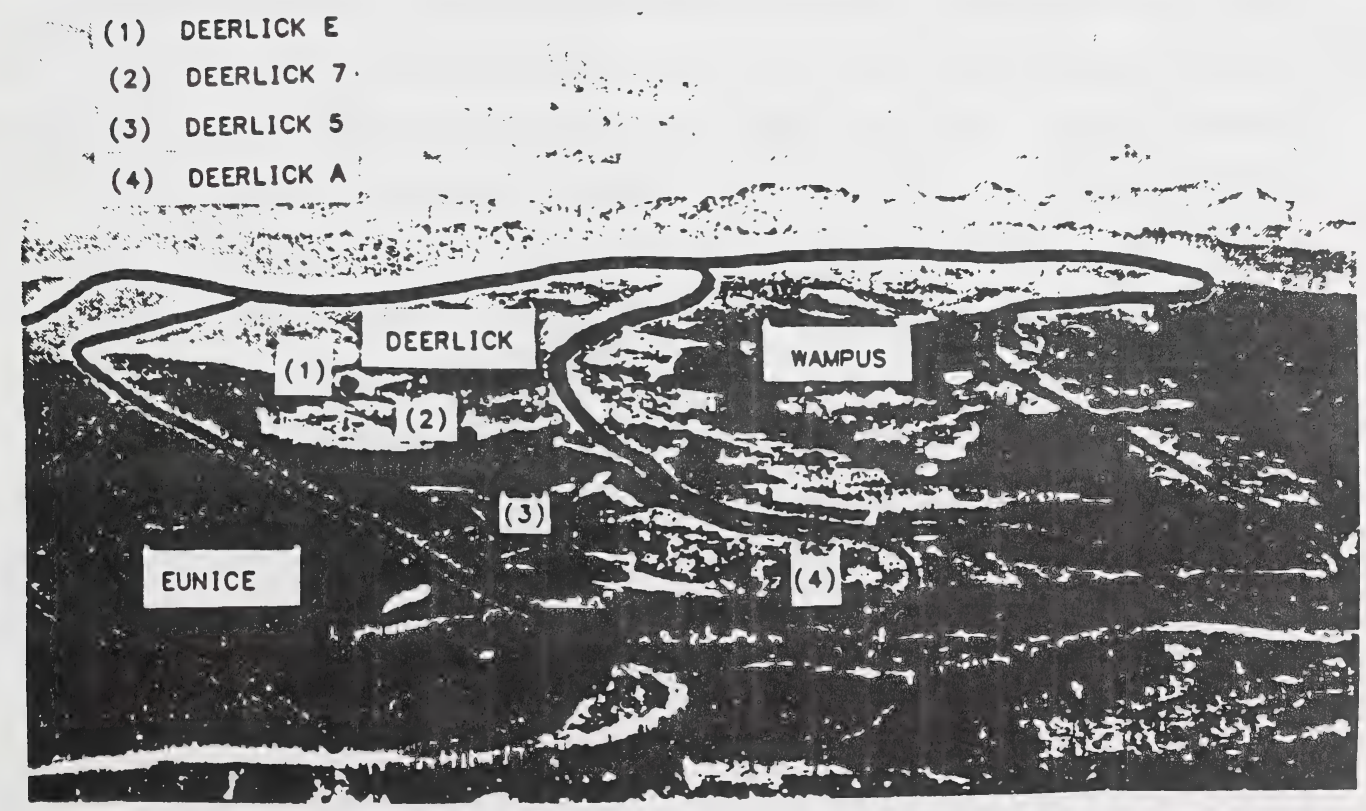

Figure 4. Logged areas of the Tri-Creek basin. 


\section{LOGGING IMPACTS ON THE WATER TEMPERATURE REGIME}

\section{Method}

In the lumped basin approach, where inputs such as air temperature and precipitation, and outputs such as runoff and air temperature, are compared between the treated basins and the control basin, the impact of logging can be assessed by defining changes in the outputs of the treated basin with respect to the outputs of the control basin. The data for this analysis consisted of daily maximum, minimum and mean water temperatures collected at outlets of all three creeks from June to September for the years 1967-1985. Daily discharges were also measured at the same locations for the same time period. From these data, monthly mean and maximum water temperatures and monthly mean discharge were determined (Andres et al., 1987) and monthly averages of the net heat output from each of the basins were computed by:

$$
\mathrm{H}_{\mathrm{t}}=8.64 \times 10^{-8} \mathrm{~N}_{\rho} \mathrm{C}_{\mathrm{p}} \mathrm{Q}_{\mathrm{m}} \mathrm{T}_{\mathrm{m}} \text {, }
$$

where $H_{t}$ is the total monthly energy output in gigajoubs (GJ), N is the number of days in the month, $\rho$ is the mass density of water, $C_{p}$ is the specific heat of water, $Q_{m}$ is the monthly mean discharge, and $\mathrm{T}_{\mathrm{m}}$ is the monthly mean water temperature.

\section{RESULTS AND DISCUSSION}

A comparison of pre- and post-logging heat outflow of Wampus Creek and Deerlick Creek to that from Eunice Creek suggests that there is marginally more energy coming out of the two logged basins than is leaving the control basin (Figure 5). The scatter in the Wampus Creek/Eunice Creek data is large. Even if the post-logging data generally plot above the leastsquares best-fit line of the pre-logging data, they are not significantly greater. On the other hand, the Deerlick Creek/Eunice Creek plot indicates a significant increase in the annual energy outflow following logging. Some of this increase, however, may be realized by an increase in the annual water yield.

A double-mass analysis of energy outflow from Wampus Creek and Eunice Creek (Figure 6) shows a wide variety of perturbation for a number of years, both before and after logging in the Wampus Creek basin. This lack of any consistent trends reinforces the fact that no significant changes in the mean monthly temperature regime are discernable following logging. 

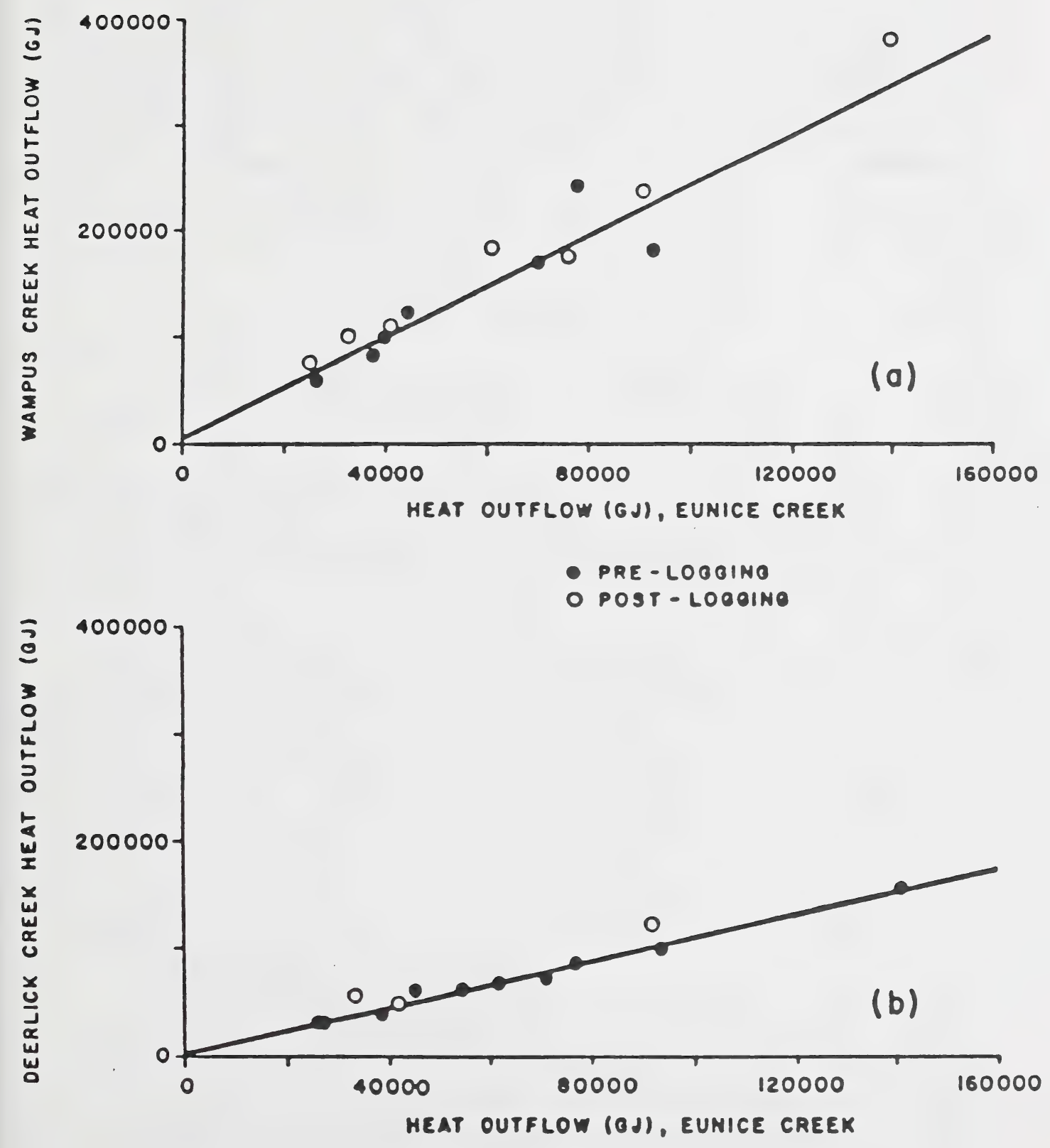

Figure 5. Comparison of annual heat outflows between (a) Wampus Creek and (b) Deerlick Creek and Eunice Creek. 

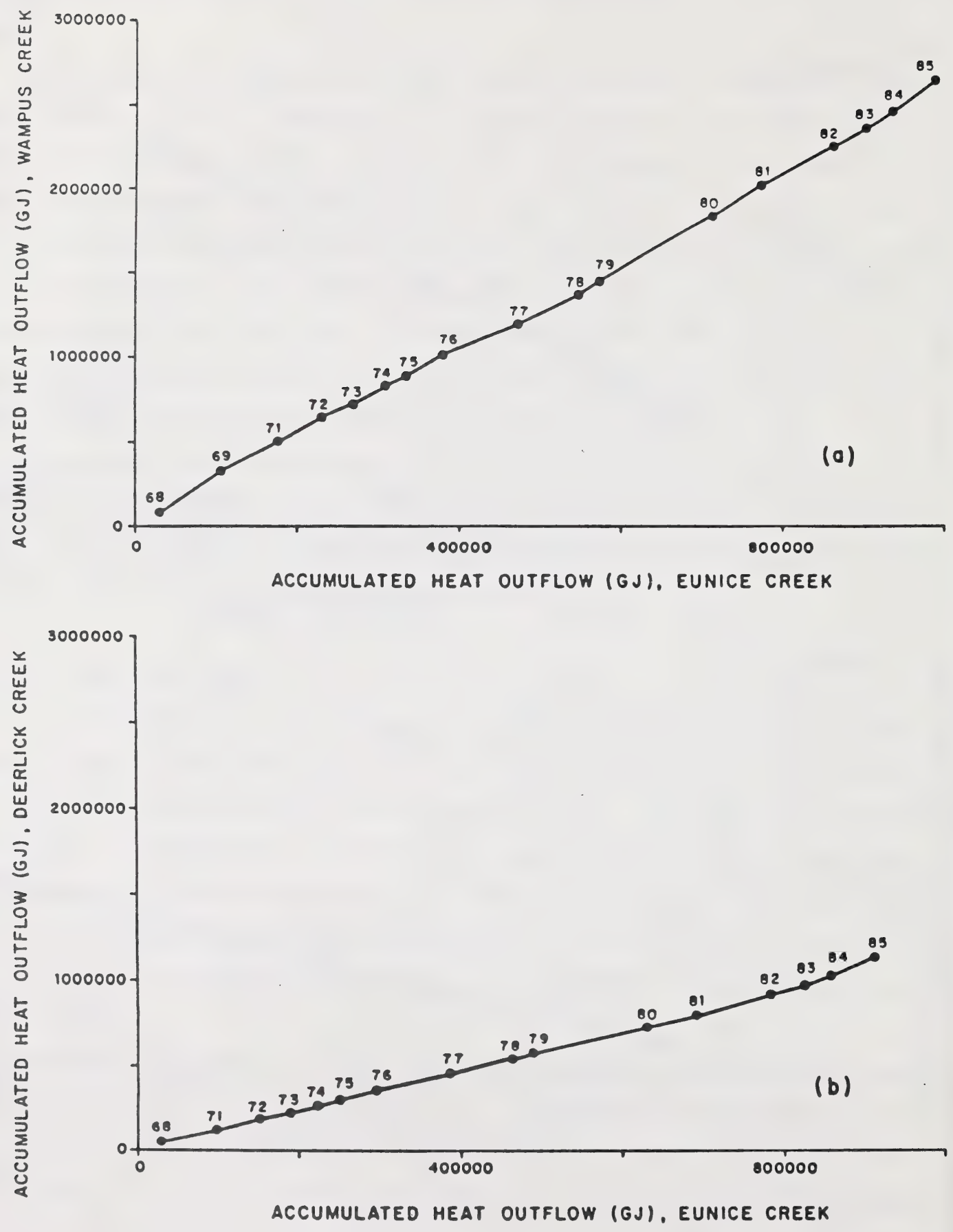

Figure 6. Double mass curves of total summer heat outflows from (a) Wampus Creek and (b) Deerlick Creek and Eunice Creeks. 
A similar analysis of heat-outflow data from Deerlick Creek and Eunice Creek illustrates somewhat different results. There is a very consistent relationship between the heat outflows of the two creeks prior to logging in 1981. Following logging, there is a pronounced change in slope, and this slope change increases with the percentage of the basin logged. It is difficult, however, to attribute the change in slope completely to the change in the thermal regime due to logging because the curve is steepest for 1985 , when no additional clear-cutting took place. In fact, the curve should have the same slope as for 1984 because the basin characteristics are the same in both years. Even though it is difficult to quantify the impact of logging on the thermal regime of Deerlick Creek, it appears that, on an annual basis, there has been some increase in the water temperature.

The impacts of logging on the monthly water temperature regime were assessed by correlating the monthly mean and maximum water temperatures of Wampus Creek and Deerlick Creek to those of Eunice Creek. These plots are shown in Figures 7 to 10. In many cases, there were insufficient data in the post-logging period to do a rigorous statistical analysis, and in all cases there is a considerable amount of scatter in the data. However, some interesting observations can be made.

There was no significant increase in the water temperature at the basin outlet of Wampus Creek for any month during the summer (Figure 7). For Deerlick Creek, an increase could only be discerned during the warm months of July and August (Figure 8), with no change evident in the other months. This suggests that there is sufficient inertia in the systems to prevent significant temperature increases on a monthly basis except during the warmest of the summer months. It also appears that the removal of the buffers along the bank of Deerlick Creek was necessary, in addition to the clear-cutting in both Wampus and Deerlick basins, to effect an increase in the mean monthly. water temperatures.

On the other hand, the maximum monthly water temperatures on both Deerlick and Wampus Creeks increased significantly following logging. This was especially evident in July and August for both streams (Figures 9 and 10), and there is some indication that, for Deerlick Creek, the increases are also evident in the cooler months (Figure 10). This emphasizes the effects that clear-cutting and buffer removal have on the heat transfer processes at the air-water interface and on the temperature of water entering the stream. 

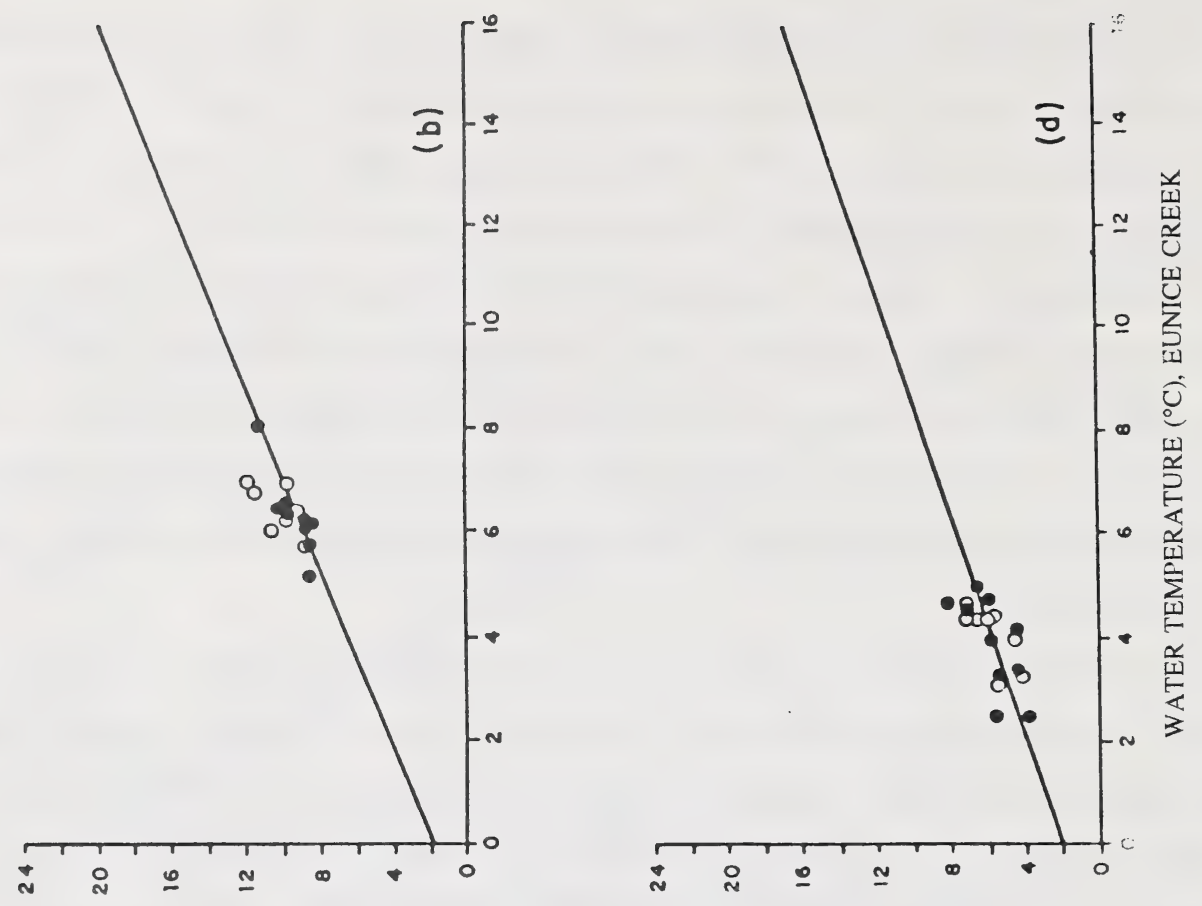

चี

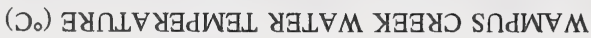
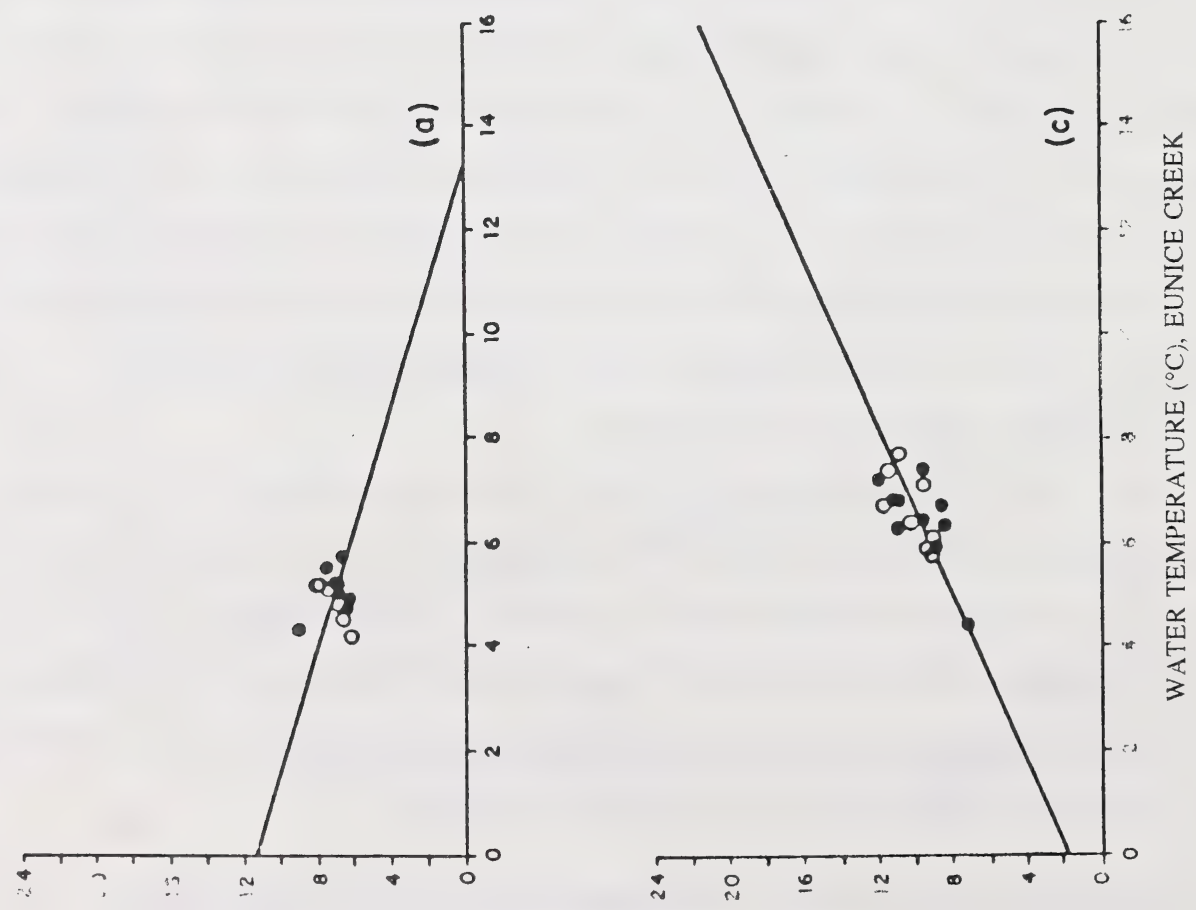

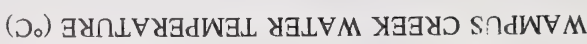



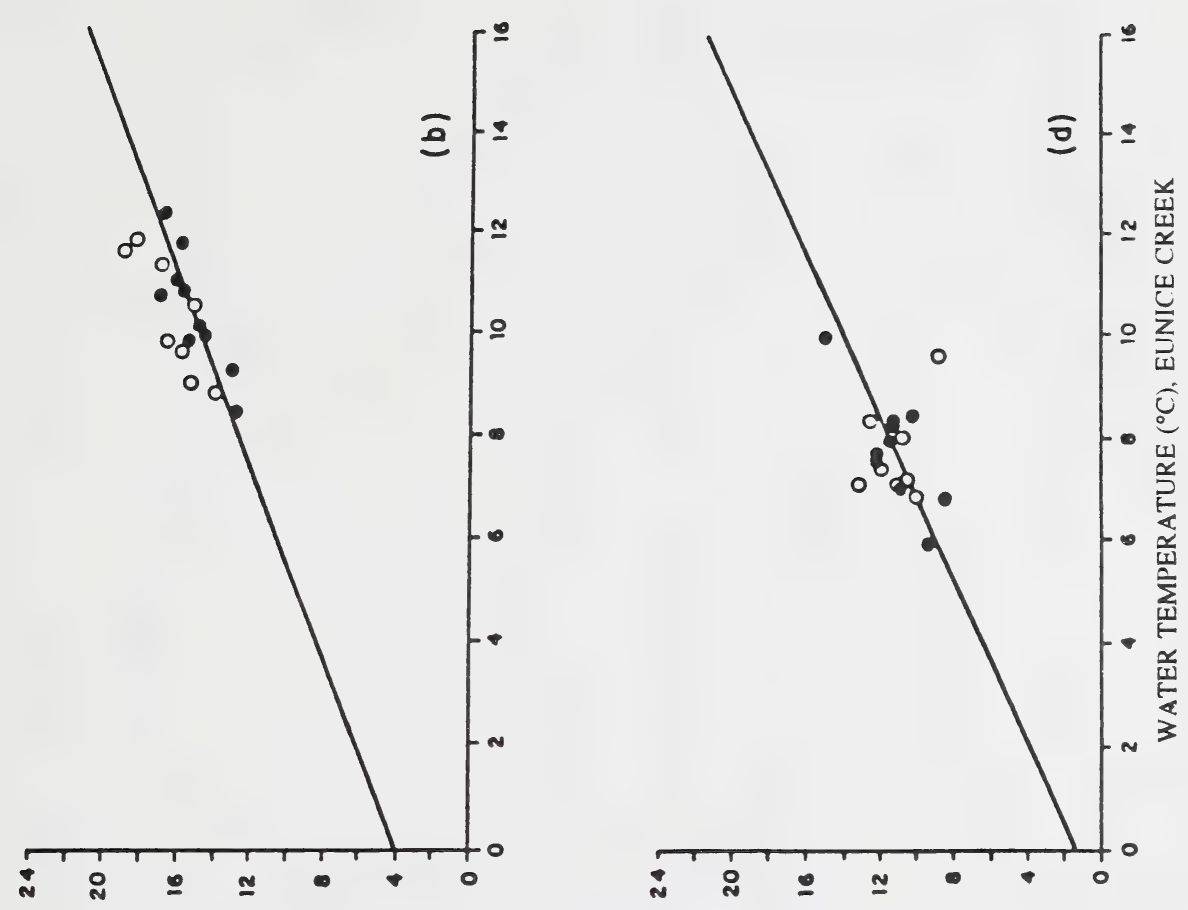

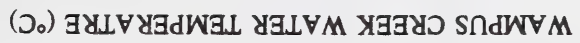
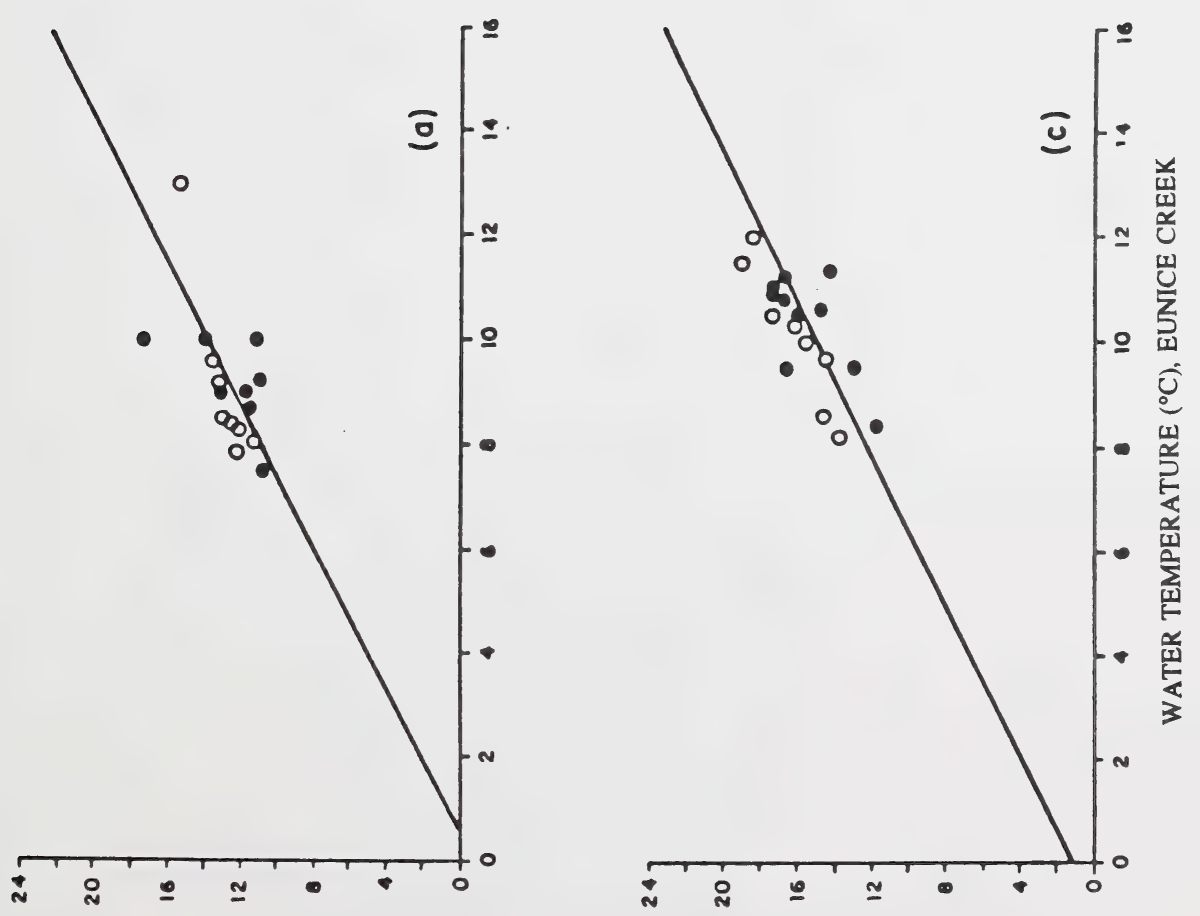

르 

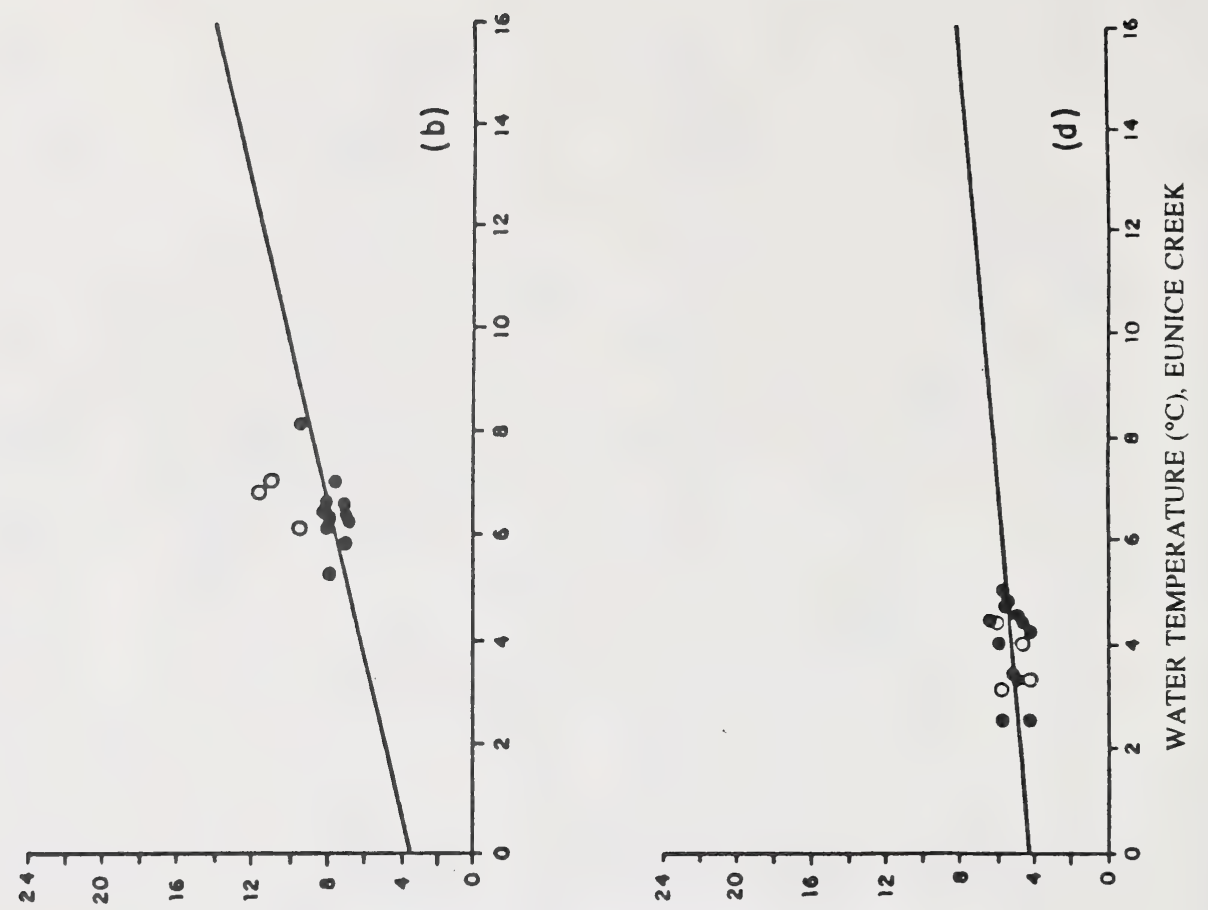

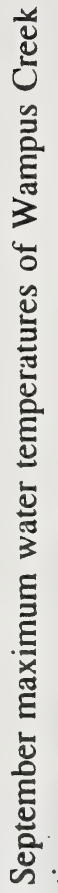

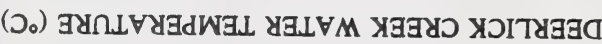
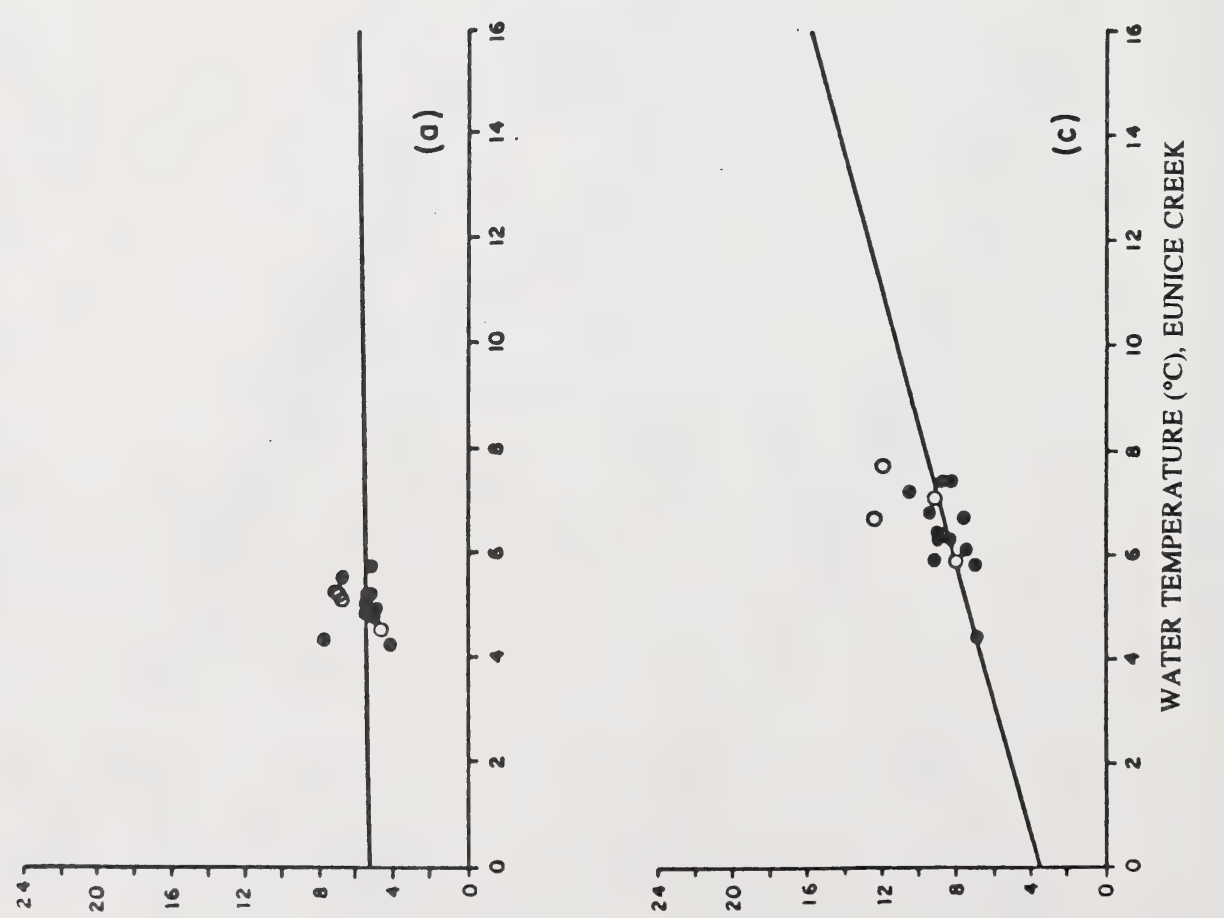

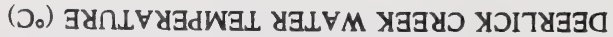



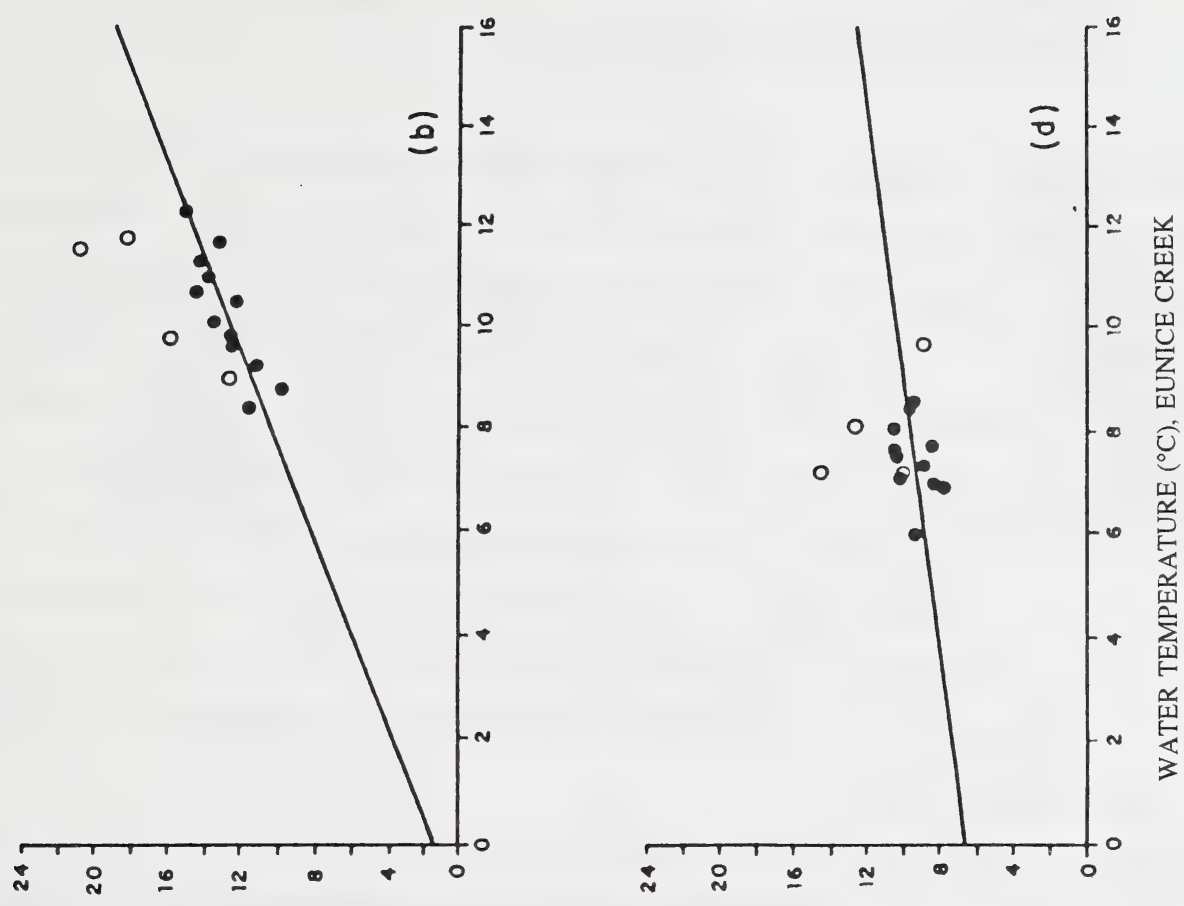

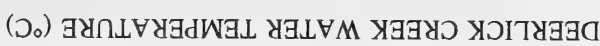
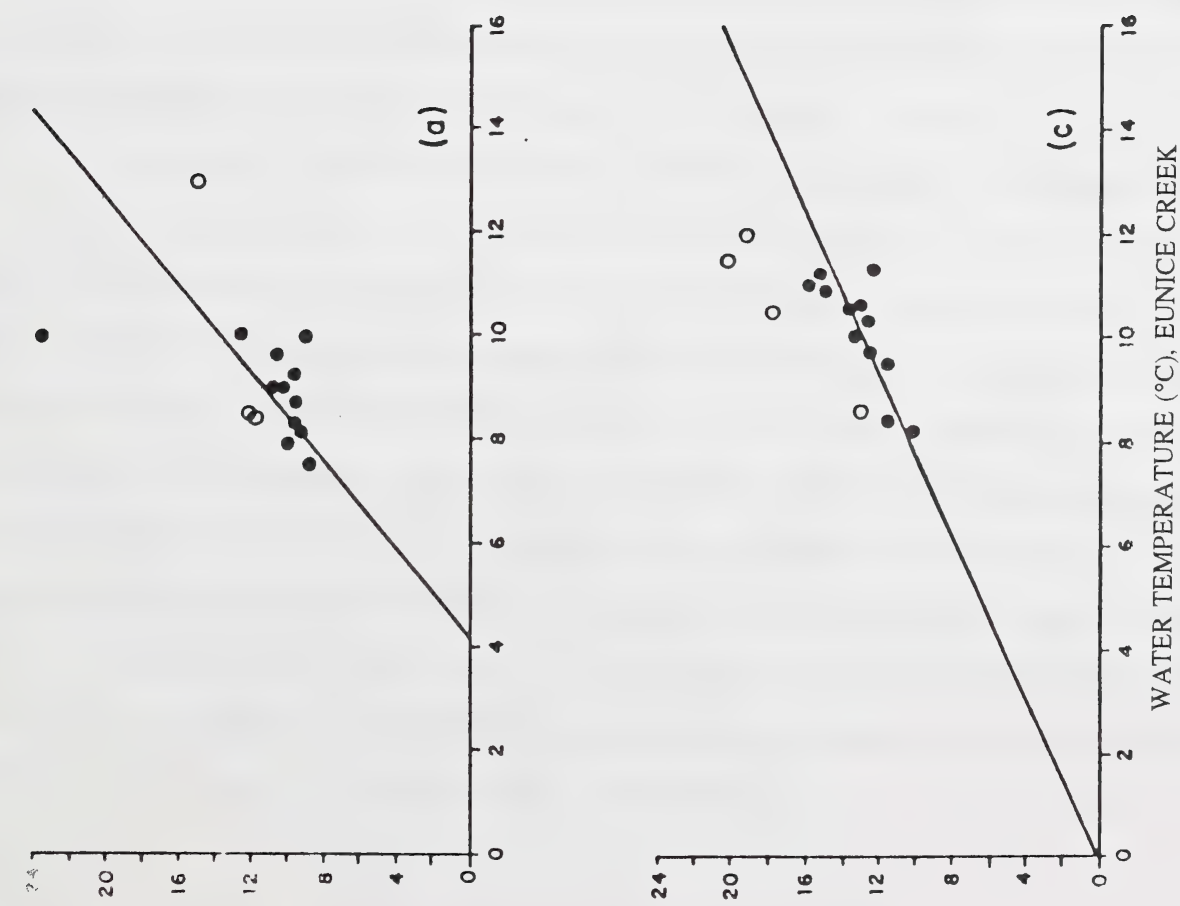

$\frac{y}{\grave{U}}$ 


\section{HEAT TRANSFER AT THE WATER SURFACE}

\section{Method}

The impact of logging and the removal of riparian vegetation on the heat transfer processes at the water surface were investigated in 1986 by a relatively intensive instrumentation of Deerlick Creek. The analysis of stream temperatures requires an evaluation of the heat transfer (flux) across the stream surface (air-water interface) and the stream bed. Heat transfer at the water surface is extremely large in comparison to heat transfer through the stream bed on which very little information currently exists. Therefore, this discussion is concerned only with the heat flux at the stream surface. Four mechanisms are identified as contributing to the net heat flux, $\mathrm{H}$. They are solar radiation, longwave radiation, evaporation, and conduction. Other components such as melting snow, precipitation, and geothermal energy can also be considered. However, these are generally much smaller than the preceding components or occur sporadically in time. They are not considered in this analysis.

The total heat flux H, can be divided into two parts (Figure 11). One component, (1- $\alpha) H_{s}$, where a is the effective albedo and $H_{s}$ is the incident solar radiation, represents the total short wave radiation absorbed by the water surface. It is always positive and is independent of temperature. The second component, $\mathrm{H}_{*}$, the sum of the net long wave radiation, $\mathrm{H}-\mathrm{H}-\mathrm{H}$, conduction, $\mathrm{H}_{\mathrm{c}}$, and evaporation, $\mathrm{H}_{\mathrm{e}}$, is a function of the difference in temperature of the air and water, and can be positive or negative. For ease in computation, the temperature-dependent component is generally linearized in form

$$
\mathrm{H}_{*}=\mathrm{h}\left(\mathrm{T}-\mathrm{T}_{\mathrm{a}}\right)
$$

where $\mathrm{h}$ is a heat transfer coefficient which accounts for wind, barometric pressure, relative humidity, cloud conditions, and other effect; $\mathrm{T}$ is water temperature; and $\mathrm{T}_{\mathrm{a}}$ is air temperature. If $\mathrm{h}>\mathrm{O}$ there is a net heat loss from the water body and if $\mathrm{h}<\mathrm{O}$ there is a net heat gain. This linear approximation is acceptable because many of the above-noted effects cannot be accounted for even for the most rigorous analysis. The value for $\mathrm{h}$, as for the albedo, a, must be determined by calibration for a particular area. Generally it cannot be considered as a universal constant, except under the most ideal circumstances.

Thus, the net heat flux at the air-water interface can be given by

$$
H=(1-\alpha) H_{s}+h\left(T-T_{a}\right)
$$




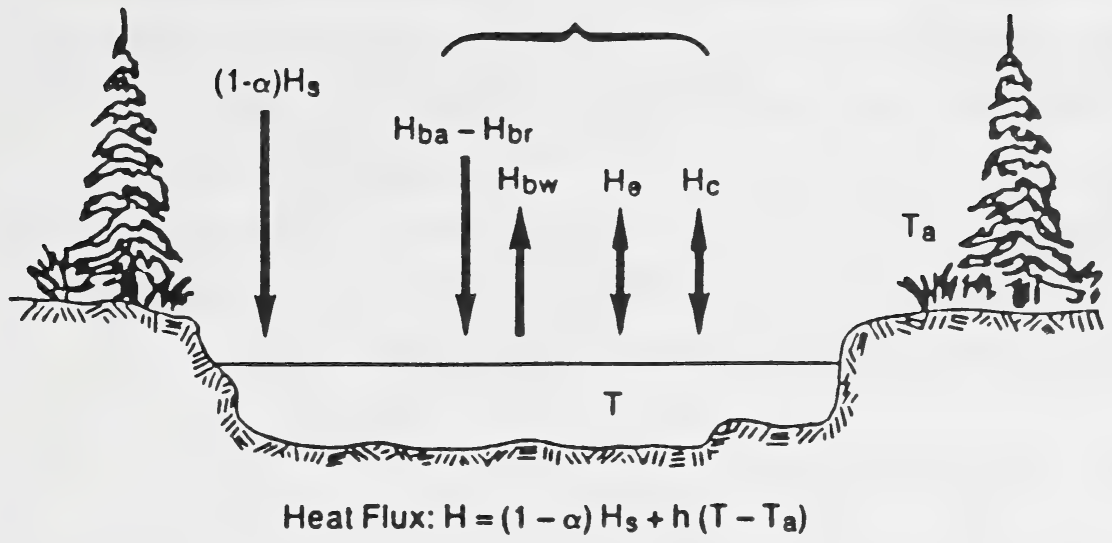

Figure 11. Heat transfer processes responsible for changes in the stream temperature.

and the impact of logging on the heat transfer processes can be identified by measuring the changes in the effective albedo of the water and the heat transfer coefficient under natural and clear cut conditions.

Air temperatures, water temperatures, incident total short wave radiation, reflected short wave radiation and discharge were measured at four locations along Deerlick Creek (Figure 4). The network extended from Deerlick E, downstream through a logged area for a distance of $2.3 \mathrm{~km}$ to Deerlick 7, located on the downstream boundary of cutblocks 34 and 35 (Jarvis, 1984). The station at Deerlick E was totally open with no vegetation affecting the solar radiation incident upon the radiometer. The reach between Deerlick E and Deerlick 7 was also void of vegetation with the buffer being completely removed. The station at Deerlick 7 was located in dense vegetation in an unlogged portion typical of the reach of the creek between there and Deerlick 5 located at the upstream end of cutblock 36. The stations at Deerlick 5 and Deerlick A at the downstream end of cutblock 36 are moderately forested with only the odd stand of trees shading the radiometers. These are typical of the buffered stream channel between them. The 
channel distance between Deerlick 7 and Deerlick 5, and Deerlick 5 and Deerlick A is $0.9 \mathrm{~km}$ and $1.2 \mathrm{~km}$, respectively.

All the data were measured at 15-minute intervals, and integrated over the whole day to give average daily values (Andres et al., 1987). The temperatures were measured using Intersil AD590 temperature transducers, and the solar radiation was measured by Kipp and Zonon albedometers. Water levels were also measured at all four locations to determine the variations in discharge along the study reach. Unfortunately, insufficient discharge measurements could be made to produce a rating curve at any of the sites. Estimates of discharge used in the subsequent analysis were based on data from the WSC gauge at Deerlick A.

\section{RESULTS AND DISCUSSION}

Albedo

Estimates of the effective albedos for various vegetation coverings were made using the four net radiometers installed along Deerlick Creek. The installation at Deerlick E was located in an open area and represented the incoming radiation at the top of the vegetation canopy. The computed albedo represented what might be expected in a totally logged environment. The sites at Deerlick E and Deerlick 5 represented partially logged areas with only low shrubs affecting the amount of radiation reaching the stream surface. These sites were designated as partially forested. The site at Deerlick 7 represented a complete forested situation with mature vegetation present immediately adjacent to the stream bank.

For each site, $\mathrm{H}_{\mathrm{s}}$ was evaluated from the incoming solar radiation measured at Deerlick $\mathrm{E}$, and the absorbed solar radiation was determined from the difference between the incoming solar radiation and the reflected solar radiation of the particular site in question. The effective albedo was then determined as the ratio of the difference between the incident solar radiation at Deerlick $\mathrm{E}$ and the absorbed solar radiation at the site being considered to the incident solar radiation at Deerlick E. The results are plotted in Figure 12 and summarized in Table 1.

There is a large amount of scatter in most of the data in Figure 12. This is typical of correlations of short term solar radiation data between two sites, particularly during the summer months when singular clouds are common and can selectively shade individual sites during different parts of the day. However, significant differences in the albedo were found between the non-forested, forested and partially forested sites. At the non-forested, completely open site, 


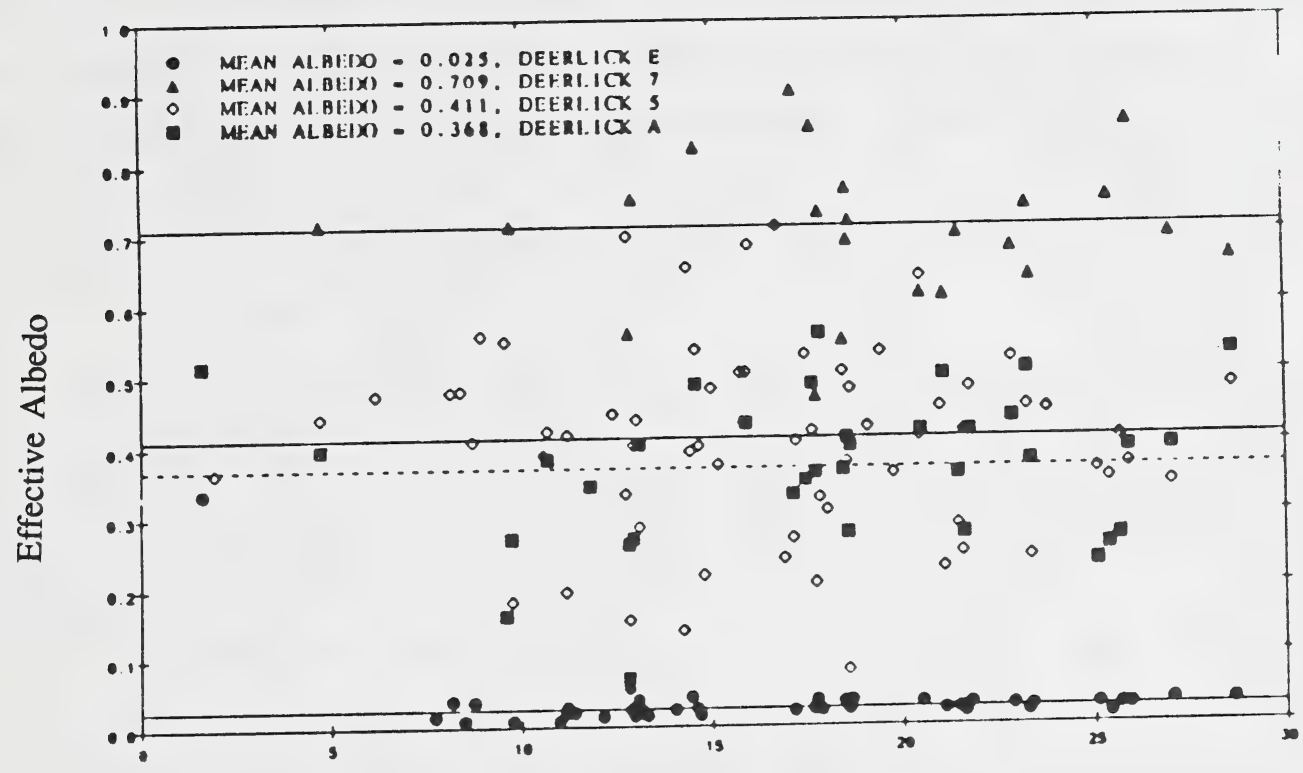

Non-forested Solar Radiation $\mathrm{H}_{\mathrm{si}}(\mathrm{MJ} / \mathrm{Day})$

Figure 12. Effects of riparian vegetation on the effective albedo of the stream surface, Deerlick Creek, 1986.

Table 1. Measured effective albedos along Deerlick Creek.

\begin{tabular}{||l|l|c||}
\hline \multicolumn{1}{|c|}{ Site } & \multicolumn{1}{|c|}{ Vegetation Characteristics } & Effective Albedo \\
\hline \hline Deerlick E & Clearcut & 0.03 \\
Deerlick 7 & Natural vegetation, no logging & 0.71 \\
Deerlick 5 & Natural buffer, partially logged & 0.41 \\
Deerlick A & Some natural vegetation, partially logged & 0.37 \\
\hline
\end{tabular}

an average of approximately 3\% of the incoming solar radiation was reflected and $97 \%$ was absorbed. At a completely forested site, of all the incoming solar radiation, an average of $71 \%$ was either intercepted or reflected and only $29 \%$ was absorbed. At two partially forested sites, the average effective albedo ranged between $37 \%$ and $41 \%$, resulting in $59 \%$ to $63 \%$ of the incoming radiation being absorbed. 


\section{Convective Heat Transfer Coefficient}

The one-dimensional, unsteady, convection-diffusion equation expressing the conservation of thermal energy and having a fluid temperature in a free surface flow may be expressed as:

$$
\frac{\partial \mathrm{T}}{\partial \mathrm{t}}+\frac{\mathrm{Q}}{\mathrm{A}} \frac{\partial \mathrm{T}}{\partial \mathrm{t}}-\frac{1}{\mathrm{~A}} \quad \frac{\partial}{\partial_{\mathrm{x}}} \frac{(\mathrm{AE} \partial \mathrm{T})}{\partial_{\mathrm{x}}}=\frac{\mathrm{B}\left[(1-\alpha) \mathrm{H}_{\mathrm{s}}+\mathrm{h}\left(\mathrm{T}-\mathrm{T}_{2}\right)\right]}{\mathrm{A} \rho \mathrm{C}_{\rho}}
$$

where $\mathrm{T}$ is the cross-sectional average water temperature, $\mathrm{t}$ is time, $\mathrm{x}$ is distance along the channel, Q is the stream discharge, A is the cross-sectional flow area, E is the longitudinal dispersion coefficient, B is the top width of the stream, and all other terms have been previously defined. In the above equation, the four terms represent four different mechanisms of heat transport in the river, namely, the heat storage within the water element, heat convected by the current, the heat dispersed by turbulent transport processes, and the heat transferred by the air-water interfacial transport processes, respectively. Some simplification can be made to make this equation easier to solve for specific situations without a significant loss of accuracy. The convective heat flux is considerably greater than the heat dispersed by turbulence. Therefore, the third term on the left side of equation 4 is very much smaller than the second term. If one is working within a reference frame independent of time, such as a long period of time in which constant averages of air temperature and solar radiation are assumed, then the first term in the equation vanishes and the equation reduces to:

$$
\frac{\mathrm{dT}}{\mathrm{dx}}=\frac{\mathrm{B}}{\mathrm{Q} \rho \mathrm{C}_{\rho}}\left[(1-\alpha) \mathrm{H}_{\mathrm{s}}+\mathrm{h}\left(\mathrm{T}-\mathrm{T}_{\mathrm{a}}\right)\right]
$$

In this case $\mathrm{H}_{\mathrm{s}}$ and $\mathrm{T}_{\mathrm{a}}$ are constant and only the water temperature varies with respect to the $\mathrm{x}$ co-ordinate. This equation is suited to analysing longitudinal temperature profiles to evaluate the albedo and/or the heat transfer coefficient.

The heat transfer coefficient can be evaluated from equation 5 provided the longitudinal temperature gradient, the discharge, the stream width, the solar radiation, the albedo, and the air temperature are known. The explicit solution of the equation for $\mathrm{h}$ is extremely tedious. Instead, a numerical approach was taken and $\mathrm{h}$ was evaluated from:

$$
\left(\frac{\left(T_{i+1}-T_{i}\right) Q p C}{\left(x_{i+1}-x_{i}\right) B}\right)-(1-\alpha) H_{s i}=h\left(T_{i}-T_{a}\right)
$$


where the subscript $i$ indicates the incoming water temperature of a stream channel reach and the subscript $i+1$ indicates the outgoing water temperature of the reach. For any reach, $i$ to $i+1$, the left hand side of the equation gives the net temperature related heat flux (with the radiation heat flux subtracted from the total heat flux) and the right hand side evaluates the effect of the temperature difference between the water and the air. Equation 6 was evaluated for the four different channel reaches discussed previously.

The results of the analysis are presented in Figure 13 in which the temperature-related heat flux is plotted against the temperature difference between the water and air. The slope of the data gives the values of the convective heat coefficient. From examination of the figure it appears that considerable scatter seems to exist when each of the reaches is individually considered.

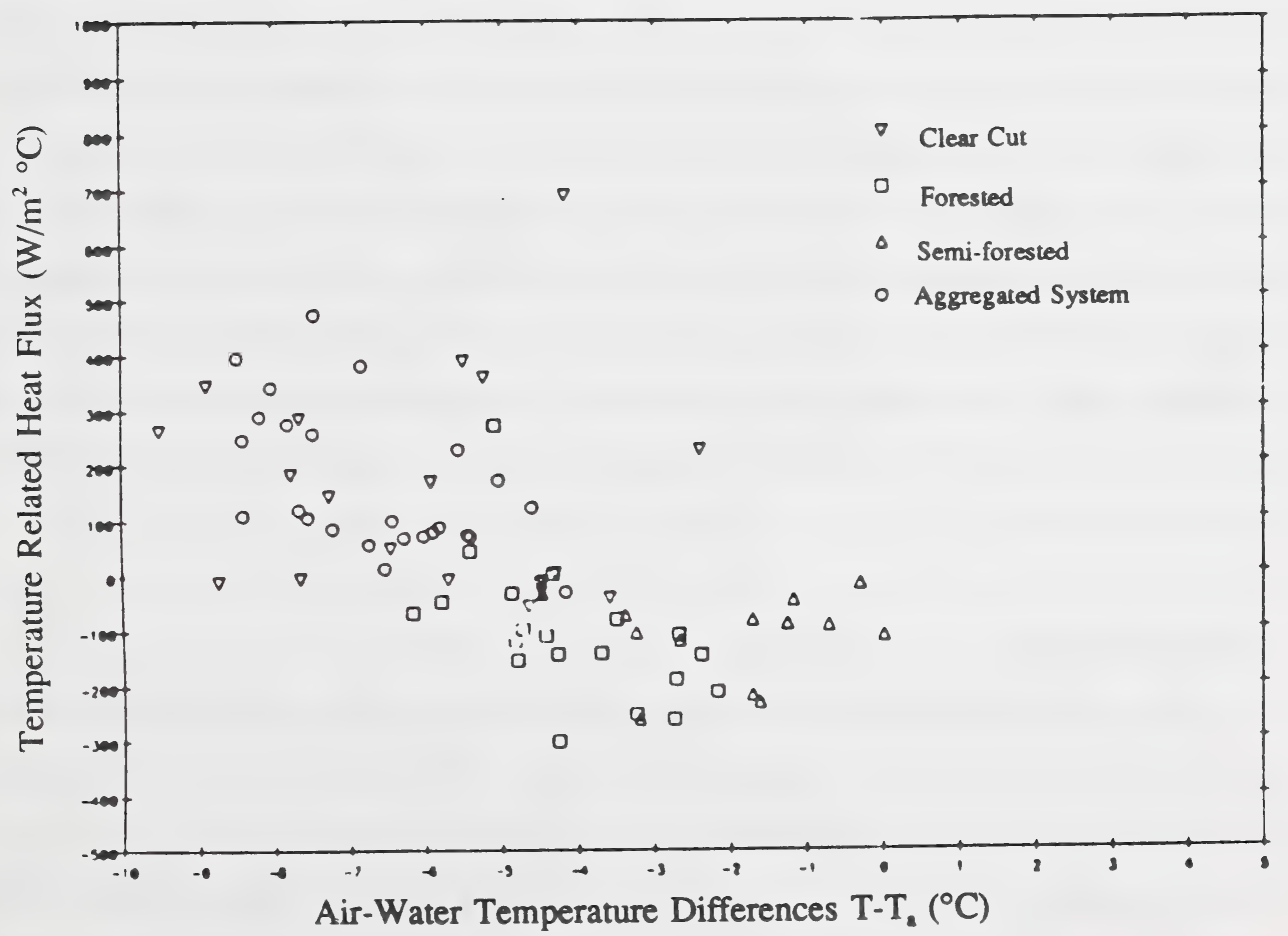

Figure 13. Evaluation of the temperature-related heat transfer coefficient, Deerlick Creek, 1986. 
For the clear-cut condition in the reach between Deerlick E and Deerlick 7, it is apparent that, over the day, a considerable amount of heat is added from the air beyond that from solar radiation. However, the data are so scattered it appears to be independent of the air-water temperature difference and no estimate of the convective heat transfer coefficient is possible.

In the forested reach between Deerlick 7 and Deerlick 5, there appears to be a net loss in energy even with air temperatures being greater than the water temperatures. The heat flux seems to correlate well with the air-water temperature difference and suggests that, when the air temperature is less than $5^{\circ} \mathrm{C}$ warmer than the water temperature, no net heat is gained by convective processes. Instead, the slope of the line suggests that heat continues to be lost at a rate of about $100 \mathrm{~W} / \mathrm{m}^{2}{ }^{\circ} \mathrm{C}$, which is the slope of the data points. In the semi-forested reach between Deerlick 5 and Deerlick A, there is also a net loss of heat even though the air temperature was greater than the water temperature. The rate of heat loss averaged about 100 $\mathrm{W} / \mathrm{m}^{2}$ and is independent of the difference in temperature between the water and the air.

Given the large amount of scatter in the data for the three specific reaches, the analysis was extended to consider an average condition of all three individual reaches by looking at an aggregate reach from Deerlick E to Deerlick A. In this overall reach, the temperature-related heat flux is positive and a function of the temperature difference of the water and air. Unfortunately, the scatter is too large to assign confidently a convective heat transfer coefficient. However, it does seem that the air temperature must be at least $5^{\circ} \mathrm{C}$ greater than the water temperature to affect heat transfer, and when this situation is satisfied, the heat transfer coefficient is about $100 \mathrm{~W} / \mathrm{m}^{2}-{ }^{\circ} \mathrm{C}$. The scatter in the data produces errors of $\pm 100 \%$ in the computed heat flux.

\section{CONCLUSIONS}

On the basis of double mass analysis between Wampus Creek and Eunice Creek, logging has no perceptible effect on the annual heat outflow of Wampus Creek. A similar analysis on Deerlick Creek suggests an apparent change on Deerlick Creek occurred in 1981, just after the onset of logging. However, this cannot be conclusively linked to logging because in 1985 the thermal deviation from pre-logged conditions is the greatest ever, though no additional logging took place in that year. 
With respect to the mean monthly water temperatures, no apparent increase occurred on Wampus Creek. On Deerlick Creek, an increase was evident only for the months of July and August. However, there was a substantial increase, for both Wampus and Deerlick Creek, of the maximum monthly temperature for all summer months. Deerlick Creek showed the largest change, probably because of the removal of the riparian vegetation which buffers the stream channels. This suggests that upland logging may have a slight impact on water temperature, but removal of the buffer zones certainly appears to magnify the effects.

From a "process" point of view, the energy flux of the water surface is the sum of the net solar radiation and of the temperature-related heat transfer. Measurements on Deerlick Creek have shown that the removal of the riparian vegetation can decrease the effective albedo almost to zero from a value of about 0.70 . Therefore, the amount of absorbed solar radiation can increase by about $300 \%$ when the vegetation is completely removed. For partially treed conditions, the effective albedo was found to be about 0.40 .

Unfortunately, estimates of the heat transfer coefficient, which relates the heat flux to the difference in temperature between the water and the air, were not conclusive. Indications are that its value may be as great as $-100 \mathrm{~W} / \mathrm{m}^{2}-{ }^{\circ} \mathrm{C}$. This is much greater than often-quoted values of -20 $\mathrm{W} / \mathrm{m}^{2}-{ }^{\circ} \mathrm{C}$ for much larger rivers. Undoubtedly, the complexity of the air flows and temperature patterns under the forest canopy has some effect on its poor definition. Also, the air temperatures measured at the four stations along Deerlick Creek may not be indicative of the relevant air temperature affecting the heat transfer process, and no data on both the quantity and temperature of groundwater inflows along the study were available. In fact, the net heat flux across the air-water interface could be significantly greater than reported if cool groundwater was entering the stream. Better results may also be produced if the data were split into daytime and nighttime periods and treated separately. Finally, it may be possible that the assumptions of linearity for the temperature-dependent heat flux is incorrect for the kinds of conditions prevailing in Tri-Creek.

\section{REFERENCES}

Andres, D.D., P.G. Van Der Vinne, and G. Sterenberg. 1987. Hydrologic, hydrogeologic, thermal, sediment, and channel regimes of the Tri-Creek experimental basin. Resource Technologies Department, Alberta Research Council, Edmonton, Alberta. 
Atlas of Canada. 1957. Department of Mines and Technical Surveys, Geographic Branch, Ottawa, Ontario.

Brown, G.W., 1983. Forestry and Water Quality. OSU Book Stores, Inc. Corvallis, Oregon.

Hudson, H.R., G.M. Greenley, and R.W. Howitt. 1985. Soils and soil erosion in the Tri-Creek experimental watershed, Alberta. Civil Engineering Department, Alberta Research Council, Edmonton, Alberta.

Jarvis, J. 1984. Final harvesting and silviculture report for the Tri-Creek experimental watershed, Forest Research Branch, Alberta Forest Service, Alberta Energy and Natural Resources, Edson, Alberta.

Nip, A. 1983. The applicability of WRENSS to the Tri-Creek region. Report No. 8. Forest Land Use Branch, Alberta Energy and Natural Resources, Edmonton, Alberta.

Winkler, R.D. 1980. Watershed statistics for flow prediction. M.Sc. Thesis, Univ. Alberta, Edmonton, Alberta. 


\title{
Comparison of Spawning Criteria and Fry Escapement of Rainbow Trout \\ (Oncorhynchus mykiss) Before and After Timber Harvest in the Tri-Creek Watershed of West-Central Alberta
}

\author{
George Sterling, Project Fisheries Biologist \\ Alberta Forestry Lands and Wildlife, Fish and Wildlife Division
}

\begin{abstract}
Spawning and fry escapement were compared in 10 study sections before and after timber harvest to determine the impact of logging on fry survival in the Tri-Creek Watershed of west-central Alberta. Spawning usually occurred during the first 10 days of June with initiation of spawning related to the rate of water warming prior to spawning. Water temperature did not increase significantly following logging and was weakly correlated with air temperature (Alberta Research Council, in press). Annual differences in spawning dates appear to be due primarily to annual climatic variations.
\end{abstract}

Spawning sites were generally located in pool-riffle transition areas (just upstream of the riffle crest). The sites had mean water velocities and depths of $31.1 \pm 0.8 \mathrm{~cm} / \mathrm{sec}$, and $14.3 \pm 0.5 \mathrm{~cm}$, respectively; substrates had a geometric mean $(\mathrm{dg})$ particle diameter of $9.95 \pm 0.51 \mathrm{~mm}$ and contained less than $12.1 \%$ fines $(<0.841 \mathrm{~mm})$. The fredle index (f) of spawning substrates used before logging was not significantly different $(\mathrm{p}>0.05)$ than substrates used following logging. Interstitial dissolved oxygen at spawning sites was significantly lower $(\mathrm{p}<0.001)$ following timber harvest but was unrelated to substrate composition $(\mathrm{p}>0.05)$. Hydrogen ion $(\mathrm{pH})$ concentration of interstitial water was not significantly different $(\mathrm{p}>0.05)$ following logging.

The length of the incubation period was significantly related $(\mathrm{p}<0.05)$ to mean water temperature during incubation. Mean egg deposition/egg pit was $88 \pm 9$ eggs and fry escapement averaged $29 \pm 5$ fry/egg pit, or $32.9 \%$, for the study period. Fry escapement before logging was not significantly different $(\mathrm{p}>0.05)$ from escapement following logging, and was not significantly related $(\mathrm{p}>0.05)$ to fredle indices of substrate quality or to oxygen content of interstitial water.

Yearling abundance in Lower Wampus Creek showed a significant inverse correlation $(p<0.05)$ when water yield exceeded critical flow $\left(0.54 \mathrm{~m}^{3} / \mathrm{s}\right)$ during the incubation period for that cohort. Critical flow is defined as that flow at which spawning substrates begin to move in 
Lower Wampus Creek. The streamflow regime during incubation may be the single most important factor limiting rainbow trout fry survival in streams of the Tri-Creek Watershed.

\section{INTRODUCTION}

Forest use conflicts exist because many watersheds that support the timber industry also contain streams supporting salmonid fishes. The potential for fishery management problems is often greatest when clearcutting is used for either economical or silvicultural reasons in harvesting.

In the Eastern Slopes Region of west central Alberta, harvesting of softwoods (principally pine), to support the kraft pulp industry, occurs by clear-cutting timber in the many small watersheds of clean but relatively infertile streams which provide the habitat for endemic strains of rainbow trout (Oncorhynchus mykiss). Since these watersheds also sustain an ever-increasing recreational demand, the ecological effects of logging become an important consideration in the multiple use concept of resource management (Alberta Energy and Natural Resources, 1984).

Eastern Slope rainbow trout, like other salmonids, exhibit some flexibility in habitat utilization, feeding and growth. However they are environmentally sensitive, requiring specific conditions for successful spawning, developing and hatching of eggs, growth and survival of young. The early life history, which encompasses egg development, sac fry and swim-up fry stages, is totally dependent on the physical (temperature, gravel porosity, etc.) and chemical (dissolved oxygen, $\mathrm{pH}$, etc.) conditions of the subgravel environment. This critical life-history period is a time when limiting factors can be expected to operate most strongly (Allen, 1969).

Sedimentation is a factor which often contributes to the mortality of salmonid embryos by altering the critical physical and chemical parameters of the incubating environment. Timber harvesting, and clear-cutting in particular (and associated road construction), increase sedimentation rates, turbidity, nutrients, streamflow, water temperatures and allochthonous detritus, and decreases gravel porosity, percolation rates and dissolved oxygen in streams (Gibbons and Salo, 1973; Iwamoto et al., 1978). These changes cause subsequent increases in egg and alevin mortality and decreases in salmonid stocks (Wydoski, 1978). Research results from the Pacific Northwest (including Canada and Alaska) and the eastern United States have generally shown a negative impact associated with the technique of timber removal (road construction, yarding, landings, etc.). Timber harvest may be beneficial, however, by increasing 
minimum flows, water temperatures and nutrient levels in infertile streams (Chapman, 1962). Murphy et al. (1981) showed that small Cascade Range streams traversing open clear-cuts had greater rates of microbial respiration and greater densities or biomasses of aufwuchs, benthos, drift, salamanders and trout than did forested sites regardless of sediment composition. They concluded that changes in trophic status and increased primary production resulting from canopy removal masked the impact of sedimentation.

The Tri-Creek Watershed study was initiated in 1965, its primary role designated as an evaluation of the impact of pulpwood harvest (clear-cutting) on the biological, physical and chemical characteristics of Eastern Slope trout streams in Alberta. Although research results were available from other experimental watersheds, regional information was essential. Other studies in the province were hydrologically orientated, and many outside the province dealt with inland and coastal fisheries of the Pacific Northwest, with major differences in climate, geology, soils, forest types, terrain, stream orientation, logging techniques and the variability of the aquatic ecosystems themselves.

Terms of Reference for the Tri-Creek Watershed study (Appendix I) state the primary objective as: "To establish the magnitude and variation of salmonid population parameters before and after pulpwood harvesting". In the context of a multiple land use strategy, the principle goal of the study was to adjust or compliment existing ground rules governing timber harvest so that Eastern Slope watershed values were protected. In the experimental design, the Eunice creek drainage was designated a control watershed in which no harvesting was to occur. Timber harvest in the Wampus and Deerlick drainages was governed by existing ground rules with the major exception of buffer strip removal adjacent to the stream channel in the Deerlick drainage.

In 1974, the main extraction road between the lower portion of the Wampus and Deerlick basins was constructed. Timber harvesting commenced as a winter operation in November, 1977. The original goal of completing the harvest in five years was extended because of weather and economic conditions during the treatment phase, and timber harvesting was not concluded until February 1984. The pre-harvesting phase for the four major studies areas was variable, concluding in 1978 for Lower Wampus, 1980 for Upper Wampus, 1981 for Lower Deerlick and 1982 for Upper Deerlick Creek. Post-treatment fisheries studies were completed in October, 1985. Timber harvesting and silvicultural treatments within the Tri-Creek Watershed were typical of most treatments in other east slopes watersheds within the St. Regis (NKA Champion Forest 
Products) Forestry Management Area except: (1) the removal of streamside buffer strips on Deerlick Creek, (2) the percentage of land area harvested was greater ( $>40 \%)$, and (3) road reclamation was more intensive (Jarvis, 1984).

\section{OBJECTIVE}

This paper evaluates the logging impacts on spawning and fry escapement of rainbow trout in the Tri-Creek Watershed as specified (in part) by the Fisheries Terms of Reference. $\underline{\text { Study Area }}$

The Tri-Creek Watershed lies approximately $40 \mathrm{~km}$ southeast of Hinton, Alberta (Figure 1) and covers an area of approximately $60 \mathrm{~km}^{2}$. The area encompasses three northward flowing tributaries of the McLeod River: Wampus, Deerlick and Eunice creeks.

The climate, geology, soils and vegetation of the Tri-Creek Watershed were summarized by Jablonski (1978). Watershed elevations range from $1707 \mathrm{~m}$ in the southern portions of the study area to $1262 \mathrm{~m}$ in the north. The three main water courses range in length from $9.0 \mathrm{~km}$ (Eunice Creek) to $15.8 \mathrm{~km}$ (Wampus Creek), and have an average drainage density of $2.6 \mathrm{~km} / \mathrm{km}^{2}$. Channel gradients range from $18.9 \mathrm{~m} / \mathrm{km}$ (Wampus Creek) to $34.9 \mathrm{~m} / \mathrm{km}$ (Eunice Creek). Mean channel widths and depths under average mid-summer flows range from $2.9 \mathrm{~m}$ (Eunice Creek) to $3.7 \mathrm{~m}$ (Wampus Creek) and $0.18 \mathrm{~m}$ (Wampus Creek) to $0.23 \mathrm{~m}$ (Eunice Creek), respectively. Streamflows during spawning (May 20 to June 10) range from 0.38 to $0.85 \mathrm{~m}^{3} / \mathrm{s}$, and maximum mid-summer water temperatures rarely exceed $18^{\circ} \mathrm{C}$. The streams are relatively unproductive as judged by mean Total Dissolved Solids (TDS) which varies from 90 to $142 \mathrm{mg} / \mathrm{L}$, and bicarbonate alkalinity which varies from 65 to $141 \mathrm{mg} / \mathrm{L}$ for the ice free period of May through October.

Rainbow trout predominate the fish populations with average yearly densities (1971 to 1985) ranging from 6 trout $/ 100 \mathrm{~m}^{2}$ (Upper Deerlick Creek) to 38 trout/100 $\mathrm{m}^{2}$ (Upper Wampus Creek) of surface area. 


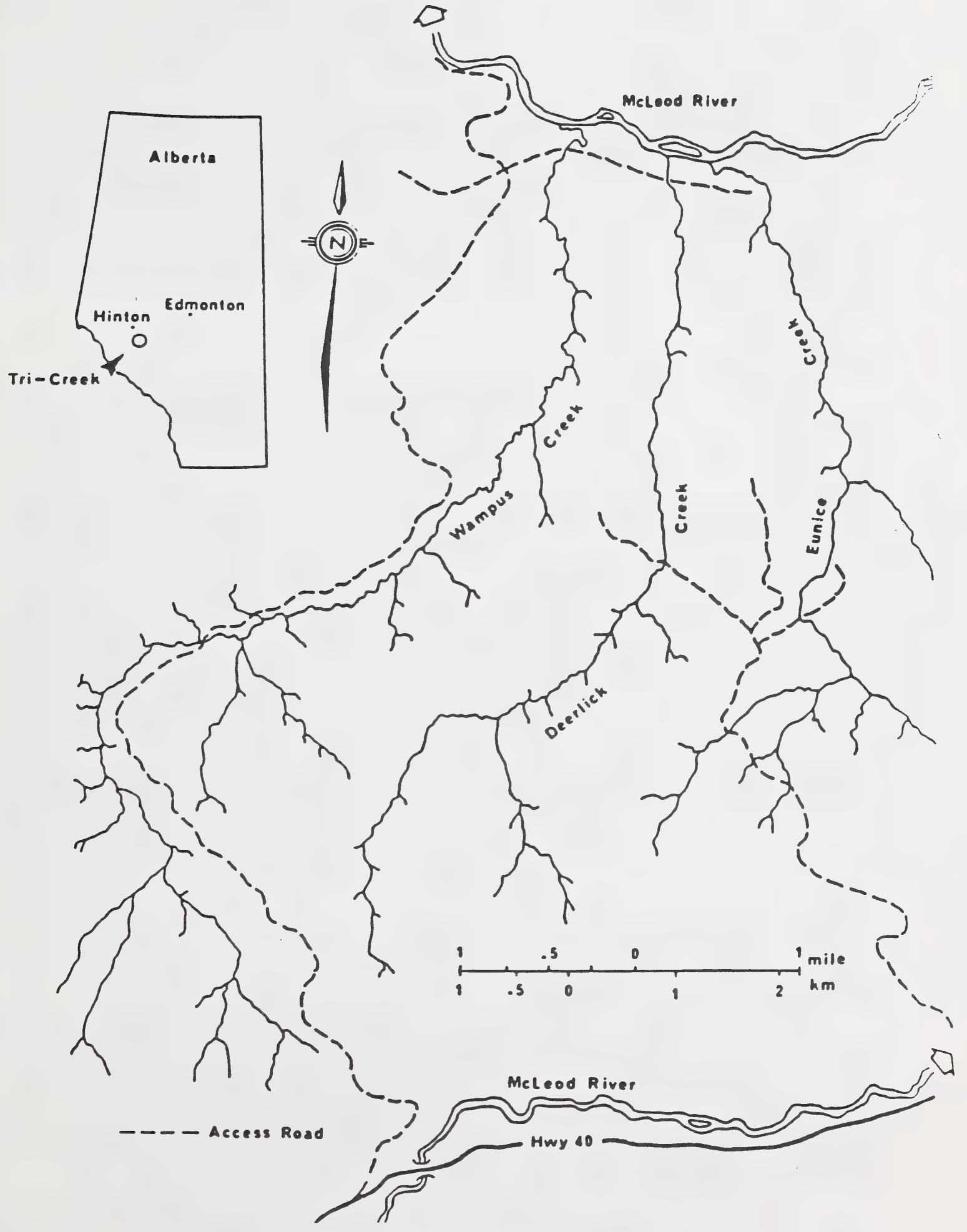

Figure 1. Location of the Tri-Creek watershed. 


\section{METHODS}

\section{Location of Study Sections}

Field studies for spawning and escapement of rainbow trout were conducted in 10 sections (Figure 2) of Wampus and Deerlick Creek (seven and three sections respectively). Two sections in each stream coincided with the 1000 -m study sections established for estimating population densities. Eunice Creek, the control stream, was omitted from spawning and escapement studies because of low spawner densities. Study sections were variable in length (Table 1), being dependent on annual spawner densities.

$\underline{\text { Location of Redds and Egg Pits }}$

Commencing in mid-May each year, known spawning areas were visited daily to establish the first day of spawning. Periods of intense spawning were recorded as was the last day of observed spawning. When spawning commenced, each study section was walked daily and individual egg pits were located by observing females spawning or by locating completed redds in known spawning areas (Figure 3). Completed redds were easily distinguished by their characteristic structure which was gradually obscured over a period of two to three weeks through the sorting of bed materials by streamflow. Each egg pit was confirmed by gently removing the overlying gravel until the eggs were observed; the eggs were then recovered. Egg pits were benchmarked by driving one flagged $15 \mathrm{~cm}$ spike into the streambed approximately $30 \mathrm{~cm}$ downstream from the egg pit centre, and a second spike at $90^{\circ}$ either to left or right, approximately $30 \mathrm{~cm}$ from the egg pit centre (Figure 4). Up to 15 egg pits were located in each section, of which five were randomly selected for emergence and physical/chemical studies. In addition, a maximum of five pits was randomly selected from each section and excavated to obtain an estimate of mean egg deposition.

Measurement of Physical and Chemical Parameters.

Data Collected by Cooperating Agencies

Streamflow, suspended sediment, water chemistry and water temperature data were collected during the ice-free period at the main gauging stations near the mouth of each stream by other agencies cooperating in the study. Daily maximum and minimum water temperatures were also recorded continuously by Ryan submersible thermographs at upper stations (one in each stream) established in 1971. 


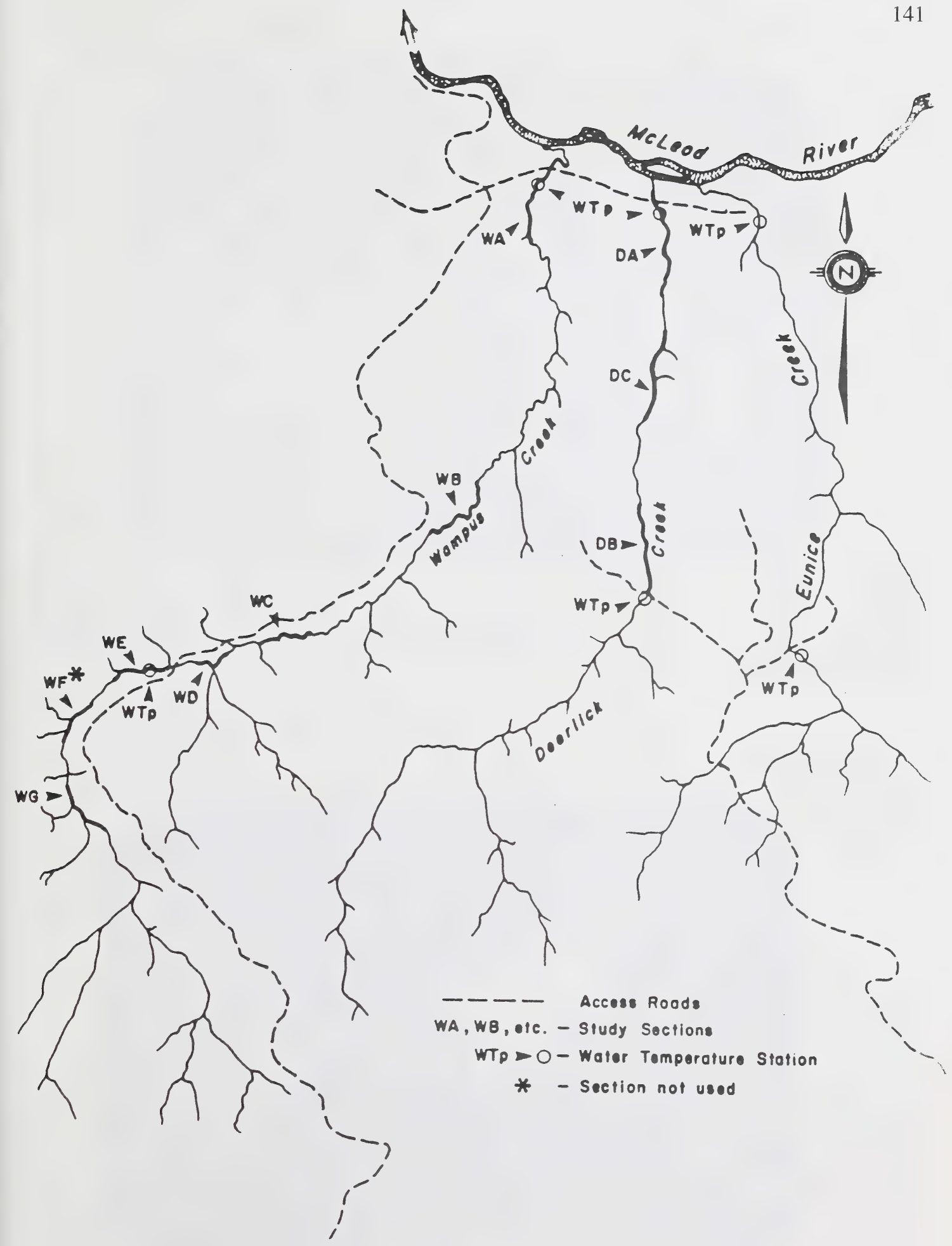

Figure 2. The location of study areas on Wampus and Deerlick Creeks, 1973-1985. 
Table 1. Length of study sections (meters) in the Tri-Creek watershed, 1973 to 1985.

\begin{tabular}{|c|c|c|c|c|c|c|c|c|c|c|}
\hline \multirow{3}{*}{ Year } & \multicolumn{10}{|c|}{ Study Sections } \\
\hline & \multicolumn{7}{|c|}{ Wampus } & \multicolumn{3}{|c|}{ Deerlick } \\
\hline & WA & WB & WC & WD & WE & WF & WG & DA & $\mathrm{DB}$ & DC \\
\hline 1973 & 750 & & & 200 & 500 & & & 1000 & & \\
\hline 1974 & 750 & & & 800 & 800 & & & 1000 & & \\
\hline 1975 & 750 & 300 & 250 & 250 & 400 & & 500 & & & \\
\hline 1976 & & & 250 & 200 & 400 & & 500 & 1500 & 1500 & \\
\hline 1977 & & & & 250 & 400 & & 500 & 1000 & 1500 & \\
\hline 1978 & 750 & 300 & 250 & 250 & 400 & & 750 & 1000 & 1500 & \\
\hline 1979 & 500 & 300 & 300 & 250 & 400 & 300 & 500 & 1000 & 1500 & 400 \\
\hline 1981 & 500 & 300 & 250 & 250 & 400 & 300 & 500 & 1000 & & \\
\hline 1984 & 750 & 300 & 250 & & 350 & 300 & 500 & 1000 & & 400 \\
\hline 1985 & 750 & 300 & 250 & & 350 & & 500 & 1000 & 1000 & 400 \\
\hline
\end{tabular}

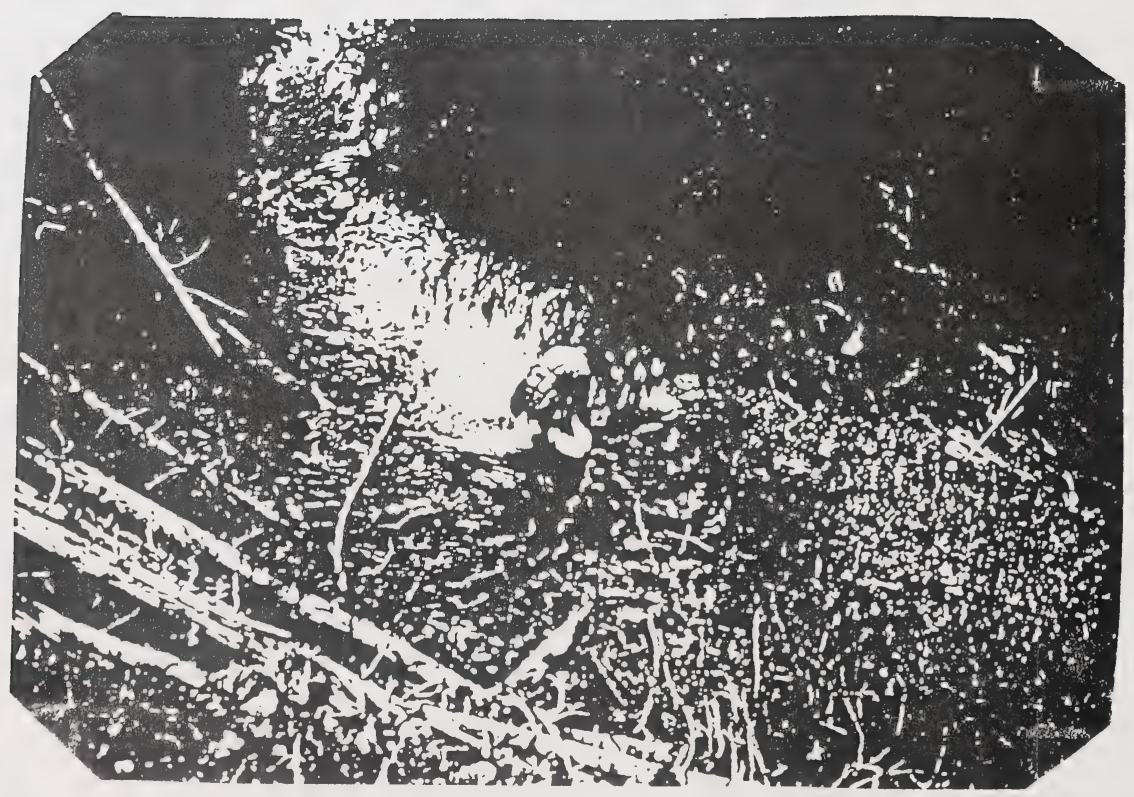

Figure 3. Locating and marking egg pits. 


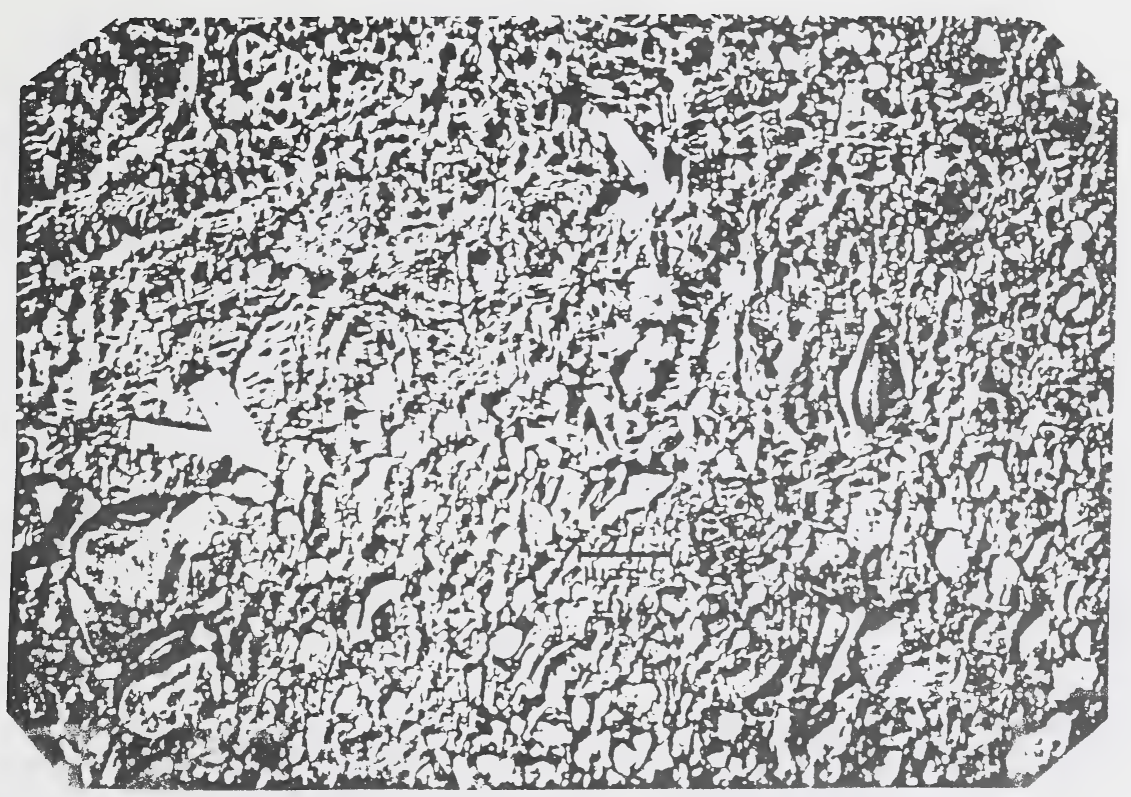

Figure 4. $\quad$ Egg pit "bench-marked" with flagged spikes.

Water Velocities and Depths at Spawning Sites

Water velocities to the nearest $0.10 \mathrm{~cm} / \mathrm{s}$ were measured over each egg pit with a Gurley current meter at three positions (right and left edge and centre) approximately $10 \mathrm{~cm}$ above the streambed surface. Water depths to the nearest centimetre were recorded at the same three positions at each egg pit.

Interstitial Dissolved Oxygen and $\mathrm{pH}$

Standpipes, constructed of an open cylinder of ABS tubing $(3.8 \mathrm{~cm}$ dia. $x 75 \mathrm{~cm}$ long) with $243.0 \mathrm{~mm}$ perforations in the sides, were located downstream and approximately $35 \mathrm{~cm}$ to one side of the sites selected for escapement studies (Figure 5). Each standpipe was driven into the substrate with a pointed steel insert (McNeil, 1962) so that the perforations were at a depth of 8 to $12 \mathrm{~cm}$. The pipe was capped to prevent atmospheric gas exchange. Dissolved oxygen to the nearest $0.1 \mathrm{mg} / \mathrm{L}$, and $\mathrm{pH}$ to the nearest 0.1 unit, of mainstream and interstitial water were measured weekly at all sites using a Hach kit (Model OX-2-P), or YSI Meter (Model 51A) and a Hellige comparator (185D or 170D), or Hach pH meter (Model 1975), respectively. 


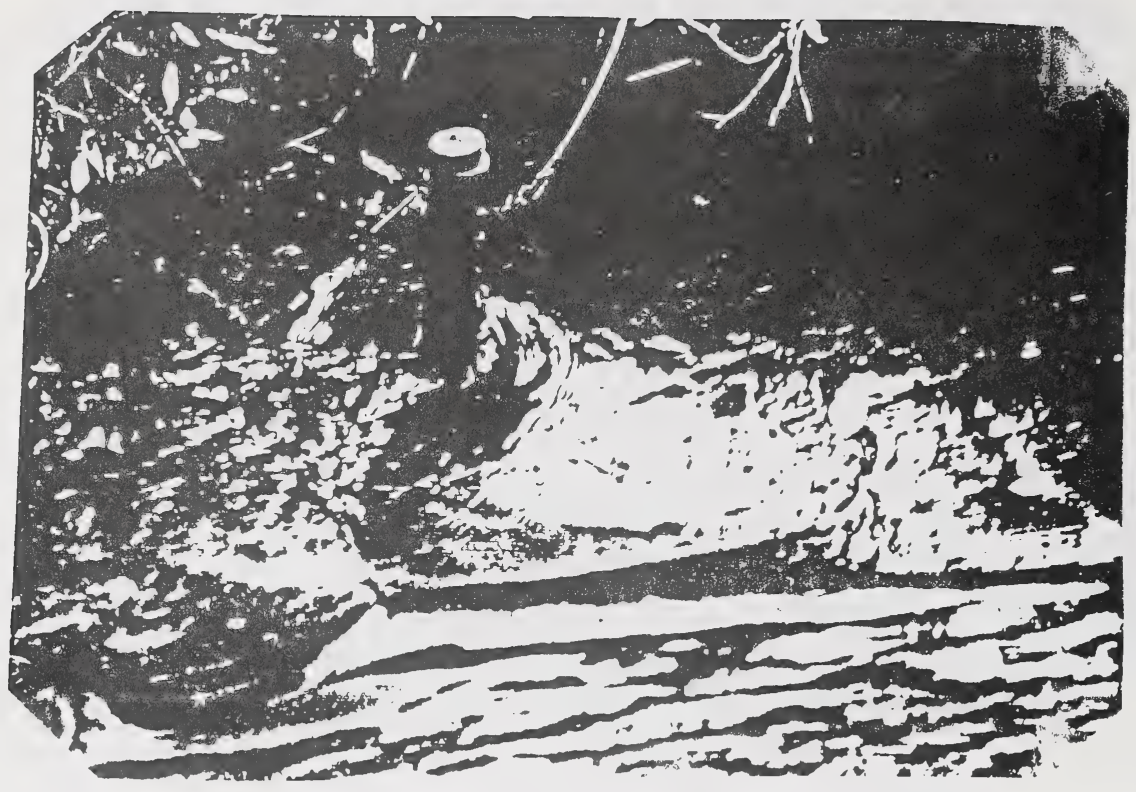

Figure 5. Standpipe located near confirmed egg pit.

$\underline{\text { Spawning Substrate Composition }}$

Spawning substrates were sampled in June at those sites randomly selected for escapement studies. Rainbow trout ova were seldom buried deeper than $12 \mathrm{~cm}$ so core samples of approximately $15 \mathrm{~cm}$ in depth were chosen to represent the substrate trout used to deposit their eggs. One core sample was collected from each site on the side opposite the standpipe location using a sampler (Figure 6), modified slightly from McNeil and Ahnell (1964). The sampler was forced into the substrate to a depth of $15 \mathrm{~cm}$ and the material within excavated; a tight fitting plunger was inserted to the bottom of the sampler to retain the finer silts and clays and the entire sampler was lifted from the substrate. Samples were transported from the field in heavy-gauge polyethylene bags.

Samples collected from 1973 to 1978 were each washed through a series of 11 standard Tyler sieves of mesh sizes $76.2,50.8,25.4,12.7,6.35,3.36,1.68,0.841,0.420,0.210$, and 0.015 $\mathrm{mm}$ (the 1.68 and $0.105 \mathrm{~mm}$ sieve were omitted in 1978). Excess water was drained from each sieve and the displaced volume, to the nearest millilitre, of retained material was determined 


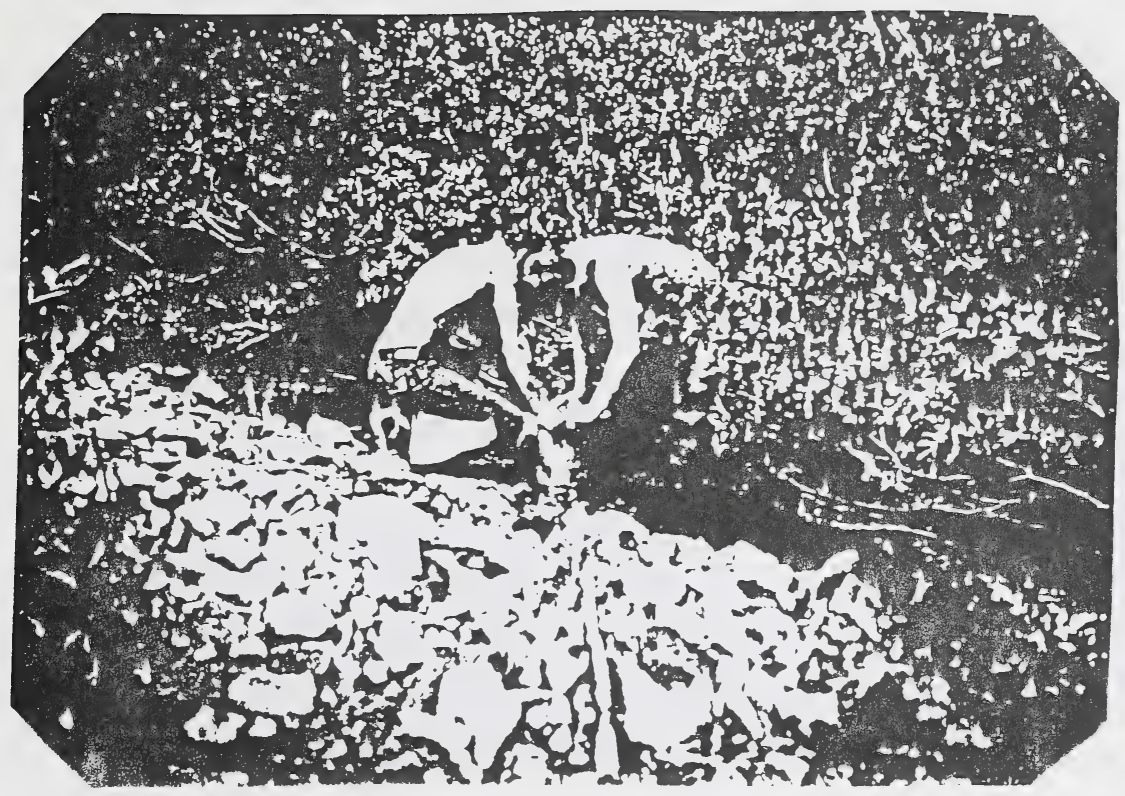

Figure 6. Core sampler used to collect samples of spawning substrate.

(McNell and Ahnell, 1964) and expressed as a percent of the total sample volume.

From 1979 through 1985, sediment samples were sieved, omitting the $0.105 \mathrm{~mm}$ sieve, and each grouping was dried, weighed to the nearest gram and the results were expressed as a percent of total weight. Starting in 1978 , tailings $(<0.210 \mathrm{~mm})$ from the washing of each sample were allowed to settle for 24 hours and the excess water removed, followed by oven drying at $250^{\circ} \mathrm{F}$. A mechanical soil analysis (Bouyoucos Method, Appendix II) was used to determine the fraction of fine sand $(0.210$ to $0.062 \mathrm{~mm})$, silt $(0.062$ to $0.004 \mathrm{~mm})$ and clay $(<0.004 \mathrm{~mm})$.

For those samples lacking certain sieve fractions in the analysis series, the percent passing each sieve in the analysis were plotted on semi-log paper, and the percentages passing the missing sieve fractions were interpolated from the plots (Platts et al., 1979). Evaluation of spawning substrate quality was based on a comparison of the fredle index (f) number for each sample by calculating:

$$
\mathrm{f}=\mathrm{d}_{\mathrm{g}} / \mathrm{S}_{\mathrm{o}}
$$


where: $\quad d_{g} \quad=\quad\left(d_{1}{ }^{W 1} \times d_{2}{ }^{W 2} \times \ldots \ldots . . d_{n}{ }^{W n}\right)$

$\mathrm{d}_{\mathrm{n}}=$ midpoint diameter of particles on the $\mathrm{n}^{\text {th }}$ sieve

$\mathrm{W}_{\mathrm{n}}=$ decimal fraction by weight of particles retained on the $\mathrm{n}^{\text {th }}$ sieve

$\mathrm{S}_{0} \quad=\quad \mathrm{d}_{75} / \mathrm{d}_{25}=$ sorting coefficient

$\mathrm{d}_{75} / \mathrm{d}_{25}=\quad$ particle size diameters at which either 75 or 25 percent of the sample is finer on a weight basis (Platts et al., 1983).

\section{Fry Escapement}

Fry escapement was estimated by using a fry trap (Figure 7) similar to Phillips and Koski (1969), but modified to compensate for the smaller redd size. The trap was constructed of $100 \%$ Dupont woven soft mesh with a circular mesh opening of $1 \mathrm{~mm}$. A drawstring closed the access sleeve and capture bag. The apron measured $1 \mathrm{~m}^{2}$, and the access sleeve and capture bag measured approximately $30 \times 30 \times 40 \mathrm{~cm}$. The apron was buried 20 to $25 \mathrm{~cm}$ below the bed surface by excavating trenches upstream, laterally and downstream around each egg pit, placing the apron and then backfilling with excavated materials. Efficiency was not determined; however, Phillips and Koski (1969) found their traps captured $99.6 \%$ of emerging fry.

Timing of trap installation was achieved by rearing eggs in a streamside incubator (Figure 8) supplied with stream water via gravity feed. Installation occurred when a $50 \%$ hatch was achieved in the incubator, providing a 10 to 14 day buffer before escapement commenced. Traps were monitored twice weekly, and, following peak emergence, were removed if no fry were captured over a one week period. Total fry escapement (S) from spawning gravel in each study section was estimated as the ratio:

$$
\mathrm{S}=\sum_{\substack{\mathrm{i}=1 \\ \mathrm{i}}} / \mathrm{D}_{\varepsilon}{ }^{*} \mathrm{n}
$$

where: $\quad \mathrm{F}_{\mathrm{i}}=$ the number of fry captured in the $\mathrm{i}^{\text {th }}$ site,

$\mathrm{D}_{\epsilon} \quad=\quad$ the estimated mean egg deposition per site and

$\mathrm{n}=$ the number of sites per section. 


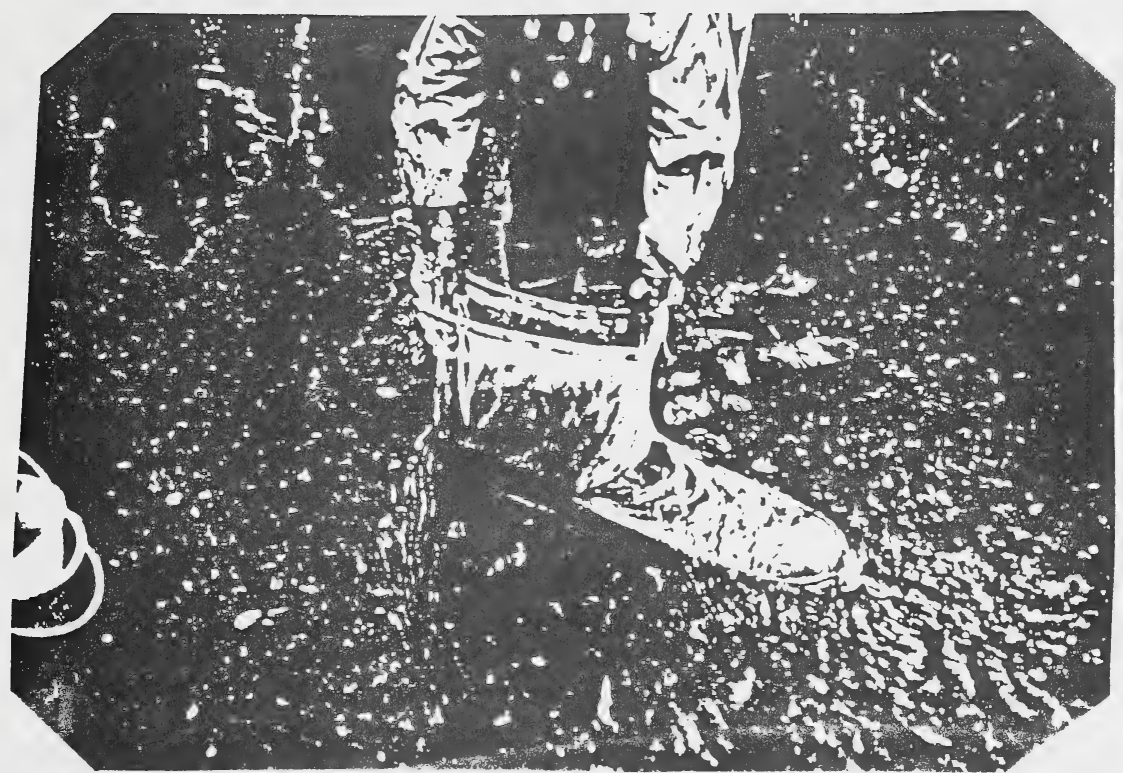

Figure 7. Fry trap installed over confirmed egg pit.

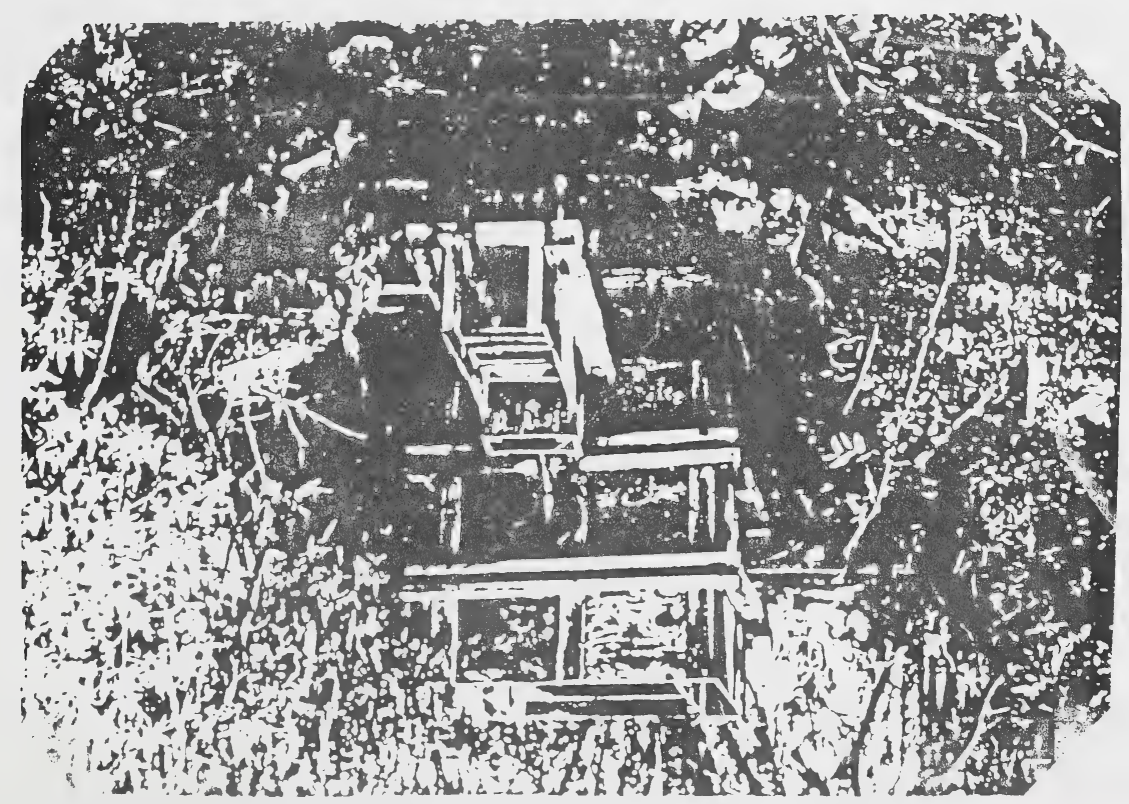

Figure 8. Streamside egg incubator. 


\section{$\underline{\text { Statistical Analysis }}$}

Correlation analysis of paired data was carried out and, in certain cases, least-squares regression analysis was used to define the linear relationship between two variables (for prediction purposes). Critical values of significance for " $\mathrm{r}$ " in the correlation analysis were obtained from Rohlf and Sokal (1969). Hypothesis testing of derived statistics involved the use of Student's t-test and ANOVA, at 95\% C.I.

\section{RESULTS}

\section{Initiation of Spawning and Egg Pit Content}

Generally, spawning occurred during the first two weeks of June with fry escapement completed by the third week of August (Figure 9). Spawning was observed as early as May 15, and isolated events as late as July. Water temperatures at first spawning were highly variable (Table 2) and no consistent pattern could be established. Dietz (1971) and Sterling (1986) reported maximum temperatures of $8^{\circ} \mathrm{C}$ and $6^{\circ} \mathrm{C}$, respectively, had to be reached before spawning was initiated. The longer term data trend, however, shows that spawning is not triggered by any specific temperature, but rather the warming rate during the pre-spawn period (Figure 10, $\mathrm{r}=-0.8142, \mathrm{p}<0.05$ ). First spawning and peak spawning in Wampus and Lower Deerlick creeks occurred at earlier dates during the post-harvest years of 1983 to 1985 (Table 2). However, spawning changes could not be attributed to altered water temperature regimes as no systematic increase in mean monthly water temperatures occurred following logging (Alberta Research Council, In press).

Egg pits were excavated each year from 1973 to 1977, and in 1985 (Table 3). There was no significant difference $(\mathrm{F}=0.7382, \mathrm{p}<0.05)$ between the annual mean egg content, which varied from 72 to 97 eggs. The entire sample mean of $88 \pm 9$ eggs/egg pit represents 3 to 4 excavations per female (based on an average fecundity of $293 \pm 16$ eggs (Sterling, 1986).

\section{Spawning Site Characteristics}

\section{Water Velocities and Depths}

Redds were generally located just upstream of the riffle crest where stream hydraulics provided appropriate particle size distribution and interstitial waterflow. Spawning was not 


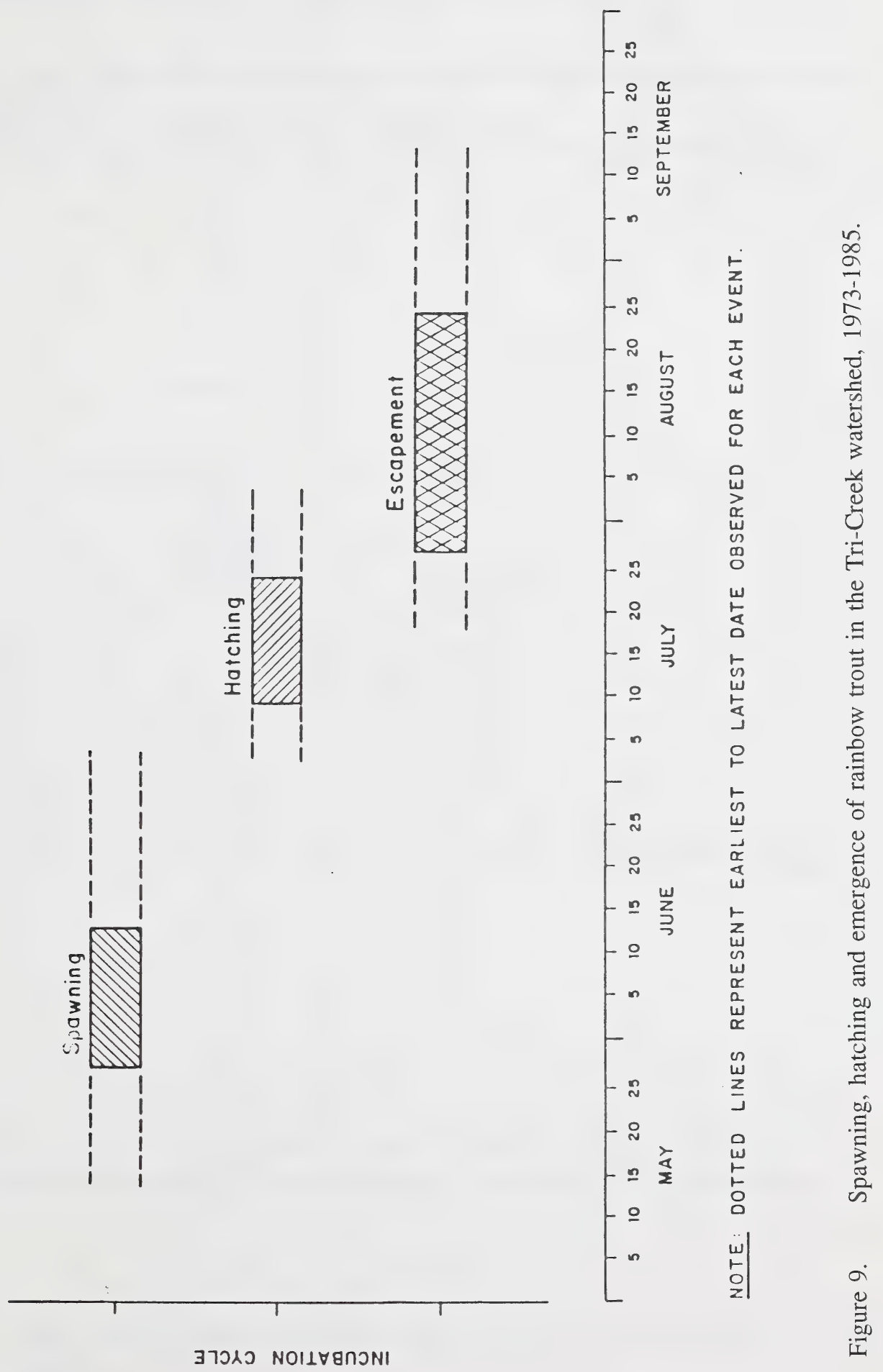


Table 2. Water temperatures and spawning dates for Wampus and Deerlick Creeks, 19731985.

\begin{tabular}{|c|c|c|c|c|}
\hline Section & Year & First Day of Spawning & Peak Spawning & $\begin{array}{c}\text { Maximum Water Temperature }{ }^{\circ} \mathrm{C} \\
\text { Pre-Spawning }\end{array}$ \\
\hline \multirow[t]{9}{*}{ Upper Wampus } & 1974 & June 1 & June 7 & 5.7 \\
\hline & 1975 & May 23 & June 3 & 4.8 \\
\hline & 1976 & May 21 & June 1 & 6.3 \\
\hline & 1977 & June 3 & June 13 & 7.1 \\
\hline & 1978 & June 2 & June 12 & 8.8 \\
\hline & 1981 & June 1 & June 5 & 9.1 \\
\hline & 1982 & June 12 & June 18 & 6.6 \\
\hline & 1983 & May 25 & June 5 & 13.3 \\
\hline & 1985 & May 15 & May 25 & 8.8 \\
\hline \multirow[t]{10}{*}{ Lower Wampus } & 1973 & June 1 & June 10 & 7.9 \\
\hline & 1974 & June 3 & June 10 & 7.5 \\
\hline & 1975 & May 30 & June 3 & 8.8 \\
\hline & 1978 & June 1 & June 11 & 7.5 \\
\hline & 1979 & June 2 & June 10 & 8.3 \\
\hline & 1981 & June 1 & June 5 & 7.9 \\
\hline & 1982 & June 12 & June 18 & 8.0 \\
\hline & 1983 & May 25 & June 6 & 10.5 \\
\hline & 1984 & May 25 & June 1 & 8.3 \\
\hline & 1985 & May 17 & May 25 & 12.4 \\
\hline \multirow[t]{9}{*}{ Lower Deerlick } & 1973 & $* *$ & June 10 & 8.8 \\
\hline & 1974 & $* *$ & June 10 & 6.8 \\
\hline & 1976 & $* *$ & June 6 & 7.9 \\
\hline & 1977 & $* *$ & June 20 & 9.0 \\
\hline & 1978 & $* *$ & June 14 & 8.7 \\
\hline & 1979 & $* *$ & June 12 & 7.0 \\
\hline & 1981 & $* *$ & June 8 & 8.4 \\
\hline & 1984 & $* *$ & June 1 & 12.3 \\
\hline & 1985 & $* *$ & May 25 & 13.5 \\
\hline
\end{tabular}


DAYS TO SPAWNING $=44.91(-58.13 \times \operatorname{Ln}($ Rate +1$)$

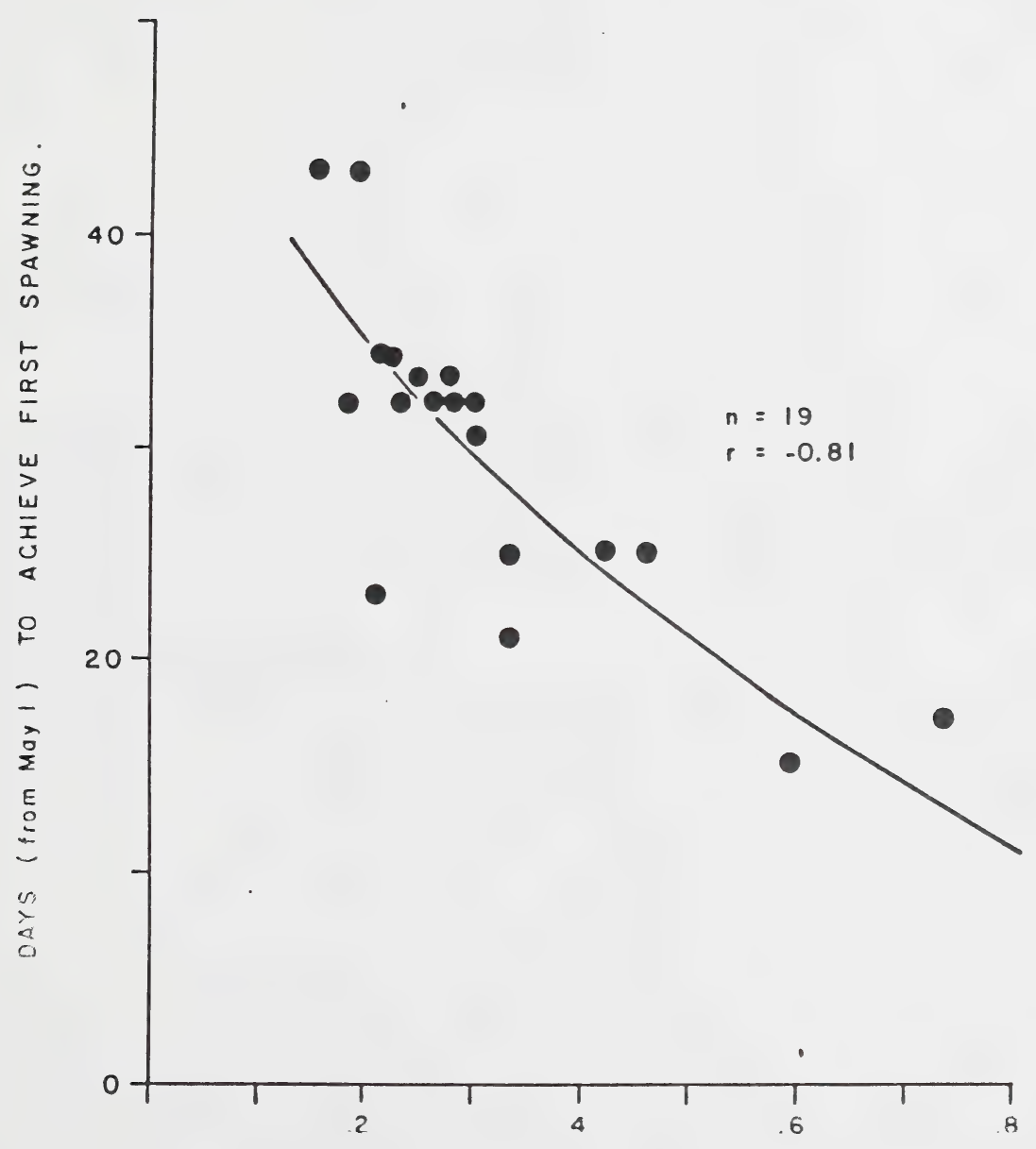

M.' XIMI:M WATER TFMPERATURE WARMING RATE ' Cilay:

Figure 10. Relationship of maximum water temperature warming rate to initiation of first spawning at Tri-Creek, 1973-1985. 
Table 3. Number of eggs in egg pits excavated in the Tri-Creek watershed, 1973-1977 and 1985.

\begin{tabular}{|c|c|c|c|c|c|}
\hline 1973 & 1974 & 1975 & 1976 & 1977 & 1985 \\
\hline 131 & 105 & 106 & 25 & 78 & 49 \\
\hline 67 & 70 & 79 & 80 & 44 & 113 \\
\hline 109 & 119 & 133 & 67 & 74 & 181 \\
\hline 135 & 38 & 48 & 130 & 87 & 210 \\
\hline 93 & 113 & 149 & 99 & 96 & 98 \\
\hline 130 & 140 & 43 & 41 & 68 & 112 \\
\hline 22 & 165 & 65 & 49 & 74 & 139 \\
\hline 90 & 106 & 93 & 95 & 56 & 47 \\
\hline 36 & 29 & 16 & 146 & 91 & 28 \\
\hline 73 & 84 & 55 & . 89 & 73 & 16 \\
\hline & 100 & 22 & 90 & 4 & 43 \\
\hline & 48 & 61 & 160 & 179 & \\
\hline & 70 & & 69 & 80 & \\
\hline & 77 & & 81 & 72 & \\
\hline & 50 & & 64 & 17 & \\
\hline & 18 & & 198 & 70 & \\
\hline & 138 & & 106 & 87 & \\
\hline & & & 94 & 144 & \\
\hline & & & 76 & & \\
\hline & & & 41 & & \\
\hline & & & 75 & & \\
\hline & & & 96 & & \\
\hline & & & 59 & & \\
\hline & & & 158 & & \\
\hline & & & 92 & & \\
\hline & & & 135 & & \\
\hline & & & 193 & & \\
\hline & & & 195 & & \\
\hline & & & 25 & & \\
\hline & & & 50 & & \\
\hline & & & 61 & & \\
\hline & & & 168 & & \\
\hline $\mathrm{N}=10$ & 17 & 12 & 32 & 18 & 11 \\
\hline Mean $=89$ & 86 & 72 & 97 & 77 & 94 \\
\hline Grand Mean $=88 \pm 9$ eggs & & & & & \\
\hline
\end{tabular}


restricted to these locations and often redds were disjunct, with individual egg pits of any one female located wherever suitable water velocities and depths measured at 474 confirmed spawning sites averaged $31.1 \pm 0.8 \mathrm{~cm} / \mathrm{s}$ and $14.3 \pm 0.5$ respectively (Figure 11).

\section{Substrate Composition}

Spawning substrates were composed of angular to subangular fragments of local bedrock (particularly in the upper reaches) and rounded pebbles and gravel of glacial deposits. The mean particle size distribution of 242 samples collected from 1973 to 1985 (Figure 12) had a geometric mean (dg) of $9.95 \pm 0.51 \mathrm{~mm}$ and a fredle index (f) of $1.54 \pm 0.13$. Approximately $72 \%$ of the material was less than $25.4 \mathrm{~mm}$ (dia), and percent fines (particles $<0.841 \mathrm{~mm}$ ) averaged $12.1 \pm 0.6$ percent. During the pre-logging phase, the fredle index (range 0.2 to 5.9 ) did not differ significantly within sections by years, between sections or between years. During the post-logging phase, the fredle index had a similar range (0.1 to 5.7); however, two-way analysis of variance with comparison of treatment means showed significant differences between sections, and between years (F-test; $\mathrm{p}<0.001,<0.001$ respectively). Wampus $\mathrm{A}$ and Deerlick $\mathrm{A}$ and $\mathrm{C}$ had larger fredle indices than other sections, and 1984 was higher than 1983 and 1985 (Table 4). The mean fredle index (Table 5) of post-logging $(1.62 \pm 0.17)$ was not significantly different than the pre-logging mean $(1.47 \pm 0.19)$.

\section{Interstitial Dissolved Oxygen and $\mathrm{pH}$}

Interstitial dissolved oxygen and $\mathrm{pH}$ during the period of egg incubation and fry emergence (1973 to 1985), was generally less than, but in most cases varied little from, mainstream values. Weekly observations of interstitial oxygen and $\mathrm{pH}$ varied from 0.5 to $13.4 \mathrm{mg} / \mathrm{L}$ and $\mathrm{pH} 6.0$ to 9.5 respectively. As measurements were obtained only weekly, the duration of extremes for both parameters was difficult to assess. A pH of 9.5 was recorded only once, and values of pH 6.0 only three times. Mean oxygen saturation below $80 \%$ during the incubation period existed in $24 \%$ of the sections monitored from 1973 to 1985 . Hydrogen ion concentration $(\mathrm{pH})$ was not significantly different between sections following logging (F-test; $\mathrm{p}<0.05)$. Mean $\mathrm{pH}$ during pre-logging $(7.8 \pm 0.1)$ was not significantly different than mean post-logging $\mathrm{pH}(7.7 \pm 0.1)$. Oxygen saturation differed significantly between sections before logging (F-test; $p<0.001$ ), but not after logging. Mean oxygen saturation (Table 6) at incubation sites post-logging $(80.5 \pm 3.6 \%)$ was significantly less (F-test; $\mathrm{p}<0.001)$ than mean pre-logging oxygen saturation $(90.3 \pm 2.4 \%)$. Interstitial oxygen saturation and $\mathrm{pH}$ were not correlated with substrate fredle indices. 


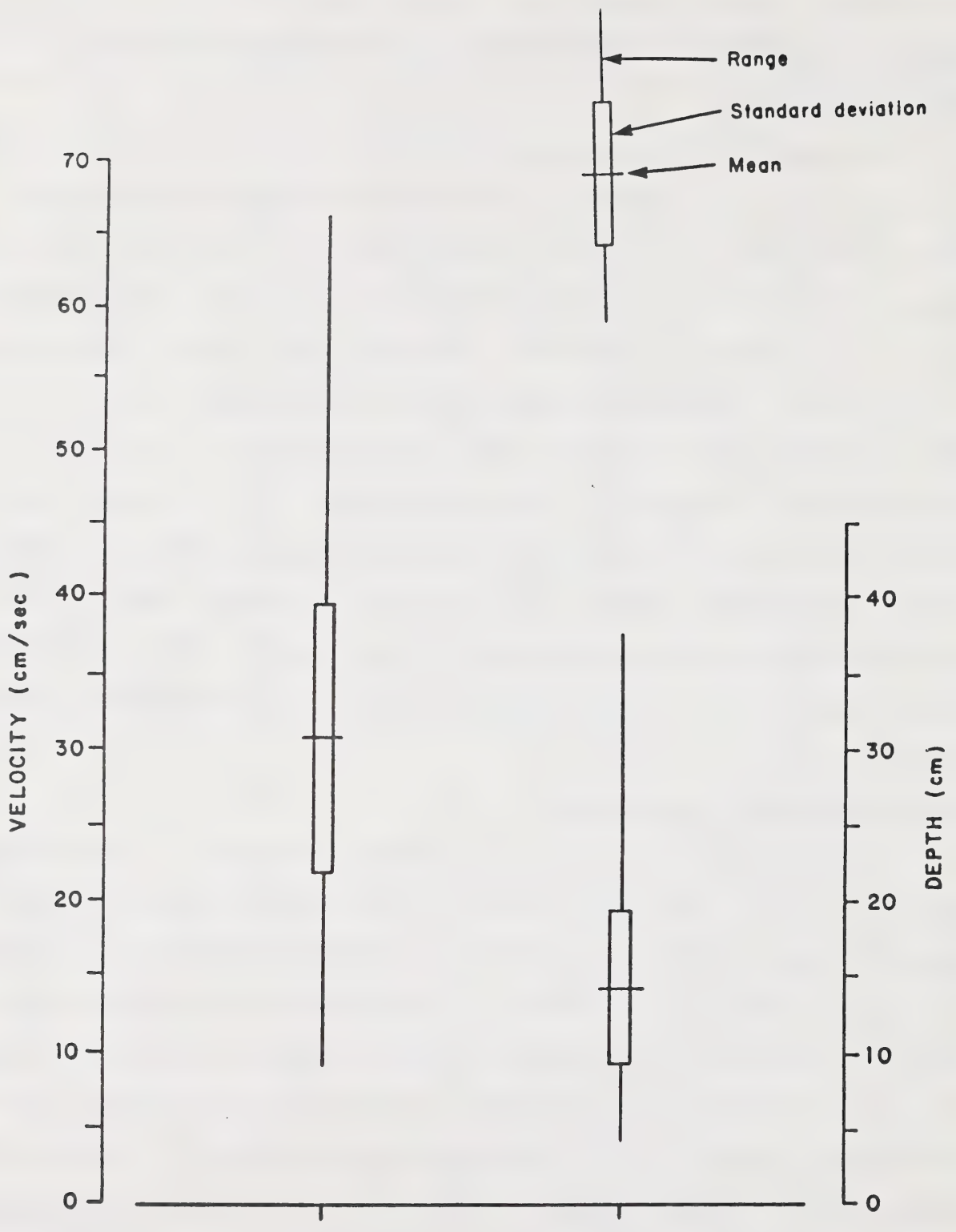

Figure 11. Water velocity and water depth at 474 spawning sites at Tri-Creek, 1973-1985. 


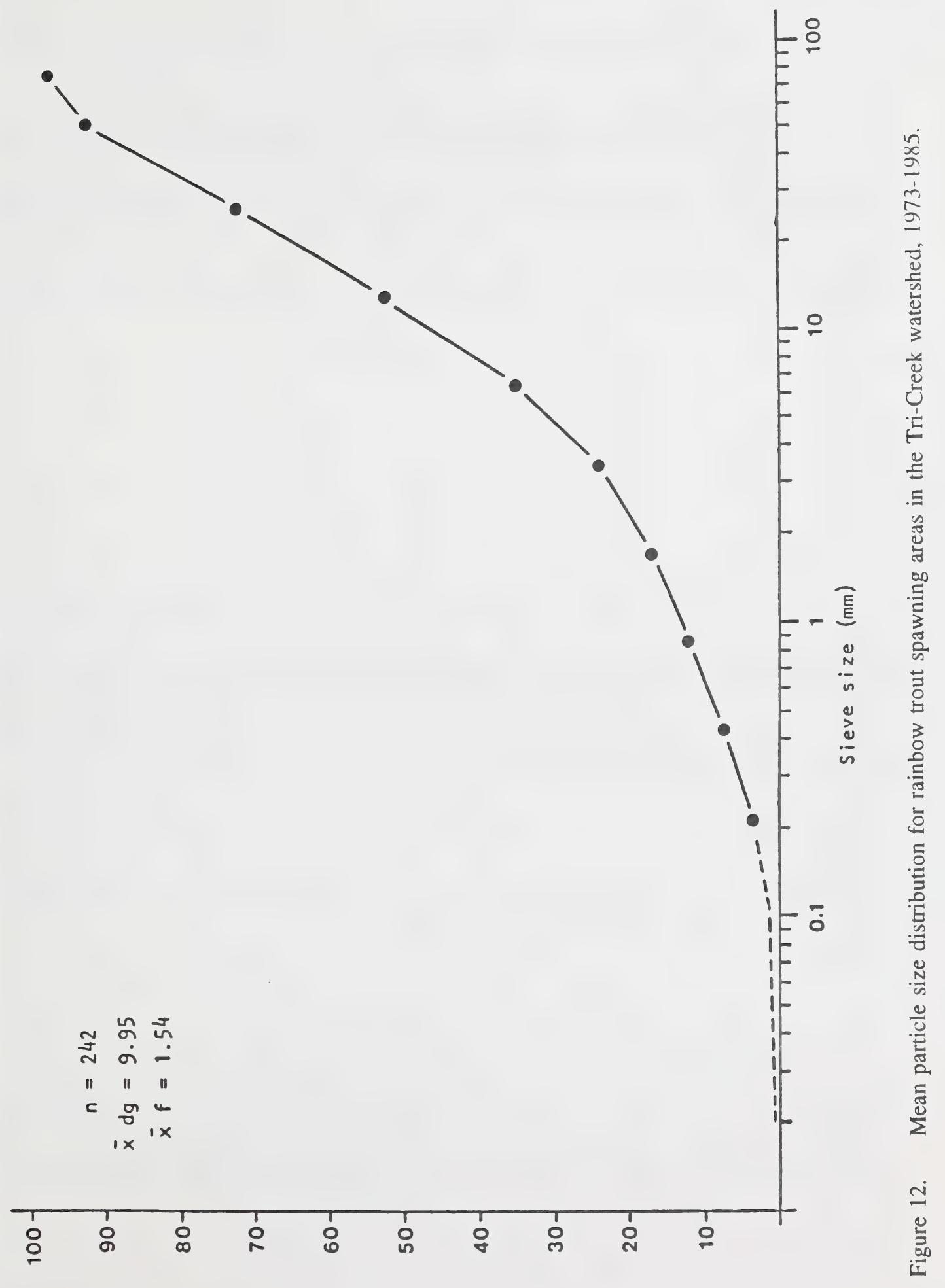

. az!s pazeu6!sap to ana!s 6u!ssed azedzsqns Gu!umeds zuajdad 
Table 4. Multiple range test (LSD procedure) for post-logging spawning substrate fredle indices (f), by section and year for the Tri-Creek watershed.

\begin{tabular}{|c|c|c|c|c|c|c|c|c|c|c|}
\hline \multirow[b]{2}{*}{ Mean } & \multirow[b]{2}{*}{ Section } & \multicolumn{9}{|c|}{ Study Sections } \\
\hline & & WD & WC & WG & WB & WF & WE & WA & DA & $\mathrm{DC}$ \\
\hline 1.14 & WD & & & & & & & & & \\
\hline 1.15 & WC & & & & & & & & & \\
\hline 1.23 & WG & & & & & & & & & \\
\hline 1.33 & WB & & & & & & & & & \\
\hline 1.40 & WF & & & & & & & & & \\
\hline 1.52 & WE & & & & & & & & & \\
\hline 2.10 & WA & & $*$ & * & $*$ & & & & & \\
\hline 2.31 & DA & * & * & * & $*$ & $*$ & $*$ & & & \\
\hline \multirow[t]{2}{*}{2.42} & DC & $*$ & $*$ & $*$ & $*$ & * & $*$ & & & \\
\hline & & \multicolumn{3}{|c|}{ Study Years } & & & & & & \\
\hline Mean & Year & 1985 & 1983 & 1984 & & & & & & \\
\hline 1.19 & 1985 & & & & & & & & & \\
\hline 1.49 & 1983 & * & * & & & & & & & \\
\hline 2.08 & 1984 & & & & & & & & & \\
\hline
\end{tabular}

*Denotes pairs significantly different at the 0.05 level. 
Table 5. Mean fredle indices (f) of spawning substrates in the Tri-Creek watershed, 19731985.

\begin{tabular}{|c|c|c|c|}
\hline \multirow[b]{2}{*}{ Pre-logging } & \multicolumn{3}{|c|}{ Fredle Index (f) } \\
\hline & $\mathrm{n}$ & Mean & St. D. \\
\hline Wampus A & 15 & 1.41 & 1.171 \\
\hline Wampus B & 7 & 2.27 & 1.546 \\
\hline Wampus C & 16 & 1.37 & 0.893 \\
\hline Wampus D & 21 & 1.51 & 1.170 \\
\hline Wampus E & 31 & 1.43 & 1.152 \\
\hline Wampus F & -- & -- & - \\
\hline Wampus G & 13 & 1.46 & 0.977 \\
\hline Deerlick A & 15 & 0.98 & 0.971 \\
\hline Deerlick B & 16 & 1.44 & 1.447 \\
\hline Deerlick C & 5 & 2.68 & 0.870 \\
\hline Total & 139 & 1.47 & 1.150 \\
\hline Post-logging & $\mathrm{n}$ & Mean & St.D. \\
\hline Wampus A & 15 & 2.01 & 1.235 \\
\hline Wampus B & 15 & 1.33 & 0.740 \\
\hline Wampus C & 11 & 1.15 & 0.281 \\
\hline Wampus D & 5 & 1.14 & 0.336 \\
\hline Wampus E & 12 & 1.52 & 0.726 \\
\hline Wampus F & 10 & 1.40 & 0.380 \\
\hline Wampus G & 14 & 1.23 & 0.741 \\
\hline Deerlick A & 15 & 2.31 & 1.372 \\
\hline Deerlick B & -- & -- & -- \\
\hline Deerlick C & 6 & 2.42 & 0.835 \\
\hline Total & 103 & 1.62 & 0.889 \\
\hline
\end{tabular}


Tables 6. Mean oxygen saturation and $\mathrm{pH}$ of interstitial water at Tri-Creek, 1973-1985.

\begin{tabular}{|c|c|c|c|c|c|c|}
\hline \multirow[b]{2}{*}{ Pre-logging } & \multicolumn{2}{|c|}{ Oxygen Saturation } & \multicolumn{3}{|c|}{$\mathrm{pH}$} & \multirow[b]{2}{*}{ St. D. } \\
\hline & $\mathrm{n}$ & $\%$ & St. D. & $\mathrm{n}$ & $\mathrm{pH}$ & \\
\hline Wampus A & 12 & 97.6 & 5.76 & 5 & 7.9 & 0.35 \\
\hline Wampus B & 9 & 95.9 & 6.44 & 4 & 7.7 & 0.05 \\
\hline Wampus C & 19 & 72.5 & 22.54 & 8 & 7.6 & 0.21 \\
\hline Wampus D & 30 & 89.3 & 21.09 & 19 & 7.7 & 0.48 \\
\hline Wampus E & 31 & 90.4 & 14.88 & 19 & 7.9 & 0.44 \\
\hline Wampus F & 10 & 87.6 & 23.91 & -- & -- & -- \\
\hline Wampus G & 21 & 92.1 & 14.12 & 13 & 7.7 & 0.23 \\
\hline Deerlick A & 26 & 95.0 & 13.47 & 10 & 7.9 & 0.15 \\
\hline Deerlick B & 28 & 91.7 & 14.39 & 16 & 8.0 & 0.28 \\
\hline Deerlick C & 8 & 97.6 & 7.67 & -- & -- & -- \\
\hline Total & 194 & 90.3 & 16.33 & 94 & 7.8 & 0.35 \\
\hline \multicolumn{7}{|l|}{ Post-logging } \\
\hline Wampus A & 23 & 84.4 & 17.01 & 13 & 7.7 & 0.41 \\
\hline Wampus B & 22 & 79.5 & 20.31 & 12 & 7.6 & 0.51 \\
\hline Wampus C & 15 & 77.9 & 213.14 & 10 & 7.4 & 0.13 \\
\hline Wampus D & 10 & 89.5 & 11.24 & 5 & 8.1 & 0.08 \\
\hline Wampus E & 16 & 84.6 & 22.47 & 9 & 7.7 & 0.37 \\
\hline Wampus F & 10 & 76.6 & 29.21 & 10 & 7.9 & 0.21 \\
\hline Wampus G & 20 & 75.1 & 22.86 & 15 & 7.6 & 0.41 \\
\hline Deerlick A & 10 & 73.5 & 25.00 & 10 & 7.6 & 0.23 \\
\hline Deerlick B & 1 & 104.0 & 0.00 & 1 & 7.4 & 0.00 \\
\hline Deerlick C & 7 & 82.3 & 17.56 & 7 & 7.6 & 0.13 \\
\hline Total & 134 & 80.5 & 21.31 & 92 & 7.7 & 0.34 \\
\hline
\end{tabular}




\section{Fry Escapement: Water Temperature Relationships}

Fry escapement generally commenced 10 to 14 days following hatching with the interval from peak spawning to peak escapement highly regulated by water temperature (Figure 13, $r=-0.754$ ). Mean water temperatures during the incubation period (for the study was 1973 to 1985) ranged from 5.3 to $11.6^{\circ} \mathrm{C}$. At a temperature of $10^{\circ} \mathrm{C}$, peak emergence occurred approximately 59 days following spawning. Water temperatures in upper Deerlick Creek were significantly colder ( $\mathrm{t}$-test, $\mathrm{p}<0.05$ ) than other sections resulting in later spawning, a prolonged incubation period and fry escapement as late as mid-September.

\section{Fry Survival to Escapement}

The percent fry escapement ranged from 0.0 to $100 \%$ (Tables 7 and 8 ) and did not differ significantly between sections (excluding the upper Deerlick) during the pre-logging or post-logging phases. The pre-logging mean fry escapement for all sections (26 \pm 5 fry/egg pit) was not significantly different than the post-logging fry escapement (34 \pm 10 fry/egg pit). Fry escapement was not correlated with interstitial oxygen saturation or with substrate fredle indices.

\section{$\underline{\text { Streamflow Relationships }}$}

The spawning substrates in lower Wampus Creek were vulnerable to scour at an estimated stream discharge of $0.54 \mathrm{~m}^{3} / \mathrm{s}$ (Alberta Research Council, In press). Water yield that potentially contributed to bed movement ranged from 4.5 to 675 hectare/metres for the years 1973 to 1984 . Annual fry production was not estimated so annual yearling (age 1 trout) abundance was compared to water yield exceeding critical flow during the incubation period for each cohort. Although unadjusted to compensate for differing parental stock abundance and cohort mortality, yearling abundance was inversely correlated $(r=-0.8188, p<0.05)$ with the log values of water yield exceeding critical flow (Figure 14).

\section{DISCUSSION}

Eastern Slope rainbow trout in central Alberta are unique in that they represent one of the few natural occurrences of $O$. mykiss east of the Continental Divide. Electrophoretic screening of trout from Wampus Creek (Seeb and Wishard, 1984) demonstrated they are unique, not resembling inland, coastal or hatchery strains of rainbow trout. They principally occupy high 


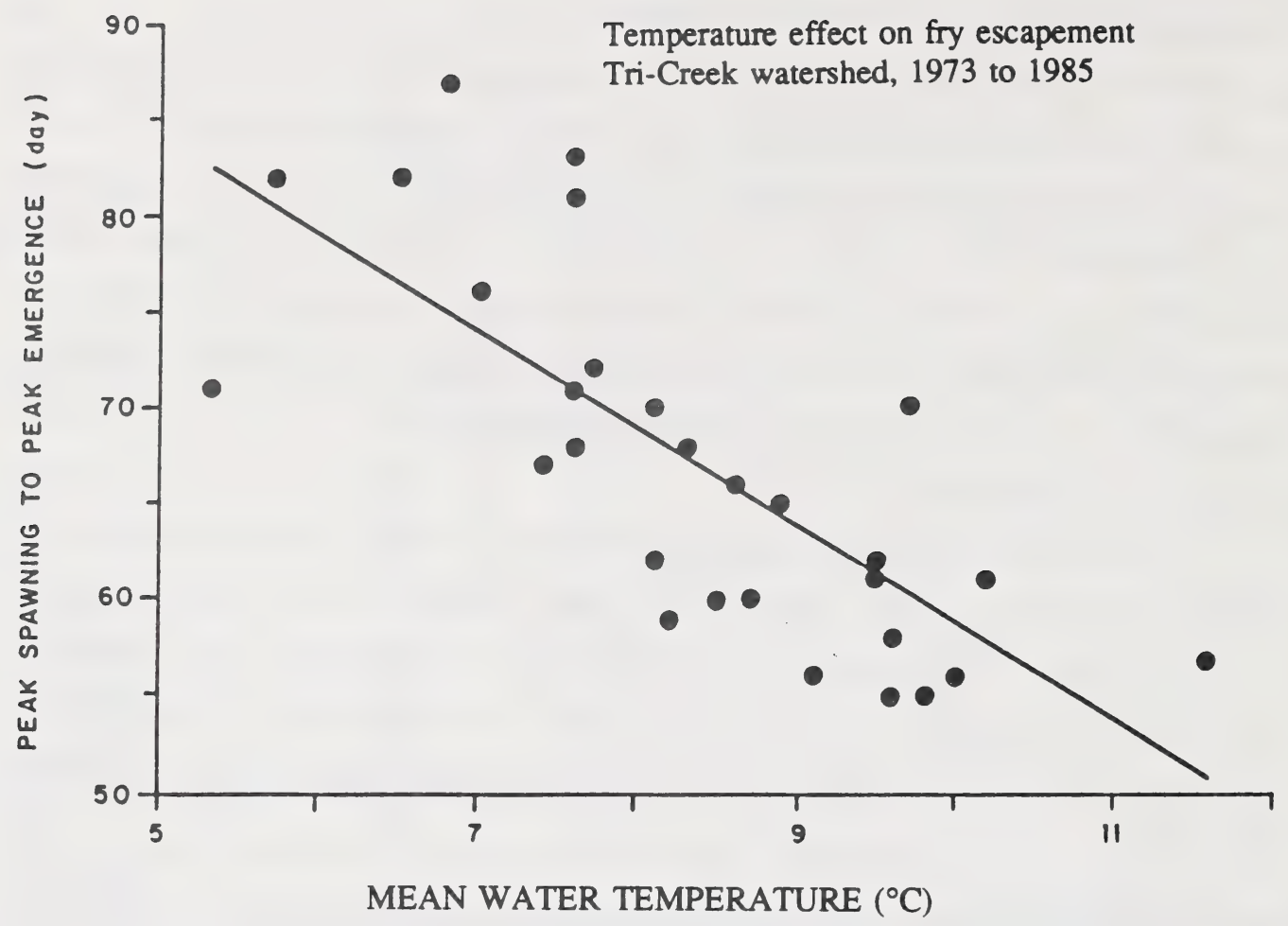

Figure 13. Relationship of mean water temperature $\left({ }^{\circ} \mathrm{C}\right)$ on days to achieve peak escapement  in the Tri-Creek watershed, 1973-1985.

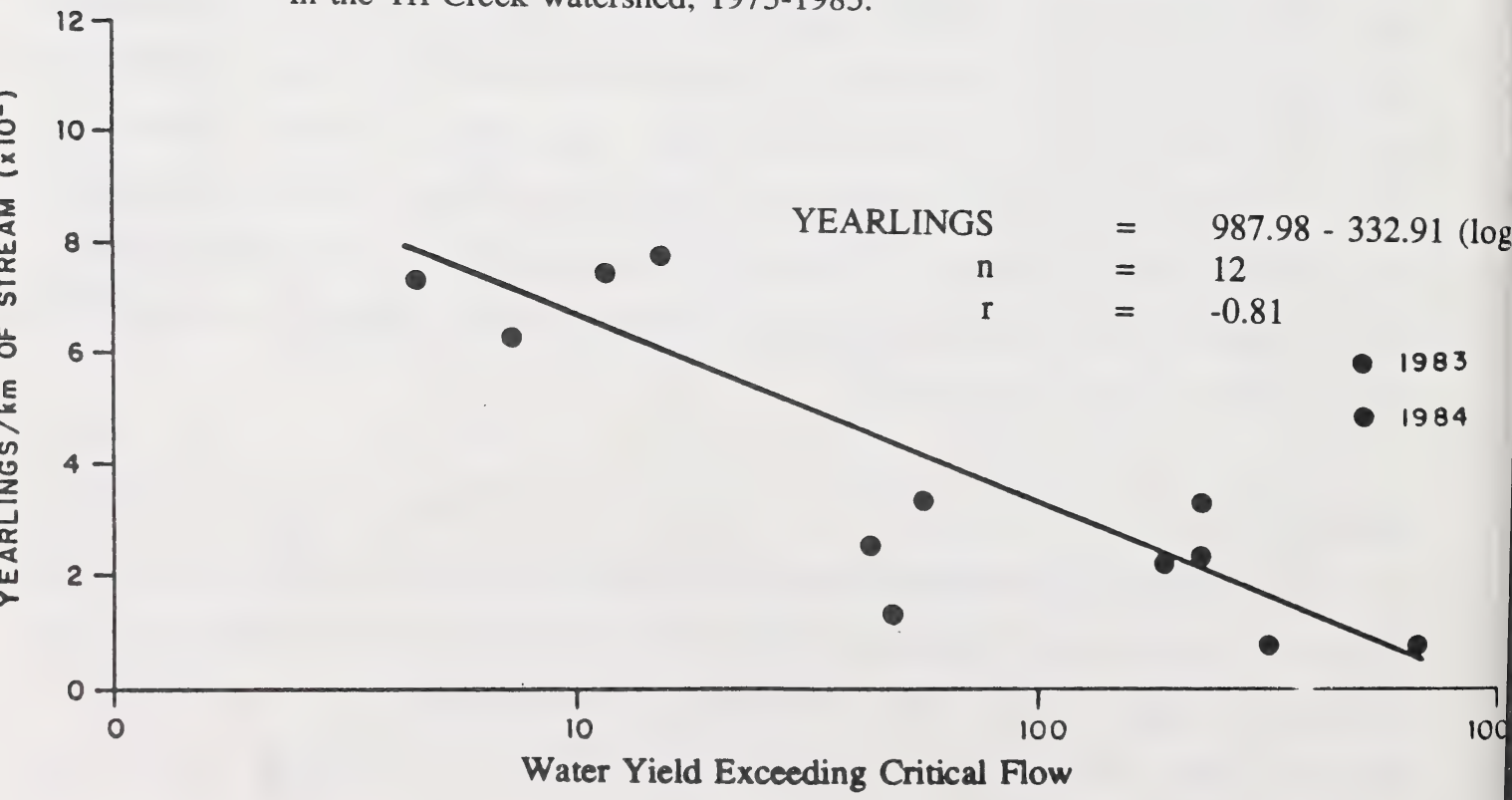

Figure 14. Relationship of streamflow (during cohort incubation) and cohort abundance (as yearlings) in Wampus Creek, 1973-1985. 
Table 7. Fry escapement in Wampus and Deerlick Creeks during the pre-logging place.

\begin{tabular}{|c|c|c|c|c|c|}
\hline Year & Section & Sites & $\begin{array}{l}\text { Mean } \\
\text { (Fry) }\end{array}$ & Std. Dev. & $\begin{array}{c}\% \\
\text { Escapement }\end{array}$ \\
\hline \multirow[t]{4}{*}{1973} & WA & 2 & 10 & 10.61 & 11.4 \\
\hline & WD & 2 & 39 & 18.38 & 44.3 \\
\hline & WE & 6 & 29 & 29.76 & 33.0 \\
\hline & DA & 2 & 4 & 5.66 & 4.6 \\
\hline \multirow[t]{4}{*}{1974} & WA & 2 & 58 & 76.37 & 65.9 \\
\hline & WD & 5 & 22 & 27.17 & 25.0 \\
\hline & WE & 7 & 40 & 47.89 & 45.4 \\
\hline & DA & 2 & 47 & 63.65 & 53.4 \\
\hline \multirow[t]{6}{*}{1975} & WA & 4 & 29 & 27.35 & 32.9 \\
\hline & WB & 4 & 26 & 21.58 & 29.5 \\
\hline & WC & 4 & 34 & 7.18 & 38.6 \\
\hline & WD & 5 & 43 & 67.17 & 48.9 \\
\hline & WE & 4 & 72 & 38.90 & 81.8 \\
\hline & WG & 4 & 26 & 39.56 & 29.5 \\
\hline \multirow[t]{6}{*}{1976} & WC & 5 & 22 & 23.50 & 25.0 \\
\hline & WD & 5 & 24 & 26.28 & 27.3 \\
\hline & WE & 3 & 3 & 3.00 & 3.4 \\
\hline & WG & 5 & 0 & 0.00 & 0.0 \\
\hline & DA & 5 & 32 & 40.98 & 36.4 \\
\hline & DB & 6 & 17 & 21.53 & 19.3 \\
\hline \multirow[t]{5}{*}{1977} & WD & 4 & 31 & 23.31 & 35.2 \\
\hline & WE & 4 & 40 & 34.55 & 45.4 \\
\hline & WG & 5 & 39 & 36.47 & 44.3 \\
\hline & DA & 4 & 34 & 30.93 & 38.6 \\
\hline & DB & 5 & I & 0.84 & 1.1 \\
\hline \multirow[t]{8}{*}{1978} & WA & 5 & 85 & 105.69 & 96.6 \\
\hline & WB & 5 & 12 & 12.05 & 13.6 \\
\hline & WC & 5 & 31 & 47.12 & 35.2 \\
\hline & WD & 5 & 40 & 30.70 & 45.4 \\
\hline & WE & 4 & 21 & 16.88 & 23.9 \\
\hline & WG & 3 & 11 & 19.05 & 12.5 \\
\hline & DA & 5 & 42 & 63.44 & 47.7 \\
\hline & DB & 5 & 0 & 0.00 & 0.0 \\
\hline
\end{tabular}




\begin{tabular}{||l|c|c|c|c|c||}
\hline \multirow{3}{*}{ Year } & Section & Sites & $\begin{array}{c}\text { Mean } \\
\text { (Fry) }\end{array}$ & Std. Dev. & $\begin{array}{c}\% \\
\text { Escapement }\end{array}$ \\
\hline & WC & 5 & 6 & 6.98 & 6.8 \\
& WD & 5 & 30 & 14.98 & 34.1 \\
& WE & 5 & 2 & 1.73 & 2.3 \\
& WF & 4 & 38 & 38.84 & 43.2 \\
& WG & 5 & 28 & 38.76 & 31.8 \\
& DA & 5 & 6 & 7.57 & 5.8 \\
& DB & 2 & 5 & 7.07 & 11.4 \\
\hline 1981 & DC & 3 & 10 & 16.46 & 13.6 \\
& WF & 5 & 12 & 22.73 & 6.8 \\
\hline $\begin{array}{l}\text { For entire } \\
\text { population }\end{array}$ & DA & 5 & 6 & 5.72 & 28.4 \\
\hline \hline
\end{tabular}

gradient headwater tributaries of the Athabasca River drainage and their small size at maturity requires unique physical criteria (water velocity, depth and substrate composition) for spawning.

Spawning and the duration of the incubation period were highly regulated by water temperature, with mean temperatures during the incubation period generally encompassing the optimum range of $7-10^{\circ} \mathrm{C}$ for rainbow trout reported by Kwain (1975). In this study, water temperature changes were not related to logging as reported in other studies (Meehan et al., 1969; Kopperdahl et al., 1971; Ringler and Hall, 1975), but associated with ambient air temperature, particularly in Wampus Creek (Alberta Research Council, in press). In some stream reaches (upper Deerlick and Eunice Creek), water temperatures were highly buffered by ground water (Alberta Research Council, in press), and canopy removal in Upper Deerlick Creek did not significantly modify the temperature regimes. The controlled manipulation of riparian vegetation to increase water temperatures during the incubation period has little value in streams where groundwater flow is a regulating mechanism.

In this study, the efficiency of natural reproduction (fry escapement) of rainbow trout is considerably less than in the Finger Lakes region of New York (Hatch, 1957), but considerably higher than reported for Young Creek in southwestern Ontario (Sowden and Power, 1985). Variations in fecundity (Sterling, 1986), differing ability to excavate redds based on female size, and differing egg deposition between first and last egg pit constructed, contributed to the large relative variability seen in the egg pit excavation and fry escapement data and were not evaluated. 
The lack of a direct relationship between fry escapement and substrate quality (fredle index and oxygen content) contrasts with results for most other studies (Gibbons and Salo, 1973; Iwamoto et al. 1978; Wydoski, 1978; Platts et al., 1983) where low embryo survival was attributed to decreased gravel permeability (which influences oxygen concentration) and/or entrapment of alevins and fry. Study streams may have remained within the natural regime of substrate composition because road reclamation following logging was atypical (Jarvis, 1984); hence, sedimentation did not become a factor regulating fry escapement.

Factors which may obscure the relationship between fry escapement, oxygen content and substrate composition at Tri-Creek include: (1) higher relative water velocities which contributed to coarser and better sorted substrates with higher mean particle diameter than reported for other, similar-sized salmonids (Witzel and MacCrimmon, 1983); (2) mean fines of approximately 12 percent which is lower than the critical level of approximately 20 percent reported by Reiser and Bjornn (1979); and (3) streamflows at spawning which were observed to regulate redd locations within the channel.

Spawning typically occurred between peaks in stream discharge in May (snowmelt) and June (heaviest annual precipitation). At higher than average flows during spawning, redds were observed nearer the edges of the channel in suitable substrates with appropriate velocity and depth criteria. Under these circumstances, the highest sites were often dewatered during the incubation period. Conversely, spawning at lower than average flows (same requirements) was observed nearer the riffle crest, making any increases in flow during the incubation period disruptive in terms of bed erosion. Under these circumstances, some sites, regardless of substrate composition, failed to produce any fry. It was impossible to select redds during spawning to exclude this variation.

Streamflows during the incubation period appear to be significant in regulating escapement, as measured indirectly by yearling abundance. Snowmelt before spawning results in streamflows of sufficient yield to move spawning substrates and naturally cleanse the streambed surface which is utilized for spawning. The subsequent intrusion of fines affects embryo survival and fry escapement (Beschta and Jackson, 1979). However, at Tri-Creek, critical flow is a mere $0.54 \mathrm{~m}^{3} / \mathrm{s}$, and streamflows exceeding this critical flow occurred during approximately $30 \%$ of the incubation period. At this frequency, streamflow causing bed erosion masks possible sedimentation impacts and is a major factor limiting fry escapement in the high 
gradient streams at Tri-Creek. No change in streamflow following logging was observed in this study (Alberta Research Council, in press), which contrasts with results reported elsewhere (McNeil, 1966; Hibbert, 1967; Swanson and Hillman, 1977). The-short term results seen in this study are not indicative of potential long term affects on streamflow, particularly when the second cutting (residual timber) of watersheds generally occurs 20 years (2-m regeneration rule applicable) following initial timber harvest.

\section{CONCLUSIONS}

Spawning and the duration of the incubation period were highly regulated by water temperature, with mean temperatures during the incubation period generally encompassing the optimum range of $7-10^{\circ} \mathrm{C}$. However, water temperature changes were not related to logging, but associated with ambient air temperature, particularly in Wampus Creek. The groundwater buffered water temperatures in some stream reaches, so canopy removal had little impact on water temperature.

Fry escapement was not affected by logging and was not related to either substrate quality or oxygen content of interstitial water. The water velocity may have contributed to coarser and better sorted substrates and lower percentages of fines, and streamflows which regulated redd locations may have contributed to obscuring the relationship between escapement, oxygen content and substrate composition at the study site.

Streamflow appeared to regulate escapement significantly as measured by yearling abundance. Logging did not appear to affect the streamflow in this study, which contrasts with results from other research (McNeil, 1966; Hibbert, 1967; Swanson and Hillman, 1977). However, the short-term results from this study are not indicative of potential long-term logging impacts on streamflow.

\section{REFERENCES}

Alberta Energy and Natural Resources. 1984. A Policy for Resource Management of the Eastern Slopes (rev.). Energy and Natural Resources Report T/38, Edmonton, Alberta.

Allen, K.R. 1969. Limitations on production in salmonid populations in streams. In: Symposium on Salmon and Trout in Streams. Institute of Fisheries, Univ. British Columbia, Vancouver, British Columbia. 
Alberta Research Council. (n.d.) Tri-Creek watershed contributing study reports. In Press, Edmonton, Alberta

Beschta, R.L., and W.L. Jackson. 1979. The intrusion of fine sediments into a stable gravel bed. J. Fish. Res. Bd. Can. 36:204-210.

Chapman, D.W. 1962. Effects of logging upon fish resources of the west coast. J. For. 60:533-537.

Dietz, K. 1971. The fish populations of three streams in the foothills of Alberta. M.Sc. Thesis., Univ. Alberta, Edmonton, Alberta.

Gibbons, D.R., and E.O. Salo. 1973. An annotated bibliography of the effects of logging on fish of the western United States and Canada. USDA Forest Service Gen. Tech. Rep. PNW-10.

Hatch, R.W. 1957. Success of natural spawning of rainbow trout in the Finger Lakes region of New York. New York Fish Game J. 4:69-87.

Hibbert, A.R. 1967. Forest treatment effects on water yield in forest hydrology. pp. 527-543. W.E. Sopper and H.W. Lull (eds.). Pergamon Press, Oxford.

Iwamoto, R.N., E.O. Salo, M. Madej, and R.L. McComas. 1978. Sediment and water quality: a review of the literature including a suggested approach for water quality criteria. U.S. Envir. Prot. Agency. Rep. EPA 910/9-78-048. Seattle, Washington.

Jablonski, P.D. 1978. The Tri-Creek watershed: a study into the effects of logging on the physical, chemical and biotic condition of three Alberta East Slope streams. Alberta Energy and Natural Resources. The Tri-Creek Watershed Study. Rep. No. 1. 30 pp. Edmonton, Alberta

Jarvis, J. 1984. Final harvesting and silviculture report for the Tri-Creek experimental watershed. Alberta Energy and Natural Resources, Alberta Forest Service, Edson, Alberta.

Kopperdahl, F.R., J.W. Burns, and G.E. Smith. 1971. Water quality of some logged and unlogged California streams. Calif. Fish and Game. Inland Admin. Rep. 71-12. 19 pp.

Kwain, W. 1975. Embryonic development, early growth, and meristic variation in rainbow trout (Salmo gairdneri) exposed to combinations of light intensity and temperature. J. Fish. Res. Bd. Can. 32:397-402.

McNeil, W.J. 1962. Variations in the dissolved oxygen content of intragravel water in four spawning streams of southeastern Alaska. U.S. Fish and Wildl. Serv., Spec. Sci. Rep. No. 402. $15 \mathrm{pp}$. 
McNeil, W.J. 1966. Effect of the spawning bed environment on reproduction of pink and chum salmon. U.S. Fish and Wildl. Serv. Fish Bull. 65:495-523.

McNeil, W.J., and W.H. Ahnell. 1964. Success of pink salmon spawning relative to size of spawning bed materials. U.S. Fish and Wildl. Serv., Spec. Sci. Rep. No. 490. 15 pp.

Meehan, W.R., W.A. Farr, D.M. Bishop, and J.H. Patric. 1969. Some effects of clearcutting on salmon habitat of two southeast Alaska streams. USDA For. Serv. Res. Rep. PNW-82. $45 \mathrm{pp}$.

Murphy, M.L., C.P. Hawkins, and N.H. Anderson. 1981. Effects of canopy modification and accumulated sediment on stream communities. Trans. Amer. Fish. Soc. 110: 469-478.

Phillips, R.W., and K.V. Koski. 1969. A fry trap method for estimating salmonid survival from egg deposition to fry emergence. J. Fish. Res. Bd. Can. 26:133-141.

Platts, W.S., and M.A. Shirazi and D.H. Lewis. 1979. Sediment particle sizes used by salmon for spawning with methods for evaluation. USEPA. Rep. EPA-600/3-79-043. Corvallis, Oregon.

Platts, W.S., W.F. Megahan, and G.W. Minshall. 1983. Methods for evaluating stream, riparian, and biotic conditions. USDA Gen. Tech. Rep. INT-138. 70 pp.

Reiser, D.W., and T.C. Bjornn. 1979. Habitat requirements of anadromous salmonids. In: Influence of forest and rangeland management on anadromous fish habitat in western North America. USDA Gen. Tech. Rep. PNW-96.

Ringler, N.H., and J.D. Hall. 1975. Effects of logging on water temperatures and dissolved oxygen in spawning beds. Trans. Amer. Fish. Soc. 104:111-121.

Rohlf, J.F., and R.R. Sokal. 1969. Statistical tables. W.H. Green and Company, San Francisco, California.

Seeb, J.E., and L.N. Wishard. 1984. A biochemical genetic analysis of Athabasca rainbow from Wampus Creek. For Alberta Energy and Natural Resources, Fish and Wildl. Div, by Pacific Fisheries Research. Seattle, Washington.

Sowden, T.K., and G. Power. 1985. Prediction of rainbow trout embryo survival in relation to groundwater seepage and particle size of spawning substrates. Trans. Amer. Fish. Soc. 114:804-812.

Sterling, G.L. 1986. An evaluation of spawning habitat and fry escapement of rainbow trout (Salmo gairdneri Richardson) before logging in the Tri-Creek watershed of west-central Alberta. Alberta Energy and Natural Resources. Fish and Wildl. Div. Tri-Creek Watershed Study Rep. No. 8. 74 pp. 
Swanson, R.H., and G.R. Hillman. 1977. Predicted increased water yield after clear-cutting in west-central Alberta. Canadian Forestry Service. Fish. Environ. Can. Info. Rep. NOR-1-198.

Witzel, L.D., and H.R. MacCrimmon. 1983. Redd-site selection by brook trout and brown trout in southwestern Ontario streams. Trans. Amer. Fish. Soc. 112:760-771.

Wydoski, R.S. 1978. Responses of trout populations to alterations in aquatic environments: A review. In: Proc. Wild Trout-Catchable Trout Symposium, 1978. 


\section{Appendix I. Tri-Creek Experimental Watershed Terms of Reference: Fisheries.}

Project Name: $\quad$ Population Dynamics for Major Salmonid Species at Tri-Creek.

Purpose:

To determine the effects of sedimentation on fish populations.

Objectives:

To establish the magnitude and variation of salmonid population parameters before and after pulpwood harvesting.

Terms of Reference:

1. Estimate population density, age class structure, sex ratios, fecundity, growth, recruitment and mortality, once annually in August.

2. Determine egg-to-fry survival with respect to the quality of the spawn beds by measurement of sediment deposition, bed load movement, interstitial oxygen and $\mathrm{pH}$ levels, water velocity and depth data.

3. Determine the effect of winter low flows on population density.

4. Determine the structure of the food supply used by salmonids in each creek.

5. Determine the effect of water temperature regimes on trout egg incubation and fish growth.

6. Determine the vulnerability of salmonids to environmental stress in their post-emergent early life history.

7. Present an annual progress report in November.

8. Write a final report synthesizing the results from terms of reference \#1 through \#6.

Time Frame: To be concluded in November, 1986. 


\section{Appendix II. Bouyoucos Mechanical Soil Analysis.}

The determination of the percent sand, silt and clay is called a mechanical analysis. Particles suspended in water settle differentially depending on the amount of surface per unit volume. Clay particles have a high amount of surface area per unit volume and settle slowly, while sand particles settle rapidly because of their low specific surface. After the soil aggregates have been dispersed, this procedure can be used to separate the sand, silt, and clay particles. The rate at which particles settle can be calculated using Stoke's Law. In the Bouyoucos Method, the amount of particles in suspension is determined using a hydrometer to measure the density of the suspension. (In the pipette method, a portion of the suspension is withdrawn by a pipette, evaporated, and the amount of soil determined by weighing).

1. Weigh $50 \mathrm{~g}$ (oven dry) of a fine texture (100 $\mathrm{g}$ of coarse textured) soil and place in a baffled cup. Fill the cup $1 / 2$ full with distilled water and add $5 \mathrm{ml}$ of neutral sodium hexametaphosphate. Calgon powder may be used. Dissolve $10 \mathrm{~g}$ in $100 \mathrm{ml}$ of distilled water and use $10 \mathrm{ml}$ of this solution per sample. Sodium replaces cations (e.g. calcium) on the surface of clay and they precipitate as metaphosphates. The presence of sodium on the surface of the clay promotes an increase in the net negative charge of clay particles which causes the clay particles to disperse by repelling each other.

2. Place the cup on a stirrer and stir until soil aggregates are broken down (6 minutes for sands, 10 minutes for "light" sandy loams, and 15 minutes for other soils). Most soils in their natural condition tend to be aggregated. These aggregates are broken down by chemical (sodium hexametaphosphate) and physical (stirrer) dispersion techniques to enable the sand, silt and clay particles to become separated and free in the suspension.

3. Transfer suspension to a Bouyoucos cylinder and fill to the lower mark with distilled water while the hydrometer is in suspension. (If $100 \mathrm{~g}$ of soil are used, fill to the upper mark).

4. Determine percent sand in the sample.

a. Remove hydrometer and shake suspension vigorously. Place cylinder on desk and record the time. At the end of 20 seconds, carefully insert the hydrometer and read the hydrometer at the end of 40 seconds. Record the reading on the data sheet. 
b. Remove the hydrometer from the suspension. Record the temperature of the suspension.

c. For each degree above $68^{\circ} \mathrm{F}$, add 0.2 to the reading to get the corrected hydrometer reading. For each degree less than $68^{\circ} \mathrm{F}$, subtract 0.2 from the reading. Note: Check hydrometer to obtain temperature at which readings are corrected.

The hydrometer is calibrated so that the corrected reading gives the grams of soil material in suspension. The sand settles to the bottom of the cylinder within 40 seconds, therefore, the 40 second hydrometer reading actually gives the amount of silt and clay in suspension. The weight of sand in the sample is obtained by subtracting the corrected hydrometer reading from the total weight of the sample. The sand percentage is calculated by dividing the weight of sand by the weight of the sample and multiplying by 100 .

5. Determine the percent of clay in the sample.

a. Reshake the suspension and take a reading at the end of 2 hours. Insert the hydrometer just before the reading is made. Take the temperature of the suspension and correct the reading as in $4 \mathrm{c}$. At the end of 2 hours, the silt in addition to the sand has settled out of suspension. The corrected hydrometer reading then represents the grams of clay in the sample. The percent clay is calculated by dividing this weight by the weight of the sample and multiplying by 100 .

6. Calculate the percent of silt in the sample.

a. Find the percent of silt by difference. Subtract the sum of the percentages of sand and clay from 100 to get the percent of silt.

Colloidal - $24 \mathrm{~h}$.

7. Determine the class name or texture of the soil from the textural triangle in Figure 4-1. Sand settles first (0.062 mm diameter and more); $40 \mathrm{sec}$. reading.

Silt settles second $(0.002 \mathrm{~mm}$ diameter to $0.062 \mathrm{~mm}) ; 1 \mathrm{~h}$ reading.

Clay settles third $(0.002 \mathrm{~mm}$ and less $) ; 2 \mathrm{~h}$ reading. 


\title{
Surface Water Characteristics in Alberta Pertinent to Drinking Water
}

\author{
Albert van Roodselaar \\ Alberta Environmental Centre \\ Vegreville, Alberta
}

\begin{abstract}
The availability of surface waters suitable for processing to an acceptable product for human consumption is important as it affects the viability of communities in any given locale. Furthermore, the cost of the final product is tied to the level of treatment exercised. This level is based on the quality of the source and the demands of the community regarding criteria of acceptability.

This presentation examined the above considerations from within the content of water supply availability in Alberta. Parameters such as turbidity, colour, taste and odour, microbiological quality, organic loading and presence of metals were considered. Current treatment practices were discussed with respect to their effectiveness in dealing with variations in the levels of these parameters.

Canadians must be made aware of the special water management requirements to ensure that water quality is acceptable for human consumption. These requirements should be separated from water management needs pertinent to recreational uses, fisheries and other aspects of our waterways.
\end{abstract}




\title{
An Overview of Biological Control of Aquatic Weeds
}

\author{
J.T. O’Donovan and A.S. McClay \\ Alberta Environmental Centre \\ Vegreville, Alberta
}

\section{ABSTRACT}

Overabundant growth of aquatic vegetation is a major problem in irrigation canals in southern Alberta and in recreational lakes and rivers throughout the province. The weeds interfere with water flow in the canals and with fishing and boating in lakes and rivers. At present, aquatic plant management is accomplished mainly with the use of herbicides and to some extent by mechanical methods. However, the number of herbicides available for aquatic use is very limited. For example, the irrigation districts depend almost totally on one herbicide (acrolein) which is extremely toxic to fish. The chemical industry is reluctant to develop new herbicides because of the relatively small market and the environmental sensitivity of aquatic systems. Mechanical methods offer a viable alternative in some situations, but these can be time consuming, laborious and expensive.

For these reasons, interest in biological agents for aquatic weed control has increased considerably. Agents such as herbivorous fish, insects, pathogens, and low-growing, non-problem plant species (e.g. spikerushes) have been used with varying degrees of success in various parts of the world.

\section{INTRODUCTION}

Submerged aquatic macrophytes such as Richardson's pondweed [Potamogeton richardsonii (Benn) Rydb.], sago pondweed ( $P$. pectinatus L.), giant pondweed ( $P$. vaginatus Turez.) and Alisma (Alisma gramineum Lej.) are overgrown in approximately 8000 miles of irrigation canals in southern Alberta (Allan, 1983). Their presence can cause inadequate water flow for efficient irrigation, as well as clogging of sprinkler valves and flooding of farm lands. Pondweed species, as well as milfoil (Myriophyllum exalbescens Fern), coontail (Ceratophyllum demersum L.) and Canadian pondweed (Elodea canadensis Michx.) are also present in numerous recreational lakes and rivers throughout the province where they interfere with boating, fishing and swimming. 
At present, aquatic macrophytes in Alberta are controlled mainly with herbicides. Irrigation districts depend almost exclusively on one herbicide, acrolein, which is the only one registered for weed control while the canals are operational. It is extremely toxic to fish (most are killed at less than $1 \mathrm{ppm}$ while the rate of application is $2.5 \mathrm{ppm}$ ). It provides only temporary control of the weeds and, under some environmental conditions, has been found to be only marginally effective. The approach is costly, therefore, since continuous maintenance and frequent applications are required.

Since the market for aquatic herbicides is small, and the risk associated with their use is high, the chemical industry is reluctant to develop and seek registration for new compounds (for example, only two aquatic herbicides, fluoridone and glyphosate, have been registered in the U.S. in the last ten years). The possibility of cheaper, environmentally safer herbicides being available in the future is slight, therefore. Mechanical control can offer a viable alternative in some situations, but can be costly, time-consuming and laborious. Every aquatic system needs its own adapted machinery and there can be adverse effects on the aquatic ecosystem due to rigorous interruptions of aquatic life-cycles. For example, Haller et al. (1980) estimated that mechanical removal of Hydrilla [Hydrilla verticillata (L.F.) Royle] caused a fish mortality of $32 \%$.

For these reasons, interest in biological control of aquatic weeds has increased considerably in recent years. Control agents such as herbivorous fish, insects, pathogens and non-problem competitive plant species have been used with varying degrees of success in various parts of the world.

\section{OBJECTIVE}

The objective of this paper is to review the use of these control agents and to discuss their potential for aquatic weed control in Alberta.

\section{DISCUSSION}

Control With Herbivorous Fish

The most widely used and most controversial biological control agent for aquatic weeds has been the white amur (Ctenopharyngodon idella Val.), more commonly known as the grass carp. The fish is not related to the European carp (Cyprinus carpio Martyshev) which was introduced into the U.S. in the 1800 s and became a nuisance from a fisheries management 
standpoint in some areas. However, because the white amur is a carp, too, there is a considerable amount of unwarranted negative reaction associated with the introduction of the white amur for aquatic weed control.

The white amur has been introduced into a number of countries including the U.K. (Fowler, 1985), Holland (van Zon, 1977), Egypt (Khattab and El-Gharably, 1986) and parts of the U.S. (Sutton, 1977; Henderson, 1980; Pierce, 1983), where it has successfully controlled a variety of problem aquatic macrophytes in canals, lakes, ponds and rivers. In Holland, the introduction of the fish reduced the cost of aquatic weed control by 50-70\% (Hone, 1973; Janichen, 1974). It is banned, however, in 26 states of the U.S. and in Canada.

The main concerns associated with the introduction of the white amur are that it might reproduce naturally, overpopulate, adversely affect aquatic ecosystems and have a negative effect on sportfish productivity. Much of the concern, however, has been based on subjective speculation rather than scientific fact. The fish is a native of the Amur River region which borders Heilongjiang (Manchuria) and the U.S.S.R., and it requires very specific environmental conditions to spawn. These include a simultaneous rise in water flow and temperature. Reproduction outside its native habitat is unlikely, therefore, and spawning has not been found to occur naturally in the U.K. or western Europe (Fowler, 1985). Spawning has been documented in the lower Mississippi River system in the U.S. (Conner et al., 1980), but it is not clear if the larvae survived to adulthood. Siltation and predation are believed to be major factors limiting their survival. Henderson (1980) considers it highly unlikely that the white amur would be successful enough at both reproducing and surviving to become a dominant species in the U.S.

Numerous studies have been conducted to determine the effects of the white amur on aquatic ecosystems, and the results have been variable (Shireman and Smith, 1983). The effects were found to be either minimal, detrimental or beneficial depending on factors such as stocking rate, macrophyte abundance and structure of the ecosystem. Many of the reported detrimental effects of the white amur on aquatic ecosystems may have been exaggerated due to high stocking densities in laboratory experiments (Michewicz et al., 1972; van Zon et al., 1976). Some variability has also been noted in field trials. In a five-year study of 31 lakes in Arkansas, the overall fish populations showed a declining trend in six lakes, an upward trend in eight lakes and no significant change in 17 lakes (Pierce, 1983). If anything is to be gleaned from such studies it is that there are no clear-cut detrimental effects of the white amur on aquatic ecosystems. 
Pierce (1983) concluded that since the introduction of the fish into public waters in Arkansas in 1970, there have been no adverse effects on native fish populations. On the contrary, with respect to angling, the white amur has modified aquatic ecosystems very favourably. As well as maintaining aquatic vegetation at tolerable levels, it has become part of a thriving state fishery. Similarly, in the U.K., it has been confirmed that the white amur is highly unlikely to affect freshwater environments more seriously than mechanical or chemical methods which are currently routinely employed (Moore, 1983). In drainage channels in the Fens of South Lincolnshire, positive ecological advantages were associated with the introduction of the white amur (Honnor, pers. comm.). There was no sudden impact on the environment as with other methods, and floral diversity was encouraged.

In view of the contradictory reports on the effects of the white amur on aquatic ecosystems, it appears that the only effect on the environment that can be predicted with certainty is the removal of aquatic vegetation. The fish is a voracious, non-selective consumer of aquatic weeds, but does exhibit food preferences. Young fish tend to favour softer, younger plant tissue, but as they grow they become less selective and feed on older, more fibrous, tissue (Bailey, 1972). Generally, submerged weeds such as Potamogeton and Hydrilla spp. are favoured over emergent species such as water hyacinth [Eichhornia crassipes (Martius) Solms] and nymphaeid species. Temperature has a major influence on feeding and also affects food preference (Bailey, 1972). The white amur does not feed at water temperatures below $10^{\circ} \mathrm{C}$, and consumption increases as water temperatures increase above $13^{\circ} \mathrm{C}$ (Pierce, 1983). At $20^{\circ} \mathrm{C}$, the fish may consume $50 \%$ of their body weight per day and this may increase to $100 \%$ at $22^{\circ} \mathrm{C}$ (Opuszynski, 1972).

In the U.K., most of the failures of the white amur in effectively controlling aquatic weeds have been attributed to low water temperatures (Fowler, 1985). The fish tends to consume large amounts of weeds only when the water temperature is well above $16^{\circ} \mathrm{C}$. This usually occurs during June, July and August, at which time weed growth is well established. However, the introduction of the fish as a means of aquatic weed control in the U.K. has been generally successful and cost-effective (Honnor, pers. comm.).

There has been a concerted effort to develop a sterile hybrid form of the white amur to eliminate any possibility of spawning in the areas of introduction. Hybrids were first produced in the U.S.S.R. (Aliev, 1965) and in Hungary (Bakos et al., 1978) by fertilizing eggs of the 
female white amur with sperm from the bighead carp (Aristichthys nobilis Rich.). The $\mathrm{F}_{1}$ hybrid is a sterile triploid with a somatic chromosome number of $2 \mathrm{~N}=72$, compared to $2 \mathrm{~N}=48$ for each parent (Lynch, 1979; Marian and Krasznai, 1978). Some studies have indicated that it retains the voracious appetite for aquatic weeds of the female parent (Kilambi and Zdinak, 1980; Cassani, 1981), while another study conducted in Florida reported slower growth, lower feeding rates and higher mortality of the hybrids compared to the parents (Osborne, 1982). At present, a five-year study is underway at the University of Washington, Seattle, to investigate the effectiveness of the triploid hybrid in controlling aquatic weeds and its impact on the aquatic environment (Pauley et al., 1985). Techniques for rapid identification of diploid and triploid fish are also being developed (Bonar et al.,1984). Although the hybrid is now being produced commercially in Arkansas (Pierce, 1983), there have been problems with intensively culturing it at the University of Florida (Opuszynski et al., 1985). Survival of hybrids was poor, possibly due to genetic abnormalities. However, other projects are currently underway at the University of Florida to develop better methods for intensively culturing sterile white amur. One method involves "temperature shocking" fish eggs to induce sterility by immersing them in warm or cold baths at regular intervals, thus inducing an extra set of chromosomes and producing a sterile fish (Anonymous, 1985).

In view of the evidence to date, it is highly unlikely that the white amur would pose a serious threat to aquatic ecosystems if it were introduced into Alberta waterways. The unlikelihood of reproduction, coupled with the susceptibility of the larvae to predation, render the chances of the fish becoming a dominant species extremely slim. These possibilities become even more remote with the sterile hybrid. There is no information available at present on the effectiveness of the fish in controlling aquatic weeds under the environmental conditions that prevail in the province during spring and summer or on its ability to survive Alberta winters under ice in lakes and rivers. They have survived winters in Arkansas, Kansas and Iowa, however, and are reportedly very eurythermal (Pierce, 1983). Since the irrigation canals in southern Alberta are drained prior to winter, special management strategies would have to be developed for removing the fish before draining, and restocking them in the spring.

The effectiveness of the white amur as a biocontrol agent for aquatic weeds in Alberta will always remain a mystery unless it is introduced and assessed on an experimental basis. In view of the problems associated with the use of acrolein in the irrigation canals, and the general 
lack of economical, environmentally safe methods for aquatic weed control in the province, it is time to reconsider introducing a sterile form of the white amur on a research basis to assess its feasibility for controlling aquatic weeds.

\section{Control With Insects}

The most notable successes in biological control of emergent or floating aquatic weeds have been achieved by the so-called classical approach, i.e. the introduction of host-specific, natural enemies to combat an exotic weed which has become established outside its native range. To date, all the biocontrol agents responsible for successful control by this approach have been insects. In situations in which it is applicable, this type of biological control is by far the most cost-effective since, once established, it provides permanent control with no need for recurring treatments.

A biological control program of this type involves three main phases: (1) exploration in the native range of the weed to discover candidate biological control agents; (2) screening of candidate agents to determine their host specificity and, thus, whether they can be introduced without danger to non-target plants; and (3) the release and monitoring of the biocontrol agents to determine establishment and effects on the target weed.

The earliest substantial success in biological control of an aquatic weed was achieved against alligatorweed [Alternanthera philoxeroides (Martius) Grisebach]. This is a perennial weed native to South America, which grows both as rooted plants along stream and river banks and as floating mats. It has spread widely in tropical and subtropical regions of the world.

By 1960, alligatorweed had become a major problem in the southern U.S.A., and the U.S. Department of Agriculture began studies on the weed's natural enemies in South America. These surveys identified three potential biocontrol agents which were introduced into the U.S.A. (Maddox et al., 1971). Two species, the flea-beetle, Agasicles hygrophila Selman \& Vogt and the moth, Vogtia malloi Pastrana are now well established throughout the weed's U.S. range and are effectively controlling it in many areas. The flea-beetle feeds on the foliage of alligatorweed, while the moth bores into the stems, causing them to collapse. The effectiveness of the agents varies from area to area and year to year, but in Florida, Louisiana and Texas other control measures for alligatorweed are now generally unnecessary (Julien, 1981). Alligatorweed has also been controlled in aquatic habitats in New South Wales, Australia, by the introduction of the same agents (Julien, 1981). 
Water hyacinth is also native to South America. This floating weed, which can form extensive mats obstructing navigation and blocking the flow of irrigation canals, is now widespread in warmer regions. Surveys of its natural enemies were carried out in South America, and several species were identified as possible biological control agents (Bennett and Zwoelfer, 1968). The most successful of these has been the weevil, Neochetina eichhorniae Hustache. This insect has been responsible for complete or substantial control of water hyacinth in the U.S. (Julien, 1982), Australia (Wright, 1981) and the Sudan (Beshir and Bennett, 1985), and has been introduced to many other countries where water hyacinth is a problem.

The most recent and spectacular success was achieved against another tropical floating weed, the water fern (Salvinia molesta Mitchell) (Thomas and Room, 1986). This plant can form floating mats up to $1 \mathrm{~m}$ thick and can double in size in only 2.2 days. In the Sepik River floodplain in Papua New Guinea it threatened the livelihood of 80000 people who were completely dependent on lakes and rivers for access to food, fishing grounds, schools and medical facilities. It is also a problem in Australia, Sri Lanka and several African countries. The weed was initially misidentified as S. auriculata Aubl, and surveys for natural enemies were carried out in the native range of that species in northern South America. The weevil Cyrtobagous singularis Hustache was introduced to Australia and established, but did not bring about significant control. After the weed was recognized as an undescribed species, now known as S. molesta, and its native range in S.E. Brazil had been discovered, further surveys resulted in the introduction of another population of Cyrtobagous. This species produced rapid, dramatic control, and was later found to be an undescribed species, now known as C. salviniae Calder and Sands. This weevil, introduced to Papua New Guinea in 1982, destroyed 2 million tonnes of the weed within 2 years, once again allowing travel by canoe in the Sepik River floodplain (Thomas and Room, 1986). This case illustrates the importance of accurate species identification of both the target weed and the candidate biocontrol agents for successful biological control.

The aquatic weed problems of Alberta are different from the cases described in that the plants involved are mainly submerged species and native to the province and to North America. So far, examples of successful control of aquatic weeds with insects have been limited to floating, emergent species. It is possible that differences in the ecological niches of submerged species may preclude their control with insects. It is more likely, however, that the absence of examples of control of submerged exotics with insects is due to limited research with these 
species (Room, 1986). Theoretically, there is scope for biological control of a native weed by introducing agents from other parts of the native range of that weed. For instance, host-specific insects which do not occur in North America may be attacking Potamogeton spp. in Europe or Asia. These would be possible candidates as biological control agents. However, it should also be remembered that once an insect biocontrol agent has been introduced, it is not feasible to keep it confined to a restricted area such as a given irrigation canal system. If successfully established, it is likely that it will spread to any adjacent regions where the host plant is available. In some of these areas, the target weed species may play an important role in the ecology of natural water bodies, for instance in providing food for waterfowl. The importance of the target weed species in natural ecosystems would need to be evaluated carefully before any decision was made to introduce insects as biological control agents.

\section{Control With Pathogens}

There has been considerable interest in recent years in the use of plant pathogens for weed control. The pathogens are formulated as mycoherbicides and applied to the target species in the same way as conventional herbicides. Although pathogens may be present on their host weeds in nature, they are not abundant enough to give effective control. Plants showing symptoms of disease are collected and the pathogen is isolated, artificially cultured and applied to the weed at high rates. Most of the successes thus far have been with terrestrial weeds, and two mycoherbicides have already been registered and are in commercial use in the U.S.

Attempts have also been made to apply this technology to aquatic weeds. Most of the pathogens isolated thus far have been fungi. The most promising has been Cercospora rodmanii Conway which has been found to cause a high degree of damage in the floating species water hyacinth (Conway, 1976; Conway and Freeman, 1976). The fungus was most effective when combined with another fungus, Acremonium zonatum (Saw.) W. Gams, or with insects like the noctuid moth, Arzama densa Walker and the weevil, Neochetina eichhorniae. Fungi which attack submerged aquatic weeds have also been identified. In the 1920's, the decline of sago pondweed in Virginia and North Carolina was shown to be due largely to infection by the fungus, Rhizoctonia solani Kueltn (Bourn and Jenkins, 1928). The fungi, Fusarium sporotrichioides Sherb and Acremonium curvulum W. Gams showed the most promise for control of Eurasian watermilfoil (Myriophyllum spicatum L.) in Wisconsin (Andrews and Hecht, 1981; Andrews et al., 1982). However, it was concluded that the poor ability of these fungi to penetrate the plant 
may limit their usefulness as biocontrol agents. The fungus, Pythium carolinianun Matt., may have potential as a biocontrol agent for parrotfeather (Myriophyllum brasiliense Camb.), a species related to Eurasian watermilfoil (Bernhardt and Duniway, 1984). It was also isolated from several Potamogeton species including sago pondweed, but its potential as a control agent for these species was not determined.

The search for diseases of submersed weeds has focused mainly on those which attack foliage. In recent studies, however, asexual propagules of curlyleaf pondweed (P. crispus L.) were found to be frequently rotted when collected from drained irrigation canals in California (Bernhardt and Duniway, 1986). Three of the fungi isolated from the propagules, Fusarium crookwellense Burgess, Nelson and Tousssoun, Papulaspora aspera Bern. and Dun and Geotrichum sp., were found to colonize healthy propagules of pondweeds and healthy tubers of Hydrilla sp. when inoculated under laboratory conditions. Under field conditions, curlyleaf pondweed propagules inoculated with debris from any of the three fungal species were significantly more decayed than noninoculated propagules.

Some of these fungi may have potential as biological control agents for pondweeds and other submerged aquatic macrophytes in Alberta. Those which attack asexual propagules look particularly promising. Tuber production is very important in the life cycle of sago pondweed and is a major mechanism in enabling the plant to escape incidental control measures such as the application of acrolein to the water in the irrigation canals. The herbicide does not affect the tubers which survive in the sediment and result in future growth. It is also possible that some of these fungi are already associated with submerged aquatic macrophytes in irrigation canals and other water bodies in Alberta. Others with potential for biological control may also be present. A search for pathogenic agents has not been conducted in the province. Such a study would be well worthwhile and may result in an effective tool for aquatic plant management in Alberta. Control With Non-Problem Plant Species

A promising economical and enduring method for managing aquatic macrophytes has been investigated in California (Yeo, 1980; Yeo and Thurston, 1984). Three low-growing non-problem aquatic plants, dwarf spikerush [Eleocharis coloradoensis (Britt.) Gilby], barbed spikerush [E. parvula (R. and S.) Link] and slender spikerush [E. acicularis (L.) R. and S.] have been found to invade areas occupied by submersed, problem aquatic weeds and slowly displace them. The spikerush species form dense mats of lawn-like sod underwater $(Y e o, 1980)$ and are believed to 
be allelopathic (Frank and Dechoretz, 1980). Submerged macrophytes affected by the spikerush include American pondweed, sago pondweed and Eurasian watermilfoil (Yeo and Thurston, 1984). Displacement is fastest in canals and reservoirs that have a periodically fluctuating water level or that are emptied during the winter.

Slender spikerush is present in parts of the irrigation canals in southern Alberta but there is no evidence at present that it is reducing the growth of problem aquatic macrophytes. A study is currently under way there to determine the feasibility of establishing slender spikerush to control pondweed species. This should determine whether the method has any promise as a means of aquatic plant management in Alberta.

\section{SUMMARY AND CONCLUSIONS}

Due to a lack of effective, economical and environmentally safe methods for aquatic weed management, interest in biological control has increased considerably. Agents such as herbivorous fish, insects, pathogens and non-problem aquatic plants have been used with varying degrees of success in various parts of the world. The white amur or grass carp has been the agent most successful in controlling a wide range of submerged species, while insects have shown the most success as control agents for specific emergent or floating species. The use of pathogenic fungi and non-problem plant species (spikerushes) has been less spectacular but this situation may change as research continues.

In Alberta, the only biocontrol agent currently under investigation is slender spikerush. That study should determine if establishment of the species on a large scale in the irrigation canals is feasible and whether it has potential for displacement of pondweeds. There is, however, a need for considerably more research with other biocontrol agents. The white amur looks most promising, but its ability to survive Alberta winters and to feed at the temperatures which prevail in the province should first be assessed in research trials. With the development of sterile forms of the fish, concern about spawning and over-population are no longer relevant. However, there appears to be a need to develop improved methods of intensively culturing hybrid and other sterile forms of the fish. A survey of aquatic weeds in Alberta for potential pathogenic agents would also be well worth the undertaking and may result in an effective long-term management tool for aquatic weeds. 
Finally, effective aquatic plant management in Alberta may not be possible with just one biocontrol agent or management method. Some situations may require an integrated approach to the problem involving one or more biocontrol agents as well as chemical and/or mechanical methods. Determination of the best management strategy, however, will require several years of carefully conducted research.

Acknowledgements

We are grateful to Dr. D. Allen, Mr. R. Burland and Dr. R. Varma for helpful suggestions and for providing slides for the presentation.

\section{REFERENCES}

Aliev, D.S. 1961. Breeding of white amur (Ctenopharyngodon idella), silver carp (Hypophthalmichthys moltrix) and bighead carp (Aristichthys nobilis) in the Amu-Darya Basin. Vopr. Ikhtiol. 5:593-599. (In Russian).

Allan, J.R. 1983. Aquatic plant management needed for irrigation canals. Weekly Letter, Agric. Can. Res. Stn., Lethbridge, Alberta.

Andrews, J.H., and E.P. Hecht. 1981. Evidence for the pathogenicity of Fusarium sporotrichioides to Eurasian watermilfoil (Myriophyllum spicatum). Can. J. Bot. 50:1069-1077.

Andrews, J.H., E.P. Hecht, and S. Bashirion. 1982. Association between the fungus Acremonium curvulum and Eurasian watermilfoil, Myriophyllum spicatum. Can. J. Bot. 60:1216-1221.

Bailey, W.M. 1972. Arkansas evaluation of the desirability of introducing the white amur $(C$. idella Val.) for control of aquatic weeds. 102nd AFS Meeting, Hot Springs, Arkansas, Sept. 10-15, 1972.

Bakos, J., Z. Krasznai, and T. Marian. 1978. Cross-breeding experiments with carp, tench and Asian phytophagous cyprinids. Aquaculture Hungarica (Szarvas) 1:51-57.

Bennett, F.D., and H. Zwoelfer. 1968. Exploration for natural enemies of the water hyacinth in northern South America and Trinidad. Hyacinth Control J. 8:10-13.

Bernhardt, E.A., and J.M. Duniway. 1984. Root and stem rot of parrotfeather (Myriophyllum brasiliense) caused by Pythium carolinianum. Plant Disease 68:999-1003.

Bernhardt, E.A., and J.M. Duniway. 1986. Decay of pondweed and Hydrilla hibernacula by fungi. J. Aquat. Plant Manage. 24:20-24. 
Beshir, M.O., and F.D. Bennett. 1985. Biological control of water hyacinth on the White Nile, Sudan. Proc. VI Int. Symp. Biol. Contr. Weeds, Vancouver, British Columbia. pp. 491-496.

Bonar, S., G.L. Thomas, G.B. Pauley, K. Matthews, and A. Unthank. 1984. Evaluation of ploidy and separation techniques with the Grass carp (Ctenopharyngodon idella), a potential biological control for aquatic macrophytes in Washington State. Weed Sci. Soc. of Amer. Abstracts 25:44.

Bourn, W.S., and B. Jenkins. 1928. Rhizoctonia disease on certain aquatic plants. Bot. Gaz. $85: 413-429$.

Cassani, J.R. 1981. Feeding behaviour of underyearling hybrids of the grass carp, Ctenopharyngodon idella and the bighead, Hypophthalmichthys nobilis on selected species of aquatic plants. J. Fish Biol. 18:127-133.

Conner, J.V., R.P. Gallagher, and M.F. Chatry. 1980. Larval evidence for natural reproduction of the grass carp (Ctenopharyngodon idella) in the lower Mississippi River. In Proc. 4th Ann. Larval Fish Conf. Oxford, Michigan. pp. 1-19.

Conway, K.E. 1976. Cercospora rodmanii, a new pathogen of water hyacinth with biological control potential. Can. J. Bot. 54:1079-1083.

Conway, K.E., and T.E. Freeman. 1976. The potential of Cercospora rodmanii as a biological control for water hyacinth. Proc. IV Int. Symp. Biol. Contr. Weeds, Gainsville, Florida. pp. 207-209.

Fowler, M.C. 1985. The present status of grass carp (Ctenopharyngodon idella) for the control of aquatic weeds in England and Wales. Proc. VI Int. Symp. Biol. Contr. Weeds, Vancouver, British Columbia. pp. 537-542.

Frank, P.A., and N. Dechoretz. 1980. Allelopathy in dwarf spikerush (Eleocharis coloradoensis). Weed Sci. 28:499-505.

Haller, W.T., J.V. Shireman, and D.F. Duraut. 1980. Fish harvest resulting from mechanical control of Hydrilla. Trans. Am. Fish. Soc. 109:517-520.

Henderson, S. 1980. The use of grass carp for control of aquatic vegetation in Arkansas. Proc. V Int. Symp. Biol. Contr. Weeds, Brisbane, Australia. pp. 287-289.

Hone, V. 1973. Experiment in the use of the grass carp for biological weed control in water courses. Weed Abstr. 24, Abstract 3020.

Honnor, J. Personal Communication. Engineer, Welland and Deeping Internal Drainage Board, S. Lincolnshire, U.K. 
Janichen, H. 1974. Senkung der Kosten bei der Wasserpflanzerbekampfung durch den Amurkarpfen (C. idella). Jur. Binnenfisch D.D.R. 21:85-89.

Julien, M.H. 1981. Control of aquatic Alternanthera philoxeroides in Australia; another success for Agasicles hygrophila. Proc. V. Int. Symp. Biol. Contr. Weeds, Brisbane, Australia. pp. 583-588.

Julien, M.H. 1982. Biological control of weeds: a world catalogue of agents and their target weeds. CAB International, Slough, England. pp. VI-108.

Khattab, A.F., and Z. El-Gharably. 1986. Management of aquatic weeds in irrigation systems with special reference to the problem in Egypt. Proc. EWRS/AAB 7th Symp. on Aquatic Weeds. pp. 199-205.

Kilambi, R.V., and A. Zdinak. 1980. Food preference and growth of grass carp, Ctenopharyngodon idella and hybrid carp, C. idella Female X Aristichthys nobilis Male. Proc. V Int. Symp. Biol. Contr. Weeds, Brisbane, Australia. pp. 281-286.

Lynch, T. 1979. White amur experience leads to development of grass carp hybrid. Aquaculture Mag. 6:33-36.

Maddox, D.M., L.A. Andres, R.D. Hennessey, R.D. Blackburn, and N.R. Spencer. 1971. Insects to control alligatorweed, an invader of aquatic ecosystems in the United States. Bio Science 21:985-991.

Marian, T., and Z. Krasznai. 1978. Karyological investigations on Ctenopharyngodon idella and Hypophthalmichthys moltrix and their cross breeding. Aquacultura Hungarica (Szarvas) 1:44-50.

Michewicz, J.E., D.L. Sutton, and R.D. Blackburn. 1972. The white amur (Ctenopharyngodon idella) for aquatic weed control. Weed Sci. 20:106-110.

Moore, C.A.M. 1983. The ecological effects of grass carp (Ctenopharyngodon idella Val.) introduced into enclosures in a small lake. Ph.D. thesis, Reading University, U.K.

Opuszynski, K. 1972. Use of phytophagous fish to control aquatic plants. Aquaculture 1:61-74.

Opuszynski, K., J.V. Shireman, F.J. Aldridge and R. Rottmann. 1985. Intensive culture of grass carp and hybrid grass carp larvae. J. Fish Biol. 26:563-573.

Osborne, J.A. 1982. The potential of the hybrid grass carp as a weed control agent. J. Freshwat. Ecol. 1:353-360.

Pauley, G.B., G.L. Thomas, S.Bonar, K. Matthews, and A. Unthank. 1984. Overview of the use of triploid grass carp (Ctenopharyngodon idella) as a biocontrol agent for macrophytes in Lake Washington. Weed Sci. Soc. Am. Abstracts 25:43. 
Pierce, B.A. 1983. Grass carp in the United States: A Review. Envir. Manage. 7:151-160.

Room, P.M. 1986. Biological control is solving the world's Salvinia molesta problem. Proc. EWRS/AAB 7th Symp. on Aquatic Weeds. pp. 271-276.

Shireman, J.V., and C.R. Smith. 1983. Synopsis of biological data on the grass carp Ctenopharyngodon idella (Cuvier and Valenciennes, 1844). FAO Fisheries Synopsis No. 135.

Sutton, D.L. 1977. Grass carp (Ctenopharyngodon idella Val.) in North America. Aquat. Bot. 3:157-164.

Thomas, P.A., and P.M. Room. 1986. Taxonomy and control of Salvinia molesta. Nature 320:581-584.

University of Florida. 1985. Sterile grass carp being cultured. Aquaphyte, published by the Centre for Aquatic Weeds, Vol. 5, No. 1, p. 8.

van Zon, J.C.J. 1977. Grass carp in Europe. Aquat. Bot. 3:143-155.

van Zon, J.C.J., W. van der Zweede, and B.J. Hoogers. 1976. The grass carp; effects and side-effects. Proc. IV Int. Symp. Biol. Contr. Weeds, Gainsville, Florida. pp. 251-255.

Wright, A.D. 1981. Biological control of water hyacinth in Australia. Proc. V Int. Symp. Biol. Contr. Weeds, Brisbane, Australia. pp. 529-535.

Yeo, R.R. 1980. Spikerush may help control waterweeds. California Agriculture, April 1980. P. 12-13.

Yeo, R.R., and J.R. Thurston. 1984. The effect of dwarf spikerush (Eleocharis coloradoensis) on several submersed aquatic weeds. J. Aquat. Plant Manage. 22:52-56. 


\title{
Automated GC/MS Techniques for Chemical Speciation in the Aquatic Environment
}

\author{
G. E. Prill, L. Uchman, K. Hill, and J. V. Headley \\ Research \& Methods Development Branch, Chemistry Division \\ Alberta Environmental Centre \\ Vegreville, Alberta
}

\section{ABSTRACT}

The fate and environmental impact of chemicals in the aquatic environment are the subject of much concern. Gas chromatography/mass spectrometry (GC/MS) has received widespread usage in such studies, and is established as a powerful analytical tool.

At the authors' laboratory, automated techniques have been developed for the identification and quantification of a wide range of organics in water, wastewater, sediment and biological samples. For example, the classes of compounds include: aliphatic hydrocarbons, aromatic monocyclic and polycyclic hydrocarbons, chlorinated pesticides, petroleum hydrocarbons, phenolics, polychlorinated biphenyls, phthalate esters, organosulphur compounds, organophosphates, trihalomethanes and resin acids.

In this paper, applications are described for specific studies of: (1) the analysis of phthalate esters in potable water; (2) batch sample analysis of volatile organics in surface water; (3) the screening of organics in treated pulp mill effluents; and (4) the bioaccumulation of chlorinated organics in fish.

\section{INTRODUCTION}

The term "speciation" will be used to describe the qualitative or quantitative determination of chemicals. The impact of environmental contaminants has caused public concern to the extent that polychlorinated biphenyls (PCBs), dioxins and pentachlorophenol are now household names. Environmental agencies such as the Alberta Environmental Centre commonly face public questions pertaining to the fate of pesticides, the impact of discharging industrial waste into the aquatic environment and the health effects of plasticizers and trihalomethanes in potable water.

To provide answers to these questions, extensive measurements are performed to determine the fate of the organics. Details of the fate processes of interest are discussed elsewhere (Moore and Ramamoorthy, 1984a). The enormous volume of analyses presents a 
challenge to environmental laboratories and has resulted in the development of various automated techniques.

The non-specialist reader is reminded that GC/MS analyses involve three basic stages: extraction of the organics from the samples, data acquisition and data reduction. The data reduction is particularly well suited to automation and has received the most extensive development. In this paper, examples have been selected to describe the automation of all the three stages, pertaining to four specific applications.

The scope of this paper does not permit a comprehensive review. The speciation of organics and heavy metals in the environment has been reviewed recently in two volumes. They are available in the literature (Moore and Ramamoorthy, 1984a,b).

\section{Analysis of Phthalate Esters in Potable Water}

The use of plasticizers is an integral part of today's society and, consequently, the occurrence of phthalate esters in the environment is widespread. As illustrated in Table 1, human beings have a greater tolerance to plasticizers than aquatic species. For example, high levels of phthalate esters in patients arising from the storage of blood in plastic containers is evidently considered permissible.

Table 1. Permissable concentration $\mu \mathrm{g} / \mathrm{L}$ of commonly occurring phthalate esters in water (Sittig, 1985).

\begin{tabular}{lccc}
\hline \hline & Aquatic Acute & Aquatic Chronic & Human \\
\hline \hline Dibutyl Phthalate & 940 & 2944 & 34000 \\
$\begin{array}{l}\text { Diethylhexyl } \\
\text { Phthalate }\end{array}$ & -- & -- & 15000 \\
Dimethyl Phthalate & -- & -- & 313000 \\
\hline \hline
\end{tabular}

At the Research \& Methods Development Group (R\&MD), automated procedures have been developed for the analysis of 16 phthalate esters in surface water. The method employs capillary gas chromatography mass spectrometry with automated data acquisition and automated target compound analysis (Headley, 1985, 1987).

Software employed for quantitative analysis generally use the U.S. Environmental Protection Agency (EPA) protocols 624 and 625 for the analysis of extractable and purgeable 
priority pollutants, respectively (Federal Register, 1979). These protocols can be employed not only for priority pollutants, but can be used for any target compounds.

Identification is based on first locating the unknown compound in a given relative retention-time window, in, for example, the total-ion GC/MS profile.

Identification is then confirmed by matching the relative abundances of two or more ions in the mass spectrum of the unknown with the same ions in the mass spectrum of the known standard compound. The amount of the identified compound is calculated using the equation:

$$
C_{x}=\frac{A_{x}}{A_{I S}} \cdot C_{I S} \cdot R R F
$$

$\mathrm{C}_{\mathrm{x}}$ and $\mathrm{C}_{\mathrm{IS}}$ are the concentrations of component $\mathrm{x}$ and the closest eluting internal standard; $\mathrm{A}_{\mathrm{x}}$ and $A_{I S}$ are the areas of the corresponding extracted ion profiles; and RRF is the detector relative response-factor of component $\mathrm{x}$. In this calculation, the abundance of a specific ion in the mass spectrum of the component is compared with that of a known amount of the standard compound. Therefore, this quantification is based on the specific or extracted ion profiles of the compounds of interest.

The results of the GC/MS analyses are computed directly into a client report, an example of which is shown in Appendix 1. The client report contains details of the sample submission and a number of qualifiers to describe the confidence and quality associated with a given result.

Full details of the extraction procedures, recoveries, detection limits, quality control and quality-assurance protocols are given elsewhere (Alberta Environmental Centre, 1987).

Batch Analysis of Trihalomethanes and Volatile Organics in Water

In contrast to the environmental impact of phthalate esters, the permissible levels of trihalomethanes in humans are relatively low compared to aquatic species, as shown in Table 2. Rapid and sensitive analyses are therefore required to monitor the levels of trihalomethanes in drinking water throughout the province.

Table 2. Permissible concentrations ( $\mu \mathrm{g} / \mathrm{L})$ of chloroform in water (Sittig, 1985).

\begin{tabular}{lccc}
\hline \hline & Aquatic Acute & Aquatic Chronic & Human \\
\hline \hline Chloroform & 28900 & 1240 & 0 \\
& & $\begin{array}{c}\text { Cancer risk at } 1.9 \mu \mathrm{g} / \mathrm{L} \\
1 \text { in } 100000\end{array}$ \\
\hline \hline
\end{tabular}


To respond to this challenge, a method has been developed employing purge-and-trap analyses and a Tekmar autosampler equipped for batch analysis of 10 samples. The volatile organics are purged from the water sample using an inert gas. A tenax GC trap adsorbs the volatile compounds purged from the sample. This is followed by thermal desorption of the volatiles onto the gas chromatograph column and subsequent analysis using capillary gas chromatography. Data reduction and generation of client reports are as described above. Full details of the methodology are given elsewhere (Alberta Environmental Centre, 1987).

The complexity of the GC/MS ion-profiles and a list of the volatile organics in the analytical scan are given in Table 3.

\section{Screening of Organics in Pulp Mill Effluents}

A wide variety compound classes found in biodegraded kraft pulp mill effluents are known to be toxic to classes of fish. Some examples are listed in Table 4. The wastewater samples are complex mixtures, with some samples containing more than 200 components. This complexity renders the analysis difficult and time-consuming. The interpretation of the GC/MS data can present a challenge even to experienced organic mass spectroscopists.

Automated data reduction techniques can minimize this problem, however. A library of compounds actually observed in the wastewater samples has been compiled to form a GC/MS data base of mass spectra and relative retention times. This library contains over 250 organics, compiled under the following classes: resin acids, phenolics, other acids and base/neutral compounds.

Compounds are screened using the same techniques described above, to generate a client report. A list of screened compounds is given in Appendix 1. Unlike the previously described analysis, the screening is based on two categories of compounds. These categories are: (1) compounds for which authentic standards are available; and (2) target compounds which have only been tentatively identified from a study of their mass spectra. Quantification of the latter is semi-quantitative, therefore, and employs relative response factors of compounds of similar physical and chemical properties.

This screening process has been used successfully to investigate the colour removal in bleached kraft mill effluents, the results of which have been reported elsewhere (Davies et al., 1986). 
Table 3. Volatile organic in surfaces water scan - list of compounds and detection limits.

\begin{tabular}{|c|c|}
\hline Compound & Detection Limit $\mu \mathrm{g} / \mathrm{L}$ (ppb) \\
\hline Benzene & 1.0 \\
\hline Bromodichloromethane & 1.0 \\
\hline Bromoform & 5.0 \\
\hline Bromomethane & 1.0 \\
\hline Carbon tetrachloride & 1.0 \\
\hline Chlorobenzene & 1.0 \\
\hline Chloroethane & 1.0 \\
\hline 2-chloroethoxyethylene & 4.0 \\
\hline Chloroform & 1.0 \\
\hline Dibromochloromethane & 1.0 \\
\hline Dibromomethane & 1.0 \\
\hline 1,2-Dichlorobenzene & 1.0 \\
\hline 1,3-Dichlorobenzene & 1.0 \\
\hline 1,4-Dichlorobenzene & 1.0 \\
\hline 1,1-Dichloroethane & 1.0 \\
\hline 1,2-Dichloroethane & 1.0 \\
\hline 1,1-Dichloroethylene & 1.0 \\
\hline trans-1,2-Dichloroethylene & 1.0 \\
\hline 1,2-Dichloropropane & 1.0 \\
\hline cis-1,3-Dichloropropylene & 3.0 \\
\hline trans-1,3-Dichloropropylene & 3.0 \\
\hline Ethyl benzene & 1.0 \\
\hline Methylene chloride & 20 \\
\hline Styrene & 1.0 \\
\hline 1,1,2,2-Tetrachloroethane & 5.0 \\
\hline Tetrachloroethylene & 3.0 \\
\hline Toluene & 1.0 \\
\hline 1,1,-Trichloroethane & 1.0 \\
\hline 1,1,2-Trichloroethane & 1.0 \\
\hline Trichlorofluoromethane & 1.0 \\
\hline Vinyl chloride & 30 \\
\hline o-Xylene & 1.0 \\
\hline$\underline{\mathrm{m}}$-Xylene & 1.0 \\
\hline p-Xylene & 1.0 \\
\hline
\end{tabular}


Table 4. Compounds toxic to fish in pulp and paper mill effluents (Walden and Howard, 1981).

\begin{tabular}{ll}
\hline \hline Compound & Example \\
\hline \hline Resin Acids & Abietic \\
Chlorinated Resin Acids & Monochlorodehydroabietic \\
Unsaturated Fatty Acids & Oleic \\
Chlorinated Phenols & Trichlorocatechol \\
Diterpene Alcohols & Pimarol \\
Lignin Degradation Products & Eugenol \\
\hline \hline
\end{tabular}

Table 5. Toxicities of chlorinated phenolics ( $\mathrm{pH} 6.4-8.1$, Temperature $10-18^{\circ} \mathrm{C}, 10-300 \mathrm{mg}$ $\mathrm{CaCO}_{3} / \mathrm{L}$.

\begin{tabular}{lcc}
\hline \hline \multicolumn{1}{c}{ Compounds } & Fish Species & Toxicity $96-\mathrm{LCC}_{50}, \mathrm{mg} / \mathrm{L}$ \\
\hline \hline Phenol & Rainbow trout & 7.7 \\
Pentachlorophenol & Sockeye fry & 0.096 \\
Tetrachlorocatechol & Sockeye fry & $0.8-0.9$ \\
3,4,5-Trichloroguaiacol & Rainbow trout & 0.75 \\
\hline \hline
\end{tabular}

Chlorinated Organics in Fish

It is well established that phenolic compounds can have a detrimental impact on aquatic species, as exemplified by the data summarized in Table 5. Sensitive trace analyses can be optimized using automated sequences or procedures employing selected-ion monitoring (SIM). The SIM procedure (Table 6) is a standard feature on most modern GC/MS instruments and is well suited for quantitative analyses of target compounds.

\section{CONCLUSION}

State-of-the-art automated techniques for GC/MS analyses have been developed for chemical speciation in the aquatic environment. The methodology requires sophisticated software, an experienced data base manager and finally manual validation of analytical reports. 
The automation is well suited, however, for GC/MS studies and helps the laboratory maintain high-quality data while sustaining high productivity.

Table 6. $\quad$ Summary of selected ion monitoring GC/MS procedure.

\begin{tabular}{lccc}
\hline \hline \multicolumn{1}{c}{ Compound } & $\begin{array}{c}\text { Compound } \\
\text { No. }\end{array}$ & Selected Ions & $\begin{array}{c}\text { Dwell Time per Ion } \\
\text { (ms) }\end{array}$ \\
\hline \hline Methyl chloro cyclohexadiene & $(2)$ & $113,115,128$ & 100 \\
Mono chloro substituted organic & $(8)$ & $122,123,61$ & 100 \\
Mol. Wt. = 122 & & & \\
Dichlorodimethyl sulphone & $(3)$ & $83,85,147$ & 100 \\
Chloro propyl substituted & $(9)$ & $135,137,93$ & 100 \\
organic & & & \\
Mol. Wt. = 186 & $(4)$ & $198,196,200$ & 30 \\
Trichlorophenol & $(5)$ & $139,141,156$ & 100 \\
Chlorobenzoic Acid & $(1)$ & $232,230,234$ & 100 \\
Tetrachlorophenol & $(6)$ & $211,213,226$ & 100 \\
Trichloroguaiacol & $(7)$ & $247,245,249$ & 50 \\
Tetrachloroguaiacol & & $188,189,186$ & 100 \\
$\mathrm{D}_{10}$-Phenanthrene & & & \\
\hline \hline
\end{tabular}

$\underline{\text { Acknowledgements }}$

Dr. R. D. Smillie and Dr. J. G. Hardy are acknowledged for their supportive management.

\section{REFERENCES}

Alberta Environmental Centre. 1987. Methods for chemical analyses (under revision). Alberta Environmental Centre, Vegreville, Alberta.

Davies, J. S., J.V. Headley, F. Skinner, and M.A. Wilson. 1986. Colour reduction in a bleached kraft mill effluent. In: Proceedings of World Congress on Chemical Engineering, Tokyo, Japan.

Federal Register. 1979. Proposed Method 624 and 625, U.S. EPA guidelines for the analysis of priority pollutants. 44:69464-69558. 
Headley, J.V. 1985. Automated GC/MS screening. Environmental sampling laboratories need rapid, high throughput data sampling. Can. Res. 18:41-43.

Headley, J.V. 1987. GC/MS identification of organosulphur compounds in environmental samples. Biomed. Environ. Mass Spectrom. 14:275-280.

Moore, J.W., and S. Ramamoorthy. 1984a. Organic Chemicals in Natural Waters Applied Monitoring and Impact Assessment. Springer-Verlag, New York, NY.

Moore, J.W., and S. Ramamoorthy. 1984b. Heavy Metals in Natural Waters Applied Monitoring and Impact Assessment. Springer - Verlag, New York, NY.

Sittig, M. 1985. Handbook of toxic and hazardous chemicals and carcinogens. Noyes Publications, New Jersey.

Walden, C.C., and T.E. Howard. 1981. Pulp and Paper Canada 82:115-122. 


\section{Appendix 1. GC/MS analysis of target compounds in pulp mill effluents.}

Target Compounds Screened/ET Pulp Mill Project

\section{$\underline{\text { RESIN ACIDS }}$}

\section{Chlorinated}

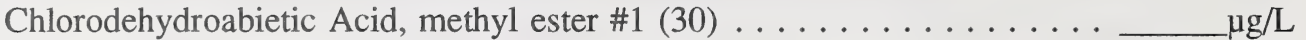

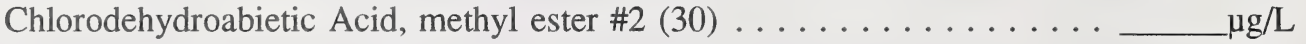

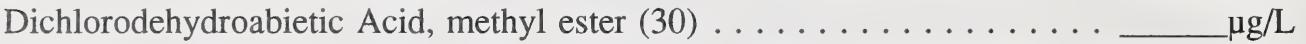

Non-chlorinated

Abietic acid $(200) \ldots \ldots \ldots \ldots \ldots \ldots \ldots \ldots \ldots \ldots \ldots \ldots \ldots \ldots \ldots \ldots \ldots \ldots \ldots \ldots$

Abietic acid, methyl ester (25) $\ldots \ldots \ldots \ldots \ldots \ldots \ldots \ldots \ldots \ldots \ldots$

Dehydroabietic acid $(200) \ldots \ldots \ldots \ldots \ldots \ldots \ldots \ldots \ldots \ldots \ldots \ldots \ldots \ldots \ldots \ldots$

Dehydroabietic acid, methyl ester $(25) \ldots \ldots \ldots \ldots \ldots \ldots \ldots \ldots \ldots \ldots \ldots \ldots \ldots$

Isopimaric acid $(200) \ldots \ldots \ldots \ldots \ldots \ldots \ldots \ldots \ldots \ldots \ldots \ldots \ldots \ldots \ldots \ldots \ldots$

Isopimaric acid, methyl ester (25) $\ldots \ldots \ldots \ldots \ldots \ldots \ldots \ldots \ldots \ldots$

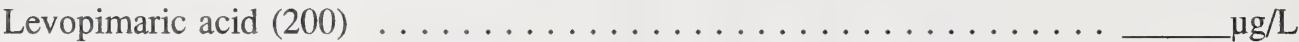

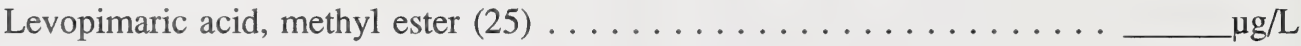

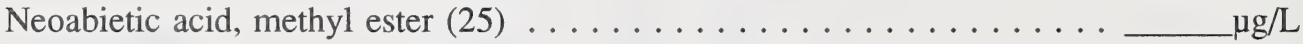

Palustric acid, methyl ester (25) $\ldots \ldots \ldots \ldots \ldots \ldots \ldots \ldots \ldots \ldots \ldots$

Sandaracopimaric acid $(200) \ldots \ldots \ldots \ldots \ldots \ldots \ldots \ldots \ldots \ldots \ldots \ldots \ldots \ldots \ldots$

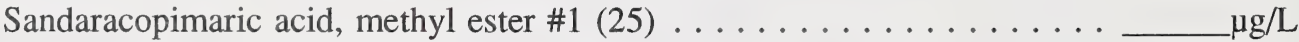

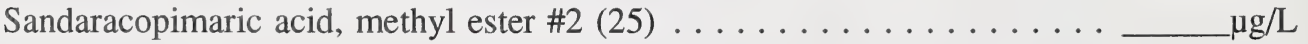

\section{PHENOLICS}

\section{Chlorinated}

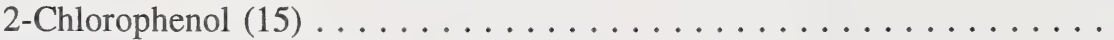

2,4-Dichlorophenol (15)

$\mu \mathrm{g} / \mathrm{L}$

2,4,5-Trichlorophenol (15)

$\mu \mathrm{g} / \mathrm{L}$

2,4,6-Trichlorophenol (15)

$\mu \mathrm{g} / \mathrm{L}$

Trichlorophenol \#1 (15)

$\mu \mathrm{g} / \mathrm{L}$

Trichlorophenol \#2 (15)

$\mu \mathrm{g} / \mathrm{L}$

2,3,4,5-Tetrachlorophenol (15)

$\mu \mathrm{g} / \mathrm{L}$

Pentachlorophenol (15)

$\mu \mathrm{g} / \mathrm{L}$

$\mu \mathrm{g} / \mathrm{L}$

4-Chlorocatechol (30)

$\mu \mathrm{g} / \mathrm{L}$

4-Chlorocatechol, methyl ester (4-chloroguaiacol) (15)

$\mu \mathrm{g} / \mathrm{L}$

Tetrachlorocatechol (40) $\mu \mathrm{g} / \mathrm{L}$

4,5-Dichloroguaiacol (20)

$\mu \mathrm{g} / \mathrm{L}$

Dichloroguaiacol (20) $\mu \mathrm{g} / \mathrm{L}$

3,4,5-Trichloroguaiacol (20) $\mu \mathrm{g} / \mathrm{L}$

Trichloroguaiacol (20) $\mu \mathrm{g} / \mathrm{L}$

Trichloroguaiacol \#2 (20) $\mu \mathrm{g} / \mathrm{L}$

Trichloroguaiacol \#3 (20) $\mu \mathrm{g} / \mathrm{L}$ 
4,5-Dichloroveratrole $(15) \ldots \ldots \ldots \ldots \ldots \ldots \ldots \ldots \ldots \ldots \ldots \ldots \ldots \ldots$

$3,4,5$-Trichloroveratrole $(15) \ldots \ldots \ldots \ldots \ldots \ldots \ldots \ldots \ldots \ldots \ldots \ldots \ldots \ldots$

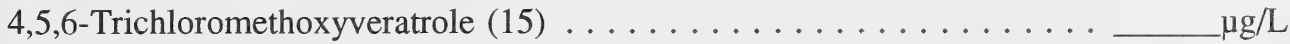

1,2,3,4-Tetrachloro-5,6-veratrole (15) ............... $\mathrm{\mu g} / \mathrm{L}$

Tetrachloroveratrole (15) $\ldots \ldots \ldots \ldots \ldots \ldots \ldots \ldots \ldots \ldots \ldots \ldots \ldots \ldots \ldots$

4-Chloro-m-cresol (15) . ................... $\mathrm{\mu g} / \mathrm{L}$

1,3,5-Trichloro-2-methoxybenzene (15) $\ldots \ldots \ldots \ldots \ldots \ldots \ldots \ldots, \mu \mathrm{g} / \mathrm{L}$

Tetrachlorophenolic, MW $>=246(15) \ldots \ldots \ldots \ldots \ldots \ldots \ldots \ldots \ldots \ldots \ldots$

Non-chlorinated

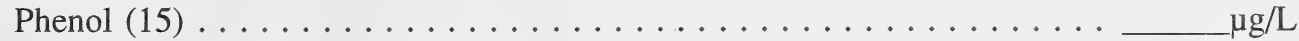

2-Nitrophenol $(15) \ldots \ldots \ldots \ldots \ldots \ldots \ldots \ldots \ldots \ldots \ldots \ldots \ldots \ldots \ldots \ldots \ldots \ldots \ldots$

4-Nitrophenol (15) ..................... $\ldots$. $/ \mathrm{L}$

Methoxy phenol \#1 (15) .................. $\mu \ldots \ldots$

Methoxy phenol \#2 (15) ................. $\mu \ldots \ldots$

Alkylphenol MW=168 (15) .................. $\ldots \ldots$

Methyl tert-butyl phenol (15) $\ldots \ldots \ldots \ldots \ldots \ldots \ldots \ldots \ldots \ldots \ldots \ldots \ldots \ldots \ldots \ldots \ldots \ldots$

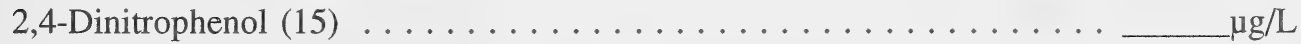

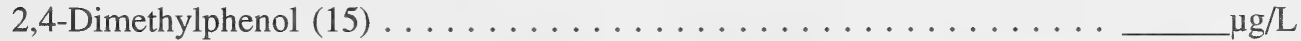

Veratrole $(15) \ldots \ldots \ldots \ldots \ldots \ldots \ldots \ldots \ldots \ldots \ldots \ldots \ldots \ldots \ldots \ldots \ldots \ldots \ldots \ldots$

Dimethoxybenzene $(15) \ldots \ldots \ldots \ldots \ldots \ldots \ldots \ldots \ldots \ldots \ldots \ldots \ldots \ldots \ldots \ldots$

Ethylmethyl phenol $(15) \ldots \ldots \ldots \ldots \ldots \ldots \ldots \ldots \ldots \ldots \ldots \ldots \ldots \ldots \ldots$

4-Ethyl guaiacol $(15) \ldots \ldots \ldots \ldots \ldots \ldots \ldots \ldots \ldots \ldots \ldots \ldots \ldots \ldots \ldots \ldots \ldots$

4-Acetoguaiacol $(15) \ldots \ldots \ldots \ldots \ldots \ldots \ldots \ldots \ldots \ldots \ldots \ldots \ldots \ldots \ldots \ldots \ldots$

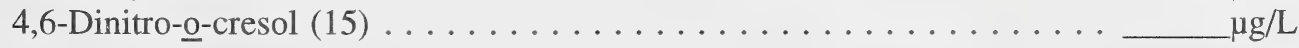

Vanillin $(15) \ldots \ldots \ldots \ldots \ldots \ldots \ldots \ldots \ldots \ldots \ldots \ldots \ldots \ldots \ldots \ldots \ldots \ldots$

Acetosyringol $(15) \ldots \ldots \ldots \ldots \ldots \ldots \ldots \ldots \ldots \ldots \ldots \ldots \ldots \ldots \ldots \ldots \ldots$

Methoxy substituted phenol (15) $\ldots \ldots \ldots \ldots \ldots \ldots \ldots \ldots \ldots \ldots$

\section{OTHER ACIDS}

Chlorinated Aromatics

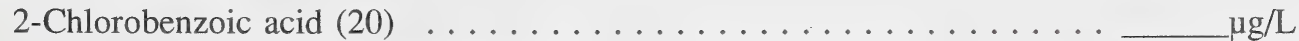

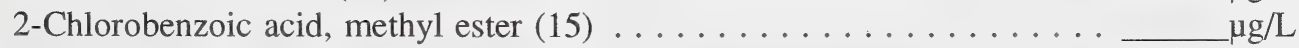

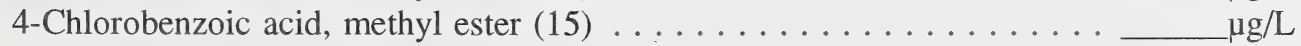

2,5-Dichlorobenzoic acid, methyl ester (15) $\ldots \ldots \ldots \ldots \ldots \ldots \ldots \ldots$

3,6-Dichloro-2-methoxy benzoic acid, methyl ester (15) $\ldots \ldots \ldots \ldots \ldots$ ug/L Non-chlorinated Aromatics

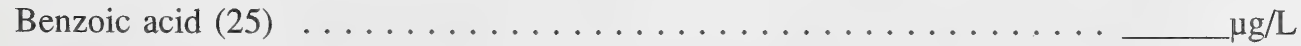

1-Naphthoic acid $(50) \ldots \ldots \ldots \ldots \ldots \ldots \ldots \ldots \ldots \ldots \ldots \ldots \ldots \ldots \ldots \ldots$

$\underline{\mathrm{m}}$-Toluic acid $(25) \ldots \ldots \ldots \ldots \ldots \ldots \ldots \ldots \ldots \ldots \ldots \ldots \ldots \ldots \ldots$

$\underline{\text { m}}$-Toluic acid, methyl ester $(10) \ldots \ldots \ldots \ldots \ldots \ldots \ldots \ldots \ldots \ldots \ldots \ldots$ 
Chlorinated Aliphatic Acids

Trichloroacetic acid, methyl ester (15) $\ldots \ldots \ldots \ldots \ldots \ldots \ldots \ldots \ldots \ldots g / \mathrm{L}$

2,3-Dichloro-2-propanoic acid (25) $\ldots \ldots \ldots \ldots \ldots \ldots \ldots \ldots \ldots \ldots$

Non-chlorinated Aliphatic Acids

Camphorocarboxylic acid $(25) \ldots \ldots \ldots \ldots \ldots \ldots \ldots \ldots \ldots \ldots \ldots \ldots \ldots \ldots \ldots \ldots \ldots \ldots \ldots$

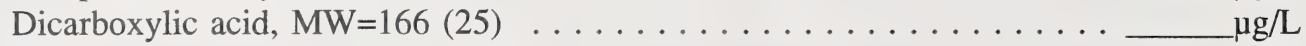

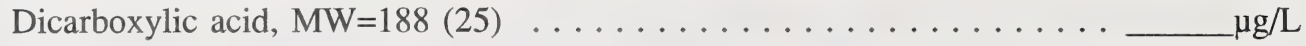

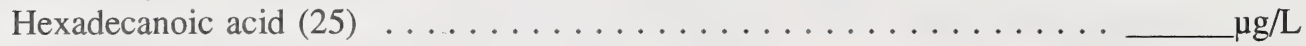

Oleic acid $(200) \ldots \ldots \ldots \ldots \ldots \ldots \ldots \ldots \ldots \ldots \ldots \ldots \ldots \ldots \ldots \ldots \ldots \ldots \ldots$

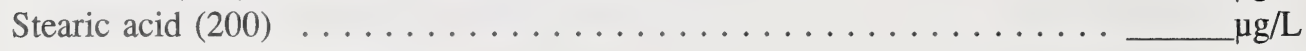

Stearic acid, methyl ester $(25) \ldots \ldots \ldots \ldots \ldots \ldots \ldots \ldots \ldots \ldots \ldots \ldots \ldots$

\section{BASE NEUTRALS}

Chlorinated Sulphones

Chlorosulphone, MW $>109(15) \ldots \ldots \ldots \ldots \ldots \ldots \ldots \ldots \ldots \ldots \ldots \ldots \ldots \ldots \ldots \ldots$

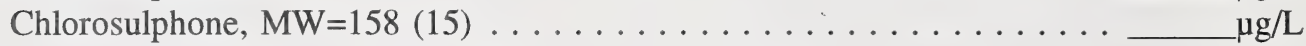

1,1-Dichlorodimethyl sulphone $(15) \ldots \ldots \ldots \ldots \ldots \ldots \ldots \ldots \ldots \ldots \ldots \ldots \ldots \ldots$

Dichlorodimethyl sulphone $(15) \ldots \ldots \ldots \ldots \ldots \ldots \ldots \ldots \ldots \ldots \ldots \ldots \ldots \ldots \ldots$

Trichlorodimethyl sulphone $(15) \ldots \ldots \ldots \ldots \ldots \ldots \ldots \ldots \ldots \ldots$

Non-chlorinated Sulphones

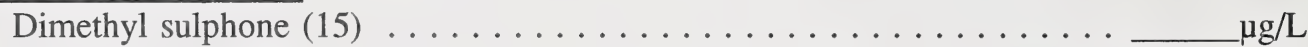

Ethyl sulphone $(15) \ldots \ldots \ldots \ldots \ldots \ldots \ldots \ldots \ldots \ldots \ldots \ldots \ldots \ldots \ldots \ldots$

Chlorinated Sulphides

2-Chloroethylmethyl sulphide (15) $\ldots \ldots \ldots \ldots \ldots \ldots \ldots \ldots \ldots \ldots \ldots \ldots \ldots$

Non-chlorinated Sulphides

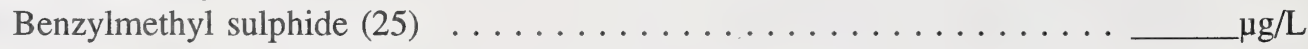

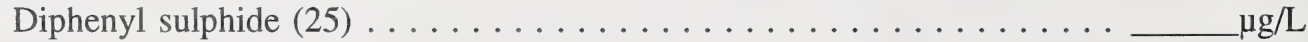

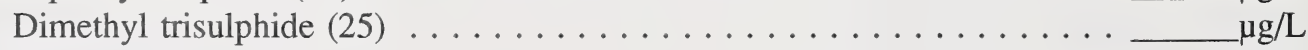

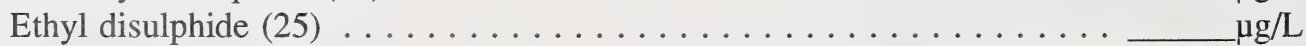

Ethyl trisulphide $(25) \ldots \ldots \ldots \ldots \ldots \ldots \ldots \ldots \ldots \ldots \ldots \ldots \ldots \ldots \ldots$

Chlorinated Thiophenes

2-Chlorothiophene $(20) \ldots \ldots \ldots \ldots \ldots \ldots \ldots \ldots \ldots \ldots \ldots \ldots \ldots \ldots \ldots \ldots$

2,5-Dichlorothiophene $(20) \ldots \ldots \ldots \ldots \ldots \ldots \ldots \ldots \ldots \ldots \ldots \ldots \ldots \ldots$

Non-chlorinated Thiophenes

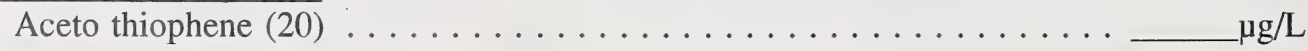

Diethyl thiophene $(20) \ldots \ldots \ldots \ldots \ldots \ldots \ldots \ldots \ldots \ldots \ldots \ldots \ldots \ldots \ldots \ldots \ldots \ldots$

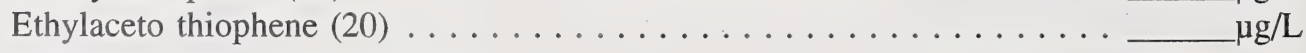

Methylethyl acetothiophene $(20) \ldots \ldots \ldots \ldots \ldots \ldots \ldots \ldots \ldots \ldots \ldots \ldots \ldots$

Methyl-5-methyl-2-thiophene carboxylate (20) $\ldots \ldots \ldots \ldots \ldots \ldots \ldots \ldots, \mu \mathrm{g} / \mathrm{L}$

Methylethyl thiophene $(20) \ldots \ldots \ldots \ldots \ldots \ldots \ldots \ldots \ldots \ldots \ldots \ldots \ldots \ldots \ldots$

Methyl-3-thiophene carboxylate $(20) \ldots \ldots \ldots \ldots \ldots \ldots \ldots \ldots \ldots \ldots \ldots$

$1-(2-$ Thienyl) thiophene $(20) \ldots \ldots \ldots \ldots \ldots \ldots \ldots \ldots \ldots \ldots \ldots \ldots$ 
Chlorinated Aromatic B/N

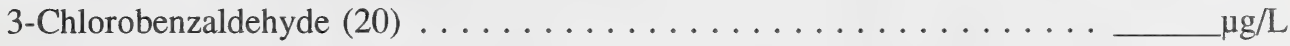

4-Chlorobenzaldehyde $(20) \ldots \ldots \ldots \ldots \ldots \ldots \ldots \ldots \ldots \ldots \ldots \ldots \ldots \ldots \ldots$

Chlorobenzene $(20) \ldots \ldots \ldots \ldots \ldots \ldots \ldots \ldots \ldots \ldots \ldots \ldots \ldots \ldots \ldots \ldots$

4-Chlorobenzene phenyl ether $(20) \ldots \ldots \ldots \ldots \ldots \ldots \ldots \ldots \ldots \ldots \ldots \ldots \ldots$

2-Chlorobenzyl alcohol (20) ................... $\mathrm{\mu g} / \mathrm{L}$

2,4-Dichlorobenzyl alcohol (20) $\ldots \ldots \ldots \ldots \ldots \ldots \ldots \ldots \ldots \ldots \ldots$

2-Chloronaphthalene $(20) \ldots \ldots \ldots \ldots \ldots \ldots \ldots \ldots \ldots \ldots \ldots \ldots \ldots \ldots \ldots$

1,2-Dichlorobenzene $(20) \ldots \ldots \ldots \ldots \ldots \ldots \ldots \ldots \ldots \ldots \ldots \ldots \ldots \ldots$

1,3-Dichlorobenzene $(20) \ldots \ldots \ldots \ldots \ldots \ldots \ldots \ldots \ldots \ldots \ldots \ldots \ldots \ldots \ldots \ldots$

1,4-Dichlorobenzene $(20) \ldots \ldots \ldots \ldots \ldots \ldots \ldots \ldots \ldots \ldots \ldots \ldots \ldots \ldots \ldots \ldots \ldots$

2,3-Dichlorobenzidine $(50) \ldots \ldots \ldots \ldots \ldots \ldots \ldots \ldots \ldots \ldots \ldots \ldots \ldots \ldots \ldots \ldots \ldots \ldots$

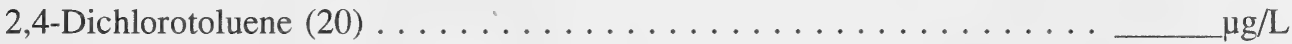

3,4-Dichloro-2-naphthelenol (20) $\ldots \ldots \ldots \ldots \ldots \ldots \ldots \ldots \ldots \ldots \ldots$

$1,2,4$-Trichlorobenzene $(20) \ldots \ldots \ldots \ldots \ldots \ldots \ldots \ldots \ldots \ldots \ldots \ldots \ldots \ldots \ldots$

Hexachlorobenzene $(20) \ldots \ldots \ldots \ldots \ldots \ldots \ldots \ldots \ldots \ldots \ldots \ldots \ldots \ldots \ldots \ldots$

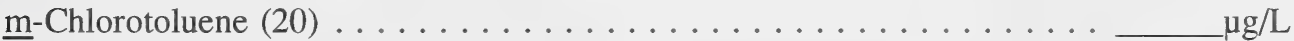

2-4-Dinitrotoluene $(20) \ldots \ldots \ldots \ldots \ldots \ldots \ldots \ldots \ldots \ldots \ldots \ldots \ldots \ldots \ldots$

Non-chlorinated Aromatic B/N

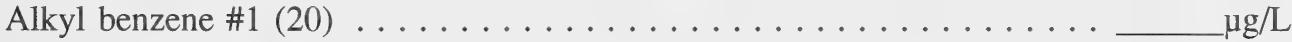

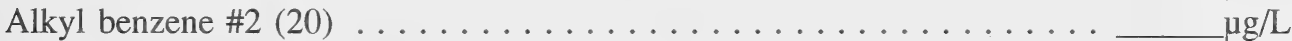

Alkylphenyl benzene $(20) \ldots \ldots \ldots \ldots \ldots \ldots \ldots \ldots \ldots \ldots \ldots \ldots \ldots \ldots \ldots \ldots \ldots$

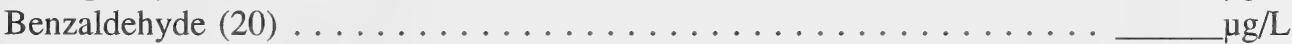

Benzidine (20) $\ldots \ldots \ldots \ldots \ldots \ldots \ldots \ldots \ldots \ldots \ldots \ldots \ldots \ldots \ldots \ldots \ldots \ldots \ldots$

2,4-Dinitrotoluene $(50) \ldots \ldots \ldots \ldots \ldots \ldots \ldots \ldots \ldots \ldots \ldots \ldots \ldots \ldots \ldots \ldots \ldots$

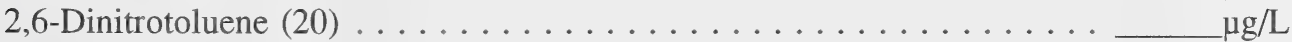

1,2-Diphenylhydrazine $(100) \ldots \ldots \ldots \ldots \ldots \ldots \ldots \ldots \ldots \ldots \ldots \ldots \ldots \ldots \ldots$

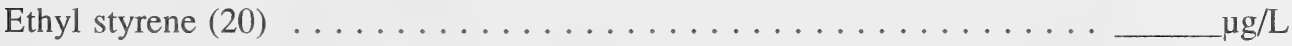

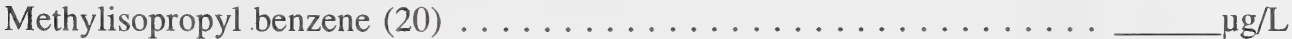

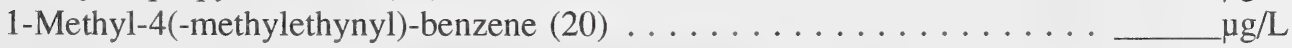

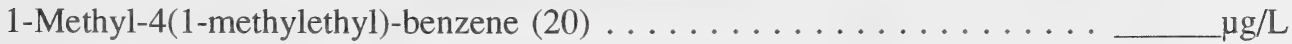

Methylpropyl benzene $(20) \ldots \ldots \ldots \ldots \ldots \ldots \ldots \ldots \ldots \ldots \ldots \ldots \ldots \ldots \ldots$

Nitrobenzene $(30) \ldots \ldots \ldots \ldots \ldots \ldots \ldots \ldots \ldots \ldots \ldots \ldots \ldots \ldots \ldots \ldots \ldots \ldots$

n-Nitrosodimethylamine $(50) \ldots \ldots \ldots \ldots \ldots \ldots \ldots \ldots \ldots \ldots \ldots \ldots \ldots \ldots \ldots \ldots$

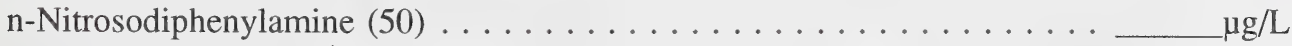

n-Nitrotoid-n-propylamine $(50) \ldots \ldots \ldots \ldots \ldots \ldots \ldots \ldots \ldots \ldots \ldots \ldots \ldots$

Chlorinated Aliphatics B/N

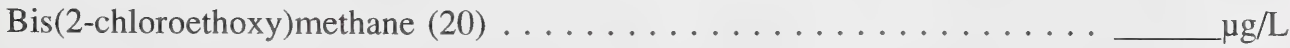

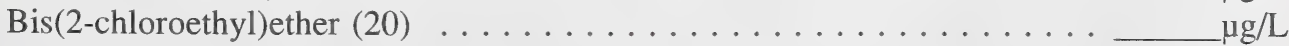

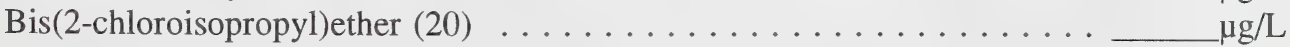

Carbon tetrachloride $(20) \ldots \ldots \ldots \ldots \ldots \ldots \ldots \ldots \ldots \ldots \ldots \ldots \ldots \ldots \ldots \ldots \ldots \ldots$

2-Chloroethyl vinyl ether $(20) \ldots \ldots \ldots \ldots \ldots \ldots \ldots \ldots \ldots \ldots \ldots \ldots \ldots \ldots$

Chloromethyl cyclohexadiene $(20) \ldots \ldots \ldots \ldots \ldots \ldots \ldots \ldots \ldots \ldots \ldots \ldots \ldots \ldots \ldots \ldots$

4-Chlorophenyl phenyl ether (20) $\ldots \ldots \ldots \ldots \ldots \ldots \ldots \ldots \ldots \ldots \ldots \ldots \ldots \ldots \ldots \ldots \ldots \ldots$

1,1-Dichlorobutane $(20) \ldots \ldots \ldots \ldots \ldots \ldots \ldots \ldots \ldots \ldots \ldots \ldots \ldots \ldots \ldots \ldots$

Hexachlorobutadiene $(30) \ldots \ldots \ldots \ldots \ldots \ldots \ldots \ldots \ldots \ldots \ldots \ldots \ldots \ldots$

Hexachlorocyclopentadiene $(30) \ldots \ldots \ldots \ldots \ldots \ldots \ldots \ldots \ldots \ldots$ 
Hexachloroethane (30) $\mu \mathrm{g} / \mathrm{L}$

Pentachloropropene (30) $\mu \mathrm{g} / \mathrm{L}$

1,1,2,2-Tetrachloroethane (20) $\mu \mathrm{g} / \mathrm{L}$ Non-chlorinated Aliphatics B/N

Abienol (50)

$\mu \mathrm{g} / \mathrm{L}$

Allocimene (25) $\mu \mathrm{g} / \mathrm{L}$

Endo-borneol (50) $\mu \mathrm{g} / \mathrm{L}$

Bicyclohexane (25) $\mu \mathrm{g} / \mathrm{L}$ Camphor (25)

4-Bromophenyl phenyl ether (30) $\mu \mathrm{g} / \mathrm{L}$

Delta-3-carene (25) $\mu \mathrm{g} / \mathrm{L}$

Delta-4-carene (25) $\mu \mathrm{g} / \mathrm{L}$

Cyclohexenone (25) $\mu \mathrm{g} / \mathrm{L}$ $\mu \mathrm{g} / \mathrm{L}$

2-Cyclopentane-1-one, methyl (25)

p-Cymen-8-ol (25) $\mu \mathrm{g} / \mathrm{L}$

$\mathrm{C}_{20} \mathrm{H}_{34} \mathrm{O}$ Alcohol (30) $\mu \mathrm{g} / \mathrm{L}$ $\mu g / L$

Dihydrofuranone (25) $\mu \mathrm{g} / \mathrm{L}$

Dihydroxycyclohexadiene (25) $\mu \mathrm{g} / \mathrm{L}$

1,2-Dimethyl cyclohexene (25) $\mu \mathrm{g} / \mathrm{L}$

Dimethyl cyclopentenone (25) $\mu \mathrm{g} / \mathrm{L}$

2,3-Dimethyl-2-cyclopentenone (25) $\mu \mathrm{g} / \mathrm{L}$

Dimethyl hexadiene (25) $\mu \mathrm{g} / \mathrm{L}$

Dimethoxycyclohexadiene (25) $\mu \mathrm{g} / \mathrm{L}$

Dimethoxycyclohexadiene \#2 $\mu \mathrm{g} / \mathrm{L}$ Eugenol (30)

Fenchone (20) $\mu \mathrm{g} / \mathrm{L}$ $\mu \mathrm{g} / \mathrm{L}$

Fenchyl alcohol (25) $\mu \mathrm{g} / \mathrm{L}$

Isopropyl substituted alcohol (25)

Limonene (25) $\mu \mathrm{g} / \mathrm{L}$ $\mu \mathrm{g} / \mathrm{L}$

4-Methyl1-1-(1-methylethyl)-3-cyclohexene-1-ol (25) $\mu \mathrm{g} / \mathrm{L}$ Methoxycyclohexadiene (20) $\mu \mathrm{g} / \mathrm{L}$ Beta-phellandrene (20) $\mu \mathrm{g} / \mathrm{L}$ 1-Phellandrene (20) $\mu \mathrm{g} / \mathrm{L}$ Alpha-pinene (20) $\mu \mathrm{g} / \mathrm{L}$

Beta-pinene (20) $\mu \mathrm{g} / \mathrm{L}$ Sabinene (25) $\mu \mathrm{g} / \mathrm{L}$

Sulphur, $\mathrm{S}_{6}(30)$ $\mu \mathrm{g} / \mathrm{L}$

Sulphur, $S_{7}(30)$ $\mu \mathrm{g} / \mathrm{L}$

Sulphur, $\mathrm{S}_{8}(30)$ $\mu \mathrm{g} / \mathrm{L}$ Alpha-terpinene (30) $\mu \mathrm{g} / \mathrm{L}$ Alpha-terpineol (30) $\mu \mathrm{g} / \mathrm{L}$ Beta-thujene (25) $\mu \mathrm{g} / \mathrm{L}$ 


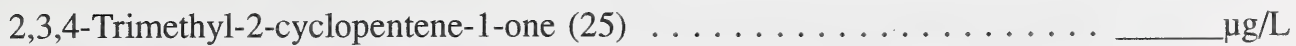

Trimethyl-2-cyclopentene-1-one $(25) \ldots \ldots \ldots \ldots \ldots \ldots \ldots \ldots \ldots \ldots \ldots \ldots$ $\underline{\text { PAHs }}$

Acenaphthene $(15) \ldots \ldots \ldots \ldots \ldots \ldots \ldots \ldots \ldots \ldots \ldots \ldots \ldots \ldots \ldots$

Acenaphthylene $(15) \ldots \ldots \ldots \ldots \ldots \ldots \ldots \ldots \ldots \ldots \ldots \ldots \ldots \ldots \ldots \ldots$

Anthracene $(15) \ldots \ldots \ldots \ldots \ldots \ldots \ldots \ldots \ldots \ldots \ldots \ldots \ldots \ldots \ldots \ldots \ldots \ldots$

Benz(a)anthracene $(15) \ldots \ldots \ldots \ldots \ldots \ldots \ldots \ldots \ldots \ldots \ldots \ldots \ldots \ldots \ldots \ldots \ldots$

Benzo(k)fluoranthene (15) $\ldots \ldots \ldots \ldots \ldots \ldots \ldots \ldots \ldots \ldots \ldots \ldots \ldots \ldots \ldots \ldots$

Benzo(ghih)perylene (15) ................. $\mathrm{\mu g} / \mathrm{L}$

Benzo(a)-pyrene (15) ........................ $\mu \mathrm{g} / \mathrm{L}$

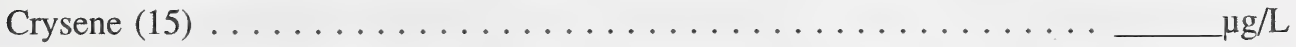

Debenz(ah)anthracene $(15) \ldots \ldots \ldots \ldots \ldots \ldots \ldots \ldots \ldots \ldots \ldots \ldots \ldots \ldots$

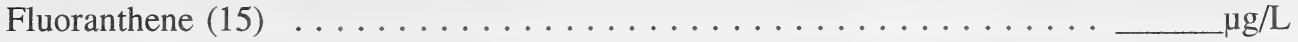

Fluorene $(15) \ldots \ldots \ldots \ldots \ldots \ldots \ldots \ldots \ldots \ldots \ldots \ldots \ldots \ldots \ldots \ldots \ldots \ldots$

Indeno(1,2,3-cd)pyrene $(20) \ldots \ldots \ldots \ldots \ldots \ldots \ldots \ldots \ldots \ldots \ldots \ldots$

Naphthalene $(15) \ldots \ldots \ldots \ldots \ldots \ldots \ldots \ldots \ldots \ldots \ldots \ldots \ldots \ldots \ldots \ldots$

1-Methyl naphthalene (15) .................. $\mathrm{\mu g} / \mathrm{L}$

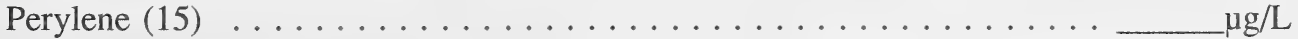

Phenanthrene $(15) \ldots \ldots \ldots \ldots \ldots \ldots \ldots \ldots \ldots \ldots \ldots \ldots \ldots \ldots \ldots \ldots \ldots$

Pyrene $(15) \ldots \ldots \ldots \ldots \ldots \ldots \ldots \ldots \ldots \ldots \ldots \ldots \ldots \ldots \ldots \ldots \ldots \ldots$

Phthalate Esters

Butylbenzyl phthalate $(20) \ldots \ldots \ldots \ldots \ldots \ldots \ldots \ldots \ldots \ldots \ldots \ldots \ldots \ldots \ldots \ldots \ldots$

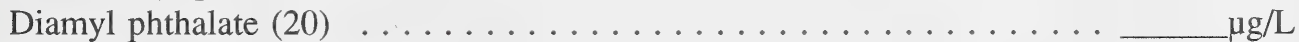

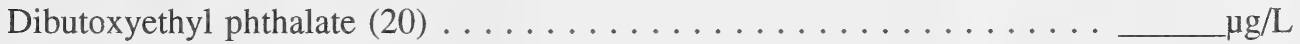

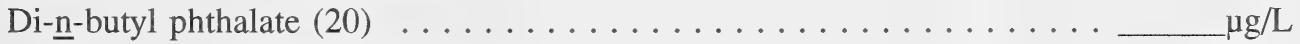

Dicyclohexyl phthalate $(20) \ldots \ldots \ldots \ldots \ldots \ldots \ldots \ldots \ldots \ldots \ldots \ldots \ldots \ldots \ldots \ldots$

Di-(2-ethylhexyl)isophthalate $(20) \ldots \ldots \ldots \ldots \ldots \ldots \ldots \ldots \ldots \ldots \ldots \ldots \ldots$

Diethyl phthalate $(20) \ldots \ldots \ldots \ldots \ldots \ldots \ldots \ldots \ldots \ldots \ldots \ldots \ldots \ldots \ldots \ldots$

Dimethyl phthalate $(20) \ldots \ldots \ldots \ldots \ldots \ldots \ldots \ldots \ldots \ldots \ldots \ldots \ldots \ldots \ldots$

Di-n- octyl phthalate $(20) \ldots \ldots \ldots \ldots \ldots \ldots \ldots \ldots \ldots \ldots \ldots \ldots \ldots \ldots \ldots \ldots \ldots$

Bis(2-ethylhexyl) phthalate (2) $\ldots \ldots \ldots \ldots \ldots \ldots \ldots \ldots \ldots \ldots \ldots \ldots \ldots$

\section{OTHERS}

3,6-Dichloro-2-Methoxybenzoic acid, methyl ester (25) $\ldots \ldots \ldots \ldots \ldots g / \mathrm{L}$

Substituted methyl ester, MW=176 (25) ............. $\ldots \ldots$

2-Chloronaphthalene $\ldots \ldots \ldots \ldots \ldots \ldots \ldots \ldots \ldots \ldots \ldots \ldots \ldots \ldots \ldots \ldots \ldots$

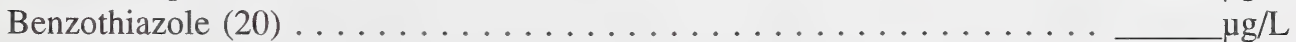

1,2-Benzothiazole $(25) \ldots \ldots \ldots \ldots \ldots \ldots \ldots \ldots \ldots \ldots \ldots \ldots \ldots \ldots \ldots \ldots \ldots \ldots \ldots \ldots$

2-Chlorobenzothiazole $(25) \ldots \ldots \ldots \ldots \ldots \ldots \ldots \ldots \ldots \ldots \ldots \ldots \ldots \ldots$

Dichlorodipropyl organic, MW=186 (25) $\ldots \ldots \ldots \ldots \ldots \ldots \ldots \ldots$

2-Chlorodipropyl organic, $\mathrm{MW}=186(25) \ldots \ldots \ldots \ldots \ldots \ldots \ldots \ldots \ldots \ldots \ldots \ldots \ldots$

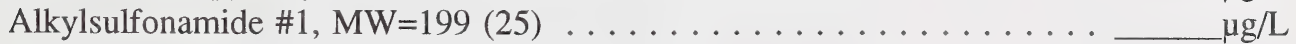

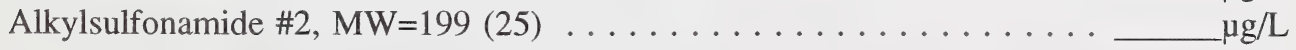

Isophorone $(50) \ldots \ldots \ldots \ldots \ldots \ldots \ldots \ldots \ldots \ldots \ldots \ldots \ldots \ldots \ldots \ldots \ldots \ldots \ldots$

Manool $(100) \ldots \ldots \ldots \ldots \ldots \ldots \ldots \ldots \ldots \ldots \ldots \ldots \ldots \ldots \ldots \ldots \ldots \ldots$ 
Organic \#1, MW $>286(50) \ldots \ldots \ldots \ldots \ldots \ldots \ldots \ldots \ldots \ldots \ldots \ldots \ldots \ldots \ldots \ldots$

Organic \#2, MW $>286(50) \ldots \ldots \ldots \ldots \ldots \ldots \ldots \ldots \ldots \ldots \ldots \ldots \ldots \ldots \ldots \ldots \ldots$

Monochloro organic, $\mathrm{MW}=122(50) \ldots \ldots \ldots \ldots \ldots \ldots \ldots \ldots \ldots \ldots \mathrm{\mu g} / \mathrm{L}$

Blank spaces indicate less than the method detection limit.

Method detection limits estimated are given in parenthesis.

Trace indicates quantitation below instrument integration limit. 


\title{
Use of Histopathological Evaluation in Aquatic Toxicity Studies
}

\author{
Leonard E. Lillie and Alfonso Lopez \\ Alberta Environmental Centre \\ Vegreville, Alberta
}

\begin{abstract}
Many tools are available for assessing the effects of chemical substances on living organisms. One tool, which is routinely used in mammalian toxicology, but which has been used only to a limited extent with aquatic species, is pathological evaluation. This paper summarized efforts to employ pathological evaluation including necropsy, histopathological examination and ultrastructural pathology in aquatic toxicity studies. The reported studies included the effects of flocculants used in coal mining, alum precipitates in municipal sludge management, pulp and paper effluent studies and other related studies.
\end{abstract}

The advantages and disadvantages of using pathological evaluation in aquatic studies were discussed. 


\title{
Aquatic Toxicology of Alum: Importance of Water pH \\ Thomas A. Heming and Karen A. Blumhagen \\ Alberta Environmental Centre \\ Vegreville, Alberta
}

\begin{abstract}
Alum (aluminum sulphate) is used in water treatment in Alberta as a coagulant for suspended solids. In some municipalities, the resultant alum sludge is discharged into nearby water courses. We investigated the effects of alum on gill function in rainbow trout, specifically on the ability to regulate plasma acid-base and electrolyte states in the face of acidic and alkaline shifts in water $\mathrm{pH}$. In water of $\mathrm{pH} 4.3$, alum exacerbated the plasma disturbances and decreased fish survival in a concentration-dependent manner, consistent with the known effects of dissolved aluminum cations on gill structure and function. In water of $\mathrm{pH} \mathrm{7.8,} \mathrm{alum} \mathrm{had} \mathrm{no} \mathrm{detectable}$ effect. In water of $\mathrm{pH} \mathrm{8.7,} \mathrm{low} \mathrm{concentrations} \mathrm{of} \mathrm{alum} \mathrm{protected} \mathrm{the} \mathrm{fish} \mathrm{from} \mathrm{the} \mathrm{effects} \mathrm{of} \mathrm{base}$ exposure and increased fish survival, probably due to competition between $\mathrm{Al}(\mathrm{OH})^{4-}$ and $\mathrm{OH}^{-}$for gill-binding sites. Higher alum concentrations $(\geq 0.9 \mathrm{mg} / \mathrm{L} \mathrm{A1})$ at $\mathrm{pH} 8.7$ exacerbated the plasma disturbances and reduced fish survival, reflective of the adverse effects of $\mathrm{Al}(\mathrm{OH})^{4-}$. Previous work at the Alberta Environmental Centre (AEC) found that aluminum is effectively bound in alum sludge, releasing less than $0.02 \%$ of the total $\mathrm{Al}$ content at $\mathrm{pH} 7.6-8.9$, but releasing relatively more $\mathrm{A} 1$ at $\mathrm{pH} 4.5-6.0$ and 10.0. Taken together, these studies suggest that discharge of alum sludge has the potential to elicit toxic responses from fish at water $\mathrm{pH}$ extremes, but not under $\mathrm{pH}$ conditions normally occurring in Albertan waters.
\end{abstract}




\title{
Biomagnification of Chemical Residues in Alberta Aquatic Habitats
}

\author{
J.D. Somers, B.C. Goski and J.M. Barbeau \\ Alberta Environmental Centre \\ Vegreville, Alberta
}

\section{ABSTRACT}

Animals at the top of food chains are potential consumers of a wide variety of environmental contaminants because of the biomagnification of agricultural and/or industrial toxicants present in aquatic systems. The Fish and Wildlife Division of Alberta Forestry, Lands and Wildlife had indicated that colonial nesting birds in some regions of Alberta are perhaps negatively affected by toxic chemicals. The double-crested cormorant (Phalacrocorax auritus) was selected as the model species. Other species, such as the white pelican (Pelecanus erythrorhynchos), the western grebe (Aechmophorus occidentalis), the ring-billed gull (Larus delawarensis) and the common tern (Sterna hirundo) are suitable for monitoring and/or are of concern. However, these latter species were deemed too cosmopolitan in feeding habits, too sensitive, too localized in distribution or generally too difficult to work with. Although pesticide and PCB residues in cormorants were of concern, colonies were selected to provide a comparison of contaminant profiles in ecosystems believed to be pristine (e.g. Frog Lake), or highly contaminated (e.g. Primrose Lake) and agriculturally associated (e.g. reservoirs). Eggs were collected and analyzed to monitor the contaminant content and impact on reproduction. Juvenile cormorants were sampled to evaluate the accumulation of chemical burdens in Alberta aquatic systems. The objectives of the study were to monitor the organochlorine residues in cormorant eggs, to document any bioaccumulation of chemical residues in juvenile cormorants and to compare the biomagnification of chemical residues in different aquatic habitats.

Cormorant eggs (7-10) were collected from colonies at Frog Lake, Lac La Biche, Lower Therien Lake, Beaverhill Lake, Hays Reservoir, Tilley South Reservoir, Irricana Reservoir, Little Bow Reservoir, St. Mary Reservoir, Murray Reservoir and Primrose Lake in Saskatchewan. Juvenile cormorants ( 5 or 10 ) of about 5 to 7 weeks of age were subsequently collected at each site, except Little Bow and St. Mary reservoirs. Five lipid samples per site were analyzed.

Low concentrations of hexachlorobenzene (HCB), lindane, oxy-chlordane, heptachlor epoxide, dieldrin, mirex, DDD and DDT, ranging from 0.0 to $0.6 \mu / g$ egg reflected the wintering-ground origin of egg residues, and were biologically insignificant. DDE and PCBs 
were the only major residues detected in cormorant eggs. DDE and PCB geometric mean residues per colony ranged from 2.5 to $6.0 \mu / \mathrm{g}$ egg and 1.5 to $5.6 \mu \mathrm{g} / \mathrm{g}$ egg, respectively. Overall DDE and PCB geometric mean residues averaged about 4.0 and $2.5 \mu \mathrm{g} / \mathrm{g}$ of egg, respectively, with a PCB:DDE ratio of 0.72:1. Eggshells averaged $0.44 \mathrm{~mm}$ thickness, and no correlation with the log DDE residues was evident $\left(r^{2}=0.17\right)$. DDE residues were highest at Primrose Lake, Lower Therien Lake, Irricana Reservoir and St. Mary Reservoir. DDE and PCBs were the only residue detected in juvenile cormorant lipid (geometric mean $1.0 \mu \mathrm{g} / \mathrm{g}$ of lipid for each compound). The highest DDE residue $(2.7 \mu \mathrm{g} / \mathrm{g})$ was detected in cormorant lipid at Beaverhill Lake, and the largest PCB residue $(2.1 \mu \mathrm{g} / \mathrm{g}$ of lipid) was detected in cormorants sampled at Irricana Reservoir. PCB:DDE ratios in cormorant lipid and eggs averaged about 1:1 for both matrices. The deviation in the PCB:DDE ratio within colonies for each matrix was a factor of one; however, PCB:DDE ratios in cormorant lipid from Hays Reservoir, Irricana Reservoir and Lower Therien Lake were 2 to 3 times greater than the ratio for eggs. This suggested that juvenile cormorants at these colonies were accumulating PCBs.

The results suggested that juvenile cormorants were accumulating PCB residues at some of the colonies. This was not statistically substantiated, and more specific monitoring of PCBs within each ecosystem would be necessary to evaluate this trend. Residues in egg samples indicated that the wintering-ground was the source of insecticide and PCB residues; however, the magnitude of the residue concentrations would not affect reproduction. Overall, no differences in residue concentrations between a pristine, an agriculturally associated or a historically contaminated ecosystem were evident. 


\title{
Winter Oxygen Depletion in Small Alberta Rivers
}

\author{
J. Babin and D.O. Trew \\ Water Quality Control Branch, Pollution Control Division \\ Alberta Environment, Edmonton, Alberta
}

\section{ABSTRACT}

The modelling of dissolved oxygen concentration (DO) depletion in rivers has focused usually on the effects of anthropogenic, point-source discharges (both municipal and industrial) during low-flow, open-water periods. In contrast, very little information is available to describe the DO depletion that occurs under prolonged ice-cover in pristine rivers, or in rivers subject to non-point source inputs. Specific water resources management studies carried out recently by Alberta Environment have required predictions of future DO under altered-flow regimes, etc. Because no adequate methods existed to address these issues, preliminary investigations concerning the spatial and temporal characteristics of winter DO depletion in smaller rivers were initiated by the Water Quality Control Board.

An intensive survey of winter DO depletion was undertaken on three reaches of the Beaver and Sand rivers during November and December, 1984. Data analyses revealed that DO was depleted at a constant rate within each reach. Although these reaches are not heavily affected by agriculture or other activities, certain trophic differences existed between them. Furthermore, the rates of DO depletion seemed to be related to the trophic state of the rivers, i.e., the most productive reach had the highest rate. The mean winter DO depletion rates and mean open-water trophic indices (Babin and Trew, 1985) are given in Table 1.

Table 1. Mean winter depletion rates and mean open-water tropic indices in 1984.

\begin{tabular}{lcccc}
\hline \hline River Reach & $\begin{array}{c}\text { DO Depletion } \\
(\mathrm{mg} / \mathrm{L} / \mathrm{km})\end{array}$ & $\begin{array}{c}\text { Trophic Prediction } \\
\left(\mathrm{mg} / \mathrm{m}^{3}\right)\end{array}$ & $\begin{array}{c}\text { Planktonic } \\
\left(\mathrm{mg} / \mathrm{m}^{3}\right)\end{array}$ & $\begin{array}{c}\text { Benthic } \\
\left(\mathrm{mg} / \mathrm{m}^{3}\right)\end{array}$ \\
\hline \hline Upper Beaver & 0.091 & 134.5 & 2.4 & -- \\
Lower Beaver & 0.014 & 49.6 & 4.4 & 73.7 \\
Sand & 0.018 & 43.0 & 2.8 & -- \\
\hline \hline
\end{tabular}


An attempt was made subsequently to extend these observations to more rivers of varying size and trophic state. Nine other rivers and reaches, as well as the Beaver and Sand, were selected for sampling during November and December, 1986. These nine rivers were the Medicine River, the Battle River above Driedmeat Lake, the Battle River below Driedmeat Lake, the Redwater River, the McLeod River, the Raven River, the Sturgeon River, the Little Red Deer River and the Vermilion River.

Unfortunately, the mild weather conditions of the winter of 1986-87 negated much of the initial field work. Many areas of the river reaches under study remained free of ice, allowing for reoxygenation to occur at miscellaneous locations. This often caused the longitudinal DO profiles to be inverted, i.e., higher DO downstream than upstream.

By the end of December 1986, only studies on two rivers other than the Beaver and Sand provided useful data. These were Medicine River and the Battle River below Driedmeat Lake. The mean DO depletion rates and trophic indices in October, 1986 are in Table 2.

Table 2. $\quad$ Mean DO depletion rates and mean trophic indices for October 1986.

\begin{tabular}{lcccc}
\hline \hline \multicolumn{1}{c}{ River Reach } & $\begin{array}{c}\text { DO Depletion } \\
(\mathrm{mg} / \mathrm{L} / \mathrm{km})\end{array}$ & $\begin{array}{c}\text { Trophic } \\
\text { Prediction } \\
\left(\mathrm{mg} / \mathrm{m}^{3}\right)\end{array}$ & $\begin{array}{c}\text { Planktonic } \\
\left(\mathrm{mg} / \mathrm{m}^{3}\right)\end{array}$ & $\begin{array}{c}\text { Benthic } \\
\left(\mathrm{mg} / \mathrm{m}^{3}\right)\end{array}$ \\
\hline \hline Upper Beaver & 0.097 & 85.1 & 2.2 & 274.2 \\
Sand River & 0.044 & 35.1 & 3.3 & 54.5 \\
Battle River below & 0.064 & 156.2 & 75.3 & 35.0 \\
Driedmeat Lake & & & & 138.2 \\
Medicine River & 0.043 & 47.4 & 2.0 & \\
\hline \hline
\end{tabular}

No simple relationship was apparent between DO depletion rates and selected trophic indicators. This may be due to the limited data base available, or may reflect the complex influence of several unaccounted factors (proportion of groundwater flow in winter, velocity and depth of flow, benthic BOD, etc.). More data are necessary to develop a reliable predictive capability for winter DO depletion in small rivers. 


\section{REFERENCES}

Babin, J., and D.O. Trew. 1985. The Impact of the Proposed Sand River Reservoir on Winter Dissolved Oxygen Levels in the Beaver and Sand Rivers. Appendix "H", Sand River Dam Alternative, Cold Lake - Beaver River Long Term Water Management Study. Alberta Environment, Edmonton, Alberta. 82 pp. 


\title{
Spikerush, Eleocharis acicularis, as a Control of Aquatic Plant Growth in Irrigation Systems in Alberta
}

\author{
Earle G. Baddaloo* and Dave Reid** \\ *Alberta Environment, Edmonton, Alberta \\ **Hardy BBT Ltd., Calgary, Alberta
}

\section{ABSTRACT}

The prolific growth of aquatic plants in irrigation canals in Alberta has caused serious problems in the past. For example it has reduced the flow of water, plugged sprinkler systems, and in some cases, flooded farm lands. As a result, these weeds are considered to pose a serious threat to the overall efficiency of irrigation. Therefore, control options should be explored.

The use of spikerush, Eleocharis spp., as a replacement species to displace problem plants is being investigated currently. Needle spikerush, E. acicularis has evidently invaded irrigation canals of south-eastern Alberta and prefers to grow in small irrigation canals on narrow terraces raised some $10-20 \mathrm{~cm}$ above the bottom of the ditch. These plants are flooded from May to September annually by neutral to slightly alkaline, nutrient-poor irrigation water from the Bow River. Field test plots have been established to determine the natural growth rates of spikerush, and sod transplants have been placed in canals to assess how well spikerush might be able to compete with established stands of pondweed, Potamogeton spp. Preliminary investigations have shown successful vegetative reproduction of spikerush from sod, sprigs, and rhizomes. Treatments to enhance seed germination, including stratification and scarification, have indicated that the tough seed coat of spikerush is limiting germination.

The management of submergent aquatic plants in irrigation canals in southern Alberta is an ongoing activity to maintain sufficient waterflows to semi-arid areas. Species such as Potamogeton pectinatus, Potamogeton richardsonii, Potamogeton vaginatus and Alisma gramineum are prolific, and the overabundance of such vegetation results in the reduction of water-use efficiency and increased operational costs.

Figure 1 illustrates that the primary effect of overabundant aquatic vegetation results in water shortage. This is caused by the reduction of current velocity and carrying capacity, increased rates of siltation and plugging of structures and equipment. Reduction in current 


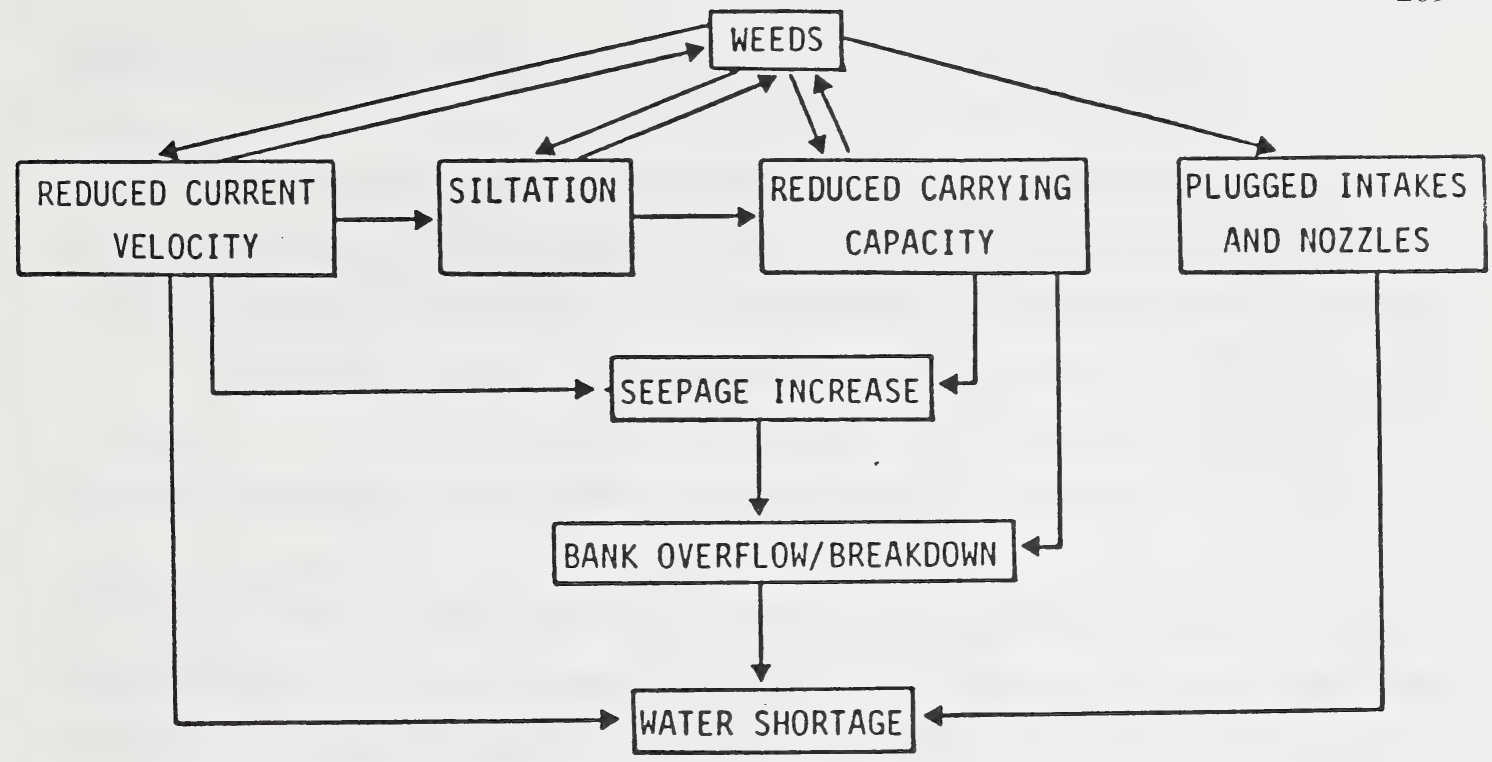

Figure 1. Primary effects of over-abundant aquatic vegetation (Pledger and Allan, 1985).

velocity could lead to increased canal seepage, breakdown, bank overflow and extensive silt deposition which will provide improved conditions for aquatic plant growth.

Reductions in canal capacity of more than $90 \%$ have been reported due to aquatic plant growth. Reed canarygrass alone can reduce the flow rate by up to $70 \%$ in small ditches. In cases where irrigation districts might attempt to compensate for decreases in the carrying capacity by reducing the "free board", this activity, again, could lead to problems such as increased seepage, canal breakdown, bank erosion and bank overflow. Table 1 outlines the flow losses of three major canal systems as a result of heavy plant growth.

There are three methods utilized at present for the purpose of aquatic plant control, They are: structural, mechanical and chemical. Presently, the irrigation districts rely heavily on chemical control using Magnacide- $\mathrm{H}$ with the active ingredient acrolein. This product is extremely toxic, produces only temporary control and its effectiveness is reduced under high water $\mathrm{pH}(>8.0)$ and low water temperatures $\left(<20.0^{\circ} \mathrm{C}\right)$.

Preliminary monitoring suggests that there are also differences among plant species in their tolerance to acrolein (Preus and Kissel, 1982). At present rates of application of acrolein, 
Table 1. Numerical losses in flow of three major canal systems as a result of heavy aquatic plant growth (Pledger and Allan, 1985).

\begin{tabular}{lccc}
\hline \hline \multicolumn{1}{c}{ Canal } & $\begin{array}{c}\text { Designed Carrying } \\
\text { Capacity (CFS) }\end{array}$ & $\begin{array}{c}\text { Carrying Capacity Under } \\
\text { Heavy Plant Growth }\end{array}$ & \% Reduction \\
\hline \hline "B" canal & 674 & 110 & 84 \\
Glenrose canal & 280 & 25 & 91 \\
Cluny South canal & 107 & 10 & 91 \\
\hline \hline
\end{tabular}

water plantain (Alisma gramineum) is not affected; this could enhance the growth of this plant in irrigation channels. It has also been observed that only the leaves of Richardson pondweed (Potamogeton richardsonii) are affected after Magnacide $\mathrm{H}$ application, while the stems show little or no effect. This activity causes reflushing of the leaves giving rise to a thicker and healthier plant and the final result is greater impedance to waterflow.

There are several biological control techniques which might be of use in reducing the growth of weeds in irrigation canals. The use of the slender spikerush (Eleocharis acicularis) to displace other species and prevent re-invasion is one technique that might be suitable for application in Alberta.

\section{OBJECTIVES}

The main objectives of the study are:

1. to investigate the distribution and identify the growth requirements of E. acicularis in Alberta irrigation canals; and

2. to determine the feasibility for culture and use of E. acicularis for aquatic manophyte displacement in irrigation canals.

This report describes an ongoing study that is being funded by the Research Management Division of Alberta Environment. 


\section{METHOD}

\section{Field Studies}

A preliminary reconnaissance of the Western Irrigation District southwest of Calgary on September 10, 1986 showed that seeds from the two most abundant species, E. palustris and E. acicularis, in irrigation canals were ripe and being dispersed from the seed heads. Seed heads from different sites were placed in labelled plastic bags and transported back to the laboratory in Calgary. The seeds were then removed, dried, cleaned and stored at room temperature $\left(21^{\circ} \mathrm{C}\right)$ in labelled, sealed glass jars.

\section{Spikerush Distribution}

Field surveys to locate spikerush distribution were conducted during the early fall. Detailed maps of the canal system were obtained for each irrigation district along with suggestions from district staff as to possible spikerush locations. The Taber District was surveyed first, followed by the Bow River, then the Eastern Irrigation District.

When spikerush was encountered, details of the site conditions, such as canal width, depth and microtopography, were recorded. The identity of the species, size of the stand and abundance (in percent) of spikerush and other species were taken from a plot representing a 10-m long portion of the canal. The exact location of the site was marked on the irrigation district map and pictures were taken.

Site characteristics which influence growth were documented by obtaining shallow soil samples from the upper $5-\mathrm{cm}$ layer. The soil samples were analyzed for texture, organic matter contents, $\mathrm{pH}$, conductivity, nitrate-nitrogen, phosphorous, potassium and sulphate-sulphur. Where possible, water samples were obtained for analyses of $\mathrm{pH}$, conductivity, nitrate-nitrogen, ammonia-nitrogen, phosphorous, potassium and sulphates. Flow conditions were noted at the time of sampling and historical flow information was obtained from irrigation district staff.

\section{Monitoring Sites}

Several sites typical of spikerush stands in the irrigation districts were selected for long-term monitoring. Each site was chosen after checking with the irrigation district manager to ensure that it was free of planned disruption activities for a five-year period. At each site, the outline of the spikerush beds was marked with painted wooden stakes. A sketch map of the spikerush stand, including stake location, was made and several photographs were taken. Four 
large bags of surface soil from the sides and bottoms of the canals and additional sods for growth trials were collected and transplanted to the laboratory. These were stored at $5^{\circ} \mathrm{C}$ until required. $\underline{\text { Sod Transplants }}$

Spikerush for laboratory research and transplanting were chosen from dense patches. Excess soil was removed without disturbing the roots. These roots were then placed on greenhouse trays where their stems (culms) were clipped to about $2 \mathrm{~cm}$ high, and then they were taken to the site for transplant within two hours of removal.

The transplant sites were representative of irrigation canals from the various districts. Two sites were chosen in each district, one with, and one without pondweed, in order to assess competition. Due to the lack of spikerush and the presence of a large number of concrete-lined canals, no monitoring or transplant sites were established in the Taber District.

At each site, six locations ( 2 on the canal bottom, 2 on one bank, and 2 on the opposite bank) were selected to receive sod transplants. The transplants $(20 \times 20 \mathrm{~cm})$ were placed in slightly deeper and wider holes, and the remaining spaces were filled with soil. Each sod was then covered with stucco wire which was held in place by five plastic stakes, one in each corner. The locations of all transplanted sods were marked with labelled wooden stakes and a sketch map was prepared. Each sod was photographed to provide a permanent record.

\section{LABORATORY TRIALS}

\section{Seed Germination}

Seeds used in the experiments were harvested from both E.palustris and E. acicularis and were collected from the Western Irrigation District. Seeds from different species were treated separately and placed on filter paper in shallow plastic dishes. These were then covered with distilled water to a depth of 2 to $4 \mathrm{~mm}$, and incubated under continuous fluorescent light at $25^{\circ} \mathrm{C}$ unless otherwise indicated. The percent germination of each treatment was compared to the germination of untreated, dry, stored seed. Each treatment was replicated three times, using 10 seeds each. Germination was considered to occur when the hypocotyl emerged from the seed coat. Seeds were counted every two to five days, depending on the rate of germination. 
$\underline{\text { Scarification }}$

The effects on germination of physically and chemically scarifying the seed coats were determined. Physical methods included ablation of the seed with fine sandpaper. Both a light sanding $(15 \mathrm{sec})$ and a heavy sanding $(1 \mathrm{~min})$ were undertaken with 120 grade sandpaper.

Chemical scarification of the seed consisted of immersion in concentrated hydrochloric acid for 12, 24 and 30 minutes. These seeds were then well rinsed with water for 5 minutes and set in plastic dishes as above. Combined treatments of heavy sanding $(1 \mathrm{~min})$ and acid scarification (at $12 \mathrm{~min}$ and $24 \mathrm{~min}$ ) were also investigated.

\section{$\underline{\text { Stratification }}$}

The effects of chilling on germination were also explored. Seeds chilled to $+2^{\circ} \mathrm{C}$ and $-15^{\circ} \mathrm{C}$ for four weeks were tested and compared against those stored at ambient temperatures $\left(+21^{\circ} \mathrm{C}\right)$. Tests were carried out utilizing plastic dishes as above.

\section{Seedling Growth}

Due to the slow rate of germination, the growth of seedlings from the above treatments could not be monitored over a short period of time. However, a large number of E. acicularis seedlings germinated from a layer of loam collected from Site B3. The loam was placed in an irrigation simulation tank to a depth of $3 \mathrm{~cm}$ and kept moist with tap water for 45 days until the seedlings were well established (Figure 2). The water level was then raised and maintained $10 \mathrm{~cm}$ above the soil surface for 44 days.

Water circulation in the tank was provided by a small electric water pump. The quality of the tap water was tested and compared to the normal irrigation canal water. Plants were carefully excavated, rosettes counted, rhizomes measured and growth patterns sketched and photographed.

\section{Sprig Growth}

The growth of E. acicularis sod, after being chilled for 70 days and prepared as sprigs, was investigated utilizing the following methods. A spikerush sod was thoroughly washed to remove mineral soil from the rhizomes and fibrous roots. After it was determined that the average distance between rosettes was $3 \mathrm{~cm}$, prepared sod was chopped into $3 \times 3 \mathrm{~cm}$ square pieces. These pieces were then mixed into the loam soil and placed in a separate portion of the simulation tank mentioned above. 


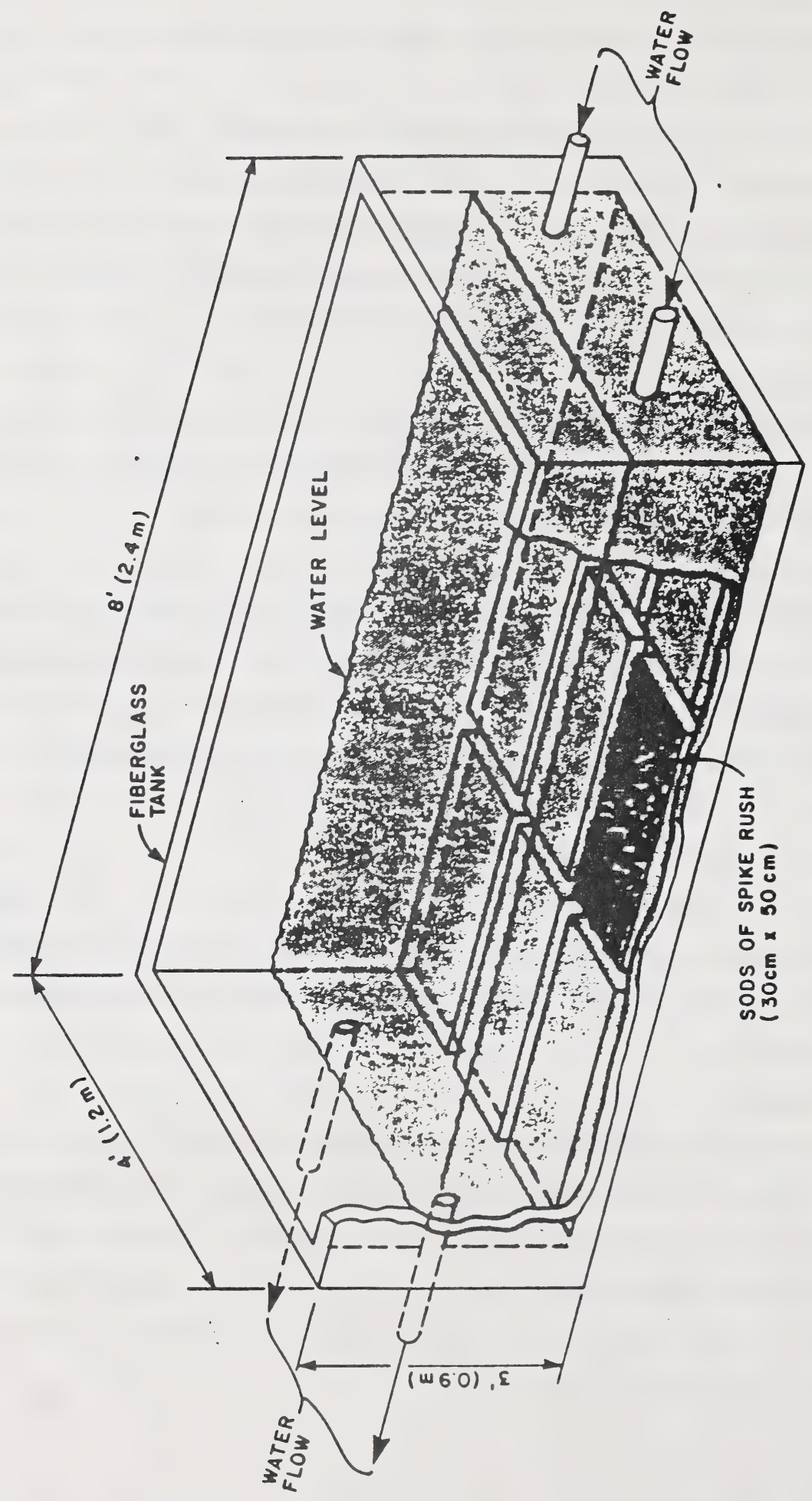

봃

ํㅡㄹ 
The second method of sprig preparation included carefully chopping spikerush sods into $3 \times 3 \mathrm{~cm}$ pieces. Excess soil was then removed from the bottom of the pieces and they were transplanted into the loam of the simulation tank at $10 \mathrm{~cm}$ intervals to allow room for growth. Three rows of 10 pieces each were planted.

The final method for testing sprig growth entailed the washing of all soil from a spikerush sod and then separating plants into pieces consisting of one to two rosettes and associated rhizomes. These rosettes were then placed on the surface of the loam at $10-\mathrm{cm}$ intervals in a separate area of the simulation tank. Three rows of 10 rosettes were planted.

The loam was then maintained in a moist condition with tap water for 45 days. The water level was gradually raised to a depth of $10 \mathrm{~cm}$ above the soil surface for an additional 45 days at a temperature of $19^{\circ} \mathrm{C}$. Lights were adjusted for a photoperiod of 18 hours per day. Water circulation was provided by a small electric water pump, as previously indicated. At the end of the specified period, plants were carefully removed from the loam, the rosettes were counted, rhizomes were measured and growth patterns were sketched and photographed.

\section{$\underline{\text { Sod Growth }}$}

The effects on growth were determined after chilling and freezing E. acicularis sod. Six pieces of sod $(20 \times 20 \mathrm{~cm})$ were chilled for 58 days between $-2^{\circ} \mathrm{C}$ to $+2^{\circ} \mathrm{C}$. These were then placed lengthwise in two rows in the simulation tank so that each sod was $15 \mathrm{~cm}$ from its neighbour and $15 \mathrm{~cm}$ from the edge of the tank. Three pieces of sod which had been chilled for 43 days at $-2^{\circ} \mathrm{C}$, then frozen at $-28^{\circ} \mathrm{C}$ for 15 days, were thawed for 3 days and then placed as the third row in the tank. The spaces between the sods were then filled with standard potting soil.

The water level in the tank was raised $10 \mathrm{~cm}$ above the sod and maintained for 75 days at temperatures of $19^{\circ} \mathrm{C}$ with 18 hours of light per day. Water circulation was provided by a small electric water pump. At the end of the experiment, sods were carefully removed, rosettes were counted, rhizomes were measured and growth patterns were sketched and photographed. 


\section{RESULTS}

\section{Biology and E. acicularis}

E. acicularis (slender spikerush) is the only species of the four present in Alberta to have invaded the sides and bottoms of irrigation canals in the southern part of the province. It is a low growing, aquatic, perennial plant that forms a dense sod. The main structure of the plant is a rosette composed of stems (culms), rhizomes and fibrous roots. The culms are green, needlelike stems that rise above the rosette and grow above the soil surface. Rosettes develop rhizomes that grow horizontally below the surface and have extensive fibrous roots. New rosettes are formed 0.5 to $5 \mathrm{~cm}$ apart (average $3 \mathrm{~cm}$ ) at nodes along the rhizomes. The plant reproduces sexually by seed (achenes) and vegetatively by rhizome growth. The abundance of slender spikerush, based on a grid examination of approximately every $1.6 \mathrm{~km}$ in selected areas of the three irrigation districts of southern Alberta, is shown in Table 2. Since spikerush rarely occurs in the Taber district, and because a large number of the distribution canals are either buried or lined with concrete, no monitoring of transplants was conducted in this area.

Most of the stands of slender spikerush were found in the older, well-established eastern portions of the Bow River Irrigation District, particularly in the vicinity of Hays. Stands of spikerush ranged in size from patches $0.5 \mathrm{~m}$ in diameter to large continuous growths extending approximately $50 \mathrm{~m}$ along the bottom of some canals.

Slender spikerush was recorded frequently throughout the Eastern Irrigation District, occurring in $20 \%$ of the sites examined. Stands also ranged in size from small patches to large continuous growths approximately $30 \mathrm{~m}$ along the bottom of some canals.

Table 2. Abundance of E. acicularis in irrigation canals of southern Alberta (Pledger and Allan, 1985).

\begin{tabular}{lcccl}
\hline \hline $\begin{array}{c}\text { Irrigation } \\
\text { District }\end{array}$ & $\begin{array}{c}\text { Sites with } \\
\text { Spikerush }\end{array}$ & $\begin{array}{c}\text { Sites without } \\
\text { Spikerush }\end{array}$ & $\begin{array}{c}\text { Total Sites } \\
\text { Checked }\end{array}$ & Abundance \\
\hline \hline Taber & 1 & 23 & 24 & Rare \\
Bow River & 8 & 46 & 54 & Occasional \\
Eastern & 23 & 90 & 113 & Frequent \\
\hline \hline
\end{tabular}




\section{Canal Size}

Slender spikerush was noted primarily along the smaller distribution, secondary irrigation channels and was not observed along any of the main canals. Spikerush usually grew on the bottom and lower sides. Favoured locations appeared to be narrow terraces 0.3 to $1.0 \mathrm{~m}$ wide, along one or both sides of the canal bottom. Terraces were often 10 to $15 \mathrm{~cm}$ above the deepest part of the canal in which standing or flowing water was found. These distribution canals ranged in depth from 2 to $6 \mathrm{~m}$.

\section{Water Regime and Quality}

The irrigation system is initiated in May, and the distribution canals generally are full of flowing water (1 to $3 \mathrm{~m}$ deep) until September when the system is shut off. The water is then drained from the canals, allowing them to dry out and freeze over the winter.

Since the irrigation system was shut off at the time of the field survey, water samples were obtained from small amounts of flowing water and pools of standing water. These samples were fairly similar to those obtained for the main canal near the Lost Lake supply reservoir of the Bow River Irrigation District (Table 3). Slender spikerush appeared to favour mildly alkaline conditions, with $\mathrm{pH}$ ranging from 7.34 to 8.10 , and total hardness and alkalinity ranging from 155 to $170 \mathrm{ppm}$ and 118 to $125 \mathrm{ppm}$, respectively. The level of nutrients, particularly nitrogen, potassium, phosphorus and sulphur, was low, but apparently adequate for spikerush growth.

Substrate, Texture and Nutrients

Slender spikerush grew in substrates with soil textures ranging from clay to sand (Table 4). Ranges for sand, silt and clay were 10 to $72 \%, 17$ to $68 \%$, and 10 to $26 \%$, respectively, while organic matter was low, ranging from 1.1 to $2.2 \%$. These plants grew best on soft loamtextured soils where roots and rhizomes were not restricted. Soil $\mathrm{pH}$ was mildly alkaline, ranging from 7.8 to 9.1 , while average electrical conductivity was $0.7 \mathrm{mS} / \mathrm{cm}$. The levels of nutrients, while wide ranging, appeared sufficient for plant growth.

\section{Associated Species}

The most common species associated with spikerush in canals were pondweeds (Potamogeton pectinatus, $P$. vaginatus, and $P$. richardsonii) and narrow-leaved water plantain (Alisma gramineum). On the lower slopes of the canals, several other species including tufted hair grass (Deschampsia cespitosa, Kentucky bluegrass (Poa pratensis) and reed canarygrass 


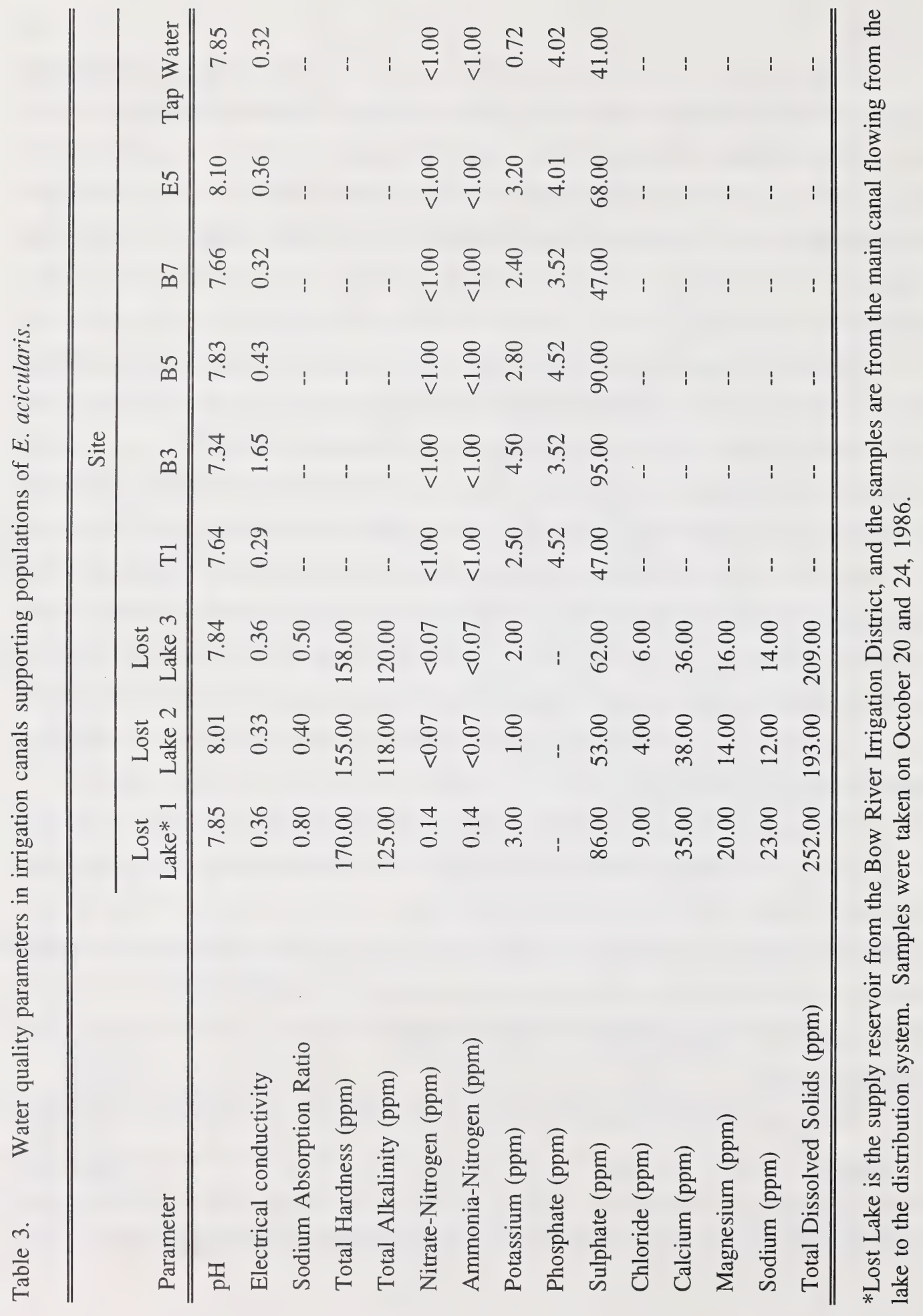


(Carex aquatilis) were found. At most sites, slender spikerush grew in pure stands; however, sedge and tufted hair grass were present in mixtures with spikerush at three of the study locations.

\section{Interaction With Other Species}

Although no evidence was observed in the field of slender spikerush interaction with other species, studies in California of dwarf spikerush have indicated that both mechanical and chemical (alleopathy) mechanisms are involved. Yeo (1980) found that dwarf spikerush displaced other species by invading their habitat when growth of the other plants was suppressed. During a three-year study, Frank and Dechoretz (1980) found that tubers of pondweed, inserted into sods of dwarf spikerush, produced one-third fewer pondweed plants than those grown without spikerush. In a second experiment, two species of pondweed supplied daily with water taken from dwarf spikerush cultures produced about half the number of plants as the control (tap water). This indicated that an inhibitory substance was likely produced by dwarf spikerush. Similarly, when leachates from soils containing dwarf spikerush and slender spikerush were placed in tomato cell suspension cultures, the tomato cell volume was reduced by $70 \%$ (Wach, 1979). Yeo and Thurston (1984) further substantiated that dwarf spikerush reduced the shoots and dry weight of several aquatic weeds, including American pondweed (Potamogeton modosus) and sago pondweed.

\section{Propagation}

Field Trials

Field plots for the purpose of obtaining the rate of natural vegetative growth, and growth of transplanted sods and sprigs, were established. Four plots to monitor the natural rate of growth of undisturbed slender spikerush were set up in the Bow River and Eastern Irrigation Districts. The extent of the growth of spikerush in each of these areas was recorded. An additional four plots to monitor the rate of growth of transplanted spikerush sods, both with and without competition from pondweed, were also created. Field-trial experiments will be monitored during the summer of 1987. 


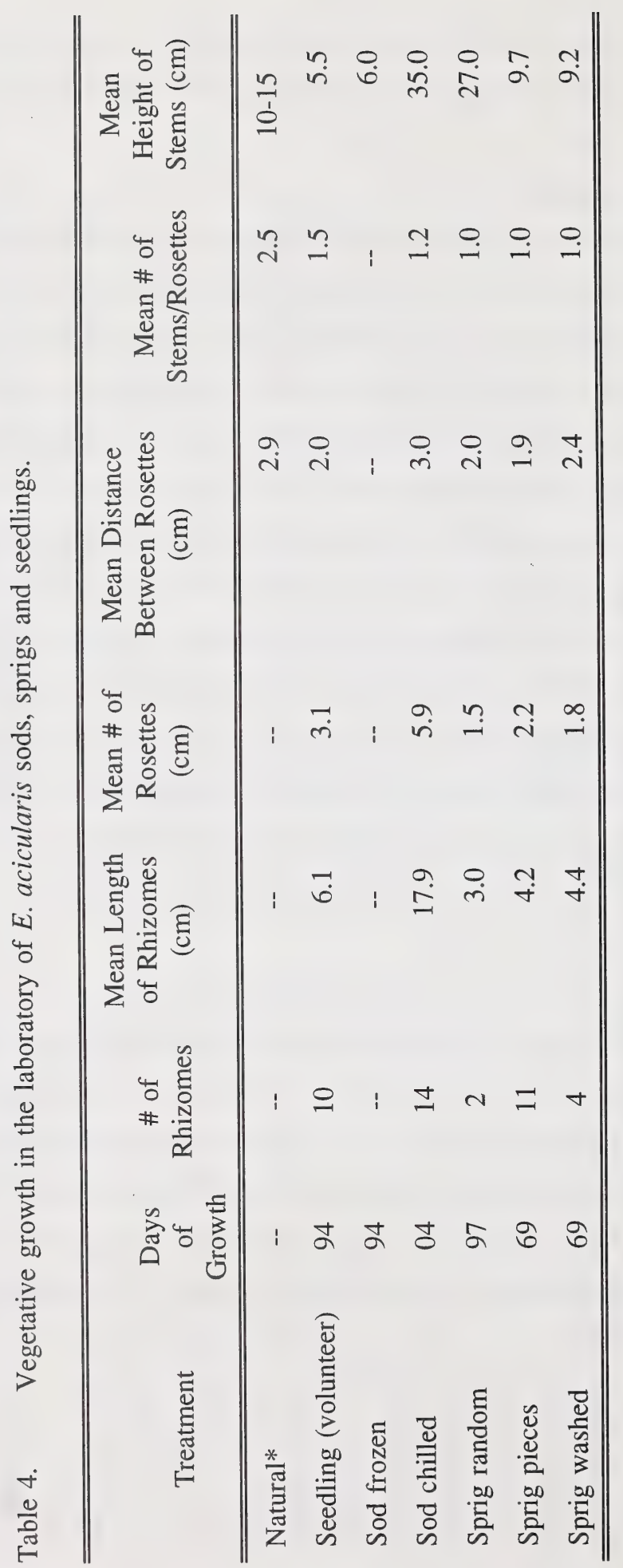




\section{Laboratory Trials}

The results of vegetative-growth trials indicated that slender spikerush was not an aggressive colonizer of bare soil (Table 4). Seedlings that emerged from soils taken from canal banks showed the densest and most prolific growth. Frozen sods did not produce any rhizomes, and stem growth was diminished. Chilled sods produced only an average of 2.3 rhizomes per sod, but these indicated good stem growth. On the other hand, sprig pieces showed the most productivity, with 8 of the 30 pieces producing rhizomes. Although random sprigs did not produce any new rhizomes, their stem growth $(27 \mathrm{~cm})$ was similar in height to that of the chilled sods.

Seed

Germination was very poor with most treatments (Table 5). After 75 days, the greatest success had been observed in E. palustris which had been chilled to $2^{\circ} \mathrm{C}$; these exhibited approximately 10 percent germination. Ambient and $-15^{\circ} \mathrm{C}$ temperature treatments of $E$. palustris resulted in less than 5 percent germination. On the other hand, E. acicularis had approximately 5 percent seed germination for each treatment (ambient, $2^{\circ} \mathrm{C}$ and $-15^{\circ} \mathrm{C}$ ) after 50 days.

Scarification treatments yielded no germination after 60 days.

\section{$\underline{\text { Response }}$}

As a result of tests for the purpose of controlling pondweed in irrigation canals, it was noted that slender spikerush did not appear to be affected by Magnacide $\mathrm{H}$ (Burland, pers. comm.). Test data for another aquatic plant herbicide, "Sonar", manufactured by Elanco Products Company, indicated that the response of spikerush species (not including slender spikerush) response ranged from susceptible to intermediate, while most pondweed species were very susceptible.

Feasibility of Using Eleocharis acicularis to Control Aquatic Weeds

The use of slender spikerush to displace aquatic weeds in irrigation canals appears attractive because of this species' ability to invade irrigation canals naturally. The species has short stems (10 to $15 \mathrm{~cm}$ tall), and produces a dense sod of rhizomes and fibrous roots. The stands appear to be self-maintaining and are usually able to exclude other species. Because the plant is not an aggressive colonizer of bare soil, it should be relatively easy to manage. 
Table 5. Percent germination of E. acicularis seed, pre-treated with cold stratifications or scarifying treatments.

\begin{tabular}{lcc}
\hline \hline \multicolumn{1}{c}{ Treatment } & E. acicularis & E. palustris \\
\hline \hline Ambient Temperature $\left(21^{\circ} \mathrm{C}\right)$ & $4 \pm 1 \%$ & $5 \pm 2 \%$ \\
Cold Treated $\left(2^{\circ} \mathrm{C}\right)$ & $4 \pm 2 \%$ & $10 \pm 4 \%$ \\
Frozen Treated $\left(-15^{\circ} \mathrm{C}\right)$ & 0 & $6 \pm 3 \%$ \\
Light Scarified $(15 \mathrm{sec}$ sanding $)$ & 0 & 0 \\
Heavy Scarified $(1 \mathrm{~min}$ sanding $)$ & 0 & 0 \\
Acid Scarified $(12 \mathrm{~min})$ & 0 & 0 \\
Acid Scarified $(24 \mathrm{~min})$ & 0 & 0 \\
Acid Scarified $(36 \mathrm{~min})$ & 0 & 0 \\
Scarified $(1 \mathrm{~min})+$ Acid $(12$ & 0 & $\mathrm{n} / \mathrm{a}$ \\
min $)$ & 0 & \\
Scarified $(1 \mathrm{~min})+$ Acid $(24$ & & \\
min $)$ &
\end{tabular}

Spikerush also appears to tolerate the water regime of irrigation canals in Alberta. That is, flooded all summer, and empty and frozen during the winter.

Based on the limited laboratory trials, slender spikerush appeared to be difficult to propagate. Seed germination rates were very slow due to the tough seed coat, and vegetative growth rate by new rhizomes was also lengthy.

The sluggish rates of natural propagation probably accounted for the lack of aggressiveness and minimal invasion of irrigation canals by this species. The major unknown factor, however, would be the field response of the transplanted sods. The response of these field transplants and their comparisons to the laboratory findings might provide some answers about the propagation of spikerush.

\section{RECOMMENDATIONS}

It is apparent that further studies should be considered in order to determine whether or not slender spikerush might be feasible for use as a replacement species for problematic flora in irrigation canals. It is recommended that the following areas of research be investigated: 
1. Existing transplanted sods should be examined in late April or early May before the irrigation season, to determine how well they have survived winter conditions and whether or not they were affected by frost action.

2. Based on the results of growth trials, sprig transplants should be placed in the canals before the irrigation season. Since sprigs are smaller and easier to handle than sods, they might prove to be a more feasible method than actual spikerush propagation.

3. Seed collection should take place in mid- to late-August so that seed trials can be conducted. Seeding trials should be established at the same sites as the existing transplanted sods, following the end of the irrigation season.

4. The status of sod and sprig transplants and seedings should be determined following one growing season.

\section{REFERENCES}

Burland, R. 1986. Personal communication. Pesticide Chemicals Branch, Alberta Environment, Lethbridge, Alberta.

Frank, P.A., and N. Dechoretz. 1980. Allelopathy in dwarf spikerush (Eleocharis acicularis). Weed Science 28:499-505.

Pledger, D., and J.R. Allan. 1986. Aquatic plant management in irrigation channels. Prep. for Pesticides Chemical Branch, Alberta Environment, Edmonton, Alberta. 6 pp.

Preus, M.W., and C.L. Kissel. 1982. Controlling plant growth in irrigation systems. Nebraska summer research with Magnacide H. Presented at Nebraska Irrigation Expo and Water Conference. $7 \mathrm{pp}$.

Wach, M.J. 1979. Phytotoxicity of leachates from terraria containing dwarf spikerush (Eleocharis coloradoensis). Master Sci. Thesis. Botany Department, Univ. California. $59 \mathrm{pp}$.

Yeo, R.R. 1980. Life history and ecology of dwarf spikerush (Eleocharis coloradoensis). Weed Sci. 26:425-431.

Yeo, R.R., and J.R. Thurston. 1984. The effect of dwarf spikerush (Eleocharis acicularis) on several submersed aquatic weeds. J. Aquat. Plant Manage. 22:52-56. 


\title{
Description of Two Treatment Methods for Detoxifying Oil Sands Tailings Pond Water
}

\author{
Hans Boerger \\ Syncrude Canada Ltd. \\ Fort McMurray, Alberta
}

\section{ABSTRACT}

The caustic hot water process for extracting bitumen from oil sands produces large quantities of toxic wastewater which is stored in large tailings ponds. Toxicity appears to be primarily due to polar organic carboxylic acids (naphthenic acids) and is augmented by high concentrations of suspended particulate matter, bitumen and dissolved solids. One method of detoxification involves the lowering of the $\mathrm{pH}$ from 8 to 5 , followed by addition of an anionic polyelectrolyte. A second treatment method involves the storage of tailings water in shallow pits for 1-2 years during which naturally-occurring physical, chemical and biological processes result in detoxification, based on tests with bacteria (Beckman Microtox Test), trout and daphnia. Ten-week tests with multi-species, simulated pond ecosystems in $10 \mathrm{~m}^{3}$ outdoor pools indicate that some chronic effects remain after treatment. However, these effects are not considered limiting to the environmental acceptability of the treated water.

The material presented has been published in the following three papers:

1. Boerger, H., M. MacKinnon, and M. Aleksiuk. 1986. Use of toxicity tests in studies of oil sands tailings water detoxification. Can. Tech. Rep. Fish. Aq. Sci. 1480:131-146.

2. Boerger, H., and M. Aleksiuk. 1987. Natural detoxification and colonization of oil sands tailings water in experimental pits. In: Vandermeulen, J.H. and S.E. Hrudey (ed). 1987 Oil and freshwater chemistry, biology and counter-measure technology. pp. 389-397. Pergamon Press, New York.

3. MacKinnon, M.D., and H. Boerger. 1987. Description of two treatment methods for detoxifying oil sands tailings pond water. Wat. Poll. Res. J. Can. 21:496-512. 


\title{
Evaluation: An Important Part of Managing the Environment
}

\author{
Jack Grainge \\ 11231 University Avenue \\ Edmonton, AB T6G 1 Y7
}

During the last quarter century, people have become keenly sensitive to environmental damage. In the haste to make corrections, some projects have been initiated without adequate foresight. At times, the corrective measures have been too extreme.

For most alternatives, the costs versus the benefits should be considered, while at the same time, planning for the next century or more is also important. For example, planning for the time when Alberta's population will be two, three or four times the present level should be undertaken now. Large deposits of coal in Alberta will attract manufacturing industries which use coal as a raw material; industries will be attracted by the relatively low cost of this thermalelectric power.

The communication process must be improved to enable administrators of the pollution protection agencies involved, the media and the public, regardless of their technical expertise, to have a better understanding of the issues.

The following six proposals will assist in making cost-benefit comparisons. The examples and suggestions are based on the experience of the author.

\section{Proposal One}

Ways in which farmers and lakeside cottage owners can reduce their contributions of phosphates to those small lakes that should be protected from eutrophication should be considered. For example, guidelines to limit herds of domestic animals from having direct access to lakes and streams that flow into these lakes should be developed. Furthermore, future lakeside cottage developments should be planned so that when expansion occurs, sewer systems can be installed at reasonable cost.

This is particularly important if the subsoil in the vicinity of the lake is clay. For example, in a study of sewage disposal practices south and east of Sherwood Park, the clay subsoil surrounding the leaching fields swelled after septic tanks began discharging and, consequently, the soil became impermeable. Under these circumstances, the householders are supposed to have their sewage hauled away. However, in many cases, the effluent either overflowed or seeped through the surface soil to form ponds nearby. 
There are cases, undiscovered by the authorities, where the soil was impermeable and, thus, septic tank effluent was piped to streams and, in one case, to a road ditch that led to a stream. It is therefore likely that lakeside cottage owners may install similar illegal effluent disposal pipes, although such cases may be difficult to discover.

\section{Proposal Two}

When there are minor deviations of concentrations of substances in water, some of the media report it as a catastrophic situation. However, journalists are usually unaware of the compromises involved in setting standards. Standards for natural waters, and companion standards for drinking water and for effluents from waste treatment plants, are prepared by committees of individuals with technical expertise. In all three cases, the figures set are compromises between what is deemed to be practical and what is desirable. From time to time, as new information becomes available and committee membership changes, the figures are revised, both upward and downward. There can be a wide divergence of opinion among members of a committee in setting standards.

For example, when proposing drinking water standards for the Northwest Territories, the desirable concentration of fluorides was recommended to be $1.5 \mathrm{mg} / \mathrm{L}, 50 \%$ higher than that acceptable under Alberta standards. The media would have construed this to be of great concern; yet the figure was based on a thorough study and was adopted by the Chief Medical Health Officer of the N.W.T.

It is important, therefore, that the media present the consequences of any deviation from the standards, in addition to reporting the deviation.

\section{Proposal Three}

Sewage effluents may be chlorinated before they are discharged into lakes and streams, based on the cost of chlorination versus the value of downstream water sports. It would be environmentally sound, also, to consider the potential value of the microorganisms and enzymes in the sewage effluent that are destroyed by chlorination. In addition, since over-chlorination is necessary to destroy bacteria effectively, the adverse effects of the chlorine on the natural organisms in the receiving water should be considered as well. Bacteria in the wastewater would not adversely affect fish or other natural organisms in the lakes and streams if the wastewater were not chlorinated. 
For example, while investigating the effects of effluents from sewage treatment plants in the rivers and lakes in the vicinity of Norway House, Manitoba, evidence of damage to organisms due to the chlorinated effluent from a sewage treatment plant was found. Fish caught in traps in water with high concentrations of chlorine died.

Bacteriological tests are frequently used in studies of water environments. However, human bacteria do not have a major impact on the health of either the flora of the fauna within aquatic ecosystems, and tests for these bacteria are of no consequence in such studies. Yet, such tests are made in studying isolated lakes that are not used for water supplies, water sports or even fishing.

Tests for human bacteria are of public health importance in pollution-control programs. Total coliform bacteria is the most sensitive indicator test for sewage pollution for several reasons: (1) These bacteria occur in large numbers in human feces; (2) they survive longer in water than most pathogenic bacteria; and (3) the test is simple, and inexpensive, and has been used so long that it has worldwide acceptance. Yet, some reports, in addition to reporting the results of total coliforms and fecal coliforms, also include four other tests: fecal streptococci, heterotrophs and specific plant counts at two different temperatures. While the test for fecal streptococci might be substituted for the test for fecal coliforms, no useful purpose is served by making so many different, costly tests. Since budget restrictions are becoming increasingly stringent and many useful environmental protection programs are underfunded, it is paramount that resources not be wasted on meaningless tests.

It may be argued that tests for coliforms are not useful for monitoring enterovirus levels; however, most agencies do not monitor for enterovirii.

\section{Proposal Four}

Edmonton officials have been aware since approximately 1954 that storm-water sewers discharging upstream of the centrally-located Rossdale water treatment plant carried tasteproducing and toxic substances. In fact, the late E.L. Smith, Chief Engineer of the Rossdale water treatment plant at the time, said that the adverse tastes and odours in Edmonton's treated water were partly due to discharges from storm-water sewers upstream of the water plant.

If, before expanding the plant in 1956 and again in 1967, authorities had considered how large Edmonton would become, particularly in an upstream direction, they might have constructed a plant further upstream then, rather than waiting until 1974. 


\section{Proposal Five}

Even in isolated areas, the thrust of cost-benefit comparison needs to be a prime consideration, particularly where the bacteriological quality of the drinking water is concerned. During the 1950s and 1960s, the federal Public Health Engineering Division cooperated with the Alberta Division of Sanitary Engineering and the administrations of Indian Affairs, National Parks and the N.W.T. to protect remote rivers and lakes, including those in national and provincial parks, from sewage pollution. In most cases, this objective was accomplished by constructing sewage treatment ponds which provided prolonged treatment of sewage.

For example, immediately downstream of Fort Smith, a town situated adjacent to the Alberta-N.W.T. border, approximately one hundred Indians used water from the Slave River without treating it. As stated by Chief Henry Beaver at a public hearing of the N.W.T. Water Board, his people, living both upstream and downstream of the border, consider that the water should be free of pollution "as long as the river flows" (N.W.T. Water Board, 1979).

In 1958, when a sewage system was constructed to serve the town of Fort Smith, a treatment pond was provided where the effluent seeped into the subsoil. A few years later, a sewage treatment pond was constructed to serve the staff of the airport at Fort Smith and, likewise, the effluent seeped into the subsoil. There was no effluent disposal to the river from either facility.

Although standard sewage-treatment ponding systems in Alberta provide a retention time of 15 or more months, a retention time of 24 months would be required if the sewage bacteria are to be completely destroyed. The farther north the ponds, the longer the time requirement because the winters are longer and virtually no treatment occurs when ice and snow block the sunlight. In fact, under ice, bacteria may be preserved.

During the 1950s and 1960s, Health and Welfare Canada officials monitored the water in the river at the border and found it to be practically free of coliforms. At present, in late water when, according to stream-flow records of Environment Canada, the flow-rate in the Slave River is lowest, the concentration of total coliforms in the river at the border is usually around 100 per litre. By comparison, untreated water is not considered safe for drinking when the total coliforms average 20 per litre.

Since the late 1970s, sewage from Fort Smith (current population 2 300) has been discharged into the Slave River after only about four months retention in sewage treatment ponds. 
In winter, this retention time is approximately two months. In addition, this practically untreated sewage flows alongside the river banks so that it is concentrated, not diluted, when it reaches the community of Salt River, $22 \mathrm{~km}$ downstream. Even if the effluent mixed thoroughly in the river, bacteriological tests on the pond effluent indicate that it would increase the concentration of coliforms by 500 per litre at minimum flow periods.

Yet, the sewage could be treated adequately by diverting either the sewage or the effluent to a huge swamp in Alberta that borders Fort Smith. This swamp is large enough to contain sewage for 2 to 3 years. A number of reports discuss the thorough treatment that swamps can provide to sewage (Hartland-Rowe et al., 1974).

Alternatively, adding a cell to the treatment ponding system would not be too costly. Fort Smith's consulting engineers consider both of these alternatives to be practical.

\section{Proposal Six}

Although the water in Alberta's rivers and lakes is adequately buffered to prevent it from being affected by acid rain, some of the province's air pollutants, like those from other countries in the northern hemisphere, are contributing to the acid rain falling on the unbuffered lakes in the Arctic Archipelago.

To date, this problem has not been thoroughly investigated. Scientists from several countries have made flights over the Arctic to take air samples for testing. They have shown that the sources of the pollutants have been primarily the highly industrialized areas of Russia, Europe and eastern North America (Schnell, 1984; Joranger and Ottar, 1984; Schnell and Raatz, 1984).

If the investigations show that emissions of acids should be reduced, then all countries in the northern hemisphere should be reducing their acid emissions; for example, from coal-fired electric generators and from automobiles.

The use of automobiles could be reduced by making bicycling around cites safer. Many people would ride bicycles to work if bicycle lanes in cities paralleled the traffic arteries. In addition, if employers did not provide cheap parking for cars, more of their employees would use public transportation. Furthermore, it would help if there were no hidden subsidies for roads, power and telephones for people living on acreages. 


\section{CONCLUSION}

These suggestions for using cost-benefit comparisons and future planning illustrate the necessity of planning for future population growth in Alberta. In the meantime, fully evaluating all aspects of problems should result in the best possible solutions.

\section{REFERENCES}

Hartland-Rowe et al. 1974. Swamplands for sewage effluents. Information Canada. Cat. No. 71-13174, 35-33.

Joranger, E., and B. Ottar. 1984. Air pollution studies in the Norwegian Arctic. Geophys. Res. Lett. 11:365-368.

N.W.T. Water Board. 1979. Minutes of the public hearing on the N.W.T. Water Board held in Fort Smith in 1979.

Schnell, R.C. 1984. Arctic haze and the Arctic gas and aerosol sampling program (AGASP). Geophys. Res. Lett. 11:361-364.

Schnell, R.C., and W.E. Raatz. 1984. Vertical and horizontal characteristics of Arctic haze during AGASP: Alaskan Arctic. Geophys. Res. Lett. 11:369-372. 


\title{
The Consequences of Muskrat Predation on the Growth of a Unionid Clam
}

\author{
J. Mark Hanson \\ Department of Zoology, University of Alberta \\ Edmonton, Alberta
}

\begin{abstract}
The unionid clam, Anodonta grandis simpsoniana, dominates the biomass of benthic fauna in Narrow Lake, a small, deep lake in the Boreal forest zone of Alberta. There was substantial variation in the length of clams at annulus, but no significant difference in growth among the $1,3,5$ and $7-\mathrm{m}$ depths in the lake. Size-selective predation could explain this lack of difference in growth among depths, and the absence of clams $>75 \mathrm{~mm}$ long supports this hypothesis. In this study, the predation hypothesis was tested by measuring the rate of clam predation and the clam size selectivity of muskrats (Ondatra zibethicus) in the lake. Muskrats were estimated to have killed over 44000 clams in one ice-free season in Narrow Lake. An estimation of biomass, using a length-weight regression, determined that muskrats were removing 8 to $9 \%$ of the measured biomass of clams in the north end of the lake. Furthermore, this predation was highly size selective. As a result, the muskrats were removing the fastest growing individuals of the age 4 to 12 year classes and may be selecting for slow-growing individuals. This result is very similar to that observed for fish populations undergoing highly size-selective fishing mortality.
\end{abstract}




\title{
Fish Tainting by Oil Sands Tailings Pond Wastewaters
}

\author{
C.W. Koning and S.E. Hrudey \\ Department of Civil Engineering \\ University of Alberta, Edmonton, Alberta
}

\begin{abstract}
Hatchery-raised rainbow trout were exposed for $24 \mathrm{~h}$ to selected tailing pond wastewaters at a Ft. McMurray oil sands plant. Sensory evaluation of the fish fillets, performed by a prescreened, trained, 10-member panel revealed a significant taint resulting from each wastewater exposure. Tissue and bile analysis of the most tainted fish revealed the presence of alkylated benzenes and phenols in the fish tissue, and conjugated, alkylated phenols in the bile. Final conclusions on the relevance of alkylated benzenes were prevented by analytical interference from a contaminated solvent.
\end{abstract}

Although alkylated benzenes and phenols have been reported as potential tainting compounds in other studies, it is still uncertain whether they were the major tainting compounds in this study.

\section{INTRODUCTION}

Impairment of fish flavour may occur due to discharges by a variety of industries such as pulp and paper, petroleum, and petrochemicals; by municipal sewage discharge; and by intensive agriculture activities. Naturally occurring, water-borne compounds such as geosmin and methylisoborneol may also cause fish tainting.

Compounds which cause tainting are found in fish tissue at concentrations well below known human acute-toxicity levels. Fish tainting is a significant problem however, because of concerns such as the following:

1. Consumer resistance and the subsequent loss in commercial value of the fisheries resource;

2. Loss of sport fishing and tourism value; and

3. Loss of a subsistence fishery by downstream native communities.

Oil sands wastewaters comprise a complex mixture of organic compounds. At least some of the compounds known to taint fish are also present in oil sands wastewaters. Specific 
compound classes identified are presented in Figure 1. Common characteristics among these compounds include relatively low molecular weight, high volatility, low taste and odour thresholds, and high bioconcentration factors for aquatic organisms.

1. alkylated naphthalenes

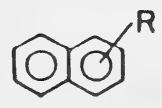

2. alkylated thiophenes

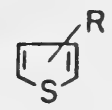

3. alkylated benzothiophenes

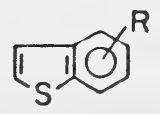

4. alkylated dibenzolhiophenes

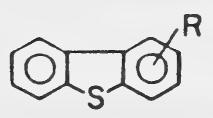

5. alkylated phenols

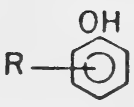

Figure 1. Compound classes known to taint fish which may exist in oil sands wastewaters.

Uptake and bioaccumulation of tainting compounds in fish occurs by transfer across the gills, uptake through the alimentary canal and epidermal adsorption. For freshwater fish, uptake by the gills is likely most significant. Waterborne tainting compounds, lipophilic in behaviour, pass across the gills to the blood stream, by which they are transported throughout the tissues.

The time required to produce an off flavour varies from less than one hour to several days, depending on fish species, water temperature and the physico-chemical characteristics of the tainting compound. In addition, there may be a number of known and unknown synergistic interactions affecting the tainting response. 


\section{OBJECTIVE}

The purpose of this study was to determine whether tailings pond wastewaters at the Syncrude oil sands plant in northern Alberta are capable of tainting fish. To this end, sensory evaluation of exposed fish was performed.

\section{MATERIALS AND METHODS}

Rainbow trout were exposed for $24 \mathrm{~h}$ to the following four tailings pond wastewaters at the Syncrude site:

1. Fresh tailings pond water, diluted to $6 \%$ of full strength.

2. One year "stored" tailings pond water - stored to reduce its toxicity.

3. "Treated" tailings pond water - treated by acidification/chemical flocculation in order to reduce its toxicity.

4. Catchment basin water - a combination of tailings pond dyke drainage water and precipitation runoff, which drain together into a common basin.

After $24 \mathrm{~h}$ exposure the fish were sacrificed, cleaned, and gutted. The fish fillets, complete with attached skin, were immediately frozen and stored until required for sensory evaluation.

Twenty-five people were recruited and screened for their sensory ability. Evaluation was based on their ability to recognize and their sensitivity towards a variety of odourous compounds. Ten of the best recruits were then chosen for the sensory panel.

Sensory evaluation was performed using a technique whereby panelists compared exposed fish tissue samples to unexposed, "reference", fish tissue. Panelists indicated, on the basis of odour, which tissue sample they judged to be most tainted.

\section{RESULTS AND CONCLUSION}

Sensory evaluation revealed that three of the four selected tailings pond wastewaters significantly tainted rainbow trout after 24-h exposure. In the fourth case, unexpected toxicity problems encountered with the one year "stored" tailings pond water forced the fish to be harvested after only $2.5 \mathrm{~h}$ exposure. A significant taint was nevertheless recorded following this short exposure period. 
The results indicate that the fish tainting potential of tailings pond wastewaters should be considered an important criterion for controlling tailings pond discharges to the Athabasca River. 


\title{
Changes in the Abundance of Fishes in the Red Deer River Below the Dickson Dam
}

\author{
Wayne Roberts \\ University of Alberta \\ Edmonton, Alberta
}

\section{ABSTRACT}

During the five years since the construction and filling of the Dickson Dam on the Red Deer River, changes in the abundance of certain fish species have occurred below the damsite. Spoonhead sculpins (Cottus ricei) are much less abundant than they were prior to impoundment of the river. Mountain whitefish (Prosopium williamsoni) have had poor reproductive success. Spawning occurs in traditional sites below the damsite, but larvae exhibit poor survivorship. Large piscivorous species such as the northern pike (Esox lucius) and walleye (Stizostedion vitreum vitreum) were declining prior to construction and continue to do so, perhaps at a relatively greater rate. Increased availability to anglers and reduced reproductive success are probably important factors in this decline. Mooneye (Hiodon tergisus) and goldeye ( $H$. alosoides) are uncommon between Red Deer and the damsite where they were formerly abundant.

The spoonhead sculpin (Cottus ricei) has suffered the greatest relative decline in abundance since impoundment. Throughout much of their range in North America, sculpins of the genus Cottus occur in the same waters as a variety of trout and char species and share with them the requirement for clean rocky or gravel bottoms for reproduction and/or protective cover. Sculpins and salmonid fishes may thus be regarded as indicators of water and substrate quality in streams where they complete their life cycles. Sculpins are able to utilize the coarse, clean rocky bottoms of large streams for spawning and are not dependent on the gravel beds of tributaries as are most salmonids. In this regard, they function as better indicators than trout of substrate cleanliness in rivers. Not generally being subject to angler harvest, changes in numbers of sculpins reflect changes in the environment rather than changes in the utilization of the fishery which may be a consideration with salmonids.

The spoonhead sculpin is present in streams and rivers of the major Eastern Slope drainages of Alberta (Paetz and Nelson, 1973). This fish reaches its greatest abundance in cleanbottomed, free-stone streams, such as the upper Red Deer River, where its life history has been 
investigated since 1975. Prior to impoundment of the river, spawning occurred from mid-April to early May when water temperatures had increased to 5-7 degrees centigrade. The male selects a suitable site, usually under a rock, and defends it against male conspecifics and other small fishes. Females are courted and deposit 280-1200 adhesive eggs on the underside of the rock. The male guards and fans the eggs for 2-3 weeks until they hatch. The protolarvae are positively phototactic and are distributed in the shallows near shore in quiet water. They are day-active and forage for microinvertebrates on and above the substrate until late in their first summer when they seek cover by day and forage at night, preying on insects and crustaceans. Spawning first occurs during the third spring at an age of about 23 months.

Prior to the impoundment of the Red Deer River, spoonhead sculpins were easily obtained by turning over flat rocks in the shallows from the damsite to the vicinity of the City of Red Deer. No quantitative estimates of abundance were made as numbers of sculpins were easily obtained at many sites along the river. Spoonhead sculpins are presently much less abundant than they were prior to impoundment of the river. Only three specimens were located during several days of searching in 1986; all were adults in excess of $100 \mathrm{~mm}$ total length. Much of the formerly occupied habitat is devoid of or sparsely occupied by sculpins. The absence of juveniles and young-of-the-year may indicate reproductive failures.

The decline in numbers of this species may be the result of altered habitat and thermal regime. The substrate of the river below the dam is coated with a dense growth of diatoms, dominated by Cymbellus, in the winter and spring. The interstices in the substrate, plugged with diatoms, no longer provide refuge for sculpins and other small fishes such as cyprinids, catostomids, troutperch and burbot. The larger invertebrates on which sculpins feed appear to be less abundant. Slower warming of the water in the spring should result in later spawning and slower development of the eggs and larvae. The larvae may find the diatom-coated substrate unsuitable. The response of the spoonhead sculpin to ecological change has been both rapid and negative. It may well foretell the fate of other small species.

The mountain whitefish (Prosopium williamsoni) is the most abundant sports species in the upper reaches of the Red Deer River below the Dickson Dam. The life history of this species has been studied in the Red Deer River since 1977. Prior to flow regulation, the river was usually icebound from November to April. The portion of the river upstream from the Highway 54 bridge west of Innisfail to the damsite included the downstream limits of the known spawning 
grounds of the mountain whitefish. Large numbers of fish spawned in this area during October. Hatching of the eggs was synchronous and associated with breakup which occurred from late March to late April. Large numbers of recently hatched larvae about $14 \mathrm{~mm}$ long were seen in the shallows 7-10 days after breakup. Young-of-the-year occupied shallow margins, riffles, backwaters and side channels throughout the summer and grew to about $70 \mathrm{~mm}$ by fall. Historically, young-of-the-year were visibly abundant.

Since the impoundment of the Red Deer River, there is no spring breakup in the river immediately below the dam. Most of the river where spawning is known to occur is either not icebound or the ice is only a temporary feature during the winter and is absent following warm weather or fluctuations in the water level. Any cues associated with breakup that may have triggered the synchronous hatching of mountain whitefish eggs are either absent or occur at an inappropriate time. Large numbers of mountain whitefish larvae and young have not been evident in the shallows of the Red Deer River during the past few years. Subadults are scarce in this portion of the river while fish four years and older are fairly common and frequently taken by anglers. Small fish, 2-3 years old, are seldom taken by anglers as they were in the past.

During mid- to late-March of 1986, larval mountain whitefish were identified from the stomachs of lake whitefish (Coregonus clupeaformis) and found to be abundant in the shallows in areas of slow current. While the numbers of larvae increased over the next three weeks, the size range of the larvae remained both uniform and small (about $14 \mathrm{~mm}$ ), indicating either slow growth or that older larvae were dying and being replaced by individuals hatching later. By late April, no young-of-the-year mountain whitefish were evident along the margin. The reasons for the poor growth and/or survival of the larvae are unclear.

The synchronous appearance of the larvae in the pre-impoundment era was followed by rapid warming of the river and increasing productivity of microinvertebrates. Currently, warming of the river immediately downstream from the dam is a much slower process and the cooler-thannormal water may not be favorable for the early growth and survival of mountain whitefish larvae. While this species still spawns successfully below the Dickson Dam, there is little or no recruitment and the-long term survival of this population of valuable sportsfish is threatened.

The northern pike (Esox lucius) and walleye (Stizostedion vitreum vitreum) have been popular sportsfish in the Red Deer River from the Raven River downstream to the badlands. The large tributaries, such as the Medicine and Little Red Deer Rivers, were focal points for fisheries 
for these species. Both species were numerous and grew large in these waters. Northern pike attained lengths greater than $1 \mathrm{~m}$ and weights of up to $10 \mathrm{~kg}$. Walleye attained lengths of up to $70 \mathrm{~cm}$ and maximum weights in excess of $5 \mathrm{~kg}$. Intensive angler harvest has severely reduced the numbers of both species, and large individuals are increasingly rare. A number of new problems exist for these species as a consequence of flow regulation.

Both species spawn in the Medicine and Little Red Deer Rivers. The lower reaches of these tributaries are major rearing areas. Historically, seasonally high water in the Red Deer River during June and July backed up in the lower reaches of the tributaries, creating large areas of deep, slow flowing, relatively warm water that provides a favorable environment for early feeding and growth of these species. Large numbers of catostomid larvae shared this habitat and provided abundant food for young pike and walleye when they became piscivorous at lengths as small as $30 \mathrm{~mm}$. The annual flooding of these rearing areas no longer occurs, as the reservoir above the dam is being filled during this critical period of early growth of these piscivores. Reduced survivorship and growth may result from this altered rearing habitat.

Access to traditional spawning sites in the lower Raven River is denied to those pike and walleye populations living above the Little Red Deer River, but below the dam. Suitable spawning habitat for pike is scarce in this portion of the Red Deer River. No protection is afforded these or indeed, any species of fish attempting to spawn in the tailwaters below the dam.

There is a great deal of open water in this portion of the river for 12 months of the year. The low summer and winter water levels make the fish more accessible to anglers. Increased angling pressure is being applied to an already diminished resource. The altered flow regime results in two detrimental changes for these and other fish species: (1) decreased reproduction and recruitment; and (2) increased angler harvest. These serve to diminish this once-rich fishery.

The mooneye (Hiodon tergisus) and goldeye ( $H$. alosoides) formerly occurred in good numbers as far upstream as the Raven River and its lower reaches. Both species were present in late May or early June prior to spawning in June. These fishes were more abundant during years with higher than average flows, at which time they penetrated further upstream in the large tributaries. With regulated flow, early-summer water levels are low and only small numbers of mooneye and goldeye are found in the lower reaches of the Medicine and Little Red Deer rivers. Both species continue to be abundant in the badlands portion of the Red Deer River downstream from the City of Red Deer. 
This represents a loss of two important sports species from the river in the vicinity of the dam. The linear distribution of these species in the Red Deer River is reduced, but it is uncertain whether the total population within this river is reduced.

Given an understanding of the life histories, within the Red Deer River, of each of the six species discussed, it was predictable that flow regulation as it is practised at present would have deleterious effects on these species. It is important that appropriate life history studies, as opposed to mere inventories, be done prior to the impoundment of rivers. For those species for which basic biology is known it is still important to study their life histories within the stream to be impounded to identify potential problems and to provide the basis for mitigative measures where necessary. In the case of the Red Deer River, such studies were not undertaken.

While fish stocks are declining, no species has been extirpated and rehabilitation of the fish fauna need not be an expensive process, requiring only changes in flow regulation and harvesting practices. A no-fishing zone should be established immediately below the dam to permit fish to spawn unmolested by anglers. Small numbers of adult fish that traditionally spawned in the lower Raven River should be introduced to the reservoir where they would eventually contribute to a more diverse fish fauna, and consequently, a richer fishery. Once established, populations within the reservoir may also contribute to the fishery below the dam. The negative downstream effects resulting from the regulated flow may be overcome by filling the reservoir and allowing the naturally-generated discharge above the dam to flow over the spillway so that the reservoir functions much like a natural lake. Fish that are both above and below the dam would then benefit.

\section{REFERENCES}

Paetz, M.J., and J.S. Nelson. 1973. Fishes of the northeastern Wood Buffalo National Park region, Alberta and Northwest Territories. Can. Field Nat. 86:133-144. 
